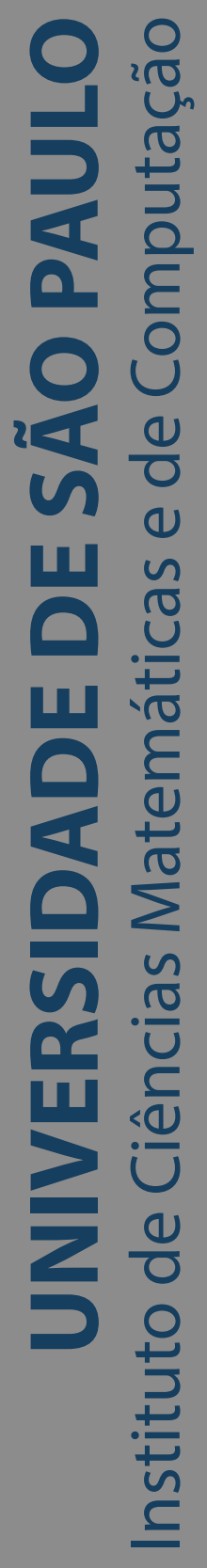

Seleção de modelos multiníveis para dados de avaliação educacional

\title{
Fabiano Rodrigues Coelho
}

Dissertação de Mestrado do Programa Interinstitucional de

Pós-Graduação em Estatística (PIPGEs) 

Assinatura:

\title{
Fabiano Rodrigues Coelho
}

\section{Seleção de modelos multiníveis para dados de avaliação educacional}

\begin{abstract}
Dissertação apresentada ao Instituto de Ciências Matemáticas e de Computação - ICMC-USP e ao Departamento de Estatística - DEs-UFSCar, como parte dos requisitos para obtenção do título de Mestre em Estatística - Programa Interinstitucional de Pós-Graduação em Estatística. VERSÃO REVISADA
\end{abstract}

Área de Concentração: Estatística

Orientadora: Profa. Dra. Cibele Maria Russo Noveli 
Ficha catalográfica elaborada pela Biblioteca Prof. Achille Bassi e Seção Técnica de Informática, ICMC/USP, com os dados fornecidos pelo(a) autor(a)

\begin{tabular}{|c|c|}
\hline \multirow[t]{3}{*}{ C672s } & $\begin{array}{l}\text { Coelho, Fabiano Rodrigues } \\
\text { Seleção de modelos multiníveis para dados de } \\
\text { avaliação educacional / Fabiano Rodrigues Coelho; } \\
\text { orientadora Cibele Maria Russo Noveli. -- São } \\
\text { Carlos, } 2017 \text {. } \\
\quad 171 \text { p. }\end{array}$ \\
\hline & $\begin{array}{l}\text { Dissertação (Mestrado - Programa } \\
\text { Interinstitucional de Pós-graduação em Estatística) -- } \\
\text { Instituto de Ciências Matemáticas e de Computação, } \\
\text { Universidade de São Paulo, } 2017 \text {. }\end{array}$ \\
\hline & $\begin{array}{l}\text { 1. Modelos multiníveis. 2. Seleção de modelos. } 3 . \\
\text { Critério de informação. } 4 . \text { Prova Brasil. I. Noveli, } \\
\text { Cibele Maria Russo, orient. II. Título. }\end{array}$ \\
\hline
\end{tabular}




\title{
Fabiano Rodrigues Coelho
}

\section{Selection of multilevel models for educational evaluation data}

\begin{abstract}
Master dissertation submitted to the Institute of Mathematics and Computer Sciences - ICMC-USP and to the Department of Statistics - DEs-UFSCar, in partial fulfillment of the requirements for the degree of the Master Interagency Program Graduate in Statistics.

FINAL VERSION
\end{abstract}

Concentration Area: Statistics

Advisor: Profa. Dra. Cibele Maria Russo Noveli 

Este trabalho é dedicado a todos aqueles que amam ciência e que nunca desiste de seus sonhos, mesmo quando se depara com dificuldades, não esmorece levanta a cabeça e segue em frente. 

Inicio os agradecimentos primeiramente a Deus, pois é Nele em que busco minhas forças para suportar os momentos mais difíceis em minha caminhada.

Agradeço também aos meus pais Celino Rodrigues Coelho e Cícera Aparecida da Silva Coelho, minha irmã Danielle da Silva Coelho e minha tia-avó Izabel Maria dos Passos por todo apoio e torcida pelo meu sucesso.

Agradeço ainda, a Eliandra de Mello Bonotto, que é mais do que minha namorada, minha outra metade, meu braço direito, minha maior incentivadora, que está comigo há muitos anos e que torce muito para que eu consiga realizar meus sonhos.

Estendo meus agradecimentos a minha orientadora Prof ${ }^{\mathrm{a}}$. Dra. Cibele Maria Russo Noveli por tudo, pelas orientações, pela paciência, pelas críticas construtivas, pelos conselhos e também pelo tratamento muito respeitoso em todas as nossas conversas.

Agradeço também os membros das bancas de Qualificação e Defesa deste trabalho: Prof. Dra. Cibele Maria Russo Noveli, Prof. Dr. Jorge Luis Bazán Guzmán, Prof. Dr. Jony Arrais Pinto Junior, Prof. Dr. Caio Lucidius Naberezny Azevedo, pelas reflexões, trocas de ideias e os mais produtivos questionamentos que me proporcionou uma evolução profissional e pessoal muito grande.

Agradeço, em especial, ao Prof. Dr. Jorge Luis Bazán Guzmán, que quando minha orientadora esteve de licença maternidade me deu todo apoio necessário.

Aos docentes: Prof. Dr. Adriano Kamimura Suzuki, Prof. Dr. Marcio Alves Diniz, Prof. Dr. Gustavo Henrique de Araújo Pereira, Prof. Dra. Juliana Cobre, Prof. Dr. Carlos Alberto Ribeiro Diniz e Prof. Dr. Adriano Polpo de Campos, os quais eu tive a honra de ser instruído e aprender muito.

Aos meus amigos da turma de mestrado ingressante em 2015: Alan Henrique de Jesus, Bárbara Beltrame Bettim, Caroline Tenório Mendes de Aquino, Diego Mattozo Bernardes da Silva, Gretta Rossi Ferreira, Juliana Cecília da Silva Teixeira, Karine Zanuto Mendes, Murilo Cantoni, Natália Lombardi de Oliveira, Nicholas Wagner Eugenio, Raul Caram de Assis, Susan Alicia Chumbimune Anyosa e Taís Roberta Ribeiro, pessoas maravilhosas, parceiros de coração com a qual pude dividir os momentos bons e ruins ao longo do mestrado, desejo tudo de bom a eles. Obrigado por tudo.

À servidora Maria Isabel Rinaldo Pessôa de Araújo e aos funcionários do serviço de Pós-Graduação do ICMC-USP, por todo suporte e solicitude quando foi necessário resolver 
algum assunto pendente.

Aos amigos que frequentam os laboratórios do ICMC-USP, em especial ao Hélio Azevedo e José Pedro Bello, pelas longas horas de conversas e por todo incentivo e apoio.

Ao CEPID-CeMEAI (Centro de Pesquisa, Inovação e Difusão do Centro de Ciências Matemáticas Aplicadas à Indústria), pela utilização do cluster Euler, sem ele, este trabalho se tornaria praticamente inviável e também aos seus funcionários que sempre que necessário, não deixaram de prestar auxílio, seja pessoalmente ou por e-mail.

A todos com quem tive a oportunidade de conviver no período, muito obrigado por tudo. 
"Não fui eu que lhe ordenei? Seja forte e corajoso! Não se apavore, nem se desanime, pois o Senhor, o seu Deus, estará com você por onde você andar"

(Josué 1:9) 



\section{RESUMO}

COELHO, F. R. Seleção de modelos multiníveis para dados de avaliação educacional. 2017. 171 p. Dissertação (Mestrado em Estatística - Programa Interinstitucional de Pós-Graduação em Estatística) - Instituto de Ciências Matemáticas e de Computação, Universidade de São Paulo, São Carlos - SP, 2017.

Quando um conjunto de dados possui uma estrutura hierárquica, uma possível abordagem são os modelos de regressão multiníveis, que se justifica pelo fato de haver uma porção significativa da variabilidade dos dados que pode ser explicada por níveis macro. Neste trabalho, desenvolvemos a seleção de modelos de regressão multinível aplicados a dados educacionais. Esta análise divide-se em duas partes: seleção de variáveis e seleção de modelos. Esta última subdivide-se em dois casos: modelagem clássica e modelagem bayesiana. Buscamos através de critérios como o Lasso, AIC, BIC, WAIC entre outros, encontrar quais são os fatores que influenciam no desempenho em matemática dos alunos do nono ano do ensino fundamental do estado de São Paulo. Também investigamos o funcionamento de cada um dos critérios de seleção de variáveis e de modelos. Foi possível concluir que, sob a abordagem frequentista, o critério de seleção de modelos BIC é o mais eficiente, já na abordagem bayesiana, o critério WAIC apresentou melhores resultados. Utilizando o critério de seleção de variáveis Lasso para abordagem clássica, houve uma diminuição de $34 \%$ dos preditores do modelo. Por fim, identificamos que o desempenho em matemática dos estudantes do nono ano do ensino fundamental do estado de São Paulo é influenciado pelas seguintes covariáveis: grau de instrução da mãe, frequência de leitura de livros, tempo gasto com recreação em dia de aula, o fato de gostar de matemática, o desempenho em matemática global da escola, desempenho em língua portuguesa do aluno, dependência administrativa da escola, sexo, grau de instrução do pai, reprovações e distorção idade-série.

Palavras-chave: Modelos multiníveis, Seleção de modelos, Critério de informação e Prova Brasil. 



\section{ABSTRACT}

COELHO, F. R. Selection of multilevel models for educational evaluation data. 2017. 171 p. Dissertação (Mestrado em Estatística - Programa Interinstitucional de Pós-Graduação em Estatística) - Instituto de Ciências Matemáticas e de Computação, Universidade de São Paulo, São Carlos - SP, 2017.

When a dataset contains a hierarchical data structure, a possible approach is the multilevel regression modelling, which is justified by the significative amout of the data variability that can be explained by macro level processes. In this work, a selection of multilevel regression models for educational data is developed. This analysis is divided into two parts: variable selection and model selection. The latter is subdivided into two categories: classical and Bayesian modeling. Traditional criteria for model selection such as Lasso, AIC, BIC, and WAIC, among others are used in this study as an attempt to identify the factors influencing ninth grade students' performance in Mathematics of elementary education in the State of São Paulo. Likewise, an investigation was conducted to evaluate the performance of each variable selection criteria and model selection methods applied to fitted models that will be mentioned throughout this work. It was possible to conclude that, under the frequentist approach, BIC is the most efficient, whereas under the bayesian approach, WAIC presented better results. Using Lasso under the frequentist approach, a decrease of $34 \%$ on the number of predictors was observed. Finally, we identified that the performance in Mathematics of students in the ninth year of elementary school in the state of São Paulo is most influenced by the following covariates: mother's educational level, frequency of book reading, time spent with recreation in classroom, the fact of liking Math, school global performance in Mathematics, performance in Portuguese, school administrative dependence, gender, father's educational degree, failures and age-grade distortion.

Keywords: Multilevel models; Model selection; Information criterion and Brazil Exam - Basic Education Assessment. 



\section{LISTA DE ILUSTRAÇÕES}

Figura 1 - Histograma da variável de interesse, PROFICIENCIA_MT_SAEB. . . . . . 29

Figura 2 - Gráfico qqplot da variável PROFICIENCIA_MT_SAEB. . . . . . . . . . . 29

Figura 3 - Box plot da variável de interesse, PROFICIENCIA_MT_SAEB em cada uma das 15 regiões destacadas anteriormente. . . . . . . . . . . . . . . 33

Figura 4 - Box plot da variável de interesse, PROFICIENCIA_MT_SAEB pelas covariáveis Q001, Q004, Q019 e Q023. . . . . . . . . . . . . . . 33

Figura 5 - Box plot da variável de interesse, PROFICIENCIA_MT_SAEB pelas covariáveis Q049, TURNO, DEPENDENCIA_ADM e LOCALIZACAO. . . . . 34

Figura 6 - Box plot da variável de interesse, PROFICIENCIA_MT_SAEB pelas covariáveis Q020, Q033, Q044 e Q054. . . . . . . . . . . . . . . . . . 34

Figura 7 - Esquema representativo de uma estrutura hierárquica de três níveis. . . . . 36

Figura 8 - Análise residual do modelo 7 por grupos. . . . . . . . . . . . 78

Figura 9 - Box plot dos resíduos do modelo 7 por grupos. . . . . . . . . . . . 79

Figura 10 - Gráfico da função densidade marginal a posteriori dos parâmetros do Modelo $4 \ldots \ldots \ldots \ldots \ldots \ldots$

Figura 11 - Histogramas da densidade a posteriori simulada via MCMC com dinâmica hamiltoniana dos parâmetros do modelo 4 . . . . . . . . . . . . . . . 86

Figura 12 - Desenvolvimento do processo MCMC durante as 20.000 iterações para cada um dos parâmetros. . . . . . . . . . . . . . . . . . . 87

Figura 13 - Gráfico dos BIC versus $\lambda$, para 21 valores de $\lambda$ tomados entre 0 e $1000 . \quad$. 87 

Tabela 1 - Análise Descritiva das Variáveis PROFICIENCIA_MT_SAEB . . . . . . . 28

Tabela 2 - Demonstrativo do número de escolas por região amostrada . . . . . . . . . 32

Tabela 3 - Configuração dos modelos estimados em cada réplica. . . . . . . . . . . . . 58

Tabela 4 - Percentual de réplicas onde os critérios de seleção optaram pelo modelo verdadeiro. . . . . . . . . . . . . . . . . . 5 59

Tabela 5 - Modelo 1: apenas com os níveis aluno e turma; Modelo 2: com os níveis aluno, turma e escola. . . . . . . . . . . . . . . . . . 63

Tabela 6 - Modelo 3: inclusão de variáveis explicativas ao nível de aluno; Modelo 4: inclusão de variáveis explicativas ao nível de escola. . . . . . . . . . . . . 66

Tabela 7 - Teste de Comparação entre os modelos 3 e $4 \ldots$. . . . . . . . . . . . 67

Tabela 8 - Comparação dos modelos ajustados nesta seção utilizando os critérios AIC, BIC, AICc. . . . . . . . . . . . . . . . . . . . 6 68

Tabela 9 - Descrição das covariáveis a serem utilizadas nos ajustes no caso clássico e no bayesiano. . . . . . . . . . . . . . . . . . 68

Tabela 10 - Estimativa dos parâmetros do modelo (6.7), aqui temos efeitos fixos apenas. 69

Tabela 11 - Procedimento de stepwise utilizado no Modelo $4 \ldots$. . . . . . . . . . . . 70

Tabela 12 - Modelo (6.8) tem intercepto aleatório para turma; Modelo (6.9) tem intercepto aleatório para escola; Modelo (6.10) tem intercepto aleatório para região. . . . . . . . . . . . . . . . . . . .

Tabela 13 - Modelo (6.11) tem intercepto e inclinações aleatórias para turma; Modelo (6.12) tem intercepto e inclinações aleatórias para escola; Modelo (6.13) tem intercepto e inclinações aleatórias para região.

Tabela 14 - Comparação dos modelos ajustados nesta seção utilizando os critérios AIC, BIC, AICc. . . . . . . . . . . . . . . . . . . . . . . 74

Tabela 15 - Configuração de ajustes para seleção de modelos. . . . . . . . . . . . . 75

Tabela 16 - Examinando as estimativas dos parâmetros e o valor p dos mesmos, nos modelos 1,2 e 3 descritos na Tabela 15 .

Tabela 17 - Examinando as estimativas dos parâmetros e o valor p dos mesmos, nos modelos 4, 5 e 6 descritos na Tabela 15 .

Tabela 18 - Examinando as estimativas dos parâmetros e o valor p do modelo 7 descritos na Tabela 15. . . . . . . . . . . . . . . . . . . . . . . . . . 77

Tabela 19 - Comparação dos modelos clássicos da Tabela 15 mais o modelo completo (6.10), utilizando os critérios AIC, AICc e BIC. 
Tabela 20 - Estimativas dos efeitos aleatórios do modelo $7 \ldots$. . . . . . . . 78

Tabela 21 - Estimativas dos parâmetros, intervalos de credibilidade e a estatística $\hat{R}$ no modelo (6.14) . . . . . . . . . . . . . . . . . . . . . . . 80

Tabela 22 - Examinando as estimativas dos parâmetros, intervalos de credibilidade e a estatística $\hat{R}$ no modelo $(6.15) . \ldots \ldots$. . . . . . . . . . 8

Tabela 23 - Examinando as estimativas dos parâmetros, intervalos de credibilidade e a estatística $\hat{R}$ no modelo (6.16).

Tabela 24 - Comparação dos modelos ajustados utilizando os critérios looic, WAIC, DIC,EAIC e EBIC.

Tabela 25 - Examinando as estimativas dos parâmetros, intervalos de credibilidade dos modelos 1,2 e 3 descritos na Tabela $15 . \ldots$. . . . . . . . . . .

Tabela 26 - Examinando as estimativas dos parâmetros, intervalos de credibilidade dos modelos 4,5 e 6 descritos na Tabela $15 . \ldots$. . . . . . . . . . . 84

Tabela 27 - Examinando as estimativas dos parâmetros, intervalos de credibilidade do modelo 7 descritos na Tabela $15 . \ldots$. . . . . . . . . . . . . . . . .

Tabela 28 - Comparação dos modelos com interceptos e inclinações aleatórias, utilizando os critérios looic, WAIC, DIC,EAIC e EBIC . . . . . . . . . . . . . . . .

Tabela 29 - Resultados referentes ao algoritmo glmmLasso com as covariáveis descritas anteriormente, para $\lambda=450$, foi selecionado no total 34 variáveis explicativas. 88

Tabela 30 - Descrição do banco de dados geral. . . . . . . . . . . . . . . . . . . 97

Tabela 31 - Codificação das variáveis . . . . . . . . . . . . . . . . . . . . . . 124

Tabela 32 - Descrição das variáveis Dicotomizadas da amostra obtida dos dados . . . . 146

Tabela 33 - Distribuição amostral das escolas da região de Presidente Prudente segundo os critérios pré-estabelecidos. . . . . . . . . . . . . . . . . 157

Tabela 34 - Distribuição amostral das escolas da região de Araçatuba segundo os critérios pré-estabelecidos. . . . . . . . . . . . . . . . 157

Tabela 35 - Distribuição amostral das escolas da região de Jales segundo os critérios pré-estabelecidos. . . . . . . . . . . . . . . . . . .

Tabela 36 - Distribuição amostral das escolas da região de São José do Rio Preto segundo os critérios pré-estabelecidos. . . . . . . . . . . . . . . . 158

Tabela 37 - Distribuição amostral das escolas da região de Marília segundo os critérios pré-estabelecidos. . . . . . . . . . . . . . . . . 158

Tabela 38 - Distribuição amostral das escolas da região de Bauru segundo os critérios pré-estabelecidos. . . . . . . . . . . . . . . . . 158

Tabela 39 - Distribuição amostral das escolas da região de São Carlos segundo os critérios pré-estabelecidos. . . . . . . . . . . . . . . . . . . .

Tabela 40 - Distribuição amostral das escolas da região de Ribeirão Preto segundo os critérios pré-estabelecidos. 
Tabela 41 - Distribuição amostral das escolas da região de Registro segundo os critérios pré-estabelecidos. . . . . . . . . . . . . . . . . . . . . 159

Tabela 42 - Distribuição amostral das escolas da região de Itapetininga segundo os critérios pré-estabelecidos. . . . . . . . . . . . . . . . . . . . . 160

Tabela 43 - Distribuição amostral das escolas da região de Piracicaba segundo os critérios pré-estabelecidos. . . . . . . . . . . . . . . . . . . . 160

Tabela 44 - Distribuição amostral das escolas da região de Campinas segundo os critérios pré-estabelecidos. . . . . . . . . . . . . . . . . . . . . 160

Tabela 45 - Distribuição amostral das escolas da região de Jundiaí segundo os critérios pré-estabelecidos. . . . . . . . . . . . . . . . . . . . 161

Tabela 46 - Distribuição amostral das escolas da região de São José dos Campos segundo os critérios pré-estabelecidos. . . . . . . . . . . . . . . . . . . 161

Tabela 47 - Distribuição amostral das escolas da região de São Paulo segundo os critérios pré-estabelecidos. . . . . . . . . . . . . . . . . . . . . . 161 



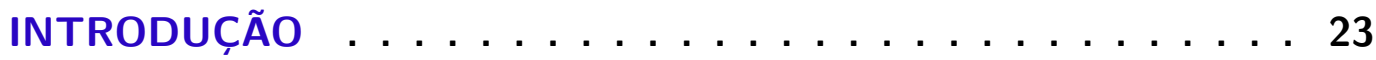

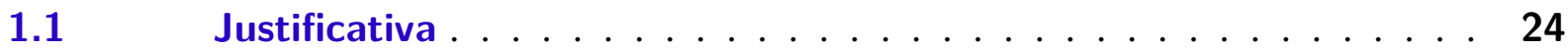

1.2 Revisão Bibliográfica . . . . . . . . . . . . . . 25

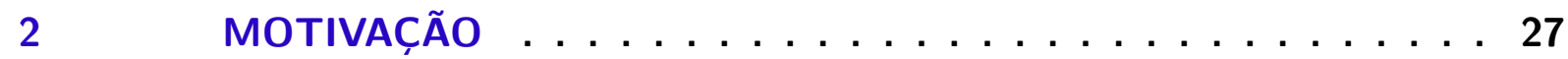

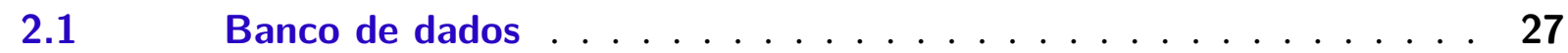

$2.2 \quad$ Análises Descritivas . . . . . . . . . . . . . . . 28

2.3 Amostragem dos dados . . . . . . . . . . . . . 30

3 MODELO MULTINÍVEL COM RESPOSTA NORMAL . . . . . . 35

3.1 Modelos de regressão e suposições . . . . . . . . . . . . . . . 35

3.2 Modelo de regressão com dois níveis . . . . . . . . . . . . 36

$3.3 \quad$ Estimação de parâmetros . . . . . . . . . . . . 38

3.4 Testes de Hipóteses . . . . . . . . . . . . . . . . . . . 39

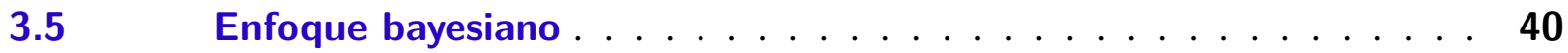

4 MÉtodos de escolha de MOdELOS . . . . . . . . . . 43

4.1 Seleção de Modelos: Caso Clássico . . . . . . . . . . . . . . 43

4.1.1 AIC (Akaike Information criterion) . . . . . . . . . . . . . 44

4.1.2 AICC (AIC Corrigido) . . . . . . . . . . . . . . 44

4.1.3 BIC (Bayesian Information Criterion) . . . . . . . . . . 45

4.2 Seleção de Modelos: Caso Bayesiano . . . . . . . . . . . . . 45

4.2.1 DIC (Deviance Information Criterion) . . . . . . . . . . . . 46

4.2.2 WAIC (Widely Applicable Information Criterion) . . . . . . . . 46

4.2.3 Ioo (Leave-one-out cross-validation ) . . . . . . . . . . . . 48

4.2.4 EAIC (Expected Akaike Information Criterion) . . . . . . . . . . 49

4.2.5 EBIC (Expected Bayesian Information Criterion) . . . . . . . . . 50

$4.3 \quad$ Seleção de Variáveis . . . . . . . . . . . . . . . . . . 50

4.3.1 Lasso . . . . . . . . . . . . . . . . . . . . . . 50

4.3.2 Modelos lineares com dois níveis e resposta Normal . . . . . . . . 51

4.3.3 Algoritmo do Gradiente Ascendente . . . . . . . . . . . . . . . . 52

4.3.3.1 Algoritmo g/mmLasso: caso particular (normal) . . . . . . . . . . . . 52

5 ESTUdO DE SIMULAÇÃO . . . . . . . . . . . . 57 
$6.1 \quad$ Modelos Multiníveis . . . . . . . . . . . . . . . . 61

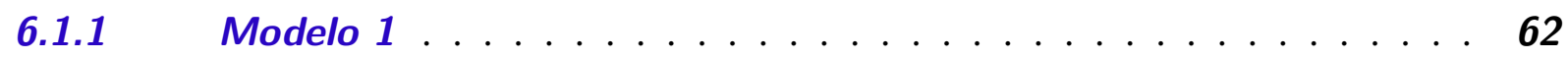

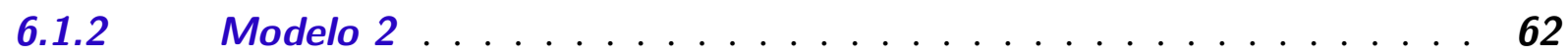

$6.1 .3 \quad$ Modelo $3 \ldots \ldots \ldots \ldots$

6.1 .4 Modelo $4 \ldots \ldots \ldots \ldots \ldots$

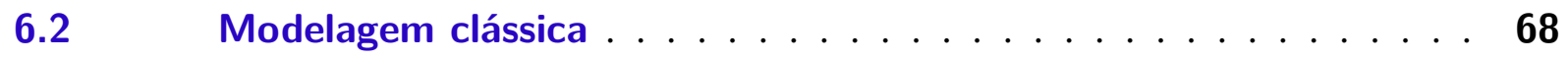

6.2.1 Modelos com efeitos fixos . . . . . . . . . . . . . . . . . 69

6.2.2 Modelos com intercepto aleatório . . . . . . . . . . . 70

6.2.3 Modelos com intercepto e inclinações aleatórios . . . . . . . . . . 72

6.3 Seleção de Modelos Clássicos . . . . . . . . . . . . . . . 74

$6.4 \quad$ Modelagem Bayesiana . . . . . . . . . . . . . . . . . 78

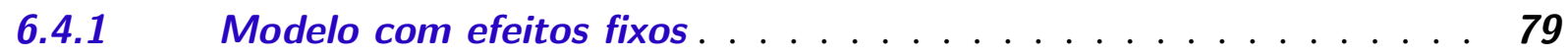

6.4.2 Modelo com interceptos aleatórios . . . . . . . . . . . 80

6.4.3 Modelo com interceptos e inclinações aleatórios . . . . . . . . . 80

6.5 Seleção de Modelos Bayesianos . . . . . . . . . . . . . . . 81

6.6 Seleção de Variáveis . . . . . . . . . . . . . . . . . . 84

7 DISCUSSÃO E PROPOSTAS FUTURAS $\ldots \ldots \ldots$

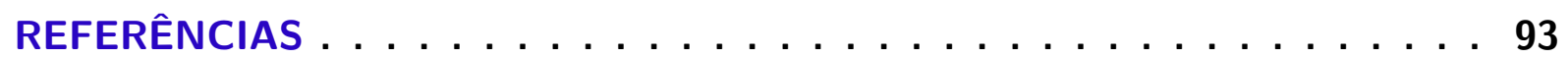

APÊNDICE A BANCO DE DADOS ..........97

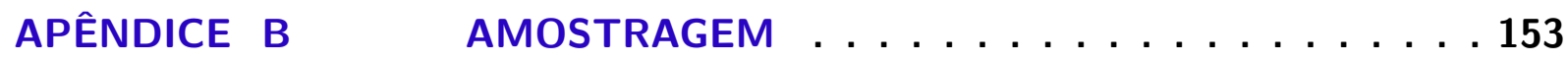

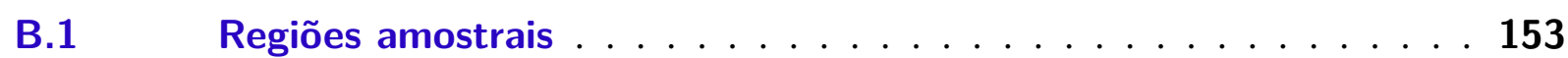

B.2 Distribuições amostrais por região $\ldots \ldots \ldots \ldots \ldots \ldots$

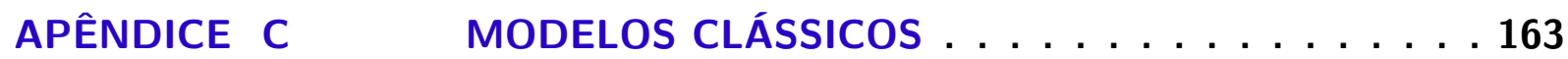

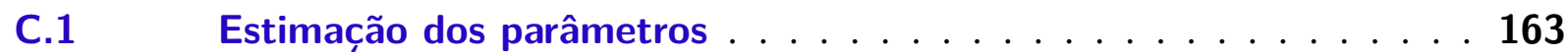

C.1.1 Modelos com efeitos fixos . . . . . . . . . . . . . . . . . 163

C.1.2 Modelo com interceptos aleatórios . . . . . . . . . . . . . . 163

C.1.3 Modelo com interceptos e inclinações aleatórios . . . . . . . . . . . 164

C.2 Seleção de Modelos . . . . . . . . . . . . . . . . . . . . . . . . 164

APÊNDICE D MODELOS BAYESIANOS: STAN $\ldots \ldots \ldots 165$

D.1 Modelos com efeitos fixos . . . . . . . . . . . . . . 166

D.2 Modelo com interceptos aleatórios . . . . . . . . . . . . . 167

D.3 Modelo com interceptos e inclinações aleatórios . . . . . . . . . 169 
Quando temos unidades observacionais formando grupos, que por sua vez também podem ser agrupados em unidades maiores, podemos afirmar que esses dados têm estrutura hierárquica. Para estudar fenômenos relativos a esse tipo de dados, uma possibilidade é considerar modelos de regressão multiníveis com dois níveis, que permitem a incorporação de efeitos aleatórios associados a cada um dos níveis. Uma diferença marcante nesses modelos em relação aos modelos de regressão linear múltipla é o fato de que leva em consideração a possível correlação existente entre os dados de um mesmo grupo, como nos diferentes níveis de hierarquia, ver por exemplo Goldstein (1986). Outra suposição comumente considerada na literatura é a de normalidade. Esses modelos têm aplicação em problemas biológicos, médicos, de economia, educacionais, de controle de qualidade, além de diversas outras áreas de aplicação.

Outra característica dos modelos usuais que merece atenção é a suposta independência entre as observações, que pode levar à superestimação dos parâmetros, quando estimados usando o método de máxima verossimilhança restrita. Os modelos multiníveis permitem avaliar a variabilidade dos dados nos diferentes níveis e ajustar um modelo mais adequado à realidade do problema.

Segundo Castro (2015), podemos resumir as vantagens do modelo de regressão multinível, da seguinte maneira:

- apresentam modelos mais flexíveis e estruturados que utilizam um maior nível de informação da amostra e, ainda permitem estabelecer uma equação para cada unidade de agrupamento, o que permite análises individuais para cada grupo;

- possibilitam a formulação e o teste de hipóteses relativas a efeitos entre os níveis a partir do uso da informação de cada agrupamento dos dados;

- possibilitam particionar a variabilidade da variável resposta entre os diferentes níveis, de acordo com a proporção explicada por cada um deles. 
Neste capítulo, apresentamos a justificativa para a realização desse trabalho, bem como uma breve revisão bibliográfica a respeito do tema aqui colocado.

\subsection{Justificativa}

Neste trabalho, apresentamos um estudo de modelos de regressão multiníveis para conjuntos de dados educacionais. Esses modelos são aplicáveis, em geral, para problemas em que os dados são estruturados de forma hierárquica. Realizamos seleção de variáveis e seleção de modelos em modelos multiníveis, como extensão do trabalho de Osio (2013), que podem ser entendidos como modelos onde os componentes aleatórios assumem distribuições de probabilidade. Como aplicação, utilizamos um conjunto de dados de avaliações educacionais do SAEB - Sistema Nacional de Avaliação da Educação Básica, cujo objetivo principal é verificar o rendimento escolar dos alunos na rede pública e privada de ensino brasileira.

A motivação para esse estudo vem da área educacional, em que os dados observados dos alunos são agrupados por turmas, as turmas são agrupadas por escolas e que por sua vez são agrupadas por cidades e regiões.

A educação é uma das principais demandas de nossa atual sociedade. Nos últimos anos, como se tem visto, o Brasil tem alcançado os últimos lugares em avaliações de larga escala, conforme tem sido divulgado pelo Ministério da Educação e organismos internacionais. Em 2012, o desempenho dos estudantes brasileiros em leitura piorou em relação a 2009. De acordo com dados do Pisa (Programa Internacional de Avaliação de Alunos), o país somou 410 pontos em leitura, dois a menos do que sua pontuação na avaliação anterior e 86 pontos abaixo da média dos países da OCDE (Organização e Cooperação e Desenvolvimento Econômico). Matemática foi a única disciplina em que os brasileiros apresentam avanço no desempenho, ainda que pequeno. $\mathrm{O}$ Brasil saiu de 386 pontos, em 2009, e foi a 391 pontos em 2012, a média da OCDE é de 494 pontos. A melhora não foi suficiente para que o país avançasse no ranking e o Brasil caiu para $58^{\circ}$ posição em matemática. Apesar da melhora, dois em cada três alunos brasileiros de 15 anos não conseguem interpretar situações que exigem apenas deduções diretas da informação dada, não são capazes de entender percentuais, frações ou gráficos.

Neste trabalho, utilizamos um conjunto de dados do SAEB, do ano de 2011, que consiste em uma avaliação de língua portuguesa e matemática, aplicada aos alunos do nono ano do ensino fundamental, juntamente com informações de diretores, docentes e escolas. Essa prova produz o IDEB, que é o índice de desenvolvimento da educação básica. Realizamos seleção de modelos e seleção de variáveis em problemas com dados correlacionados com um grande volume de dados. Será desenvolvido o processo de estimação, seleção de variáveis e modelos, entre outras análises.

Na próxima seção, fazemos uma breve revisão bibliográfica a respeito de modelos multiníveis, métodos de seleção de variáveis e seleção de modelos e também serão abordados os principais trabalhos com essa classe de modelos aplicados a avaliações educacionais. 


\subsection{Revisão Bibliográfica}

Quando se trata de modelos multiníveis, o que mais se encontra, no que diz respeito à bibliografia, são comparações em situações práticas desses modelos com modelos de regressão linear múltipla. Essas comparações mostram a importância, em alguns casos, de se considerar a correlação existente entre os grupos observados. Com relação à seleção de variáveis e seleção de modelos, pode-se notar que os métodos usuais como AIC, BIC, LASSO e outros, não tem se mostrado eficaz quando se trata de um grande volume de dados, métodos esses que foram propostos a partir da década de 1970, e que foram aperfeiçoados ao longo dos anos.

Entre os trabalhos mais relevantes sobre modelos multiníveis podemos destacar Osio (2013), Gelman e Hill (2006), Bergamo (2002), Natis (2013), com relação à seleção de variáveis e seleção de modelos podemos destacar os trabalhos de Akaike (1998), Tibshirani (1996) e Weakliem (1999).

Muitos estudos foram feitos na área educacional utilizando modelos multiníveis. Eles mostram, por exemplo, que algumas ações realizadas pela família podem aumentar o desempenho em matemática. São elas: incentivar desde a primeira infância, através de jogos e atividades lúdicas, a afinidade pelos conceitos matemáticos; evitar que seus filhos ingressem na escola e permaneçam na escola com distorção idade-série; oferecer para seus filhos com relação à aprendizagem escolar, dentre outras. (LAROS; MARCIANO; ANDRADE, 2010) aponta ações por parte das escolas para a melhoria dos indicadores educacionais, são elas: aumentar o controle sobre a incidência de faltas em sala de aula; sanar as causas da repetência do ano letivo; estimular o trabalho colaborativo entre os professores; melhoria do clima disciplinar na escola prevenindo roubos, depredações e outros atos violentos.

Já o estudo realizado por Moreira e Jacinto (2013), no Rio Grande do Sul, mostrou que a infraestrutura da residência dos estudantes afeta positivamente no desempenho dos mesmos em matemática, o que não acontece quando se diz respeito á escola, mostrando que a escola pode contribuir muito para melhoria do desempenho em matemática. A mesma conclusão foi obtida por Andrade e Soares (2008) em seu estudo feito a nível nacional em todos os ciclos.

Em seu estudo comparativo entre duas escolas do Distrito Federal, Santos (2013) tomou uma escola com boas notas em matemática na PROVA BRASIL e outra com desempenho abaixo da média e a diferença mais marcante constatada pela autora foi organizacional.

. Utilizando dados do SARESP 97, Natis (2000) conclui que os modelos multiníveis constituem uma nova formulação para dados de efeitos aleatórios que permitem uma descrição e análise mais apropriada das diferentes fontes de variação, a autora deixa como proposta modelos para dados binários, ou ainda dados com distribuição Poisson.

Um texto de extrema importância no que diz respeito a estimação é colocado em Searle et al. (1994). Nele encontramos de maneira bem detalhada a obtenção dos estimadores de máxima verossimilhança restrita e do melhor preditor linear não-viesado dos efeitos aleatórios realizados, 
mas não observáveis em modelos multiníveis.

O trabalho mais importante sobre o Lasso (least absolute shrinkage and selection operator) é Tibshirani (1996). Neste texto é proposto um novo método para a estimatição dos parâmetros em modelos lineares. O Lasso minimiza a soma de quadrados dos resíduos submetidos à soma do valor absoluto dos coeficientes, sendo menos do que uma constante. Devido à natureza deste encolhimento ele tende a produzir alguns coeficientes que são exatamente zero e assim possibilitando a eliminação das variáveis cujo os coeficientes foram estimados como zero. As propriedades favoráveis ao método proposto é verificado neste artigo através de estudos de simulação.

Para obter uma noção intuitiva dos critérios de seleção de modelos, Emiliano (2013), em sua tese de doutorado, utiliza critérios AIC, BIC e outros em muitas áreas, tais como: seleção de modelos normais, séries temporais e modelos de crescimento. Após estudos de simulação ele conclui que quando falamos de modelos normais, o uso do BIC mostrou-se superior para amostras grandes, porém para amostras pequenas o BIC teve desempenho similar ao AIC e AIC corrigido. No caso de modelos de séries temporais, mesmo para amostras de tamanho pequeno, o desempenho dos critérios AIC e AIC corrigido foi similar e inferiores ao BIC, para todos os modelos simulados.

O texto está organizado da seguinte forma: No Capítulo 2 é apresentado a motivação para esse estudo, que consiste de um banco de dados educacional proveniente de uma avaliação em larga escala aplicada aos alunos da rede pública de ensino brasileira. No Capítulo 3 apresenta-se aspectos teóricos referentes ao modelo multinível com resposta normal, tais como: formulação teórica, estimação, testes de hipótese e ainda abordamos essa classe de modelos sob o enfoque bayesiano. No Capítulo 4, métodos de seleção de modelos e seleção variáveis que foram utilizados neste estudo são discutidos sob ponto de vista teórico. No Capítulo 5 apresenta-se um breve estudo de simulação para os critérios de seleção de modelos clássicos. No Capítulo 6 vemos uma aplicação a dados educacionais, utilizando o banco de dados mencionado anteriormente. Por fim, no Capítulo 7 discute-se os resultados obtidos e coloca-se proposta para trabalhos futuros. 
Neste capítulo, apresentamos a motivação para este estudo. Trata-se de um banco de dados educacional advindo de uma prova de larga escala aplicada a estudantes brasileiros. $\mathrm{O}$ objetivo principal é selecionar as variáveis que influenciam no desempenho dos alunos em matemática, do nono ano do ensino fundamental do Estado de São Paulo. A seguir destacamos alguns detalhes a respeito dos dados e sobre o processo de amostragem.

\subsection{Banco de dados}

A educação é uma das demandas mais importantes do país, uma vez que se espera que a educação básica forneça subsídios para que os alunos se tornem cidadãos conscientes de seus deveres e saibam pensar com competência. Desse modo, percebemos um crescimento significativo do número de estudos científicos com o objetivo de identificar os fatores, sejam eles socioeconômicos ou até mesmo estruturais, que interferem na aprendizagem do educando e assim fornecer condições para que os governantes tenham condições de elaborar políticas públicas que contribuam para a melhoria dos indicadores educacionais.

O banco de dados refere-se à Prova Brasil do ano de 2011. Essa prova de larga escala é aplicada de dois em dois anos em todas as escolas do Brasil. Os alunos do quinto e nono do ensino Fundamental são submetidos a esta prova, que verifica a proficiência em língua portuguesa e matemática.

A Prova Brasil faz parte do Sistema de Avaliação da Educação Básica (SAEB), que possui como principal objetivo avaliar a educação básica brasileira e contribuir para a melhoria de sua qualidade e para a universalização do acesso à escola, oferecendo subsídios concretos para a formulação, reformulação e o monitoramento das políticas públicas voltadas para a educação básica. Além disso, procura também oferecer indicadores que possibilitem maior compreensão dos fatores que influenciam o desempenho dos alunos nas áreas e anos avaliados. 
Na ocasião da pesquisa, 5.201.730 alunos realizaram a prova em 72.808 escolas no Brasil. Foram entrevistados no total 304.412 professores destas escolas e todos os 72.808 diretores. No entanto, para esse estudo, consideramos apenas os alunos do Estado de São Paulo e do nono ano do Ensino Fundamental, totalizando assim 502.479 alunos que realizaram a Prova Brasil, em 18.139 turmas de 5.018 escolas, em 640 municípios do Estado de São Paulo.

Além de informações referentes ao desempenho dos alunos, possuímos também dados referentes aos questionários sócio-econômico que foram aplicados aos alunos, professores, escolas e diretores. O questionário do aluno é composto por 58 questões, o questionário da escola tem 66 questões, há 212 questões no questionário do diretor e 152 questões no questionário de professor.

Nosso objetivo é identificar fatores que influenciam no desempenho do aluno na disciplina de matemática, utilizando a nota na prova de matemática da PROVA BRASIL. Os dados podem ser encontrados no site do INEP, ver por exemplo Microdados (2011). Na próxima seção, apresentamos a análise descritiva dos dados de modo a entender algumas das particularidades dos mesmos.

\subsection{Análises Descritivas}

O histograma da variável PROFICIENCIA_MT_SAEB, que representa a proficiência em matemática pelo aluno, é apresentado a seguir e fornece uma ideia de que a distribuição dos dados é simétrica. Apresentamos também a análise descritiva dessa variável, que será a variável resposta do nosso futuro modelo.

A partir da Figura 1 e da Figura 2, não há evidências que nos leve a descartar a suposição de normalidade dos dados. Pela Tabela 1, também temos indício que os dados são normalmente distribuídos em torno da média.

Tabela 1 - Análise Descritiva das Variáveis PROFICIENCIA_MT_SAEB

\begin{tabular}{ccccccc}
\hline Nome da variável & Mín. & $\mathbf{1}^{\mathbf{0}}$ Quartil & Mediana & Média & $\mathbf{3}^{\mathbf{0}}$ Quartil & Máx. \\
\hline PROFICIENCIA_MT & 109,4 & 215,2 & 247,9 & 247,1 & 278,9 & 398,3 \\
\hline
\end{tabular}

Note que a PROFICIENCIA_MT_SAEB, tem um desvio padrão de 45,93, uma curtose de 2,73 (sinalizando uma distribuição platicúrtica), e a assimetria é de -0,01 (indicando uma leve assimetria negativa da distribuição).

No apêndice A, temos a Tabela 30, onde podemos encontrar a organização geral do banco de dados, consta lá, o código original da variável, o novo código da variável, nome da variável, enunciado relativo à variável (caso haja), tipo de variável e o valor p relativo a uma regressão individual, tendo como variável resposta a PROFICIENCIA_MT_SAEB e variável explicativa cada uma das variáveis listadas na referida tabela. 


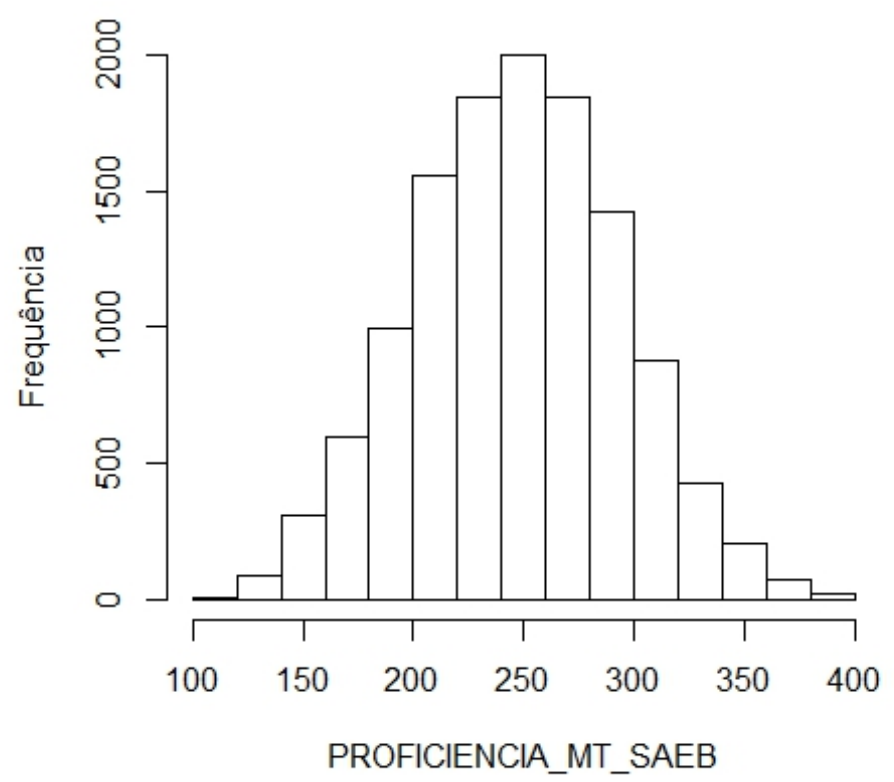

Figura 1 - Histograma da variável de interesse, PROFICIENCIA_MT_SAEB.

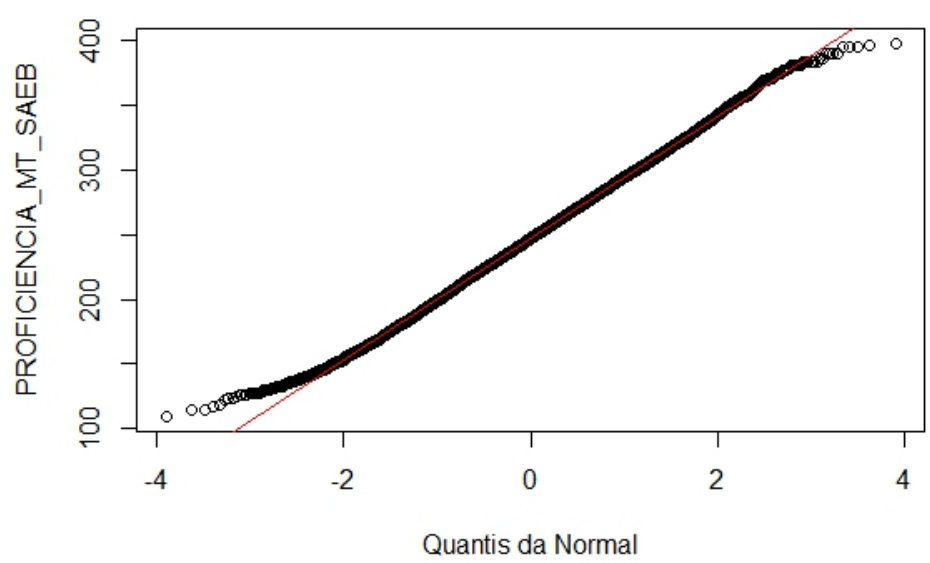

Figura 2 - Gráfico qqplot da variável PROFICIENCIA_MT_SAEB.

Das 498 variáveis explicativas listadas, tomando um nível de significância de 5\%, há evidência de que apenas as variáveis D119 (Eventos abertos a comunidade), E027 (Proteção de equipamento de alto custo) e LOCALIZACAO (Localização) não são significativas e ainda foi constatado que em 436 variáveis o valor p é menor do que $2.10^{-16}$.

Como existe no banco de dados uma grande quantidade de variáveis significativas, um fator importante a ser considerado é a significância teórica das variáveis em trabalhos acadêmicos, ver, por exemplo, (LAROS; MARCIANO; ANDRADE, 2010; NATIS, 2013; GONÇALVES; 
FRANÇA, 2013). A partir desses trabalhos, vemos que as covariáveis mais importantes são: Q001 (Sexo), Q002 (Raça auto-atribuída), Q019 (Escolaridade da mãe ou a mulher responsável), Q023 (Escolaridade do pai ou homem responsável), Q049 (Reprovas), PROFICIENCIA_LP_SAEB (Proficiência em língua portuguesa do SAEB), DEPENDENCIA_ADM (Dependência Administrativa), LOCALIZACAO (Localização) e TURNO (Turno). Essas variáveis serão considerados nos primeiros ajustes deste trabalho.

Esse banco de dados inicial tem 10 variáveis contínuas e 488 variáveis categóricas, dos quais 238 possuem apenas duas opções de respostas, as variáveis restantes têm três ou mais opções de respostas, sendo assim, estas foram dicotomizadas, ficando com duas categorias de respostas.

\subsection{Amostragem dos dados}

Após a definição do universo da pesquisa como sendo alunos do nono ano do ensino fundamental do Estado de São Paulo, conduzimos um procedimento amostral, após excluir os alunos que estudam no turno noturno, pois esses tem pouca representatividade. Tomamos como unidade amostral as escolas, definimos o tamanho amostral, considerando uma amostragem aleatória simples de proporção para populações finitas. Segundo Silva (1998), considera-se a seguinte relação:

$$
n=\frac{N Z^{2} p(1-p)}{(N-1) e^{2}+Z^{2} p(1-p)}
$$

onde:

- $n$ representa o tamanho da amostra que queremos calcular;

- $N$ é o tamanho populacional;

- $e$ é a margem de erro que queremos admitir;

- Z é o desvio do valor médio associado ao nível de confiança desejado;

- $p$ é a proporção que esperamos encontrar.

Para esse estudo consideramos orientações do Banco Mundial, mais detalhes em Pesquisa (2011), com objetivo de manter certa similaridade com outros estudos com mesmos objetivos, baseados nisso consideramos o nível de confiança como sendo $95 \%$, o que significa pela forma da distribuição normal padrão que $Z=1,96$. A margem de erro que admitimos será de $e=0,037$ e como não se tem nenhuma informação sobre o valor que esperamos encontrar, usamos $p=0,5$; o tamanho populacional será $N=4.900$, ficando assim após a aplicação direta da equação (2.1), $\operatorname{com} n=614$. 
Para a realização desse processo foram definidos 4 critérios de precisão: Região, dependência administrativa, porte da escola e a proficiência em matemática de 2009 no IDEB. Primeiramente construímos a variável Região, baseado em classificação colocada pelo IBGE (Instituto Brasileiro de Geografia e Estatística), o Estado de São Paulo está dividido em 15 regiões, são elas: Presidente Prudente, Araçatuba, Jales, São José do Rio Preto, Marília, Bauru, São Carlos, Ribeirão Preto, Registro, Itapetininga, Piracicaba, Campinas, Jundiaí, São José dos Campos, São Paulo.

No Apêndice B, temos a relação das regiões e os municípios que as compõe. Tendo como base critérios empíricos, consideramos sendo uma classe um conjunto de 40 alunos, convencionou-se que quando uma escola tem 2 turmas ou menos ela é uma escola pequena e acima de 5 turmas é uma escola grande, foi construída assim a variável PORTE_ESCOLAR, que será dada da seguinte forma:

- PEQUENO, se a escola tem menos de 80 alunos cursando o nono ano do ensino fundamental;

- MÉDIO, se a escola tem entre 80 e 160 alunos cursando o nono ano do ensino fundamental;

- GRANDE, se a escola tem mais de 160 alunos cursando o nono ano do ensino fundamental.

Baseado na proficiência em matemática da Prova Brasil do ano de 2009, foi construída também a variável QUARTIS onde as notas dos alunos são agrupadas em quatro grupos baseados em seus quartis, essa variável foi construída da forma:

- ABAIXO DO PERCENTIL 25, se a proficiência em matemática média de 2009 foi menor do que 8.785;

- ENTRE O PERCENTIL 25 E 50, se a proficiência em matemática média de 2009 estiver entre 8.785 e 9.807 ;

- ENTRE O PERCENTIL 50 E 75, se a proficiência em matemática média de 2009 estiver entre 9.807 e 10.910 ;

- ACIMA DO PERCENTIL 75, se a proficiência em matemática média de 2009 foi maior do que 10.910 .

Para alocar as escolas segundo o tamanho amostral considerado, multiplicamos o número de escolas por região pela fração $n / N$. Na Tabela 2, temos o número de escolas a ser sorteadas por região mediante ao número de escolas por região.

Nas Tabelas 33 até 47, que podem ser encontradas no apêndice B, temos uma visão específica da amostra dos dados em cada região, aqui é importante ressaltar que as informações nas tabelas aqui referidas diferem da Tabela 2, por questões de arredondamento. 
Tabela 2 - Demonstrativo do número de escolas por região amostrada

\begin{tabular}{ccc}
\hline Região & Número de escolas & Quantidade amostrada \\
\hline Presidente Prudente & 119 & 15 \\
Araçatuba & 88 & 11 \\
Jales & 73 & 9 \\
São José do Rio Preto & 137 & 18 \\
Marília & 141 & 18 \\
Bauru & 181 & 23 \\
São Carlos & 104 & 13 \\
Ribeirão Preto & 269 & 34 \\
Registro & 87 & 11 \\
Itapetininga & 147 & 19 \\
Piracicaba & 162 & 21 \\
Campinas & 462 & 59 \\
Jundiaí & 327 & 42 \\
São José dos Campos & 321 & 41 \\
São Paulo & 2182 & 280 \\
\hline
\end{tabular}

Após serem fixadas, os quatro critérios acima citados e alocados as 614 escolas sorteamos 20 alunos por escola e por fim temos uma amostra com 12.280 alunos, que constituem em 2.204 turmas, 614 escolas, 225 municípios e 15 regiões. Na Figura 3, temos um boxplot da proficiência em matemática em cada região, a partir desse comparativo há evidências de que não há diferença entre a proficiência em matemática nas diferentes regiões.

Na Tabela 32 temos as variáveis dicotomizadas, bem como as categorias resultantes, os códigos resultante (serão sempre 0 ou 1) e a frequência amostral. Na Tabela 31 temos a codificação das variáveis com mais de uma categoria, essa codificação é usada para a dicotomização das variáveis.

Nas Figuras 4 até 6, baseado nos dados amostrados, temos o boxplot das variáveis mencionadas na seção anterior, variáveis essas que foram mais utilizadas em outros estudos educacionais, aos observarmos esses gráficos há indícios de que não há diferença significativa entre grupos para cada uma das variáveis.

No próximo capítulo abordamos os aspectos teóricos relativos aos modelos multiníveis, são eles: formulação matemática, estimação dos parâmetros, testes de hipótese, entre outros. 


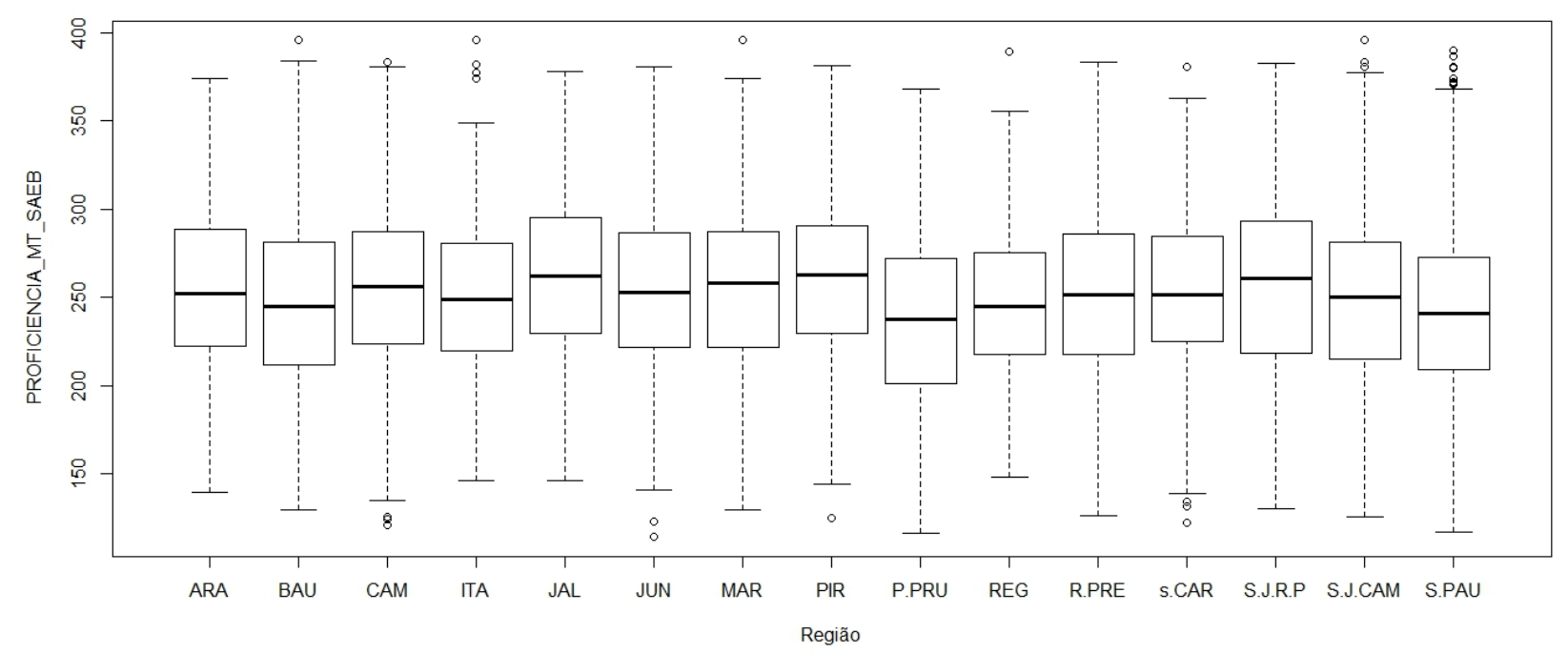

Figura 3 - Box plot da variável de interesse, PROFICIENCIA_MT_SAEB em cada uma das 15 regiões destacadas anteriormente.
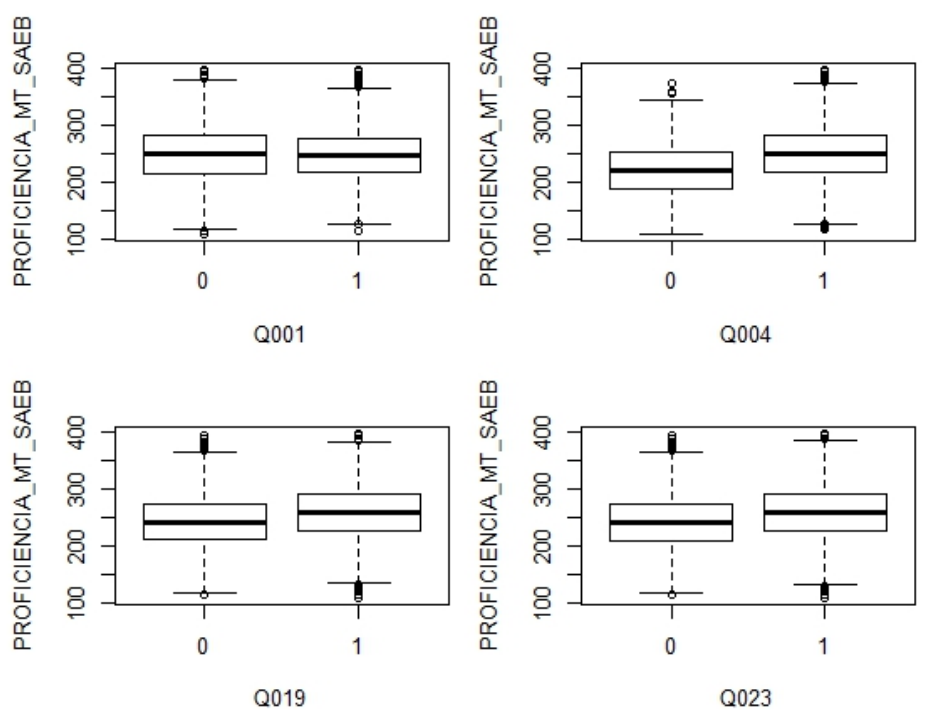

Figura 4 - Box plot da variável de interesse, PROFICIENCIA_MT_SAEB pelas covariáveis Q001, Q004, Q019 e Q023. 

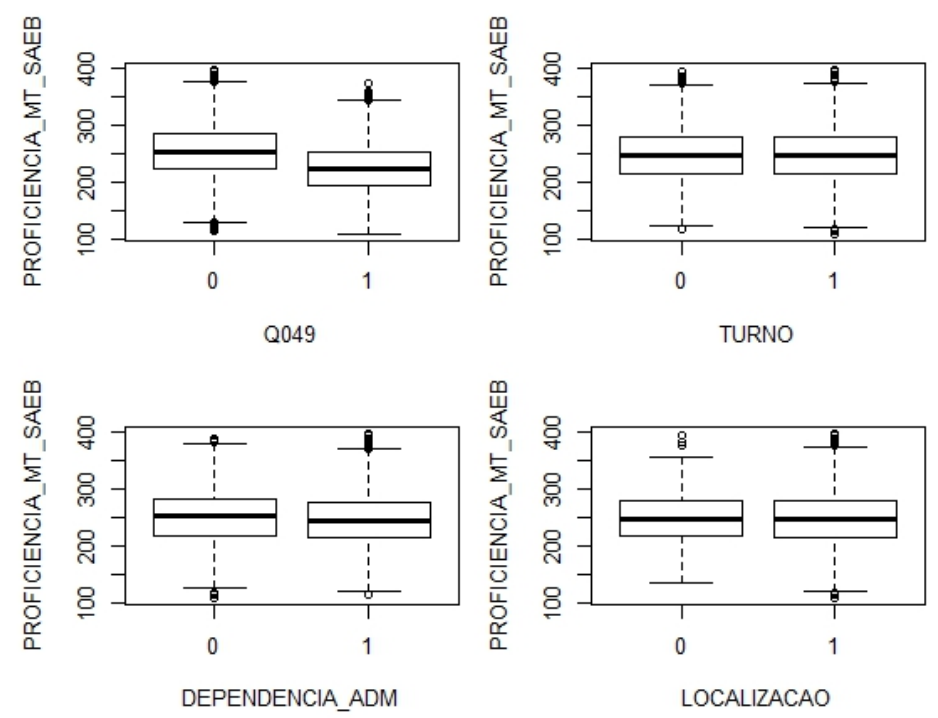

Figura 5 - Box plot da variável de interesse, PROFICIENCIA_MT_SAEB pelas covariáveis Q049, TURNO, DEPENDENCIA_ADM e LOCALIZACAO.

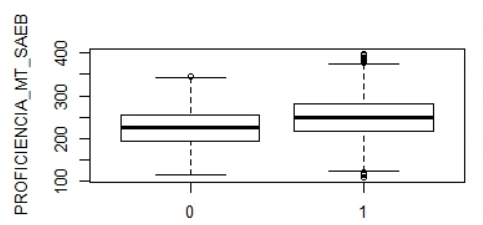

Q020

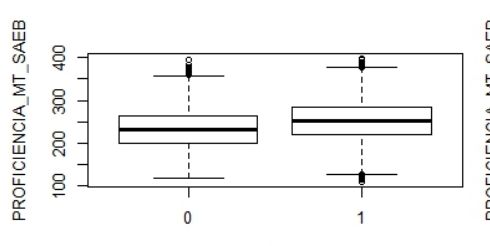

Q044

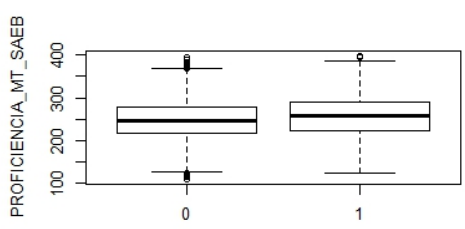

Q033

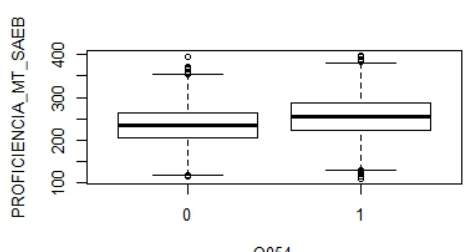

0054

Figura 6 - Box plot da variável de interesse, PROFICIENCIA_MT_SAEB pelas covariáveis Q020, Q033, Q044 e Q054. 
CAPÍTULO

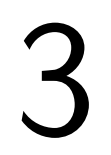

\section{MODELO MULTINÍVEL COM RESPOSTA NORMAL}

Neste capítulo apresentamos a estrutura geral dos modelos multiníveis, falamos a respeito da estimação de parâmetros dessa classe de modelos e testes de hipóteses. Partimos de uma abordagem bem simples que é um modelo de regressão linear simples para uma mais elaborada, com coeficientes aleatórios e por fim falamos a respeito do enfoque bayesiano.

Quando, em alguns casos, a independência das observações é violada, como o contexto escolar, as observações podem ser separadas em grupos (alunos, turmas, escolas, municípios, etc.), que possuem certas similaridades, que têm uma relevância considerável para o desempenho dos alunos, por exemplo, dois alunos de uma mesma turma podem compartilhar de características similares, por isso é usual incluir essa correlação no modelo. Uma alternativa para resolver esse problema seria o ajuste de um modelo de regressão multinível, tal modelo possibilitaria a correção de problemas relativos à estimação dos parâmetros, testes de hipóteses e intervalos de confiança.

Na Figura 7, apresentamos uma estrutura de três níveis, considerando a ótica de um problema com dados educacionais.

\subsection{Modelos de regressão e suposições}

No modelo de regressão linear simples, pode-se estudar a relação de uma variável explicativa e uma variável resposta, da seguinte forma:

$$
y_{i}=\beta_{0}+\beta_{1} x_{i}+\varepsilon_{i}
$$

com $i=1,2, \ldots, n$, onde:

- $y_{i}$ representa a resposta do $i$-ésimo indivíduo; 


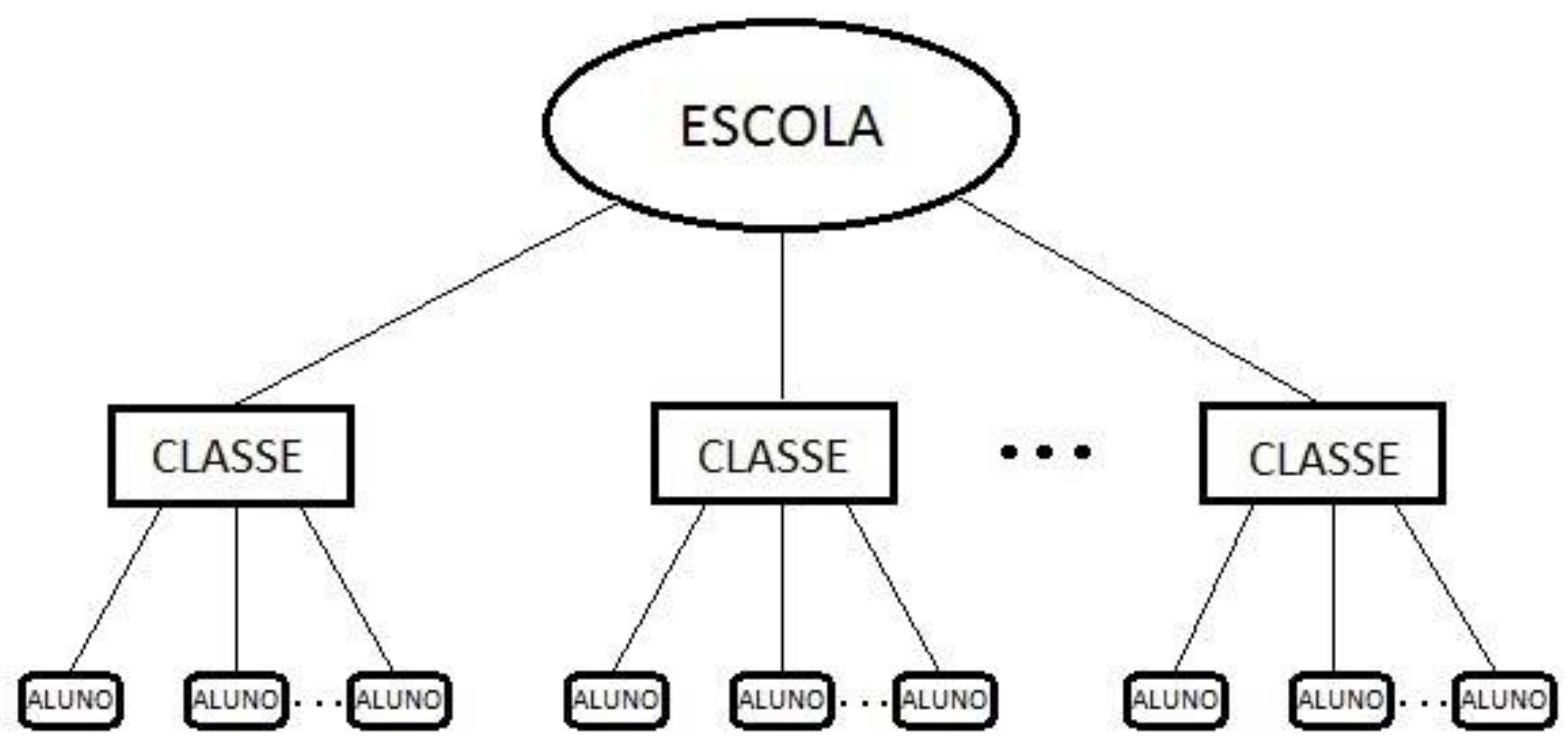

Figura 7 - Esquema representativo de uma estrutura hierárquica de três níveis.

- $\beta_{0}$ é o valor esperado da variável resposta $y_{i}$, quando $x_{i}$ é zero;

- $\beta_{1}$ é a mudança esperada na variável resposta $y_{i}$, quando $x_{i}$ aumenta uma unidade;

- $x_{i}$ é a variável explicativa do $i$-ésimo indivíduo;

- $\varepsilon_{i} \sim N\left(0, \sigma^{2}\right)$ e todos os $\varepsilon_{i}$ são independentes.

Na próxima seção fazemos a construção de modelos multiníveis, para dois níveis e também abordamos sua forma matricial.

\subsection{Modelo de regressão com dois níveis}

Em um exemplo de modelo de regressão com dois níveis, há $n_{j}$ unidades do nível 1, para cada uma das $j$ unidades do nível 2, com $j=1,2, \ldots, J$. Assim no nível 1, o modelo será representado na forma:

$$
y_{i j}=\beta_{0 j}+\beta_{1 j} x_{i j}+\varepsilon_{i j}
$$

com $i=1,2, \ldots, n_{j}$ e $j=1,2, \ldots, J$ em que:

- $y_{i j}$ é a variável resposta do $i$-ésimo indivíduo do nível 1, do j-ésimo grupo;

- $x_{i j}$ é a variável explicativa referente ao $i$-ésimo indivíduo do nível 1, agrupadas para a j-ésimo grupo do nível 2 ;

- $\beta_{0 j}$ é o intercepto para a $j$-ésimo grupo; 
- $\beta_{1 j}$ é a inclinação associada a variável explicativa $x_{i j}$, da $i$-ésima unidade do nível 1 para a $j$-ésimo grupo;

- $\varepsilon_{i j}$ é o erro aleatório associado a $i$-ésima unidade do nível 1, do $j$-ésimo grupo do nível 2 , com as suposições: $\varepsilon_{i j} \sim N\left(0, \sigma^{2}\right)$ e todos os $\varepsilon_{i j}$ são independentes.

O intercepto $\beta_{0 j}$ é o valor esperado da variável resposta $y_{i j}$ no $j$-ésimo grupo, quando $x_{i j}$ for igual a zero, assim para o nível 2 teremos $J$ modelos iguais aos mostrados em (3.2), em que para cada modelo há interceptos aleatórios $\beta_{0 j}$ e inclinações aleatórias $\beta_{1 j}$ diferentes para $j=1,2, \ldots, J$. Esses coeficientes podem ser modelados na seguinte forma:

$$
\begin{aligned}
& \beta_{0 j}=\gamma_{00}+v_{0 j}, \\
& \beta_{1 j}=\gamma_{10}+v_{1 j},
\end{aligned}
$$

onde:

- $\gamma_{00}$ é o valor esperado dos interceptos nas unidades do nível 2;

- $\gamma_{10}$ é o valor esperado das inclinações na população de nível 2;

- $v_{0 j}$ é o efeito aleatório no intercepto $\beta_{0 j}$ da j-ésima unidade do nível 2;

- $v_{1 j}$ é o efeito aleatório na inclinação $\beta_{1 j}$ da j-ésima unidade do nível 2.

Assumimos ainda as suposições: $v_{0 j} \sim N\left(0, \tau_{00}\right) ; v_{1 j} \sim N\left(0, \tau_{11}\right)$; todos os $v_{0 j}$ e $v_{1 j}$ são independentes entre si e também de cada $\varepsilon_{i j}$ correspondente. Logo podemos afirmar que $\beta_{0 j} \sim N\left(\gamma_{00}, \tau_{00}\right)$ e $\beta_{1 j} \sim N\left(\gamma_{10}, \tau_{11}\right)$.

- $\tau_{00}$ é a variância populacional dos interceptos;

- $\tau_{11}$ é a variância populacional das inclinações;

- $\tau_{01}$ é a covariância entre $\beta_{0 j}$ e $\beta_{1 j}$.

Com o intuito de melhor explicar a variabilidade do nível 2, pode ser necessária a inclusão variáveis explicativas no respectivo nível 2, considere $w_{j}$ essa variável, assim podemos reescrever as equações (3.3) da seguinte forma:

$$
\begin{aligned}
& \beta_{0 j}=\gamma_{00}+\gamma_{01} w_{j}+v_{0 j}, \\
& \beta_{1 j}=\gamma_{10}+\gamma_{11} w_{j}+v_{1 j}
\end{aligned}
$$

em que: 
- $\gamma_{01}$ é o coeficiente associado a variável explicativa $w_{j}$ do nível 2 , referente ao intercepto do nível 1;

- $\gamma_{11}$ é o coeficiente associado a variável explicativa $w_{j}$ do nível 2, referente à inclinação do nível 1.

Aqui assumimos as suposições: $v_{0 j} \sim N\left(0, \tau_{00}\right) ; v_{1 j} \sim N\left(0, \tau_{11}\right)$; todos os $v_{0 j}$ e $v_{1 j}$ são independentes entre si e também de cada $\varepsilon_{i j}$ correspondente; $\operatorname{cov}\left(v_{0 j}, v_{1 j}\right)=\tau_{01}$. Observe que $\tau_{00}, \tau_{11}, \tau_{01}$ são componentes de variância. Substituindo as equações (3.4) em (3.2), temos que:

$$
y_{i j}=\gamma_{00}+\gamma_{01} w_{j}+\gamma_{10} x_{i j}+\gamma_{11} w_{j} x_{i j}+v_{0 j}+v_{1 j} x_{i j}+\varepsilon_{i j},
$$

Assim $y_{i j}=\left(\gamma_{00}+\gamma_{01} w_{j}+v_{0 j}\right)+\left(\gamma_{10}+\gamma_{11} w_{j}+v_{1 j}\right) x_{i j}+\varepsilon_{i j}$. O modelo (3.5) leva em consideração diversos tipos de componentes, sejam eles de nível 1, nível 2, interações entre os níveis.

Os resultados que apresentamos nesta seção retratam um modelo com apenas uma covariável. De forma natural, eles podem ser estendidos para $t$ covariáveis. Sejam $x_{1}, x_{2}, \ldots, x_{r}$, covariáveis do nível 1 e $w_{1}, w_{2}, \ldots, w_{s}$, covariáveis de nível 2 , assim o modelo com essas $t=r+s$ covariáveis será dado, no nível 1 e nível 2, respectivamente, por:

$$
\begin{aligned}
& y_{i j}=\beta_{0 j}+\beta_{1 j} x_{1 i j}+\beta_{2 j} x_{2 i j}+\ldots+\beta_{r j} x_{r i j}+\varepsilon_{i j}, \\
& \beta_{q j}=\gamma_{q 0}+\gamma_{q 1} w_{1 j}+\gamma_{q 2} w_{2 j}+\ldots+\gamma_{q s} w_{s j}+v_{q j},
\end{aligned}
$$

onde $i=1,2, \ldots, n_{j}, j=1,2, \ldots, J$ e $q=1,2, \ldots, p$.

Aqui, temos suposições que:

- $\varepsilon_{i j} \sim N\left(0, \sigma_{e}^{2}\right)$

- $\beta_{q j} \sim N\left(0, \sigma_{v}^{2}\right)$

- todos os $\beta_{q j}$ são independentes entre si e com relação aos $\varepsilon_{i j}$.

Na próxima seção apresentamos técnicas de estimação dos parâmetros dos modelos aqui apresentados.

\subsection{Estimação de parâmetros}

O método de máxima verossimilhança é a maneira mais utilizada para obter as estimativas dos coeficientes nos modelos multiníveis, pois tem a vantagem de produzir estimativas que são eficientes, assintoticamente eficientes e consistentes, quando as condições de regularidade estão satisfeitas, por exemplo, o parâmetro $\boldsymbol{\beta}$ é identificável, $f(\mathbf{y} \mid \boldsymbol{\beta})$ é diferenciável em $\boldsymbol{\beta}$, note ainda 
que o espaço paramétrico contém um conjunto aberto $\Omega$, do qual o verdadeiro valor do parâmetro está no interior de $\Omega$, a densidade $f(\mathbf{y} \mid \boldsymbol{\beta})$ é três vezes diferenciável em relação à $\boldsymbol{\beta}$, mais detalhes ver Casella e Berger (2002).

No método de máxima verossimilhança, podem ser usadas duas funções:

- verossimilhança completa: coeficientes da regressão e os componentes da variância são incluídos na função de verossimilhança.

- verossimilhança restrita: os componentes da variância são incluídos na função de verossimilhança e os coeficientes da regressão são estimados na segunda etapa.

A verossimilhança completa não pode ser maximizada analiticamente, para isso podemse utilizar alternativas como o algoritmo de escore de Fisher, descrito com detalhes em Osio (2013). Quando trabalhamos com a verossimilhança restrita, os estimadores REML podem ser obtidos, segundo Patterson e Thompson (1971), dividindo-se a função de verossimilhança em duas partes, uma referente aos efeitos fixos e outra aos efeitos aleatórios.

Computacionalmente, a estimação de parâmetros é feita utilizando os pacotes lme4 ou nlme, mais detalhes sobre estes pacotes podem ser vistos em Bates (2010) e Bliese (2006), respectivamente.

\subsection{Testes de Hipóteses}

O modelo com diversos níveis, deve ser testado em relação a muitos aspectos, um primeiro problema a ser testado é em que nível uma determinada variável deve ser inserida, para obter uma resposta a essa questão deve levar em consideração o contexto em que o banco de dados está inserido e o objetivo da análise.

A hipótese de interesse neste caso é da forma $H_{0}: \gamma_{k}=0$, onde $\gamma_{k}$ é um elemento do vetor de efeitos fixos. A estatística de teste é obtida considerando o estimador de máxima verossimilhança restrita para o erro padrão, dado por:

$$
t=\frac{\hat{\gamma}_{k}}{\sqrt{\hat{m}_{k}}}
$$

onde $m_{k}$ é a variância de $\hat{\gamma}_{k}$. A estatística dada em (3.6) segue uma distribuição t-student para dados balanceados e para algumas situações de desbalanceamento, para saber mais a respeito dos graus de liberdade ver, por exemplo Sullivan, Dukes e Losina (1999). Para testar os componentes de variância da matriz $D$, a hipótese de interesse é da forma $H_{0}: \tau_{k l}=0$. Ressaltamos que pelo fato da hipótese de interesse estar alocada na fronteira do espaço paramétrico, não é possível encontrar um conjunto aberto $\Omega$, que contenha a hipótese $\tau_{k l}=0$ e ainda esteja contido no 
espaço paramétrico. Desta forma não é tarefa fácil realizar teste de hipótese para componentes de variância, Russo, Aoki e Paula (2012) traz uma alternativa viável para solucionar esse problema.

Em Sullivan, Dukes e Losina (1999), há outros testes que também podem ser feitos para efeitos aleatórios. Neste caso a hipótese de interesse será da por $H_{0}: v_{k}=0$, onde $v_{k}$ é um elemento do vetor de efeitos aleatórios, segundo Sullivan, Dukes e Losina (1999), tal estatística é obtida levando em consideração a estimativa do efeito aleatório e erro padrão, ela será da forma:

$$
t=\frac{\hat{v_{k}}}{\sqrt{\hat{r_{k}}}}
$$

onde $r_{k}$ é a variância de $\hat{v_{k}}$.

Assim como no caso dos efeitos fixos, a estatística dada em (3.7) segue uma distribuição t-student para dados balanceados e para algumas situações de desbalanceamento.

Na próxima seção apresentamos uma breve introdução de como são tratados os modelos multiníveis bayesianos.

\subsection{Enfoque bayesiano}

Quando se trata de um modelo de regressão usual, o problema se resume a aplicação do teorema de Bayes para a obtenção de uma distribuição a posteriori do parâmetro de interesse, quando assumimos distribuição a priori uniforme(proporcional a uma constante), a distribuição a posteriori é igual à verossimilhança. Quando se trata de uma regressão multinível, Gelman e Hill (2006) considera um modelo simples sem preditores, com um nível, dado por:

$$
\begin{aligned}
& y_{i j} \sim N\left(\beta_{0 j}, \sigma_{\varepsilon}^{2}\right), \\
& \beta_{0 j} \sim N\left(\gamma_{00}, \sigma_{v}^{2}\right),
\end{aligned}
$$

para $i=1,2, \ldots, n_{j}$ e para $j=1, \ldots, J$. Se pensarmos em estimativas clássicas todos os elementos do segundo nível são considerados equivalentes, isto é, $\beta_{01}=\beta_{02}=\ldots=\beta_{0 J}=\gamma_{00}$, desta forma o modelo (3.8) se reduz a $y_{i j} \sim N\left(\gamma_{00}, \sigma_{\varepsilon}^{2}+\sigma_{v}^{2}\right)$, para qualquer observação de $y$. Assim, para cada um dos $j$ indivíduos do nível 2 , teremos que $\hat{\beta_{0 j}}=\gamma_{00}$.

No modelo multinível, cada elemento do nível é estimado sozinho, de modo que, cada $\beta_{0 j}$ é dado por $\overline{y_{i j}}$, a média das observações de um dos $j$ indivíduos no nível 2. O modelo (3.8) têm coeficientes da regressão ao nível 2, dado por $\beta_{01}=\beta_{02}=\ldots=\beta_{0 J}$ e hiperparâmetros $\gamma_{00}, \sigma_{\varepsilon}^{2}$ e $\sigma_{v}^{2}$, a estimativa multinível é obtida supondo que os hiperparâmetros são conhecidos e daí é feita a estimação de cada $\beta_{0 j}$, observe que a estimativa estará compreendida entre $\overline{y_{i j}}$ e $\gamma_{00}$, 
isto é, se considerarmos os hiperparâmetros conhecidos teremos que:

$$
\beta_{0 j} \mid y, \gamma_{00}, \sigma_{\varepsilon}^{2}, \sigma_{v}^{2} \sim N\left(\hat{\gamma_{00}}, V_{j}\right)
$$

para $j=1, \ldots, J$. Assim a estimativa e a variância da estimativa são, respectivamente, dadas por:

$$
\hat{\beta_{0 j}}=\frac{\frac{n_{j}}{\sigma_{\varepsilon}^{2}} y_{i j}+\frac{1}{\sigma_{v}^{2}} \gamma_{00}}{\frac{n_{j}}{\sigma_{\varepsilon}^{2}}+\frac{1}{\sigma_{v}^{2}}}, V_{j}=\frac{1}{\frac{n_{j}}{\sigma_{\varepsilon}^{2}}+\frac{1}{\sigma_{v}^{2}}},
$$

onde $n_{j}$ é o tamanho do grupo $j$ no nível 2. Note que a estimativa $\hat{\beta_{0 j}}$ pode ser interpretada como a média ponderada entre $\overline{y_{i j}}$ e $\gamma_{00}$. Para o grupo $j$ para qual $n_{j}=\sigma_{\varepsilon}^{2} / \sigma_{v}^{2}$, teremos que $\hat{\beta_{0 j}}=0,5 \overline{y_{i j}}+0,5 \gamma_{00}$.

Assim tendo estimado os coeficientes da regressão no nível 2, segundo Gelman e Hill (2006), podemos estimar os hiperparâmetros, a variância dos dados $\sigma_{\varepsilon}^{2}$ pode ser estimada como:

$$
\hat{\sigma}_{\varepsilon}^{2}=\frac{1}{n} \sum_{j=1}^{J} \sum_{i=1}^{n}\left(y_{i j}-\beta_{0 j}\right)^{2} .
$$

A média $\gamma_{00}$ para o nível 2, que pode ser estimado por:

$$
\hat{\gamma_{00}}=\frac{1}{J} \sum_{j=1}^{J} \beta_{0 j}
$$

com uma variância estimada de $\sigma_{v}^{2} / J$, como pode-se notar que na equação (3.12), temos que a estimativa $\gamma_{00}$ é a média dos interceptos $\beta_{0 j}$.

A variância no nível 2, pode ser estimado por:

$$
\hat{\sigma_{v}^{2}}=\frac{1}{J} \sum_{j=1}^{J}\left(\beta_{0 j}-\gamma_{00}\right)^{2}
$$

Para caso com intercepto aleatório, podemos modelar a variável resposta como:

$$
\begin{array}{r}
y_{i j} \sim N\left(\beta_{0 j}+\sum_{k=1}^{m} \beta_{m} x_{m i j}, \sigma_{\varepsilon}^{2}\right), \\
\beta_{0 j} \sim N\left(\gamma_{00}+\gamma_{10} w_{j}, \sigma_{v}^{2}\right),
\end{array}
$$

onde, $m$ é o número de variáveis explicativas no nível 1, $w_{j}$ é uma variável explicativa inserida no nível 2, $\varepsilon_{i j} \sim N\left(0, \sigma_{\varepsilon}^{2}\right)$ e $v_{0 j} \sim N\left(0, \sigma_{v}^{2}\right)$ são os erros aleatórios respectivamente do nível 1 e 
do nível 2. Segundo Gelman e Hill (2006), os $\beta_{0 j}$ têm distribuições a priori distintas e $\gamma_{00}, \gamma_{10} \mathrm{e}$ $w_{j}$ são estimados a partir dos dados e suas distribuições $a$ priori são não informativas.

No processo de estimação dos parâmetros numa perspectiva bayesiana feita ao longo deste trabalho, com execeção dos efeitos aleatórios, no qual assumimos como tendo uma distribuição normal a priori com média 0 e variância $\sigma_{v}^{2}$, assumimos distribuições a priori proporcionais a uma constante para todos os outros hiperparâmetros.

Se considerarmos as inclinações aleatórias podemos reescrever (3.14), como

$$
\begin{gathered}
y_{i j} \sim N\left(\beta_{0 j}+\sum_{k=1}^{m} \beta_{k j} x_{k i j}, \sigma_{\varepsilon}^{2}\right), \\
\left(\begin{array}{c}
\beta_{0 j} \\
\beta_{1 j} \\
\cdots \\
\beta_{m j}
\end{array}\right) \sim N_{m+1}\left(\left(\begin{array}{c}
\gamma_{00}+\gamma_{01} w_{j} \\
\gamma_{10}+\gamma_{11} w_{j} \\
\cdots \\
\gamma_{m 0}+\gamma_{m 1} w_{j}
\end{array}\right),\left(\begin{array}{cccc}
\sigma_{v_{0 j}}^{2} & \rho_{01} \sigma_{v_{0 j}} \sigma_{v_{1 j}} & \cdots & \rho_{0 m} \sigma_{v_{0 j}} \sigma_{v_{m j}} \\
\rho_{10} \sigma_{v_{1 j}} \sigma_{v_{0 j}} & \sigma_{v_{1 j}}^{2} & \cdots & \rho_{1 m} \sigma_{v_{1 j}} \sigma_{v_{m j}} \\
\vdots & \cdots & \ddots & \vdots \\
\rho_{m 0} \sigma_{v_{m j}} \sigma_{v_{0 j}} & \rho_{m 1} \sigma_{v_{m j}} \sigma_{v_{1 j}} & \cdots & \sigma_{v_{m j}}^{2}
\end{array}\right)\right),
\end{gathered}
$$

onde $\rho_{t u}$ é a correlação entre $\beta_{t j}$ e $\beta_{u j}$, para $t=0,1, \ldots, m$ e $u=0,1, \ldots, m$.

Com relação as distribuições a priori, tanto dos parâmetros quanto dos hiperparâmetros, seguem a mesma diretriz dos casos anteriores, conforme é colocado por Gelman e Hill (2006). A estimação dos modelos propostos nesta seção é feita utilizando o pacote RStan, que é uma adaptação da interface Stan, adaptada para ser utilizada na linguagem R. O stan estima modelos bayesianos utilizando um processo Monte Carlo Hamiltoniano (HMC), que é uma adapatação de processo de Monte Carlo cadeia de Markov.

No apêndice D, falamos sobre o processo de HMC e também trazemos os códigos para estimação de modelos de regressão multinível bayesianos. No próximo capítulo falamos a respeito de técnicas para escolhas de modelos, alguns critérios de informação e seleção de variáveis são descritos. 


\section{MÉTODOS DE ESCOLHA DE MODELOS}

Neste capítulo discutimos alguns métodos de seleção de modelos de regressão multinível, sob o enfoque clássico e também sob o enfoque bayesiano e ainda falamos sobre o critério de seleção de modelos Lasso, para posteriormente serem aplicados a dados educacionais. Falamos a respeito dos critérios de informação que geralmente são os mais usados, para modelos clássicos e também para modelos bayesianos, abordamos as seguintes medidas de informação: AIC, AICc, BIC, DIC, looic, WAIC, EAIC e EBIC.

\subsection{Seleção de Modelos: Caso Clássico}

O critério mais utilizado na atualidade é o AIC (Akaike Information Criterion), proposto por Akaike (1998). Esse método foi construído baseado na distância de Kullback-Leiber, sendo assim ele pode ser enxergado como sendo a distância entre um modelo verdadeiro e um modelo candidato. É aconselhável utilizar AIC apenas para uma amostra de tamanho superior a 40 vezes o número de parâmetros do modelo. Diante de tais dificuldades, Sugiura (1978) propôs uma correção para o critério AIC, o AICc que leva em consideração o tamanho da amostra. É fácil ver que o AIC e o AICc coincidem assintoticamente. Ao contrário desses métodos o BIC (Bayesian Information Criterion), proposto por Schwarz et al. (1978), é um método consistente, ou seja, ele escolhe o modelo correto, desde que ele esteja entre aqueles que estão sendo testados. Emiliano (2009) faz algumas considerações acerca desses métodos e ressalta que:

- tanto o AIC quanto o BIC fundamentam-se no logaritmo da função de verossimilhança, impondo entretanto diferentes penalizações;

- o AIC e o BIC podem ser utilizados não somente para modelos encaixados, como também para modelos não encaixados; 
- para $n>8$, o valor do AIC para um determinado modelo será sempre menor que o valor do BIC, mas os resultados não necessariamente serão menores;

- o AIC e o BIC servem para comparar quaisquer quantidades de modelos, e não somente dois;

- o AIC e o BIC são critérios assintóticos e já existem correções para esses;

- o AIC e o BIC servem para estudar estruturas de covariâncias;

- a seleção de modelos é feita pelo pesquisador e, se somente modelos ruins forem selecionados, o AIC fará a seleção do melhor dentre eles.

A seguir, descrevemos os critérios mencionados.

\subsubsection{AIC (Akaike Information criterion)}

O critério AIC, proposto por Akaike (1998), é dado por:

$$
A I C=-2 \sum_{i=1}^{n} \ln \left(\hat{\boldsymbol{y}_{i j}}, \boldsymbol{y}_{i j}\right)+2 m
$$

onde $\boldsymbol{y}_{i j}$ é o $i$-ésimo valor da variável resposta paro o $j$-ésimo grupo, $\hat{\boldsymbol{y}_{i j}}$ é o valor predito de $\boldsymbol{y}_{i j}$, $\sum_{i=1}^{n} \ln \left(\hat{y_{i j}}, \boldsymbol{y}_{i j}\right)$ é o logaritmo da função de verossimilhança do modelo e $m$ é o número real de parâmetros. O AIC pode ser enxergado como a distância entre o "modelo verdadeiro" e o "modelo candidato". Ele surgiu no intuito de escolher o melhor modelo de regressão, quando temos um modelo completo e um modelo reduzido, uma vez que um modelo de ajuste ineficiente pode não trazer uma modelagem estatística adequada, fazendo assim que não seja possível enxergar a verdadeira natureza da variabilidade dos dados. Outro problema que pode ser encontrado é a perda de generalidade do modelo.

O critério AIC é então uma maneira de selecionar o modelo que melhor equilibra esses inconvenientes. Sempre que um melhor modelo é selecionado, outras análises podem ser feitas. É importante destacar que o modelo selecionado é aquele que tem o menor AIC, ressaltando sempre a importância de todos os modelos candidatos estarem bem estimados.

\subsubsection{AICC (AIC Corrigido)}

Uma das deficiências encontradas ao se utilizar o critério de informação AIC, é que quando se tinha pequenas amostras, há uma situação de overfit. Isto se deve ao fato de que o critério de informação de Akaike foi construído levando em consideração propriedades assintóticas, 
sendo assim Sugiura (1978) propôs uma correção para este critério de informação, sua expressão pode ser obtida da seguinte forma:

$$
A I C c=-2 \sum_{i=1}^{n} \ln \left(\hat{y_{i j}}, \boldsymbol{y}_{i j}\right)+\left(\frac{2 n}{n-p-1}\right) m
$$

onde $n$ é o tamanho amostral. Observe que a medida que $n$ cresce os critérios de informação AIC e AICc se aproximam, assim ao comparar modelos escolhemos sempre o modelo com o menor AICc.

\subsubsection{BIC (Bayesian Information Criterion)}

O Critério BIC, proposto por Schwarz et al. (1978), é dado por:

$$
B I C=-2 \sum_{i=1}^{n} \ln \left(\hat{y_{i j}}, \boldsymbol{y}_{i j}\right)+m \log (n),
$$

onde $\boldsymbol{y}_{i j}$ é o $i$-ésimo valor da variável resposta para o $j$-ésimo grupo, $\hat{y_{i j}}$ é o valor predito de $\boldsymbol{y}_{i j}$, $m$ é o número de parâmetros, $\sum_{i=1}^{n} \ln \left(\hat{y_{i j}}, \boldsymbol{y}_{i j}\right)$ é o logaritmo da função de verossimilhança do modelo e $n$ é o número de observações.

Umas das características mais interessantes desse critério é que ele é baseado no cálculo do logaritmo da função de verossimilhança não sendo necessário a especificação de distribuições a priori. Um dos critérios de comparação de modelos sob enfoque bayesiano é o fator de Bayes, mais detalhes sobre esse critério, ver por exemplo Missão (2010). Nota-se que em certos casos a seleção de modelos utilizando o fator de Bayes e o BIC são equivalentes, desta forma o BIC é usado em muitos problemas de modelagem bayesiana onde as distribuições a priori são difíceis de definir com precisão.

Assim como no caso do AIC, o BIC penaliza modelos com muitas variáveis, sendo que valores menores são preferíveis.

\subsection{Seleção de Modelos: Caso Bayesiano}

Entre os critérios Bayesianos apresentados, o que é mais utilizado é o DIC (Deviance Information Criterion), proposto por Spiegelhalter et al. (2002). Ele foi construído baseado no número efetivo de parâmetros, essa medida leva em consideração a complexidade do modelo, e talvez essa seja sua maior deficiência, pois se o modelo em questão contiver uma quantidade muito elevada de parâmetros, a medida número efetivo de parâmetros será negativa.

Spiegelhalter et al. (2014) elenca as críticas mais recorrentes a esse critério de informação, são elas:

- o número efetivo de parâmetros é variante a parametrizações, falta de consistência; 
- não é baseado em um critério preditivo adequado;

- tem uma justificativa teórica fraca.

Ele também traz algumas iniciativas que têm sido feitas com intuito de melhorar o DIC, como por exemplo, uma medida de complexidade alternativa. Contudo nos últimos anos têm se popularizado o critério de informação WAIC, proposto por Watanabe (2010), ele é visto como uma melhoria do DIC para modelos bayesianos. O WAIC foi construído totalmente numa abordagem bayesiana que se assemelha a um processo de validação cruzada leave-one-out. Ele também é invariante a parametrização, ao contrário do DIC. O WAIC e a validação cruzada leave-one-out, são critérios baseados no logaritmo da função densidade de probabilidade $a$ posteriori preditiva. Este trabalho utiliza ainda os critérios EAIC e EBIC, que assim como o DIC, baseiam-se no desvio médio. É importante salientar que esses dois últimos critérios de informação são, o valor esperado dos critérios AIC e BIC.

A seguir descrevemos os critérios de seleção de modelos bayesianos.

\subsubsection{DIC (Deviance Information Criterion)}

O critério de informação do desvio foi proposto por Spiegelhalter et al. (2002) como uma generalização dos critérios AIC e BIC, ele usa em seu cálculo uma medida que leva em consideração a complexidade do modelo. Uma vantagem é que ele é facilmente calculado em amostras geradas via MCMC, o DIC é definido de maneira análoga ao AIC, da seguinte forma:

$$
D I C=p_{D}+\bar{D}
$$

onde $\bar{D}=E_{\boldsymbol{\theta}}(D(\boldsymbol{\theta}))$ é o desvio médio esperado, ou seja, mede o quão bem o modelo se ajusta aos dados. Note que $D(\boldsymbol{\theta})=-2 \log p(\boldsymbol{y} \mid \boldsymbol{\theta})$ é o desvio onde $\boldsymbol{y}$ são os dados, $\boldsymbol{\theta}$ são os parâmetros desconhecidos do modelo e $p(\boldsymbol{y} \mid \boldsymbol{\theta})$ é função de verossimilhança, temos também que $p_{D}=\bar{D}-D(\hat{\boldsymbol{\theta}})$, onde $\hat{\boldsymbol{\theta}}$ é a estimativa pontual da distribuição a posteriori dos parâmetros de interesse. Assim como no critério AIC, o modelo com o menor DIC deve ser selecionado. No caso específico de modelos multiníveis, Gelman e Hill (2006) nos fala de certa instabilidade no cálculo do número efetivo de parâmetros sugerindo que, nesta classe de modelos de regressão, o DIC não seja usado como critério definitivo.

\subsubsection{WAIC (Widely Applicable Information Criterion)}

O critério WAIC proposto por Watanabe (2010) pode ser visto como uma melhoria do critério informação desvio (DIC) para modelos bayesianos, pois o DIC produz estimativas pontuais que em alguns casos podem ser negativos, já o WAIC utiliza distribuições a posteriori, o que o torna invariante à parametrizações. Esse critério baseia-se também numa medida conhecida como o número efetivo de parâmetros, que pode ser interpretado segundo Vehtari, Gelman e 
Gabry (2016) como o grau de complexidade do modelo. Lembrando que o critério de informação desvio, proposto por Spiegelhalter et al. (2002), é obtido pela expressão $D I C=2 \bar{D}-D(\overline{\boldsymbol{\theta}})$, onde $\bar{D}=E_{\boldsymbol{\theta}}(D(\boldsymbol{\theta}))$ e $D(\boldsymbol{\theta})=-2 \log (p(\boldsymbol{y} \mid \boldsymbol{\theta}))+C$, note que $C$ é uma constante desconhecida.

Para a construção da medida em questão, Vehtari, Gelman e Gabry (2016) define uma medida de precisão preditiva esperada para um novo conjunto de observações, que será dada por:

$$
e l p d=\sum_{i=1}^{n_{j}} \sum_{j=1}^{J} \int p_{t}\left(\widetilde{y}_{i j}\right) \log p\left(\widetilde{y}_{i j} \mid \boldsymbol{y}\right) d \widetilde{y}_{i j}
$$

onde $p_{t}\left(\widetilde{y}_{i j}\right)$ é função de distribuição preditiva para novas observações de $\widetilde{y}_{i j}$ e $n_{j}$ é o número de observações do grupo $j$. Lembrando sempre que em inferência bayesiana temos que a distribuição preditiva a posteriori será dada por:

$$
p(\widetilde{y} \mid \boldsymbol{y})=\int p\left(\widetilde{y}_{i j} \mid \boldsymbol{\theta}\right) p(\boldsymbol{\theta} \mid \boldsymbol{y}) d \boldsymbol{\theta}
$$

onde $p(\boldsymbol{\theta} \mid \boldsymbol{y})$ é a distribuição a posteriori e $p(\boldsymbol{\theta})$ é a distribuição a priori.

Define-se também, conforme pode ser encontrado em Vehtari, Gelman e Gabry (2016), o logaritmo da função densidade preditiva, que pode ser obtida pela seguinte expressão:

$$
l p d=\sum_{i=1}^{n_{j}} \sum_{j=1}^{J} \log p\left(y_{i j} \mid \boldsymbol{y}\right)=\sum_{i=1}^{n_{j}} \sum_{j=1}^{J} \log p\left(y_{i j} \mid \boldsymbol{\theta}\right) p(\boldsymbol{\theta} \mid \boldsymbol{y}) d \boldsymbol{\theta} .
$$

Na prática, para estimar lpd usaremos métodos de reamostragem, para a obtenção de simulações da distribuição a posteriori, usamos $\boldsymbol{\theta}^{s}, s=1,2, \ldots, S$, assim teremos que:

$$
l \hat{p} d=\sum_{i=1}^{n_{j}} \sum_{j=1}^{J} \log \left(\frac{1}{S} \sum_{s=1}^{S} p\left(y_{i j} \mid \boldsymbol{\theta}^{s}\right)\right)
$$

Segundo Watanabe (2010), podemos estimar a medida log de precisão preditiva esperada da seguinte forma:

$$
e \hat{p} d_{\text {waic }}=l \hat{p} d-\hat{p}_{\text {waic }}
$$

onde $\hat{p}_{\text {waic }}$ é o número de parâmetros efetivos estimados e pode ser calculado usando a variância a posteriori da distribuição log da densidade preditiva para cada ponto $y_{i j}$ e então, somando todos os pontos obtemos, segundo Vehtari, Gelman e Gabry (2016), que:

$$
\hat{p}_{\text {waic }}=\sum_{i=1}^{n_{j}} \sum_{j=1}^{J} V_{s=1}^{S}\left(\log \left(y_{i j} \mid \boldsymbol{\theta}^{S}\right)\right)
$$


onde $V_{s=1}^{S}$ representa a variância amostral. Se multiplicarmos a medida obtida na equação (4.9) por -2, ela pode ser utilizada para comparar os modelos ajustados, isto é, dados dois modelos (modelo A e modelo B), podemos estimar dois valores $-2 e l p d A_{\text {waic }} \mathrm{e}-2 e l p d B_{\text {waic }}$, das duas medidas aquela que for menor indicará o melhor modelo.

\subsection{3 loo (Leave-one-out cross-validation )}

Assim como o WAIC, o loo (leave-one-out cross-validation) é um método que utiliza o logaritmo da função de verossimilhança avaliada nas simulações da distribuição a posteriori dos parâmetros, apresentamos este conceito via amostragem de importância utilizando a distribuição de Pareto generalizada.

A amostragem por importância consiste em forçar a seleção de um maior número de amostras nas partes mais importantes do problema (eventos que mais contribuem para os parâmetros a serem inferidos), isto é, faz um deslocamento da distribuição para áreas de maior interesse. Esta distorção se faz introduzindo uma nova função distribuição e os valores devem ser corrigidos por um fator peso para não alterar os resultados esperados.

Segundo Vehtari, Gelman e Gabry (2016), podemos estimar a medida log de precisão preditiva loo da seguinte forma:

$$
\operatorname{elpd}_{\text {loo }}=\sum_{i=1}^{n_{j}} \sum_{j=1}^{J} \log p\left(y_{i j} \mid y_{i j-1}\right),
$$

onde $p\left(y_{i j} \mid y_{i j-1}\right)=\int p\left(y_{i j} \mid \boldsymbol{\theta}\right) p\left(\boldsymbol{\theta} \mid y_{i j-1}\right) d \boldsymbol{\theta}$ é a densidade preditiva leave-one-out dada a amostra sem o i-ésimo ponto dos dados para o $j$-ésimo grupo. Vehtari, Gelman e Gabry (2016) propõe uma abordagem utilizando pesos de importância alisados por uma distribuição generalizada de Pareto, ou seja, encaixa-se a essa distribuição na cauda, que consiste nos $20 \%$ de maior importância.

Segundo Vehtari, Gelman e Gabry (2016), esse procedimento baseia-se nos seguintes passos:

- ajustar uma distribuição de Pareto para os raios de importância maiores do que 20\%, esses raios podem ser obtidos pela expressão:

$$
\frac{1}{p\left(y_{i j} \mid \boldsymbol{\theta}^{S}\right)}
$$

- estabilize os raios de importância substituindo os raios maiores do que certo $M$, pelos valores esperados das estatísticas de ordem da distribuição de Pareto ajustada $G^{-1}\left(\frac{z-0.5}{M}\right)$, onde $z=1,2, \ldots, M$, onde é o número de simulações usadas no ajuste da distribuição de Pareto generalizada e $G^{-1}$ é a inversa acumulada da distribuição de Pareto e denote $(w)_{i j}^{s}$, onde $s$ é o índice de da simulação e $i j$ é o índice associado às observações. 
- para garantir a variância finita das estimativas, vamos reescrever o vetor de pesos $\boldsymbol{S}$, como $\boldsymbol{S}^{\frac{3}{4}} \bar{w}$ onde $\bar{w}$ é a média dos pesos suavizados.

Por fim, Vehtari, Gelman e Gabry (2016), ressalta ainda que as etapas anteriormente descritas devem ser realizadas para cada observação e o resultado é um vetor de pesos melhor comportados dos raios de importância bruta descritas acima.

Para analisar a confiabilidade das estimativas é observado o parâmetro de forma da distribuição de Pareto generalizada. Se o parâmetro de forma for menor que 0,5, a variância dos raios de importância bruta é finita e as estimativas convergem rapidamente. Se o parâmetro de forma estiver entre 0,5 e 1, a variância dos raios de importância é infinita, a média existe e assim o teorema do limite central garante a convergência das estimativas. Se o parâmetro de forma for maior que 1, a média dos pesos não existe, sinalizando assim que nesse caso as estimativas loo não são confiáveis, daí seria necessário o uso de outras técnicas. Portanto, a estimativa leave-one-out pode ser calculada pela expressão:

$$
e \hat{p} d_{l o o}=\sum_{i=1}^{n_{j}} \sum_{j=1}^{J} \log \left(\frac{\sum_{s=1}^{S} w_{i}^{s} p\left(y_{i j} \mid \boldsymbol{\theta}^{s}\right)}{\sum_{s=1}^{S} w_{i}^{s}}\right) .
$$

Assim, o critério de informação leave-one-out (looic) será dado por:

$$
\text { looic }=-2 e \hat{l p} d_{l o o}
$$

O modelo que deve ser escolhido é aquele que tem o menor looic. Outros critérios de informação que podem ser calculados utilizando saídas MCMC, em particular o EAIC e o EBIC.

\subsubsection{EAIC (Expected Akaike Information Criterion)}

O EAIC, foi proposto por Brooks et al. (2002), como sendo o valor esperado do AIC, sua expressão é obtida da seguinte forma:

$$
E \hat{A I C}=\bar{D}+2 m
$$

onde, $\bar{D}$ é o desvio médio e $m$ é a quantidade real de parâmetros do modelo em ajuste. Quando estamos comparando dois modelos, consideramos o modelo mais parcimonioso, aquele que possui o menor EAIC. 


\subsubsection{EBIC (Expected Bayesian Information Criterion)}

O EBIC, foi proposto por Carlim e Louis (2001), ele é obtido calculando a esperança matemática da expressão (4.3), sua expressão é dada por:

$$
E \hat{B} I C=\bar{D}+m \log (n),
$$

onde, $\bar{D}$ é o desvio médio, $n$ é o tamanho amostral e $m$ é a quantidade real de parâmetros do modelo em ajuste. Novamente, consideramos o modelo mais preciso, o modelo com o menor EBIC.

\subsection{Seleção de Variáveis}

Outro método que discutimos é o Lasso, que, ao contrário de outros métodos, seleciona variáveis e não modelos, o que de um ponto de vista prático é muito interessante quando se tem uma grande quantidade de preditores, pois se fossem utilizados critérios de seleção de modelos, seria necessário testar todas as combinações possíveis de modelos, o que seria imensamente trabalhoso quando se tem muitas variáveis explicativas. Utilizar o Lasso significa impor uma penalização a função de verossimilhança do modelo, e obter as estimativas do modelo, maximizando essa função, assim alguns coeficientes do modelo serão estimados como sendo zero.

\subsubsection{Lasso}

O estimador lasso foi proposto inicialmente por Tibshirani (1996) para modelos de regressão linear simples, ele minimiza a soma de quadrados das diferenças entre o resultado observado e o modelo ajustado, desde que a soma em módulo dos coeficientes seja inferior a algum valor $s$, ou seja, tal método consiste em utilizar a soma

$$
S=\sum_{i=1}^{n}\left(y_{i^{-}} \beta_{0^{-}} \sum_{j=1}^{p} \beta_{j} x_{j i}\right)^{2}
$$

para estimar $\hat{\beta_{0}}, \hat{\boldsymbol{\beta}}$, onde $\hat{\boldsymbol{\beta}}=\left(\hat{\beta_{1}}, \ldots, \hat{\beta_{p}}\right)^{T}$, sendo que $S$ está sujeito a restrição $\sum_{j=1}^{p}\left|\beta_{j}\right| \leq g$, onde $g \geq 0$ é o parâmetro de restrição, associado ao ajuste deste modelo. Obtemos para $n=2$ estimativas de $\beta_{1}$ e $\beta_{2}$ em função das estimativas de mínimos quadrados, assumindo que elas são ambas positivas.

Nesta seção falamos a respeito desse estimador para modelos lineares multiníveis com dois níveis (mistos) com resposta normal, primeiramente fazemos uma breve introdução dessa classe de modelos bem como de sua notação, posteriormente apresentamos o algoritmo do gradiente ascendente, proposto por Groll e Tutz (2014). 


\subsubsection{Modelos lineares com dois níveis e resposta Normal}

Considere um modelo de regressão, onde a $i$-ésima observação do j-ésimo grupo é obtida através da expressão:

$$
y_{i j}=\boldsymbol{x}_{i j}^{\top} \boldsymbol{\beta}+\boldsymbol{w}_{i j}^{\top} \mathbf{v}_{j}+\varepsilon_{i j}=\eta_{i j}^{\text {param }}+\eta_{i j}^{\text {aleat }}+\varepsilon_{i j}
$$

onde:

- $y_{i j}$ é a $i$-ésima observação no $j$-ésimo grupo, com $i=1,2, \ldots, n_{j}$ e $j=1,2, \ldots, J$;

- $x_{i j}^{\top}=\left(1, x_{i 1}, x_{i 2}, \ldots, x_{i J}\right)$ é o vetor de covariáveis associadas aos efeitos fixos;

- $w_{i j}^{\top}=\left(1, w_{i 1}, w_{i 2}, \ldots, w_{i J}\right)$ é o vetor de covariáveis associadas aos efeitos aleatórios;

- $y_{i j}$ é condicionalmente independente com média $\mu_{i j}=E\left(\mathbf{y}_{i j} \mid \mathbf{v}_{j}, x_{i j}, w_{i j}\right)$ e a variância $\operatorname{var}\left(y_{i j} \mid \mathbf{v}_{j}\right)=\Phi v\left(\mu_{i j}\right)$, onde $v$ é função de variância conhecida e $\Phi$ é o parâmetro de escala;

- $\varepsilon_{i j}$ é o erro aleatório associado a $i$-ésima unidade do nível 1, do $j$-ésimo grupo do nível 2 , com as suposições: $\varepsilon_{i j} \sim N\left(0, \sigma^{2}\right)$ e todos os $\varepsilon_{i j}$ são independentes.

Na componente sistemática do modelo temos que $\eta_{i j}^{\text {param }}=x_{i j}^{\top} \boldsymbol{\beta}$ é dito parâmetro linear, com vetor parâmetro $\boldsymbol{\beta}^{\top}=\left(\beta_{0}, \beta_{1}, \ldots, \beta_{p}\right)^{\top}$ e $\eta_{i j}^{\text {aleat }}=w_{i j}^{\top} \boldsymbol{v}_{j}$ contém um grupo específico de efeitos aleatórios, onde $\boldsymbol{v}_{j} \sim N(\mathbf{0}, Q)$.

Alternativamente para o $j$-ésimo grupo, obtemos que:

$$
y_{j}=X_{j} \boldsymbol{\beta}+W_{j} v_{j}+\boldsymbol{\varepsilon}_{j}
$$

Considerando todas as observações, temos que:

$$
y=X \boldsymbol{\beta}+W \boldsymbol{v}+\boldsymbol{\varepsilon},
$$

onde $X^{\top}=\left[X_{1}^{\top}, \ldots, X_{n}^{\top}\right], W=\operatorname{diag}\left(W_{1}, \ldots, W_{n}\right), \boldsymbol{\varepsilon}^{\top}=\left(\varepsilon_{1}^{\top}, \ldots, \boldsymbol{\varepsilon}_{n}^{\top}\right)$ e $\mathbf{v}^{\top}=\left(v_{1}^{\top}, \ldots, v_{n}^{\top}\right)$ tem distribuição normal com matriz de covariância $Q_{v}=\operatorname{diag}(Q, \ldots, Q)$.

Considere $f\left(y_{i j} \mid x_{i j}, \mathbf{v}_{j}\right)$ a função de verossimilhança. A matriz de covariância $Q_{v} \operatorname{dos}$ efeitos aleatórios $\mathbf{v}_{j}$, depende do vetor de parâmetros desconhecidos. Segundo Groll e Tutz (2014), em problemas de penalização, a função de probabilidade conjunta é especificada por $\boldsymbol{\gamma}^{\top}=\left(\Phi, Q^{\top}\right)$ e o vetor $\boldsymbol{\delta}^{\top}=\left(\boldsymbol{\beta}^{\top}, \boldsymbol{v}^{\top}\right)$.

O logaritmo da função de verossimilhança, nesse caso é:

$$
l(\boldsymbol{\delta}, \boldsymbol{\gamma})=\sum_{j=1}^{n} \log \left(\int f\left(y_{j} \mid \boldsymbol{\delta}, \boldsymbol{\gamma}\right) p\left(v_{j}, \boldsymbol{\gamma}\right) d v_{j}\right)
$$


onde $p\left(v_{j}, \boldsymbol{\gamma}\right)$ é a densidade dos efeitos aleatórios. A equação (4.18) foi resolvida de forma aproximada, por Breslow e Clayton (1993) utilizando o método de Laplace e a sua solução será:

$$
l^{\text {aprox }}(\boldsymbol{\delta}, \boldsymbol{\gamma})=\sum_{j=1}^{n} \log \left(f\left(y_{j} \mid \boldsymbol{\delta}, \boldsymbol{\gamma}\right)\right)-\frac{1}{2} \boldsymbol{v}^{\top} Q Q^{-1} \boldsymbol{v}
$$

onde a penalidade $\boldsymbol{v}^{\top} Q Q^{-1} \boldsymbol{v}$ é devido a aproximação do método de Laplace. Incluindo a penalidade $\lambda \sum_{j=1}^{p}\left|\beta_{i}\right|$ na equação (4.19), teremos que:

$$
l_{\text {pen }}(\boldsymbol{\beta}, \boldsymbol{v}, \boldsymbol{\gamma})=l_{\text {pen }}(\boldsymbol{\delta}, \boldsymbol{\gamma})=l^{\text {aprox }}(\boldsymbol{\delta}, \boldsymbol{\gamma})-\lambda \sum_{j=1}^{p}\left|\beta_{i}\right|
$$

Sendo assim, nosso problema de estimação de parâmetros se reduz a maximização da equação (4.20), para um $\hat{\gamma}$ conhecido, analisamos esse problema de maneira mais profunda na subseção seguinte.

\subsubsection{Algoritmo do Gradiente Ascendente}

Para cada $\boldsymbol{\delta}$ e toda direção $h \in \mathbb{R}^{p+n q}$ podemos definir:

$$
l_{p e n}^{\prime}(\boldsymbol{\delta}, \boldsymbol{h}, \boldsymbol{\gamma})=\lim _{t \rightarrow 0} \frac{1}{t}\left(l_{p e n}(\boldsymbol{\delta}+t \boldsymbol{h}, \boldsymbol{\gamma})-l_{p e n}(\boldsymbol{\delta}, \boldsymbol{\gamma})\right)
$$

O algoritmo do gradiente ascendente usa aproximação em série de Taylor localmente a partir de uma estimativa de $\hat{\boldsymbol{\delta}}$ na direção do gradiente da aproximação de Taylor de segunda ordem, dada por:

$$
\begin{aligned}
& l_{\text {pen }}\left(\hat{\boldsymbol{\delta}}+t s^{\text {pen }}(\hat{\boldsymbol{\delta}}, \boldsymbol{\gamma}), \boldsymbol{\gamma}\right) \approx l_{\text {pen }}(\hat{\boldsymbol{\delta}}, \boldsymbol{\gamma})+t l_{\text {pen }}^{\prime}\left(\hat{\boldsymbol{\delta}}, s^{\text {pen }}(\hat{\boldsymbol{\delta}}, \boldsymbol{\gamma}), \boldsymbol{\gamma}\right)+ \\
& 0,5 t^{2} l_{\text {pen }}^{\prime \prime}\left(\hat{\boldsymbol{\delta}}, s^{\text {pen }}(\hat{\boldsymbol{\delta}}, \boldsymbol{\gamma})\right)
\end{aligned}
$$

onde $t>0$ e onde $s^{\text {pen }}(.,$.$) e l_{\text {pen }}^{\prime \prime}(.,$.$) são definidos no passo 2$ do algoritmo. Uma questão central nesse processo é encontrar o $t$ ótimo para a penalização.

\subsubsection{Algoritmo g/mmLasso: caso particular (normal)}

\section{Inicialização}

Computar os valores iniciais $\hat{\boldsymbol{\beta}}^{(0)}, \hat{\boldsymbol{v}}^{(0)}, \hat{\boldsymbol{\gamma}}^{(0)}$ e $\hat{y}^{(0)}=X \hat{\boldsymbol{\beta}}^{(0)}+W \hat{\boldsymbol{v}}^{(0)}$.

\section{Iteração}


Para $l=1,2, \ldots$ até a convergência utilize os seguintes procedimentos:

Calcule o gradiente da função log verossimilhança para um dado $\hat{\boldsymbol{\gamma}}^{(l-1)}$, para tanto considere

$$
s(\boldsymbol{\delta})=\frac{\partial l^{\text {aprox }}(\boldsymbol{\delta})}{\partial \boldsymbol{\delta}}
$$

e a partir daí teremos que $s_{0}^{\text {pen }}\left(\hat{\boldsymbol{\delta}}^{(l-1)}\right)=s_{0}\left(\hat{\boldsymbol{\delta}}^{(l-1)}\right), s_{i}^{\text {pen }}\left(\hat{\boldsymbol{\delta}}^{(l-1)}\right)=s_{i}\left(\hat{\boldsymbol{\delta}}^{(l-1)}\right), i=p+1, \ldots, p+$ $n s$. Além disso, para $i=1, \ldots, p$ temos que $s_{i}^{p e n}\left(\hat{\boldsymbol{\delta}}^{(l-1)}\right)=s_{i}\left(\hat{\boldsymbol{\delta}}^{(l-1)}\right)-\lambda \operatorname{sign}\left(\hat{\boldsymbol{\beta}}_{i}^{(l-1)}\right)$, se $\hat{\boldsymbol{\beta}}_{i}^{(l-1)} \neq$ $0 ; s_{i}^{\text {pen }}\left(\hat{\boldsymbol{\delta}}^{(l-1)}\right)=s_{i}\left(\hat{\boldsymbol{\delta}}^{(l-1)}\right)-\lambda \operatorname{sign}\left(\hat{\boldsymbol{\delta}}_{i}^{(l-1)}\right)$, se $\hat{\boldsymbol{\beta}}_{i}^{(l-1)}=0$ e $\left|s_{i}\left(\hat{\boldsymbol{\delta}}_{i}^{(l-1)}\right)\right|>\lambda ; s_{i}^{\text {pen }}\left(\hat{\boldsymbol{\delta}}^{(l-1)}\right)=0$, caso contrário.

Onde $\operatorname{sign}(x)=\left\{\begin{array}{l}1, \text { se } x>0 \\ 0, \text { se } x=0 \\ -1, \text { se } x<0\end{array}\right.$

\section{Calculando a segunda derivada direcional}

Seja $A:=[X, W]$ e $K=\operatorname{diag}\left(0, \ldots, 0, Q^{-1}, \ldots, Q^{-1}\right)$ uma matriz bloco-diagonal com uma diagonal de $p+1$ zeros que correspondentes aos efeitos fixos e, em seguida, a matriz $Q^{-1} n$ vezes. Então a matriz de informação de Fisher é dada em sua forma fechada por $F^{\text {pen }}(\boldsymbol{\delta})=$ $A^{\top} R(\boldsymbol{\delta}) A+K \operatorname{com} R(\boldsymbol{\delta})=D(\boldsymbol{\delta}) \Sigma^{-1}(\boldsymbol{\delta}) D(\boldsymbol{\delta})^{\top}$ e $D(\boldsymbol{\delta})=\mathbb{I}, \Sigma(\boldsymbol{\delta})=\operatorname{cov}(y \mid \boldsymbol{\delta})$, onde I denota a matriz identidade.

A segunda derivada direcional é dada para cada $\delta$ e cada vetor direcional $h \in \mathbb{R}^{p+1+n s}$ por $l_{\text {pen }}^{\prime \prime}(\boldsymbol{\delta} ; h)=-h^{\top} F^{p e n}(\boldsymbol{\delta}) h$.

\section{Aproximação de Taylor ótima}

Maximizando a aproximação de Taylor (4.22) com relação a $t$, usando $l_{\text {pen }}^{\prime}\left(\boldsymbol{\delta} ; s^{\text {pen }}(\boldsymbol{\delta}, \boldsymbol{\gamma}), \boldsymbol{\gamma}\right)=$ $\left\|s^{\text {pen }}(\boldsymbol{\delta})\right\|_{2}$,

$$
t_{\text {otimo }}^{l-1}=-\frac{\left\|s^{\text {pen }}\left(\hat{\boldsymbol{\delta}}^{(l-1)}\right)\right\|_{2}}{l_{\text {pen }}^{\prime \prime}\left(\hat{\boldsymbol{\delta}}^{(l-1)}, s^{p e n}\left(\hat{\boldsymbol{\delta}}^{(l-1)}\right)\right)}
$$

e

$$
t^{(l-1)_{\text {edge }}}=\min _{i}\left\{-\frac{\hat{\boldsymbol{\delta}}_{i}^{(l-1)}}{s_{i}^{\text {pen }}\left(\hat{\boldsymbol{\delta}}_{i}^{(l-1)}\right)}: \operatorname{sign}\left(\boldsymbol{\delta}_{i}^{(\hat{l-1})}\right)=-\operatorname{sign}\left[s_{i}^{\text {pen }}\left(\boldsymbol{\delta}_{i}^{(\hat{l-1})}\right)\right] \neq 0 .\right.
$$

com norma $\|\cdot\|_{2}$ denotando a norma $L_{2}$ (norma euclidiana).

\section{Atualização}




$$
\hat{\boldsymbol{\delta}}^{(l)}=\left\{\begin{array}{c}
\hat{\boldsymbol{\delta}}^{(l-1)}+t_{\text {edge }}^{(l-1)} s^{\text {pen }}\left(\hat{\boldsymbol{\delta}}^{(l-1)}\right), \text { se } t_{\text {otimo }}^{(l-1)} \geq t_{\text {edge }}^{(l-1)} \\
\hat{\boldsymbol{\delta}}_{F S}^{(l-1)}, \text { se } t_{\text {otimo }}^{(l-1)}<t_{\text {edge }}^{(l-1)} \text { e } \operatorname{sign}\left(\hat{\boldsymbol{\delta}}_{F S}^{(l)}\right)=\operatorname{sign}\left(\hat{\boldsymbol{\delta}}^{(l-1)}\right) ; \\
\hat{\boldsymbol{\delta}}^{(l-1)}+t_{\text {edge }}^{(l-1)} s^{\text {pen }}\left(\hat{\boldsymbol{\delta}}^{(l-1)}\right), \text { caso contrário. }
\end{array}\right.
$$

onde $\hat{\boldsymbol{\delta}}_{F S}^{(l)}$ denota o escore de Fisher estimado.

Estimativas $\hat{Q}^{l}$ são obtidos como estimativas aproximadas do tipo EM ou por métodos alternativos que produzam a atualização $Q^{l}$. Se for necessário, todo o vetor de $\hat{\gamma}^{(l)}$ é completado por uma estimativa do parâmetro de dispersão.

\section{Reestimação}

Numa etapa final, utilizando apenas as variáveis correspondentes aos parâmetros cujos $\hat{\boldsymbol{\beta}}$ que são não nulos, uma nova estimativa dos parâmetros é feita, para isso utilizamos um escore de Fisher, conforme descrito no capítulo 3.

Para uma iteração arbitrária definimos $J=\left\{j: \beta_{j} \neq 0, j=0,1, \ldots, p\right\}$ o conjunto dos índices das covariáveis ativas, correspondendo para as $m=\operatorname{card}(J) \leq p+1$ coeficientes nãonulos. Considerando, $\widetilde{\boldsymbol{\delta}}^{\top}=\left(\beta_{J 1}, \ldots, \beta_{J m}, \boldsymbol{v}^{T}\right)$, e seja

$$
\widetilde{s}^{p e n}(\boldsymbol{\delta})=\left\{s_{J 1}^{p e n}(\boldsymbol{\delta}), \ldots, s_{J m}^{p e n}(\boldsymbol{\delta}), s_{p+1}^{p e n}(\boldsymbol{\delta}), \ldots, s_{p+n s}^{p e n}(\boldsymbol{\delta})\right\}^{\top}
$$

o gradiente em domínio restrito e $\widetilde{F}^{\text {pen }}(\boldsymbol{\delta})=A_{j}^{\top} R(\boldsymbol{\delta}) A_{j}+K_{j}$, com $A_{j}:=\left[X_{j}, W\right]$ enquanto que $X_{j}$ contém apenas aquelas colunas de $X$ correspondente a $J$,

$$
K_{j}=\operatorname{diag}\left(0, \ldots, 0, Q^{-1}, \ldots, Q^{-1}\right)
$$

é uma matriz de penalização em bloco com uma diagonal de $m$ zeros correspondente aos efeitos fixos não nulos e $n$ vezes a matriz $Q^{-1}$.

Em algum passo do escore de Fisher as estimativas assumem a forma

$$
\hat{\widetilde{\boldsymbol{\delta}}}^{(l)}=\hat{\widetilde{\boldsymbol{\delta}}}^{(l-1)}+\left(\widetilde{F}^{\text {pen }}\left(\hat{\boldsymbol{\delta}}^{(l-1)}\right)\right)^{-1} \widetilde{\boldsymbol{s}}^{p e n}\left(\hat{\boldsymbol{\delta}}^{(l-1)}\right) .
$$

O estimador obtido na equação (4.23), pode ser expresso por um vetor da forma $\hat{\boldsymbol{\delta}}_{F S}^{(l)}$ aumentando $\hat{\boldsymbol{\delta}}^{(l)}$ com zeros para todas as covariáveis não-ativas, para que a aproximação de Taylor obtida no passo seguinte se mantenha dentro das características colocadas anteriormente, isto é, $\hat{\boldsymbol{\delta}}_{F S}^{(l)}$ é aceito somente quando $\operatorname{sign}\left(\hat{\boldsymbol{\delta}}_{F S}^{(l)}\right)=\hat{\boldsymbol{\delta}}_{F S}^{(l-1)}$.

Observamos que as sugestões de escolha de modelos ou variáveis são baseadas em critérios objetivos. Porém, muitas vezes a experiência do pesquisador da área pode se sobrepor aos métodos aqui utilizados. No próximo capítulo falaremos a respeito de aplicações a dados educacionais, tanto no caso clássico como no caso bayesiano. 
Para o caso clássico usamos os critérios de seleção de modelos AIC, BIC e AICc e o critério de seleção de variáveis Lasso. Para o caso bayesiano usamos os critérios WAIC, looic, DIC, EAIC e EBIC. 



\section{5}

ESTUDO DE SIMULAÇÃO

O objetivo deste capítulo é desenvolver um breve estudo de simulação para analisar a eficiência dos critérios de seleção clássicos AIC, AICc e BIC. Dessa forma, consideramos alguns cenários para gerar observações vindas de um modelo normal e assim comparar os critérios de seleção citados anteriormente. Primeiramente, geramos três covariáveis $\left(x_{1}, x_{2}\right.$ e $\left.x_{3}\right)$ dicotômicas, que foram fixadas para todos os cenários, e daí fixamos valores teóricos para os efeitos fixos de nosso modelo $\gamma_{00}=100, \gamma_{01}=3, \gamma_{02}=3$ e $\gamma_{03}=-15$. Feito isso, geramos uma variável de grupo, em que a quantidade de grupos varia de acordo com o tamanho da amostra, com exceção da amostra de tamanho $n=50$, onde são considerado grupos de tamanho 10 .

Para a variância dos erros e da matriz de variâncias e covariâncias, fixamos como valores teóricos $\tau_{00}=11, \tau_{01}=5, \tau_{02}=1, \tau_{03}=1, \tau_{11}=5, \tau_{12}=1, \tau_{13}=1, \tau_{22}=6, \tau_{23}=1, \tau_{33}=4$ e $\sigma^{2}=33$. Foram geradas 1000 réplicas, de acordo com o seguinte procedimento:

- geramos os efeitos aleatórios $b_{0}, b_{1}, b_{2}$ e $b_{3}$, respectivamente, para o intercepto;

- obtemos os coeficientes, utilizamos as equações $\beta_{0 j}=\gamma_{00}+b_{0 j}, \beta_{1 j}=\gamma_{01}+b_{1 j}, \beta_{2}=$ $\gamma_{02}+b_{2}$ e $\beta_{3}=\gamma_{03}+b_{3}$

- geramos o vetor de erros, com a distribuição normal com média zero e variância 33;

- geramos a variável resposta $y$, utilizando uma equação da forma $y_{i j}=\beta_{0 j}+\beta_{1 j} x_{1 i j}+$ $\beta_{2 j} x_{2 i j}+\beta_{3 j} x_{3 i j}+\varepsilon_{i j}$, dados $\left(x_{1}, x_{2}\right.$ e $\left.x_{3}\right)$, que foram fixados inicialmente.

Note que a equação utilizada no último item varia de acordo com o cenário em questão, devido à variação no número de covariáveis. Os tamanhos amostrais utilizados são 50, 100, 1000, 5000, 10000. Os cenários utilizados foram os seguintes:

- Cenário 1: utilizamos apenas a covariável $x_{1 i j}$; 
- Cenário 2: utilizamos apenas a covariável $x_{2 i j}$;

- Cenário 3: utilizamos apenas a covariável $x_{3 i j}$;

- Cenário 4: utilizamos as covariáveis $x_{1 i j}$ e $x_{2 i j}$;

- Cenário 5: utilizamos as covariáveis $x_{1 i j}$ e $x_{3 i j}$;

- Cenário 6: utilizamos as covariáveis $x_{2 i j}$ e $x_{3 i j}$;

- Cenário 7: utilizamos as covariáveis $x_{1 i j}, x_{2 i j}$ e $x_{3 i j}$.

Após a geração da variável resposta, estimam-se sete modelos de acordo com a configuração descrita na Tabela 3 e calculam-se o valor das estatísticas de comparação de modelo, daí verifica-se quantas vezes dentre as réplicas foi escolhido o modelo teórico. Observe que o modelo teórico é aquele sob o qual os dados foram gerados, por exemplo, no cenário 1, o modelo 1 é o modelo teórico.

O percentual de vezes onde as estatísticas de comparação de modelos nos levaram a optar pelo modelo teórico encontram-se disponíveis na Tabela 4.

Tabela 3 - Configuração dos modelos estimados em cada réplica.

\begin{tabular}{rrrr}
\hline & $x_{1 i j}$ & $x_{2 i j}$ & $x_{3 i j}$ \\
\hline Modelo 1 & $\mathrm{x}$ & & \\
Modelo 2 & & $\mathrm{x}$ & \\
Modelo 3 & & & $\mathrm{X}$ \\
Modelo 4 & $\mathrm{x}$ & $\mathrm{x}$ & \\
Modelo 5 & $\mathrm{x}$ & & $\mathrm{x}$ \\
Modelo 6 & & $\mathrm{x}$ & $\mathrm{x}$ \\
Modelo 7 & $\mathrm{x}$ & $\mathrm{x}$ & $\mathrm{x}$ \\
\hline
\end{tabular}

Ao observar a Tabela 4, podemos notar que quando aumentamos o tamanho amostral há um aumento na eficiência dos três critérios de informação, ao compararmos os três critérios pode-se afirmar que o critério BIC é o mais eficiente dos três para todos tamanhos amostrais, quando temos um número menor de variáveis explicativas. Outro ponto importante a se destacar é que para grandes tamanhos amostrais o AIC e o AICc assemelham-se no percentual de escolha do modelo correto. Como o contexto prático em que estamos trabalhando é de uma amostra grande e uma grande quantidade de covariáveis, é razoável esperar que o BIC seja o critério mais eficiente. No próximo capítulo trabalharemos com as estatísticas de seleção de modelos utilizadas no capítulo 4 numa situação de dados reais. 


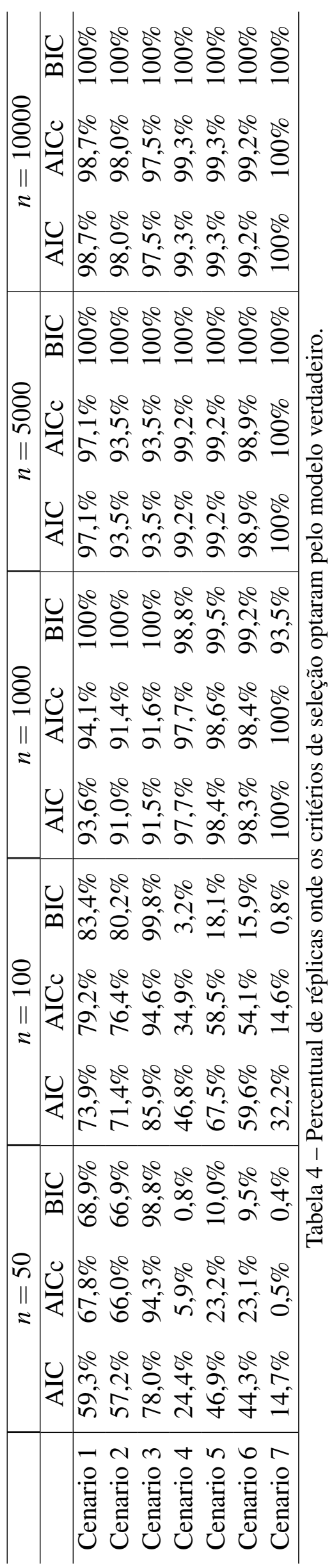



CAPÍTULO

\section{6}

\section{APLICAÇÕES A DADOS EDUCACIONAIS}

Neste capítulo, analisamos uma aplicação de modelos multiníveis com reposta normal para dados educacionais. Temos aqui o objetivo principal de analisar e identificar os fatores que influenciam no desempenho educacional em matemática, dos alunos do $9^{\circ}$ ano do ensino fundamental do Estado de São Paulo. Para isso foi usado o banco de dados da Prova Brasil de 2011, disponível em Microdados (2011), que em sua forma amostral consiste em 12.280 alunos, em 614 escolas do Estado de São Paulo. Foram analisados além das notas dos alunos, seus questionários socioeconômicos e também relativos a entes escolares. Por se tratar de dados com uma estrutura hierárquica propomos a utilização de uma abordagem multinível. Começamos com um modelo de dois níveis (aluno e turma) e depois inserimos o nível escola.

\subsection{Modelos Multiníveis}

Quando temos dados estruturados de forma que haja uma correlação entre seus grupos, faz-se necessário a construção de modelos multiníveis com dois ou mais níveis. Segundo Laros, Marciano e Andrade (2010), faz parte do processo básico para a construção do modelo hierárquico começar com um modelo simplificado, ou seja, sem covariáveis, a partir daí faz-se a inclusão de variáveis explicativas até chegar a um modelo mais completo. O modelo nulo serve como base para analisar um modelo mais completo e a variância da variável resposta do modelo é representada pela soma das variações entre os níveis. O modelo nulo (sem variáveis explicativas) é útil para estimar a variância explicada versus variância não explicada em comparação a outros modelos condicionais estimados a posteriori, o que facilita o cálculo do coeficiente de correlação intra-classe (ICC). Note que quando o ICC é próximo de zero, significa que as unidades nível macro são homogêneas entre si, caracterizando pouca ou nenhuma influência no desempenho do aluno, se o ICC for zero, não há necessidade do uso de regressão multinível.

Como foi dito no Capítulo 2, a amostra dos dados é constituída de 12.280 alunos, que constituem 2.187 turmas, 614 escolas, 236 municípios e 15 regiões. Vimos também a análise 
descritiva da variável PROFICIENCIA_MT_SAEB. Podemos afirmar que não há evidências que nos leve a rejeitar suposição de normalidade dos dados. Nosso objetivo aqui é apontar os fatores que influenciam no desempenho do aluno na disciplina de matemática, utilizando a prova de matemática da PROVA BRASIL. Por se tratar de uma estrutura hierárquica propomos uma abordagem multinível.

Para ajustar os modelos sob abordagem clássica, usaremos o software R, com os pacotes lme4, nlme, entre outros, mais detalhes em Gelman e Hill (2006) e Bates et al. (2015). Os ajustes são obtidos via REML (estimativa de máxima verossimilhança restrita), conceito esse que foi detalhado no Capítulo 3.

Para escolha das covariáveis utilizadas nessa seção, conforme dito na Seção 2.2, consideramos critérios de significância teórica, ou seja, ao analisar trabalhos publicados na área recentemente, foi feito um levantamento dos preditores mais utilizados, dentre esses trabalhos podemos destacar Goldstein (1986), Castro (2015), Osio (2013), Natis (2013), Tibshirani (1996) e Weakliem (1999).

\subsubsection{Modelo 1}

O Modelo 1 é um modelo sem variáveis explicativas com os níveis aluno e turma. Esse modelo no nível 1 será dado por:

$$
y_{i j}=\beta_{0 j}+\varepsilon_{i j}
$$

onde $\beta_{0 j}=\gamma_{00}+v_{0 j}, \operatorname{com} i=1, \ldots, n_{j}$ e $j=1, \ldots, 2.187$. Note que, $y_{i j}$ é a nota de matemática do i-ésimo aluno da j-ésima turma, $E\left(\varepsilon_{i j}\right)=0, \operatorname{cov}(\varepsilon)=\sigma^{2}, \gamma_{00}$ é o efeito fixo e $v_{0 j}$ é o efeito aleatório de turma, assumimos aqui que $v_{0 j} \sim N\left(\mathbf{0}, \tau_{00}\right)$. Assumimos ainda, independência entre o efeito fixo e os efeitos aleatórios, bem como entre os efeitos aleatórios.

\subsubsection{Modelo 2}

O Modelo 2 é um modelo sem variáveis explicativas com os níveis aluno, turma e escola. As equações desse modelo no nível 1, nível 2 e nível 3, respectivamente, saão dadas por:

$$
\begin{gathered}
y_{i j k}=\beta_{0 j k}+\varepsilon_{i j k}, \\
\beta_{0 j k}=\gamma_{00 k}+v_{0 j k}, \\
\gamma_{00 k}=\alpha_{000}+u_{00 k} .
\end{gathered}
$$

onde $i=1, \ldots, n_{j}, j=1, . ., n_{k}$ e $k=1, \ldots, 614$. As suposições são:

$$
\begin{aligned}
& \text { - } \varepsilon_{i j k} \sim N\left(0, \sigma_{\varepsilon}^{2}\right) \\
& \text { - } v_{0 j k} \sim N\left(0, v_{0}\right)
\end{aligned}
$$


- $u_{00 k} \sim N\left(0, \tau_{00}\right)$.

Note que, $\alpha_{000}$ é o efeito fixo do modelo, $u_{00 k}$ é o efeito aleatório da escola e $v_{0 j k}$ é o efeito aleatório de turma. Observe também que $u_{00 k}$ e $v_{0 j k}$ são independentes para diferentes valores de $k$ e também são independentes entre si para diferentes valores de $j$ e $k$.

Na Tabela 5, vemos as estimativas do modelo 1 (à esquerda) e do modelo 2 (à direita).

Tabela 5 - Modelo 1: apenas com os níveis aluno e turma ; Modelo 2: com os níveis aluno, turma e escola.

\begin{tabular}{c|cc|cc}
\hline & \multicolumn{2}{|c|}{ Modelo 1 } & \multicolumn{2}{c}{ Modelo 2 } \\
\hline Variáveis Explicativas & \multicolumn{2}{c}{} & & \\
\hline Efeito fixo & Estimativa & valor p & Estimativa & valor p \\
\hline Intercepto & 246,79 & $<0,001$ & 247,08 & $<0,001$ \\
\hline Efeito aleatório & & & & \\
\hline $\begin{array}{c}\text { Nível 1 (Aluno) } \\
\text { Variância (Resíduo) }\end{array}$ & 1886,60 & - & 1884,20 & - \\
\hline $\begin{array}{c}\text { Nível 2 (Turma) } \\
\text { Variância (intercepto) }\end{array}$ & 326,60 & - & 121,80 & - \\
\hline $\begin{array}{c}\text { Nível 3 (Escola) } \\
\text { Variância (intercepto) }\end{array}$ & - & - & 204,60 & - \\
\hline ICC & 0,14 & - & - & - \\
\hline
\end{tabular}

No modelo 1 (ver Tabela 5 à esquerda), temos que o ICC é de 0,147 , ou seja, aproximadamente $14,75 \%$ da variabilidade do desempenho escolar em matemática dos alunos estão associados à variabilidade das turmas, o intercepto 246,79 é a média das proficiências em matemática de cada grupo. Observe que, o coeficiente de correlação intra-classe (ICC), é dado por:

$$
\rho=\frac{\sigma_{u}^{2}}{\sigma_{u}^{2}+\sigma^{2}},
$$

onde $\sigma_{u}^{2}$ é a variância do efeito aleatório associado as turmas e $\sigma^{2}$ é a variância dos resíduos.

Ao inserirmos o nível escola (ver Tabela 5 à direita) vemos que aproximadamente 9,25\% da variabilidade do desempenho escolar em matemática dos alunos está associado à variabilidade das escolas e aproximadamente 5,50\% está associado à turma. É importante ressaltar que com a inclusão do nível escola o intercepto do modelo passa ser 247,08. Destacamos também que aproximadamente $62,68 \%$ da variabilidade acumulada nas turmas é explicada pela variabilidade entre as escolas, indicando uma importância relativamente alta da escola no processo de ensino e aprendizagem de suas turmas.

\subsubsection{Modelo 3}

O Modelo 3 tem a mesma estrutura do Modelo 2, acrescido das variáveis explicativas gênero, raça auto atribuída, escolaridade da mãe e escolaridade do pai ao nível de aluno. As 
equações desse modelo no nível 1, nível 2 e nível 3, respectivamente, são:

$$
\begin{aligned}
& y_{i j k}=\beta_{0 j k}+\beta_{1 j k} Q 001_{i j k}+\sum_{q=2}^{6} \beta_{q j k} Q 002_{i j k}^{(q)}+\beta_{7 j k} Q 019_{i j k}+\beta_{8 j k} Q 023_{i j k}+\varepsilon_{i j k}, \\
& \beta_{q j k}=\gamma_{q 0 k}+v_{q j k}, q=0, \ldots, 8, \\
& \gamma_{q 0 k}=\alpha_{q 00}+u_{q 0 k} .
\end{aligned}
$$

onde $i=1, \ldots, n_{j}, j=1, . ., n_{k}$ e $k=1, \ldots, 614$. Temos ainda que:

$$
\begin{aligned}
& Q 002_{i j k}^{(2)}=\left\{\begin{array}{l}
1, \text { se o estudante autodeclarou ser da raça amarela; } \\
0, \text { caso contrário } .
\end{array}\right. \\
& Q 002_{i j k}^{(3)}=\left\{\begin{array}{l}
1, \text { se o estudante autodeclarou ser da raça branca; } \\
0, \text { caso contrário . }
\end{array}\right. \\
& Q 002_{i j k}^{(4)}=\left\{\begin{array}{l}
1, \text { se o estudante autodeclarou ser da raça indígena; } \\
0, \text { caso contrário . }
\end{array}\right. \\
& Q 002_{i j k}^{(5)}=\left\{\begin{array}{l}
1, \text { se o estudante autodeclarou ser da raça parda; } \\
0, \text { caso contrário . }
\end{array}\right. \\
& Q 002_{i j k}^{(6)}=\left\{\begin{array}{l}
1, \text { se o estudante autodeclarou ser da raça preta; } \\
0, \text { caso contrário . }
\end{array}\right.
\end{aligned}
$$

As suposições são:

- $\varepsilon_{i j k} \sim N\left(0, \sigma_{\varepsilon}^{2}\right)$

- $v_{q j k} \sim N\left(0, v_{q j k}\right)$;

- $u_{q 0 k} \sim N\left(0, \tau_{q 0 k}\right)$.

Note que, $\alpha_{q 00}$ é o efeito fixo do modelo, $u_{q 0 k}$ é o efeito aleatório da escola e $v_{q j k}$ é o efeito aleatório de turma. Observe também que $u_{q 0 k}$ e $v_{q j k}$ são independentes para diferentes valores de $k$ e também são independentes entre si para diferentes valores de $j$ e $k$.

\subsubsection{Modelo 4}

O Modelo 4 tem a mesma estrutura do Modelo 3, acrescido das variáveis explicativas dependência administrativa, localização, turno e proficiência em língua portuguesa ao nível de aluno e dependência administrativa e localização ao nível de escola. As equações desse modelo 
no nível 1, nível 2 e nível 3, respectivamente, por:

$$
\begin{aligned}
& y_{i j k}=\beta_{0 j k}+\beta_{1 j k} Q 001_{i j k}+\sum_{q=2}^{6} \beta_{q j k} Q 002_{i j k}^{(q)}+\beta_{7 j k} Q 019_{i j k}+\beta_{8 j k} Q 023_{i j k}+ \\
& \beta_{9 j k} D E P E N D E N C I A \_A D M_{i j k}+\beta_{10 j k} L O C A L I Z A C A O_{i j k}+\beta_{11 j k} T U R N O_{i j k}+ \\
& \beta_{12 j k} P R O F I C I E N C I A \_L P \_S A E B_{i j k}+\varepsilon_{i j k}, \\
& \beta_{q j k}=\gamma_{q 0 k}+v_{q j k}, q=0, \ldots, 12, \\
& \gamma_{q 0 k}=\alpha_{q 000}+\alpha_{q 001} D E P E N D E N C I A \_A D M_{k}+\alpha_{q 002} L O C A L I Z A C A O_{k}+u_{q 0 k} .
\end{aligned}
$$

onde $i=1, \ldots, n_{j}, j=1, . ., n_{k}$ e $k=1, \ldots, 614$. Temos ainda que:

$$
\begin{aligned}
& Q 002_{i j k}^{(2)}=\left\{\begin{array}{l}
1, \text { se o estudante autodeclarou ser da raça amarela; } \\
0, \text { caso contrário } .
\end{array}\right. \\
& Q 002_{i j k}^{(3)}=\left\{\begin{array}{l}
1, \text { se o estudante autodeclarou ser da raça branca; } \\
0, \text { caso contrário . }
\end{array}\right. \\
& Q 002_{i j k}^{(4)}=\left\{\begin{array}{l}
1, \text { se o estudante autodeclarou ser da raça indígena; } \\
0, \text { caso contrário . }
\end{array}\right. \\
& Q 002_{i j k}^{(5)}=\left\{\begin{array}{l}
1, \text { se o estudante autodeclarou ser da raça parda; } \\
0, \text { caso contrário } .
\end{array}\right. \\
& Q 002_{i j k}^{(6)}=\left\{\begin{array}{l}
1, \text { se o estudante autodeclarou ser da raça preta; } \\
0, \text { caso contrário } .
\end{array}\right.
\end{aligned}
$$

As suposições são:

- $\varepsilon_{i j k} \sim N\left(0, \sigma_{\varepsilon}^{2}\right)$

- $v_{q j k} \sim N\left(0, v_{q j k}\right)$;

- $u_{q 0 k} \sim N\left(0, \tau_{q 0 k}\right)$.

Note que, $\alpha_{q 00}$ é o efeito fixo do modelo, $u_{q 0 k}$ é o efeito aleatório da escola e $v_{q j k}$ é o efeito aleatório de turma. Observe também que $u_{q 0 k}$ e $v_{q j k}$ são independentes para diferentes valores de $k$ e também são independentes entre si para diferentes valores de $j$ e $k$. Na Tabela 6 à esquerda, temos o ajuste do modelo 3 e à direita o ajuste do modelo 4.

No modelo 3 (Tabela 6 à esquerda) inserimos as variáveis explicativas gênero, raça autodeclarada, escolaridade do pai e escolaridade da mãe, consideramos ainda três níveis: alunos, turma e escolas, temos $8,01 \%$ da variabilidade do desempenho escolar em matemática dos alunos é explicada pelas escolas, ou seja, ao inserirmos variáveis explicativas diminui a influência das escolas na nota dos alunos e 0,36\% da variabilidade do desempenho escolar em matemática é explicado pelas turmas. Temos ainda que $31,40 \%$ da variabilidade da turma é explicada pela escola. Pode-se concluir então que quando inserimos preditores no nível aluno, há uma 
Tabela 6 - Modelo 3: inclusão de variáveis explicativas ao nível de aluno; Modelo 4: inclusão de variáveis explicativas ao nível de escola.

\begin{tabular}{|c|c|c|c|c|}
\hline & \multicolumn{2}{|c|}{ Modelo 3} & \multicolumn{2}{|c|}{ Modelo 4} \\
\hline \multicolumn{5}{|l|}{ Variáveis Explicativas } \\
\hline Efeito fixo & Estimativa & valor $\mathrm{p}$ & Estimativa & valor $\mathrm{p}$ \\
\hline Intercepto & 221,03 & $<0,001$ & 95,58 & $<0,001$ \\
\hline Sexo: Feminino & $-2,41$ & $5,38 \cdot 10^{-3}$ & $-14,01$ & $<0,001$ \\
\hline Sexo: Masculino & - & - & - & - \\
\hline Raça: Amarelo & 23,02 & $<0,001$ & 9,47 & 0,00 \\
\hline Raça: Branco & 25,90 & $<0,001$ & 8,18 & 0,00 \\
\hline Raça: Indígena & 11,35 & 0,01 & 1,22 & 0,75 \\
\hline Raça: Pardo & 19,43 & $<0,001$ & 6,44 & 0,10 \\
\hline Raça: Preto & 10,50 & $1,22.10^{-4}$ & 1,68 & 0,09 \\
\hline Raça: Não Sei & - & - & - & - \\
\hline $\begin{array}{l}\text { Escolaridade(Mãe): Ingressou no } \\
\text { Ensino Superior ou mais }\end{array}$ & 10,32 & $<0,001$ & 3,47 & 0,00 \\
\hline $\begin{array}{l}\text { Escolaridade(Mãe): Terminou o } \\
\text { Ensino Médio ou Menos }\end{array}$ & - & - & - & - \\
\hline $\begin{array}{l}\text { Escolaridade(Pai): Ingressou no } \\
\text { Ensino Superior ou mais }\end{array}$ & 10,00 & $<0,001$ & 3,38 & $<0,001$ \\
\hline $\begin{array}{l}\text { Escolaridade(Pai): Terminou o } \\
\text { Ensino Médio ou Menos }\end{array}$ & - & - & - & - \\
\hline DEPENDENCIA_ADM: Estadual & - & - & $-4,24$ & 0,00 \\
\hline DEPENDENCIA_ADM: Municipal & - & - & - & - \\
\hline LOCALIZACAO: Urbana & - & - & $-5,66$ & 0,06 \\
\hline LOCALIZACAO: Rural & - & - & - & - \\
\hline TURNO: Matutino & - & - & 1,10 & 0,86 \\
\hline TURNO: Vespertino & - & - & - & - \\
\hline PROFICIENCIA_LP_SAEB & - & - & 0,64 & $<0,001$ \\
\hline \multicolumn{5}{|l|}{ Efeito aleatório } \\
\hline \multicolumn{5}{|l|}{ Nível 1 (Aluno) } \\
\hline Variância (Resíduo) & $1.825,83$ & - & $1.131,00$ & - \\
\hline Nível 2 (Turma) & & & & \\
\hline Variância (intercepto) & 75,89 & - & 3,68 & - \\
\hline Nível 3 (Escola) & & & & \\
\hline Variância (intercepto) & 165,77 & - & $<0,001$ & - \\
\hline Variância (DEPENDENCIA_ADM) & - & - & 41,99 & - \\
\hline Variância (LOCALIZACAO) & - & - & 83,59 & - \\
\hline
\end{tabular}

diminuição da influência da escola na variabilidade da proficiência em matemática, no entanto, há uma diminuição da variabilidade total que era 2.210,60 e agora passa a ser 2.067,74.

Aparentemente, o modelo 3 sugere que a raça autodeclarada interfere na proficiência em matemática, sendo a categoria "preto" a que leva a menores notas. Outro fator importante a ser destacado é que a escolaridade do pai ou da mãe tem uma influência menor na variável resposta do que raça auto declarada, como pode ser visto nas estimativas da Tabela 6 à esquerda. 
No modelo 4 (Tabela 6 á direita), incluímos as variáveis explicativas proficiência em língua portuguesa, dependência administrativa, localização e turno no nível de aluno e incluímos também os preditores dependência administrativa e localização ao nível de escola, obviamente que com a inclusão das variáveis explicativas ao nível de escola, há um aumento da variabilidade da proficiência em matemática explicada pelas escolas, que passa de 8,01\% para aproximadamente $9,96 \%$, por outro lado $0,29 \%$ da variabilidade das notas em matemática é explicada pelas turmas, temos ainda que $97,15 \%$ da variabilidade da turma é explicada pela escola. Assim como no modelo anterior, há indícios de que a raça autodeclarada interfere na proficiência em matemática, note que os alunos que se autodeclararam pretos, pardos e indígenas parecem ter notas menores do que os alunos que autodeclararam amarelo ou branco, mas os valores p para esses casos são grandes, assim esta hipótese é prontamente descartada.

Depois que houve uma inserção de quatro variáveis explicativas no nível aluno, houve uma diminuição da variabilidade das notas explicadas pelas escolas, e no último modelo inserimos mais quatro variáveis no nível aluno e duas variáveis explicativas ao nível de escola, e por fim temos que aproximadamente $89,74 \%$ da variabilidade da variável resposta é explicada pelos alunos, aproximadamente $0,29 \%$ é explicada pelas turmas e aproximadamente 9,96\% é explicada pelas escolas, em contraste com outros estudos onde a escola tem uma importância maior na variabilidade do desempenho.

As estimativas dos modelos 3 e 4 nos dão evidências de que a escolaridade da mãe e a escolaridade do pai tem uma importância considerável no desempenho do estudante. Observe que tanto no caso do pai quanto no caso da mãe, o fato deles terem uma escolaridade mais elevada contribui positivamente em seu desempenho em matemática. Na Tabela 7 , temos um teste de comparações múltiplas entre os modelos 3 e 4, como valor p é pequeno, há evidência, considerando um nível de significância de 5\%, que o modelo 4 é melhor.

Tabela 7 - Teste de Comparação entre os modelos 3 e 4

\begin{tabular}{rrrrrrrrr}
\hline & Df & AIC & BIC & log Veros. & desvio & $\chi$ & g.l. & valor $\mathrm{p}$ \\
\hline Modelo 3 & 12 & 108951,16 & 109038,20 & $-54463,58$ & 108927,16 & & & \\
Modelo 4 & 21 & 103428,26 & 103580,59 & $-51693,13$ & 103386,26 & 5540,90 & 9 & 0 \\
\hline
\end{tabular}

Na Tabela 7, temos um teste de razão de verossimilhança, onde a estatística teste será dada por:

$$
\chi_{\left(m_{4}-m_{3}\right)}=-2 \ln \left(M_{3}\right)+2 \ln \left(M_{4}\right),
$$

em que $M_{3}$ é a função de verossimilhança do modelo $3, M_{4}$ é a função de verossimilhança do modelo $4, m_{4}$ é o número de parâmetros do modelo 4 e $m_{3}$ é o número de parâmetros do modelo 3. 
Por fim, vamos comparar todos os modelos ajustados nesta seção usando os critérios AIC, BIC e AICc, temos que nos três casos o modelo 4 é o modelo mais adequado aos dados, mais detalhes a respeito podem ser vistos na Tabela 8 .

Tabela 8 - Comparação dos modelos ajustados nesta seção utilizando os critérios AIC, BIC, AICc.

\begin{tabular}{rrrr}
\hline & AIC & BIC & AICc \\
\hline Modelo1 & 109649,7 & 109671,4 & 109649,7 \\
Modelo2 & 109474,8 & 109503,8 & 109474,8 \\
Modelo3 & 108928,1 & 109015,1 & 108928,1 \\
Modelo4 & $\mathbf{1 0 3 4 1 1 , 0}$ & $\mathbf{1 0 3 5 6 3 , 3}$ & $\mathbf{1 0 3 4 1 1 , 1}$ \\
\hline
\end{tabular}

Assim, devido a porção considerável da variabilidade da variável resposta que é explicada pela variabilidade entre as turmas e entre as escolas, não há evidências que nos façam descartar a utilização de modelos multiníveis.

Na seção seguinte apresentamos novos ajustes, outra configuração de variáveis é utilizada, primeiramente trabalhamos com o enfoque clássico, posteriormente o enfoque bayesiano.

\subsection{Modelagem clássica}

Considerando novamente como variável reposta a proficiência em matemática do SAEB (PROFICIENCIA_MT_SAEB), vamos ajustar modelos usando os preditores listados na Tabela 9.

Tabela 9 - Descrição das covariáveis a serem utilizadas nos ajustes no caso clássico e no bayesiano.

\begin{tabular}{ccc}
\hline Covariável & Código na base de Dados & Código no ajuste \\
\hline Dependência administrativa & DEPENDENCIA_ADM & $x_{1}$ \\
Localização & LOCALIZACAO & $x_{2}$ \\
Turno & TURNO & $x_{3}$ \\
Sexo do aluno & Q001 & $x_{4}$ \\
Idade & Q004 & $x_{5}$ \\
Escolaridade da mãe & Q019 & $x_{6}$ \\
Escolaridade do pai & Q023 & $x_{7}$ \\
Reprovas & Q049 & $x_{8}$ \\
Proficiência em língua portuguesa do SAEB & PROFICIENCIA_LP_SAEB & $X_{9}$ \\
\hline
\end{tabular}

Com exceção da variável explicativa proficiência em língua portuguesa do SAEB, todos os outros preditores são variáveis dicotômicas, sua definição pode ser encontrada na Tabela 32, no apêndice A.

Nesta seção ajustamos modelos de regressão multiníveis com dois níveis: aluno e escola; aluno e turma e também aluno e região. Primeiramente buscamos qual a metodologia de ajuste deve ser escolhida (efeitos fixos, intercepto aleatórios e intercepto e inclinações aleatórias), 
utilizando os critérios de informação (AIC, AICc e BIC) e partir daí verificamos quais das variáveis explicativas estariam no modelo final.

\subsubsection{Modelos com efeitos fixos}

A equação de um modelo de regressão linear com efeitos fixos, considerando todos os preditores e a variável resposta acima, será da seguinte forma:

$$
y_{i}=\beta_{0}+\sum_{m=1}^{9} \beta_{m} x_{m i}+\varepsilon_{i},
$$

com $i=1,2, \ldots, 12.280$, onde:

- $y_{i}$ representa a proficiência em matemática do $i$-ésimo indivíduo;

- $\varepsilon_{i} \sim N\left(0, \sigma^{2}\right)$ e todos os $\varepsilon_{i}$ são independentes.

Na Tabela 10, temos as estimativas do modelo (6.7).

Tabela 10 - Estimativa dos parâmetros do modelo (6.7), aqui temos efeitos fixos apenas.

\begin{tabular}{lrrrr}
\hline Parâmetro & Estimativa & Erro Padrão & valor t & valor p \\
\hline$\hat{\beta}_{0}$ (Intercepto) & 103,90 & 3,14 & 33,00 & $<0,001$ \\
$\hat{\beta}_{1}$ (Dep. Admin.) & $-4,19$ & 0,77 & $-5,40$ & $<0,001$ \\
$\hat{\beta_{2}}$ (Localização) & $-5,74$ & 2,17 & $-2,63$ & 0,008 \\
$\hat{\beta_{3}}$ (Turno) & 0,94 & 0,77 & 1,21 & 0,224 \\
$\hat{\beta_{4}}$ (Q001) & $-14,77$ & 0,68 & $-21,46$ & $<0,001$ \\
$\hat{\beta}_{5}$ (Q004) & 2,04 & 1,33 & 1,53 & 0,125 \\
$\hat{\beta}_{6}$ (Q019) & 2,93 & 0,81 & 3,61 & $<0,001$ \\
$\hat{\beta}_{7}$ (Q023) & 3,26 & 0,82 & 3,94 & $<0,001$ \\
$\hat{\beta}_{8}$ (Q049) & $-9,84$ & 1,01 & $-9,72$ & $<0,001$ \\
$\hat{\beta}_{9}$ (Nota Port.) & 0,64 & 0,00 & 84,67 & $<0,001$ \\
\hline
\end{tabular}

Ao analisar o teste $\mathrm{t}$ de significância individual, ao nível de significância de $5 \%$, há evidências, a partir da consulta do valor p na Tabela 10, de que as variáveis explicativas TURNO e distorção idade-série (Q004) são não significativa.

Ao analisarmos as estimativas dos parâmetros do modelo (6.7), destaca-se que o aluno ter sofrido reprovas em sua vida escolar influencia negativamente seu desempenho em matemática na Prova Brasil, fixado os outros preditores, o mesmo pode-se dizer o fato do aluno declarar ser do sexo feminino. Por outro lado, as estimativas contidas na Tabela 10, mostram que os alunos cujos pais tem escolaridade mais elevada tendem a ter um desempenho mais elevado em matemática, fixado outras covariáveis. 
Contudo ao realizarmos o procedimento de stepwise, eliminamos apenas a variável TURNO, indicando a importância do aluno não ter defasagem idade série para o modelo. Mais detalhes pode ser visto na Tabela 11 .

Tabela 11 - Procedimento de stepwise utilizado no Modelo 4

\begin{tabular}{rrrrrrr}
\hline & Step & g.l. & Desvio & g.l. Resid. & Resid. Dev & AIC \\
\hline 1 & & & & 10424 & 12177770,07 & 73708,01 \\
2 & - TURNO & 1 & 1723,95 & 10425 & 12179494,02 & 73707,49 \\
\hline
\end{tabular}

\subsubsection{Modelos com intercepto aleatório}

Nesta subseção ajustamos mais três modelos, será colocado no modelo (6.7), efeitos aleatórios relacionados à turma, escola e região. $\mathrm{O}$ modelo linear com intercepto aleatório para turma será dado no nível 1, por:

$$
y_{i j}=\beta_{0 j}+\sum_{m=1}^{9} \beta_{m} x_{m i j}+\varepsilon_{i j}
$$

com $i=1,2, \ldots, n_{j}$ e $j=1,2, \ldots, 2187$, onde:

- $y_{i j}$ representa a proficiência em matemática do i-ésimo aluno para a j-ésima turma;

- $\varepsilon_{i j} \sim N\left(0, \sigma^{2}\right)$ e todos os $\varepsilon_{i j}$ são independentes.

Temos também que $\beta_{0 j}=\gamma_{00}+v_{0 j}$, onde $\gamma_{00}$ é a proficiência em matemática esperada de cada turma, $v_{0 j}$ é o efeito aleatório da $j$-ésima turma no intercepto do modelo (6.8) e $v_{0 j} \sim N\left(0, \tau_{00}\right)$.

O modelo linear com intercepto aleatório para escola será dado no nível 1, por:

$$
y_{i j}=\beta_{0 j}+\sum_{m=1}^{9} \beta_{m} x_{m i j}+\varepsilon_{i j}
$$

com $i=1,2, \ldots, n_{j}$ e $j=1,2, \ldots, 614$, onde:

- $y_{i j}$ representa a proficiência em matemática do $i$-ésimo aluno da j-ésima escola;

- $\varepsilon_{i j} \sim N\left(0, \sigma^{2}\right)$ e todos os $\varepsilon_{i j}$ são independentes.

Temos também que $\beta_{0 j}=\gamma_{00}+v_{0 j}$, onde $\gamma_{00}$ é a proficiência em matemática esperada de cada escola, $v_{0 j}$ é o efeito aleatório da $j$-ésima escola no intercepto do modelo (6.9) e $v_{0 j} \sim N\left(0, \tau_{00}\right)$. 
O modelo linear com intercepto aleatório para região será dado no nível 1, por:

$$
y_{i j}=\beta_{0 j}+\sum_{m=1}^{9} \beta_{m} x_{m i j}+\varepsilon_{i j}
$$

com $i=1,2, \ldots, n_{j}$ e $j=1,2, \ldots, 15$, onde:

- $y_{i j}$ representa a proficiência em matemática do $i$-ésimo aluno da $j$-ésima região;

- $\varepsilon_{i j} \sim N\left(0, \sigma^{2}\right)$ e todos os $\varepsilon_{i j}$ são independentes.

Temos também que $\beta_{0 j}=\gamma_{00}+v_{0 j}$, onde $\gamma_{00}$ é a proficiência em matemática esperada de cada região, $v_{0 j}$ é o efeito aleatório da $j$-ésima região no intercepto do modelo (6.9) e $v_{0 j} \sim N\left(0, \tau_{00}\right)$. Na Tabela 12 , temos as estimativas para o modelo (6.8), modelo (6.9) e modelo (6.10).

Tabela 12 - Modelo (6.8) tem intercepto aleatório para turma; Modelo (6.9) tem intercepto aleatório para escola; Modelo (6.10) tem intercepto aleatório para região.

\begin{tabular}{|c|c|c|c|c|c|c|}
\hline \multirow{2}{*}{ Efeito fixo } & \multicolumn{2}{|c|}{ Modelo (6.8) } & \multicolumn{2}{|c|}{ Modelo (6.9) } & \multicolumn{2}{|c|}{ Modelo (6.10) } \\
\hline & & & & & & \\
\hline Parâmetro & Estimativa & Valor $\mathrm{p}$ & Estimativa & valor $\mathrm{p}$ & Estimativa & valor $\mathrm{p}$ \\
\hline$\widehat{\gamma_{00}}$ & 105,80 & $<0,001$ & 107,20 & $<0,001$ & 106,40 & $<0,001$ \\
\hline$\widehat{\beta_{1}}$ (Dep. Admin.) & $-4,09$ & $<0,001$ & $-4,25$ & $<0,001$ & $-4,61$ & $<0,001$ \\
\hline$\widehat{\beta_{2}}$ (Localização) & $-6,03$ & 0,02 & $-5,85$ & 0,04 & $-2,69$ & 0,22 \\
\hline$\widehat{\beta_{3}}$ (Turno) & 0,74 & 0,38 & 1,04 & 0,26 & $-0,24$ & 0,75 \\
\hline$\widehat{\beta_{4}}(\mathrm{Q} 001)$ & $-14,79$ & $<0,001$ & $-14,62$ & $<0,001$ & $-14,64$ & $<0,001$ \\
\hline$\widehat{\beta_{5}}(\mathrm{Q} 004)$ & 2,35 & 0,07 & 2,25 & 0,08 & 2,35 & 0,07 \\
\hline$\widehat{\beta_{6}}(\mathrm{Q} 019)$ & 2,81 & $<0,001$ & 3,02 & $<0,001$ & 3,54 & $<0,001$ \\
\hline$\widehat{\beta_{7}}(\mathrm{Q} 023)$ & 3,35 & $<0,001$ & 3,38 & $<0,001$ & 3,46 & $<0,001$ \\
\hline$\widehat{\beta_{8}}(\mathrm{Q} 049)$ & $-9,78$ & $<0,001$ & $-10,03$ & $<0,001$ & $-9,98$ & $<0,001$ \\
\hline$\widehat{\beta_{9}}$ (Nota Port.) & 0,63 & $<0,001$ & 0,63 & $<0,001$ & 0,63 & $<0,001$ \\
\hline \multicolumn{7}{|l|}{ Efeito aleatório } \\
\hline Nível 1 (Aluno) & & & & & & \\
\hline Var. (Resíduo) & 1116,19 & - & 1117,53 & - & 1152,53 & - \\
\hline $\begin{array}{l}\text { Nível } 2 \text { (Turma) } \\
\text { Var. (intercepto) }\end{array}$ & 52,43 & - & & & & \\
\hline $\begin{array}{l}\text { Nível } 2 \text { (Escola) } \\
\text { Var. (intercepto) }\end{array}$ & & & 51,63 & - & & \\
\hline $\begin{array}{l}\text { Nível } 2 \text { (Região) } \\
\text { Var. (intercepto) }\end{array}$ & & & & & 8,234 & - \\
\hline
\end{tabular}

Observando a Tabela 12, podemos notar que há evidências, a um nível de significância de 5\%, que as variáveis explicativas turno e distorção idade série são não significativas nos três 
modelos disponíveis. Quando tomamos interceptos aleatórios para região, a variável explicativa localização não é significativa, diferentemente dos outros modelos.

Assim, a interpretação das estimativas do modelo (6.8), modelo (6.9) e do modelo (6.10) são parecidas com a interpretação das estimativas do modelo (6.7).

\subsubsection{Modelos com intercepto e inclinações aleatórios}

O modelo linear com intercepto e inclinações aleatórios para turma será dado por:

$$
y_{i j}=\left(\beta_{0 j}+v_{0 j}\right)+\sum_{m=1}^{9}\left(\beta_{m j}+v_{m j}\right) x_{m i j}+\varepsilon_{i j},
$$

com $i=1,2, \ldots, n_{j}$ e $j=1,2, \ldots, 2187$, onde:

- $y_{i j}$ representa a proficiência em matemática do i-ésimo aluno para a j-ésima turma;

- $\varepsilon_{i j} \sim N\left(0, \sigma^{2}\right)$ e todos os $\varepsilon_{i j}$ são independentes;

- $v_{0 j}$ é o efeito aleatório no intercepto $\beta_{0 j}$ da j-ésima turma;

- $v_{m j}$ é o efeito aleatório na inclinação $\beta_{m j}$ da j-ésima turma, onde $m=1, \ldots, 9$.

As suposições aqui são que: $v_{m j} \sim N\left(0, \tau_{m m}\right)$, onde os coeficientes aleatórios $v_{m j}$ são independentes entre si e também de cada $\varepsilon_{i j}$, onde $m=0, \ldots, 9$.

O modelo linear com intercepto e inclinações aleatórios para escola será dado por:

$$
y_{i j}=\left(\beta_{0 j}+v_{0 j}\right)+\sum_{m=1}^{9}\left(\beta_{m j}+v_{m j}\right) x_{m i j}+\varepsilon_{i j},
$$

com $i=1,2, \ldots, n_{j}$ e $j=1,2, \ldots, 614$, onde:

- $y_{i j}$ representa a proficiência em matemática do i-ésimo aluno para a j-ésima escola;

- $\varepsilon_{i j} \sim N\left(0, \sigma^{2}\right)$ e todos os $\varepsilon_{i j}$ são independentes;

- $v_{0 j}$ é o efeito aleatório no intercepto $\beta_{0 j}$ da j-ésima escola;

- $v_{m j}$ é o efeito aleatório na inclinação $\beta_{m j}$ da j-ésima escola, onde $m=1, \ldots, 9$.

O modelo linear com intercepto e inclinações aleatórios para escola será dado por:

$$
y_{i j}=\left(\beta_{0 j}+v_{0 j}\right)+\sum_{m=1}^{9}\left(\beta_{m j}+v_{m j}\right) x_{m i j}+\varepsilon_{i j},
$$


com $i=1,2, \ldots, n_{j}$ e $j=1,2, \ldots, 15$, onde:

- $y_{i j}$ representa a proficiência em matemática do i-ésimo aluno para a j-ésima região;

- $\varepsilon_{i j} \sim N\left(0, \sigma^{2}\right)$ e todos os $\varepsilon_{i j}$ são independentes;

- $v_{0 j}$ é o efeito aleatório no intercepto $\beta_{0 j}$ da j-ésima região;

- $v_{m j}$ é o efeito aleatório na inclinação $\beta_{m j}$ da j-ésima região, onde $m=1, \ldots, 9$.

As suposições para os modelos (6.12) e (6.13) são as mesmas do modelo (6.11). Na Tabela 13, temos as estimativas para o modelo (6.11), modelo (6.12) e modelo (6.13).

Tabela 13 - Modelo (6.11) tem intercepto e inclinações aleatórias para turma; Modelo (6.12) tem intercepto e inclinações aleatórias para escola; Modelo (6.13) tem intercepto e inclinações aleatórias para região.

\begin{tabular}{|c|c|c|c|c|c|c|}
\hline \multirow{2}{*}{ Efeito fixo } & \multicolumn{2}{|c|}{ Modelo (6.11) } & \multicolumn{2}{|c|}{ Modelo (6.12) } & \multicolumn{2}{|c|}{ Modelo (6.13) } \\
\hline & & & & & & \\
\hline Parâmetro & Estimativa & Valor $\mathrm{p}$ & Estimativa & valor $\mathrm{p}$ & Estimativa & valor $\mathrm{p}$ \\
\hline$\widehat{\beta_{0 j}}($ Intercepto $)$ & 103,90 & 0,00 & 106,58 & 0,00 & 104,13 & 0,00 \\
\hline$\widehat{\beta_{1 j}}$ (Dep. Admin.) & $-4,19$ & 0,00 & $-3,87$ & 0,00 & $-8,42$ & 0,00 \\
\hline$\widehat{\beta_{2 j}}($ Localização $)$ & $-5,74$ & 0,00 & $-4,75$ & 0,25 & $-1,56$ & 0,63 \\
\hline$\widehat{\beta_{3 j}}$ (Turno) & 0,94 & 0,22 & 0,61 & 0,53 & 1,78 & 0,08 \\
\hline$\widehat{\beta_{4 j}}(\mathrm{Q} 001)$ & $-14,77$ & 0,00 & $-14,53$ & 0,00 & $-14,07$ & 0,00 \\
\hline$\widehat{\beta_{5 j}}(\mathrm{Q} 004)$ & 2,04 & 0,12 & 2,70 & 0,05 & 2,93 & 0,05 \\
\hline$\widehat{\beta_{6 j}}(\mathrm{Q} 019)$ & 2,93 & 0,00 & 2,92 & 0,00 & 4,46 & 0,00 \\
\hline$\widehat{\beta_{7 j}}(\mathrm{Q} 023)$ & 3,26 & 0,00 & 3,32 & 0,00 & 2,75 & 0,00 \\
\hline$\widehat{\beta_{8 j}}(\mathrm{Q} 049)$ & $-9,84$ & 0,00 & $-9,79$ & 0,00 & $-10,82$ & 0,00 \\
\hline$\widehat{\beta_{9 j}}$ (Nota Port.) & 0,64 & 0,00 & 0,62 & 0,00 & 0,64 & 0,00 \\
\hline \multicolumn{7}{|l|}{ Efeito aleatório } \\
\hline \multicolumn{7}{|l|}{ Nível 1 (Aluno) } \\
\hline Var. (Resíduo) & 134,17 & - & 32,69 & - & 33,81 & - \\
\hline Nível 2 & Turma & & Escola & & Região & \\
\hline Var. $\left(\widehat{v_{0 j}}\right)$ & $6,65 \cdot 10^{-11}$ & - & 11,75 & - & 7,40 & - \\
\hline $\operatorname{var} .\left(\widehat{v_{1 j}}\right)$ & $5,54 \cdot 10^{-14}$ & - & 8,88 & - & 5,12 & - \\
\hline $\operatorname{var}\left(\widehat{v_{2 j}}\right)$ & $3,90.10^{-7}$ & - & 12,04 & - & 7,04 & - \\
\hline $\operatorname{var}\left(\widehat{v_{3 j}}\right)$ & $1,33 \cdot 10^{-14}$ & - & 5,98 & - & 2,06 & - \\
\hline $\operatorname{var}\left(\widehat{v_{4 j}}\right)$ & $1,02 \cdot 10^{-13}$ & - & 4,65 & - & 2,37 & - \\
\hline $\operatorname{var}\left(\widehat{v_{5 j}}\right)$ & $2,11.10^{-11}$ & - & 9,03 & - & 2,04 & - \\
\hline $\operatorname{var}\left(\widehat{v_{6 j}}\right)$ & $1,10.10^{-13}$ & - & 6,11 & - & 1,91 & - \\
\hline $\operatorname{var}\left(\widehat{v_{7 j}}\right)$ & $6,71 \cdot 10^{-14}$ & - & 4,80 & - & 1,75 & - \\
\hline $\operatorname{var} .\left(\widehat{v_{8 j}}\right)$ & $1,37 \cdot 10^{-13}$ & - & 8,07 & - & 2,89 & - \\
\hline $\operatorname{var}\left(\widehat{v_{9 j}}\right)$ & $3,26.10^{-9}$ & - & 0,06 & - & 0,02 & - \\
\hline
\end{tabular}


Observando a Tabela 13, considerando um nível de 5\% de significância, há evidências que:

- as covariáveis turno e série são não significativas no modelo (6.11);

- as covariáveis localização e turno são não significativas no modelo (6.12);

- as covariáveis localização e turno são não significativas no modelo (6.13).

Podemos ainda notar nos três modelos da Tabela 13, que o fato do aluno declarar ser do sexo feminino e já ter obtido reprovação escolar são os fatores que mais influenciam negativamente, fixado as outras covariáveis. Por outro lado, é possível destacar que o fato dos pais dos estudantes terem pelo menos ingressado no ensino superior, exerce uma influência positiva na proficiência em matemática.

Na próxima seção realizamos seleção de modelos, e decidimos qual o melhor modelo clássico deve ser utilizado a partir das covariáveis testadas.

\subsection{Seleção de Modelos Clássicos}

Primeiramente, comparamos os modelos ajustados na seção anterior e daí definimos qual será a metodologia de ajuste a ser utilizada, para isso utilizamos três critérios de informação, são eles: AIC, AICc e BIC. Na Tabela 14, temos os valores dos critérios de informação AIC, BIC e AICc, para cada um dos sete modelos, observe que nos três critérios o modelo (6.10) tem o menor valor, assim este deve ser o modelo que deve ser escolhido.

Tabela 14 - Comparação dos modelos ajustados nesta seção utilizando os critérios AIC, BIC, AICc.

\begin{tabular}{|c|c|c|c|}
\hline & AIC & $\mathrm{BIC}$ & $\mathrm{AICc}$ \\
\hline Modelo (6.7) & 103320,4 & 103400,2 & 103320,4 \\
\hline Modelo (6.8) & 103269,9 & 103356,9 & 103269,9 \\
\hline Modelo (6.9) & 103207,2 & 103294,3 & 103207,3 \\
\hline Modelo (6.10) & 103195,4 & 103282,4 & 103195,4 \\
\hline Modelo (6.11) & 103425,1 & 103903,7 & 103425,9 \\
\hline Mo & 103293,1 & 103771,7 & 103294,0 \\
\hline Modelo (6.13) & 103260,0 & 103738,6 & 103260,8 \\
\hline
\end{tabular}

A metodologia de ajuste clássico escolhida é um modelo de regressão multinível com dois níveis com intercepto aleatório para região. Ao analisarmos as estimativas do modelo (6.10), conforme já destacamos anteriormente, podemos notar que as variáveis explicativas turno, localização e idade são não significativas, isto pode ser visto, há uma nível de significância de $5 \%$, observando os valores $\mathrm{p}$ associado a cada um dos coeficientes. Assim ajustamos sete novos modelos com todas as variações possíveis de covariáveis, levando em consideração o descarte ou não de uma, duas ou das três covariáveis não significativas para o modelo (6.10) e posteriormente 
calculamos o AIC, BIC e AICc para os três modelos. Na Tabela 15, temos a configuração desses ajustes.

Tabela 15 - Configuração de ajustes para seleção de modelos.

\begin{tabular}{lccccccc}
\hline Covariáveis & Mod. 1 & Mod. 2 & Mod. 3 & Mod. 4 & Mod. 5 & Mod. 6 & Mod. 7 \\
PROFIC._LP_SAEB & $\mathrm{x}$ & $\mathrm{x}$ & $\mathrm{x}$ & $\mathrm{x}$ & $\mathrm{x}$ & $\mathrm{x}$ & $\mathrm{x}$ \\
DEPENDEN._ADM & $\mathrm{x}$ & $\mathrm{x}$ & $\mathrm{x}$ & $\mathrm{x}$ & $\mathrm{x}$ & $\mathrm{x}$ & $\mathrm{x}$ \\
LOCALIZAÇÃO & & $\mathrm{x}$ & $\mathrm{x}$ & & & $\mathrm{x}$ & \\
TURNO & $\mathrm{x}$ & & $\mathrm{x}$ & & $\mathrm{x}$ & & \\
Q001 (Sexo) & $\mathrm{x}$ & $\mathrm{x}$ & $\mathrm{x}$ & $\mathrm{x}$ & $\mathrm{x}$ & $\mathrm{x}$ & $\mathrm{x}$ \\
Q004 (Idade) & $\mathrm{x}$ & $\mathrm{x}$ & & $\mathrm{x}$ & & & \\
Q019 (Escol. Mãe) & $\mathrm{x}$ & $\mathrm{x}$ & $\mathrm{x}$ & $\mathrm{x}$ & $\mathrm{x}$ & $\mathrm{x}$ & $\mathrm{x}$ \\
Q023 (Escol. Pai) & $\mathrm{x}$ & $\mathrm{x}$ & $\mathrm{x}$ & $\mathrm{x}$ & $\mathrm{x}$ & $\mathrm{x}$ & $\mathrm{x}$ \\
Q049 (Reprovas) & $\mathrm{x}$ & $\mathrm{x}$ & $\mathrm{x}$ & $\mathrm{x}$ & $\mathrm{x}$ & $\mathrm{x}$ & $\mathrm{x}$ \\
\hline
\end{tabular}

Nas Tabelas 16, 17 e 18 temos as estimativas dos modelos descritos na Tabela 15, reparem que dos sete modelos que estão apresentados nessas tabelas, apenas no modelo 7 temos todas as covariáveis significativas, para isso basta observar o valor $\mathrm{p}$ associado a cada coeficiente estimado, a um nível de significância de $5 \%$.

Tabela 16 - Examinando as estimativas dos parâmetros e o valor p dos mesmos, nos modelos 1, 2 e 3 descritos na Tabela 15.

\begin{tabular}{|c|c|c|c|c|c|c|}
\hline \multirow{2}{*}{ Efeito fixo } & \multicolumn{2}{|c|}{ Modelo 1} & \multicolumn{2}{|c|}{ Modelo 2} & \multicolumn{2}{|c|}{ Modelo 3} \\
\hline & & & & & & \\
\hline Parâmetro & Estimativa & Valor $\mathrm{p}$ & Estimativa & valor $\mathrm{p}$ & Estimativa & valor $\mathrm{p}$ \\
\hline$\widehat{\gamma_{00}}$ & 103,87 & 0,00 & 106,50 & 0,00 & 108,40 & 0,00 \\
\hline$\widehat{\beta_{1}}$ (Dep. Admin.) & $-4,66$ & 0,00 & $-4,60$ & 0,00 & $-4,57$ & 0,00 \\
\hline$\widehat{\beta_{2}}$ (Localização) & - & - & $-2,65$ & 0,23 & $-2,68$ & 0,22 \\
\hline$\widehat{\beta_{3}}$ (Turno) & 0,19 & 0,80 & - & - & 0,26 & 0,73 \\
\hline$\widehat{\beta_{4}}(\mathrm{Q} 001)$ & $-14,63$ & 0,00 & $-14,63$ & 0,00 & $-14,61$ & 0,00 \\
\hline$\widehat{\beta_{5}}(\mathrm{Q} 004)$ & 2,34 & 0,07 & 2,35 & 0,07 & - & - \\
\hline$\widehat{\beta_{6}}(\mathrm{Q} 019)$ & 3,51 & 0,00 & 3,54 & 0,00 & 3,57 & 0,00 \\
\hline$\widehat{\beta_{7}}(\mathrm{Q} 023)$ & 3,43 & 0,00 & 3,46 & 0,00 & 3,49 & 0,00 \\
\hline$\widehat{\beta_{8}}(\mathrm{Q} 049)$ & $-9,98$ & 0,00 & $-9,98$ & 0,00 & $-10,93$ & 0,00 \\
\hline$\widehat{\beta_{9}}$ (Nota Port.) & 0,63 & 0,00 & 0,63 & 0,00 & 0,63 & 0,00 \\
\hline \multicolumn{7}{|l|}{ Efeito aleatório } \\
\hline Nível 1 (Aluno) & & & & & & \\
\hline Var. (Resíduo) & 1152,57 & - & 1152,42 & - & 1152,78 & - \\
\hline Nível 2 (Região) & & & & & & \\
\hline Var. (intercepto) & 8,37 & - & 8,28 & - & 8,14 & - \\
\hline
\end{tabular}

Na Tabela 19, temos o valor dos três critérios de seleção (AIC, AICc e BIC) para o modelo completo (6.10) e para os sete modelos reduzidos. Ao analisarmos o desempenho do três critérios que estão sendo utilizados, constatamos que o AIC e o AICc tem comportamentos parecidos, 
Tabela 17 - Examinando as estimativas dos parâmetros e o valor p dos mesmos, nos modelos 4, 5 e 6 descritos na Tabela 15.

\begin{tabular}{|c|c|c|c|c|c|c|}
\hline \multirow{2}{*}{ Efeito fixo } & \multicolumn{2}{|c|}{ Modelo 4} & \multicolumn{2}{|c|}{ Modelo 5} & \multicolumn{2}{|c|}{ Modelo 6} \\
\hline & & & & & & \\
\hline Parâmetro & Estimativa & Valor $\mathrm{p}$ & Estimativa & valor $\mathrm{p}$ & Estimativa & valor $\mathrm{p}$ \\
\hline$\widehat{\gamma_{00}}$ & 104,01 & 0,00 & 105,92 & 0,00 & 108,56 & 0,00 \\
\hline$\widehat{\beta_{1}}$ (Dep. Admin.) & $-4,66$ & 0,00 & $-4,63$ & 0,00 & $-4,57$ & 0,00 \\
\hline$\widehat{\beta_{2}}$ (Localização) & - & - & - & - & $-2,64$ & 0,23 \\
\hline$\widehat{\beta_{3}}$ (Turno) & - & - & 0,21 & 0,78 & - & - \\
\hline$\widehat{\beta_{4}}(\mathrm{Q} 001)$ & $-14,63$ & 0,00 & $-14,61$ & 0,00 & $-14,61$ & 0,00 \\
\hline$\widehat{\beta_{5}}(\mathrm{Q} 004)$ & 2,35 & 0,07 & - & - & - & - \\
\hline$\widehat{\beta}_{6}(\mathrm{Q} 019)$ & 3,51 & 0,00 & 3,55 & 0,00 & 3,57 & 0,00 \\
\hline$\widehat{\beta}_{7}(\mathrm{Q} 023)$ & 3,44 & 0,00 & 3,46 & 0,00 & 3,49 & 0,00 \\
\hline$\widehat{\beta_{8}}(\mathrm{Q} 049)$ & $-9,98$ & 0,00 & $-10,93$ & 0,00 & $-10,94$ & 0,00 \\
\hline$\widehat{\beta_{9}}$ (Nota Port.) & 0,63 & 0,00 & 0,63 & 0,00 & 0,63 & 0,00 \\
\hline \multicolumn{7}{|l|}{ Efeito aleatório } \\
\hline Nível 1 (Aluno) & & & & & & \\
\hline Var. (Resíduo) & 1152,46 & - & 1152,81 & - & 1152,67 & - \\
\hline $\begin{array}{l}\text { Nível } 2 \text { (Região) } \\
\text { Var. (intercepto) }\end{array}$ & 8,41 & - & 8,27 & - & 8,19 & - \\
\hline
\end{tabular}

isto se deve ao fato de termos 12.280 observações, como já foi destacado anteriormente o AIC têm problemas assintóticos, ou seja, quando temos poucas observações ele deve ser substituído por outros critérios.

Observando a Tabela 19, vemos que os critérios AIC e o AICc optam pelo modelo 2, que exclui apenas a covariável turno, contudo as covariáveis localização e Q004(mede a distorção idade-série) são não significativas para a variável resposta. O critério BIC seleciona o modelo 7, que exclui as covariáveis turno, localização e Q004(mede a distorção idade-série). Como o modelo 7 não tem covariáveis não significativas, fato esse que pode ser notado via teste $\mathrm{t}$ de significância individual com 5\% de significância, ele será escolhido como melhor modelo sob enfoque clássico, lembrando sempre que esse modelo não é necessariamente o modelo verdadeiro e sim o melhor dentre aqueles aqui ajustados.

Por fim sugerimos o uso do critério BIC para modelos multiníveis com dados normais, pois além de selecionar modelo apenas com variáveis significativas, seleciona também modelo com menor número de covariáveis, facilitando a interpretação das estimativas. Fato esse que Emiliano (2009), verificou ao concluir em seu trabalho que para dados simulados com distribuição normal, o critério BIC é o mais eficiente.

Na Figura 8 temos o gráfico dos resíduos por região, na Figura 9 temos o box plot dos resíduos por região, na Tabela 20 temos a estimativa dos efeitos aleatórios associados a cada uma das regiões que foram estimados no modelo 7. 
Tabela 18 - Examinando as estimativas dos parâmetros e o valor p do modelo 7 descritos na Tabela 15.

\begin{tabular}{l|rr}
\hline & \multicolumn{2}{|c}{ Modelo 7 } \\
\hline Efeito fixo & & \\
\hline Parâmetro & Estimativa & Valor $\mathrm{p}$ \\
\hline$\widehat{\gamma_{00}}$ & 106,08 & 0,00 \\
$\widehat{\beta}_{1}$ (Dep. Admin.) & $-4,62$ & 0,00 \\
$\widehat{\beta_{2}}$ (Localização) & - & - \\
$\widehat{\beta_{3}}$ (Turno) & - & - \\
$\widehat{\beta}_{4}(\mathrm{Q} 001)$ & $-14,61$ & 0,00 \\
$\widehat{\beta}_{5}(\mathrm{Q} 004)$ & - & - \\
$\widehat{\beta_{6}}$ (Q019) & 3,55 & 0,00 \\
$\widehat{\beta_{7}}$ (Q023) & 3,47 & 0,00 \\
$\widehat{\beta}_{8}$ (Q049) & $-10,93$ & 0,00 \\
$\widehat{\beta}_{9}$ (Nota Port.) & 0,63 & 0,00 \\
\hline Efeito aleatório & & \\
\hline Nível 1 (Aluno) & & \\
Var. (Resíduo) & 1152,70 & - \\
\hline Nível 2 (Região) & & \\
Var. (intercepto) & 8,31 & - \\
\hline
\end{tabular}

Tabela 19 - Comparação dos modelos clássicos da Tabela 15 mais o modelo completo (6.10), utilizando os critérios AIC, AICc e BIC.

\begin{tabular}{crrr}
\hline & AIC & BIC & AICc \\
\hline Modelo (6.10) & 103195,4 & 103282,4 & 103195,4 \\
Modelo 1 & 103198,3 & 103278,1 & 103198,3 \\
Modelo 2 & $\mathbf{1 0 3 1 9 4 , 8}$ & 103274,6 & $\mathbf{1 0 3 1 9 4 , 9}$ \\
Modelo 3 & 103198,9 & 103278,7 & 103199,0 \\
Modelo 4 & 103197,7 & 103270,2 & 103197,7 \\
Modelo 5 & 103201,8 & 103274,4 & 103201,9 \\
Modelo 6 & 103198,4 & 103270,9 & 103198,4 \\
Modelo 7 & 103201,2 & $\mathbf{1 0 3 2 6 6 , 5}$ & 103201,3 \\
\hline
\end{tabular}

Ao analisar as estimativas do modelo 7 (18), podemos concluir que os alunos do sexo feminino tem desempenho inferior em matemática fixado as outras variáveis, o mesmo podemos afirmar com relação aos alunos que foram reprovados pelo menos uma vez em sua vida escolar. Por outro lado vemos que alunos cuja mãe ou mulher responsável pelo menos ingressou no ensino superior tem um desempenho superior em matemática, fixado os outros preditores, similarmente, os alunos cujo pai ou homem responsável por ele, ao menos ingressou no ensino superior têm um desempenho superior aos demais.

Analisando a Tabela 20, temos que as regiões que têm pior desempenho em matemática na Prova Brasil são as regiões de São Carlos e São Paulo, por outro lado as regiões que têm melhor desempenho em matemática na Prova Brasil são as regiões de Jales e Piracicaba, fixando todas as covariáveis com sendo zero. Quando observamos as Figuras 8 até 9, podemos validar as 
Tabela 20 - Estimativas dos efeitos aleatórios do modelo 7

\begin{tabular}{lc}
\hline Região & Estimativa \\
\hline Araçatuba & $-0,20$ \\
Bauru & $-0,09$ \\
Campinas & 1,75 \\
Itapetininga & 0,17 \\
Jales & 2,51 \\
Jundiaí & 1,73 \\
Marília & $-0,27$ \\
Piracicaba & 2,47 \\
Presidente Prudente & $-0,86$ \\
Registro & $-1,49$ \\
Ribeirão Preto & 1,62 \\
São Carlos & $-3,14$ \\
São José do Rio Preto & 1,41 \\
São José dos Campos & 1,15 \\
São Paulo & $-6,78$ \\
\hline
\end{tabular}

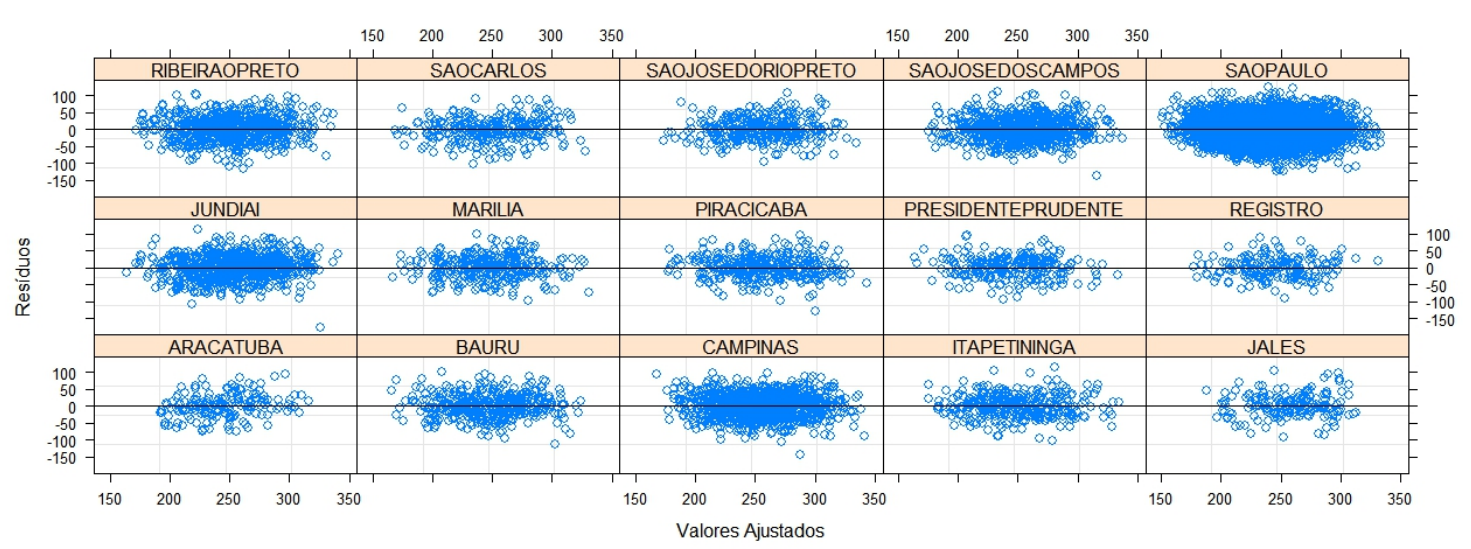

Figura 8 - Análise residual do modelo 7 por grupos.

suposições do modelo, isto é, os erros têm variância constante e têm distribuição normal com média zero.

Note que, embora na Figura 3 não haja indícios de diferenças entre a proficiência em matemática das 15 regiões, a inclusão do efeito aleatório para região se justifica, conforme nós pudemos notar ao longo dessa seção. Na próxima seção temos a análise bayesiana, com efeitos aleatórios para escola.

\subsection{Modelagem Bayesiana}

Nesta seção ajustamos modelos com abordagem bayesiana. Primeiramente estimamos os parâmetros de três modelos e comparamos três metodologias distintas, são elas: modelo com efeitos fixos, modelo com interceptos aleatórios e modelo com interceptos e inclinações 


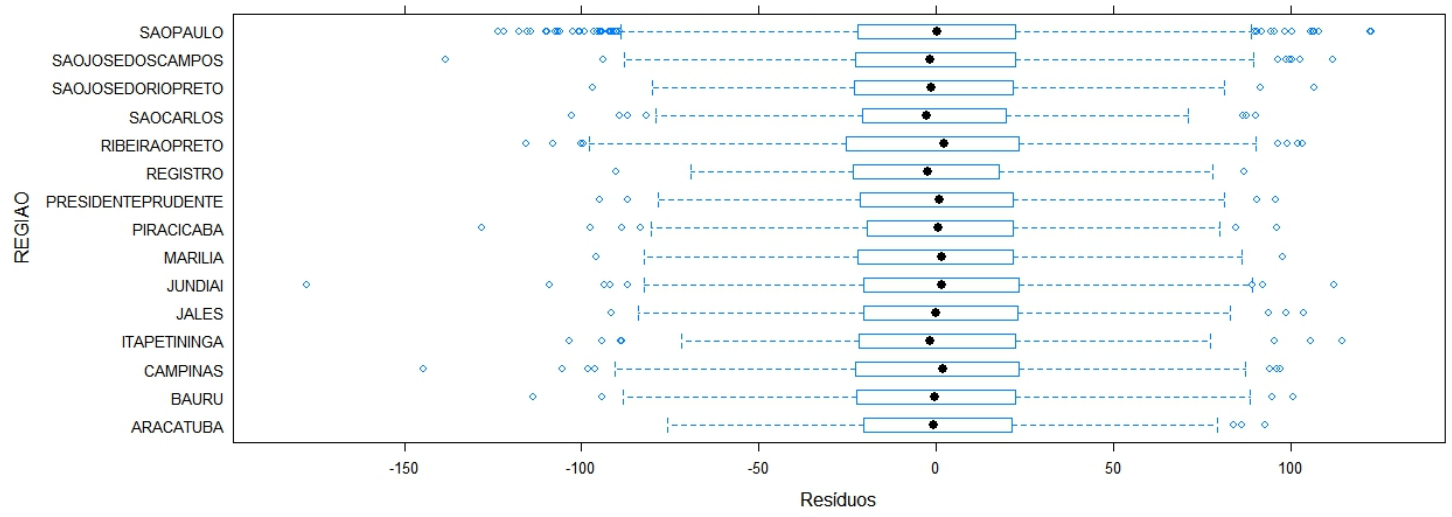

Figura 9 - Box plot dos resíduos do modelo 7 por grupos.

aleatórias. Aqui usamos efeitos aleatórios de escola, para ajustar esses modelos utilizamos a interface Stan, adaptada ao software R, para mais detalhes a respeito, ver por exemplo, Sorensen e Vasishth (2015). O Stan utiliza como método de estimação o processo MCMC com dinâmica hamiltoniana, mais detalhes a respeito pode ser visto em Neal et al. (2011), em cada cadeia ele trabalha com um período de aquecimento, ou seja, na primeira metade da cadeia há ajustes à distribuição dos dados, o período de aquecimento pode ser ajustado pelo usuário.

Para os estudos realizados nesta seção foram excluídos os missings dos dados, ficando assim com 10311 alunos, o que corresponde a aproximadamente 83,96\% dos dados da amostra. No Apêndice D, temos os códigos no stan que foram usados para a obtenção das estimativas desta seção, ressaltamos que foram utilizados distribuições a priori não informativas para os efeitos fixos. As covariáveis aqui utilizadas foram escolhidas utilizando critérios empíricos, conforme visto no capítulo 2.

\subsubsection{Modelo com efeitos fixos}

Considere um modelo com a seguinte estrutura:

$$
y_{i} \sim N\left(\mu, \sigma_{\varepsilon}\right)
$$

onde $i=1, \ldots, 10311$. Temos ainda que $\mu=\beta_{0}+\sum_{m=1}^{9} \beta_{m} x_{m i}$. Esse é o modelo de efeitos fixos, suas estimativas poderão ser encontradas na Tabela 21.

$\mathrm{Na}$ Tabela 21, temos a distribuição a posteriori conjunta dos parâmetros $\beta_{0}, \beta_{1}, \beta_{2}, \beta_{3}$, $\beta_{4}, \beta_{5}, \beta_{6}, \beta_{7}, \beta_{8}, \beta_{9}$ e $\sigma_{e}$ do modelo (6.14), observe que o intervalo com $95 \%$ de credibilidade para $\beta_{3}$ e $\beta_{5}$ contém o zero, sinalizando que as covariáveis turno e idade, nesse caso é não significativa para a variável resposta desse modelo, note que a estatística $\widehat{R}$ é 1 em todos os casos sinalizando que as cadeias de distribuições que contêm 2.000 vetores de parâmetros estimados 
Tabela 21 - Estimativas dos parâmetros, intervalos de credibilidade e a estatística $\hat{R}$ no modelo (6.14).

\begin{tabular}{lcccc}
\hline Parâmetro & média & $2,5 \%$ & $97,5 \%$ & $\widehat{R}$ \\
\hline$\widehat{\beta_{0}}$ (Intercepto) & 103,92 & 97,99 & 109,74 & 1 \\
$\widehat{\beta_{1}}$ (Dep. Admin.) & $-4,22$ & $-5,59$ & $-2,85$ & 1 \\
$\widehat{\beta_{2}}$ (Localização) & $-5,76$ & $-9,84$ & $-1,74$ & 1 \\
$\widehat{\beta_{3}}$ (Turno) & $\mathbf{0 , 9 5}$ & $\mathbf{- 0 , 4 6}$ & $\mathbf{2 , 3 7}$ & $\mathbf{1}$ \\
$\widehat{\beta_{4}}(\mathrm{Q} 001)$ & $-14,75$ & $-16,12$ & $-13,45$ & 1 \\
$\widehat{\beta_{5}}(\mathrm{Q} 004)$ & $\mathbf{2 , 1 0}$ & $\mathbf{- 0 , 5 0}$ & $\mathbf{4 , 7 8}$ & $\mathbf{1}$ \\
$\widehat{\beta_{6}}(\mathrm{Q} 019)$ & 2,92 & 1,38 & 4,48 & 1 \\
$\widehat{\beta_{7}}(\mathrm{Q} 023)$ & 3,32 & 1,74 & 4,74 & 1 \\
$\widehat{\beta_{8}}(\mathrm{Q} 049)$ & $-9,83$ & $-11,83$ & $-7,79$ & 1 \\
$\widehat{\beta_{9}}$ (Nota Port.) & 0,65 & 0,63 & 0,65 & 1 \\
$\widehat{\sigma_{\varepsilon}}$ & 34,19 & 33,77 & 34,63 & 1 \\
\hline
\end{tabular}

convergem.

\subsubsection{Modelo com interceptos aleatórios}

Vamos considerar agora um modelo com a seguinte estrutura:

$$
\begin{array}{r}
y_{i j} \sim N\left(\mu, \sigma_{\varepsilon}+\sigma_{v}\right), \\
\varepsilon_{i j} \sim N\left(0, \sigma_{\varepsilon}\right),
\end{array}
$$

onde $i=1, \ldots, 10311 \mathrm{e} j=1, \ldots, 614$. Temos ainda que $\mu=\beta_{0 j}+\sum_{m=1}^{9} \beta_{m} x_{m i j}$. Temos ainda que $\beta_{0 j} \sim N\left(0, \sigma_{v}\right)$. Na Tabela 22, vemos a distribuição conjunta a posteriori dos parâmetros $\beta_{0 j}, \beta_{1}$, $\beta_{2}, \beta_{3}, \beta_{4}, \beta_{5}, \beta_{6}, \beta_{7}, \beta_{8}, \beta_{9}, \sigma_{\varepsilon}$ e $\sigma_{v}$ do modelo, foram estimados 10.000 vetores de parâmetros em 1 cadeia onde os 5.000 primeiros são um período de aquecimento, observe que a estatística $\widehat{R}$ é 1 , indicando que as cadeias estão convergindo.

Observe na Tabela 22 que o intervalo com $95 \%$ de credibilidade para a estimativa $a$ posteriori marginal de $\beta_{3}$ e $\beta_{5}$, contém o 0 indicando novamente que as covariáveis turno e idade são não significativa, note também que há uma pequena diminuição $\widehat{\sigma_{\varepsilon}}$, isto ocorre devido a existência do componente de variância $\widehat{\sigma}_{v}$.

\subsubsection{Modelo com interceptos e inclinações aleatórios}

O modelo com intercepto e inclinações aleatórias para escola será dado pela equação:

$$
y_{i j}=\left(\beta_{0 j}+v_{0 j}\right)+\sum_{m=1}^{9}\left(\beta_{m j}+v_{m j}\right) x_{m i j}+\varepsilon_{i j},
$$


Tabela 22 - Examinando as estimativas dos parâmetros, intervalos de credibilidade e a estatística $\hat{R}$ no modelo (6.15).

\begin{tabular}{lcccc}
\hline Parâmetro & média & $2,5 \%$ & $97,5 \%$ & $\widehat{R}$ \\
\hline$\widehat{\beta_{0}}$ (Intercepto) & 107,16 & 100,29 & 114,40 & 1 \\
$\widehat{\beta_{1}}$ (Dep. Admin.) & $-4,26$ & $-6,23$ & $-2,26$ & 1 \\
$\widehat{\beta_{2}}$ (Localização) & $-5,83$ & $-11,51$ & $-0,37$ & 1 \\
$\widehat{\beta_{3}}$ (Turno) & $\mathbf{1 , 0 5}$ & $\mathbf{- 0 , 8 2}$ & $\mathbf{2 , 9 2}$ & $\mathbf{1}$ \\
$\widehat{\beta_{4}}$ (Q001) & $-14,62$ & $-15,91$ & $-13,32$ & 1 \\
$\widehat{\beta_{5}}$ (Q004) & $\mathbf{2 , 2 5}$ & $\mathbf{- 0 , 2 8}$ & $\mathbf{4 , 8 3}$ & $\mathbf{1}$ \\
$\widehat{\beta_{6}}(\mathrm{Q} 019)$ & 3,02 & 1,44 & 4,63 & 1 \\
$\widehat{\beta_{7}}$ (Q023) & 3,40 & 1,77 & 5,01 & 1 \\
$\widehat{\beta_{8}}$ (Q049) & $-10,04$ & $-11,94$ & $-8,07$ & 1 \\
$\widehat{\beta_{9}}$ (Nota Port.) & 0,63 & 0,62 & 0,65 & 1 \\
$\widehat{\sigma_{\varepsilon}}$ & 32,44 & 32,97 & 33,92 & 1 \\
$\widehat{\sigma_{v}}$ & 7,20 & 6,25 & 8,17 & 1 \\
\hline
\end{tabular}

onde $i=1, \ldots, 10311$ e $j=1, \ldots, 614$. Na Tabela 23, temos a distribuição de probabilidade $a$ posteriori conjunta dos parâmetros do modelo (6.16), inclusive dos componentes de variância associados a cada um dos efeitos aleatórios.

No modelo (6.16), o intervalo com 95\% de credibilidade para $\beta_{2}, \beta_{3}$ e $\beta_{5}$ contém o 0 , sendo assim, há indícios de que a localização da escola não tem interferência na proficiência em matemática dos alunos avaliados, assim turno em que o aluno estuda bem como sua idade.

\subsection{Seleção de Modelos Bayesianos}

Agora vamos selecionar qual tipo de modelo será utilizado, para isso usamos os critérios de informação looic, WAIC, DIC, EAIC e EBIC, vistos no capítulo 4. Na Tabela 24, temos o valor desses critérios de informação para cada um dos modelos bayesianos ajustados até aqui.

Analisando a Tabela 24, podemos ver que em qualquer um dos cinco critérios o modelo (6.16) tem o menor valor. Assim o melhor modelo seria um modelo com intercepto e inclinações aleatórias com efeito aleatório para escola.

Na Tabela 23, podemos ver as estimativas do modelo (6.16). Observe que há três covariáveis (Localização, Turno e Q004) cujo intervalo de credibilidade contem o zero, o que nos fornece evidências que elas podem não ser significativas para modelar a variabilidade de PROFICIENCIA_MT_SAEB. Para analisar essa questão com mais profundidade ajustamos mais sete modelos, cuja configuração pode ser vista na Tabela 15.

$\mathrm{Na}$ Tabela 25, temos as estimativas dos modelos 1, 2 e 3, da mesma forma na Tabela 26, temos as estimativas dos modelos 4, 5 e 6, e na Tabela 27 temos as estimativas do modelo 7. Observe que, em cada um dos modelos, foi calculado a média a posteriori conjunta dos 
Tabela 23 - Examinando as estimativas dos parâmetros, intervalos de credibilidade e a estatística $\hat{R}$ no modelo (6.16).

\begin{tabular}{lcccc}
\hline Parâmetro & média & $2,5 \%$ & $97,5 \%$ & $\widehat{R}$ \\
\hline$\widehat{\beta_{0}}$ (Intercepto) & 107,04 & 99,85 & 114,34 & 1 \\
$\widehat{\beta_{1}}$ (Dep. Admin.) & $-4,16$ & $-6,20$ & $-2,10$ & 1 \\
$\widehat{\beta_{2}}$ (Localização) & $\mathbf{- 5 , 4 8}$ & $\mathbf{- 1 1 , 1 0}$ & $\mathbf{0 , 1 6}$ & $\mathbf{1}$ \\
$\widehat{\beta_{3}}$ (Turno) & $\mathbf{0 , 8 6}$ & $\mathbf{- 0 , 9 9}$ & $\mathbf{2 , 7 1}$ & $\mathbf{1}$ \\
$\widehat{\beta_{4}}$ (Q001) & $-14,59$ & $-15,94$ & $-13,23$ & 1 \\
$\widehat{\beta_{5}}(\mathrm{Q} 004)$ & $\mathbf{2 , 3 9}$ & $\mathbf{- 0 , 2 4}$ & $\mathbf{5 , 0 1}$ & $\mathbf{1}$ \\
$\widehat{\beta_{6}}(\mathrm{Q} 019)$ & 2,95 & 1,34 & 4,55 & 1 \\
$\widehat{\beta_{7}}(\mathrm{Q} 023)$ & 3,36 & 1,72 & 4,96 & 1 \\
$\widehat{\beta_{8}}(\mathrm{Q} 049)$ & $-9,95$ & $-11,99$ & $-7,93$ & 1 \\
$\widehat{\beta_{9}}($ Nota Port.) & 0,63 & 0,61 & 0,64 & 1 \\
$\widehat{\sigma_{\varepsilon}}$ & 32,24 & 32,77 & 33,71 & 1 \\
$\widehat{\sigma_{v 0}}$ & 2,17 & 0,08 & 5,83 & 1 \\
$\widehat{\sigma_{v 1}}$ & 2,74 & 0,13 & 6,75 & 1 \\
$\widehat{\sigma_{v 2}}$ & 2,41 & 0,12 & 6,20 & 1 \\
$\widehat{\sigma_{v 3}}$ & 2,04 & 0,09 & 5,38 & 1 \\
$\widehat{\sigma_{v 4}}$ & 1,87 & 0,07 & 4,88 & 1 \\
$\widehat{\sigma_{v 5}}$ & 4,45 & 0,41 & 7,87 & 1 \\
$\widehat{\sigma_{v 6}}$ & 3,29 & 0,19 & 6,82 & 1 \\
$\widehat{\sigma_{v 7}}$ & 1,66 & 0,07 & 4,45 & 1 \\
$\widehat{\sigma_{v 8}}$ & 3,75 & 0,25 & 7,75 & 1 \\
$\widehat{\sigma_{v 9}}$ & 0,02 & 0,00 & 0,04 & 1 \\
\hline
\end{tabular}

Tabela 24 - Comparação dos modelos ajustados utilizando os critérios looic, WAIC, DIC,EAIC e EBIC.

\begin{tabular}{lrrrrr}
\hline & EAIC & EBIC & WAIC & looic & DIC \\
\hline modelo (6.14) & 103330,8 & 103410,6 & 103319,3 & 103319,3 & 103319,10 \\
modelo (6.15) & 102871,9 & 102958,9 & 103131,3 & 103131,8 & $-4017,71$ \\
modelo (6.16) & $\mathbf{1 0 2 7 6 5 , 6}$ & $\mathbf{1 0 2 9 1 7 , 9}$ & $\mathbf{1 0 3 1 1 2 , 1}$ & $\mathbf{1 0 3 1 1 3 , 9}$ & $\mathbf{- 4 3 1 5 4 1}$ \\
\hline
\end{tabular}

parâmetros em questão. Na Tabela 28 comparamos os sete modelos reduzido ajustados e também com o modelo completo (Modelo (6.16)), para isso utilizamos os critérios de informação EAIC, EBIC, WAIC, Looic e DIC.

Observando a Tabela 28, temos que os critérios EBIC, WAIC, looic indicam que o Modelo 4 (sem as covariáveis localização e turno) é o melhor. Já o critério EAIC, nos fala que o Modelo 1 (sem a covariável localização) é o melhor. O Critério DIC nos leva a optar pelo Modelo 6 (sem as covariáveis turno e idade). Note que os valores do critério de informação desvio (DIC), diferem dos demais em todos os oito modelos disponíveis na Tabela 28, isto se deve ao fato de que ao se construir o DIC usa-se uma medida que quantifica a complexidade do modelo, que segundo Spiegelhalter et al. (2014) e Gelman e Hill (2006), para modelos com muitos parâmetros, que é o caso do modelo multinível com dois níveis, essa medida se distancia 
Tabela 25 - Examinando as estimativas dos parâmetros, intervalos de credibilidade dos modelos 1, 2 e 3 descritos na Tabela 15 .

\begin{tabular}{|c|c|c|c|}
\hline & Modelo 1 & Modelo 2 & Modelo 3 \\
\hline Parâmetro & média (I.C.) & média (I.C.) & média (I.C.) \\
\hline$\widehat{\beta_{0}}($ Intercepto $)$ & $101,77(96,77 ; 106,73)$ & $107,60(100,47 ; 114,73)$ & $108,54(101,54 ; 115,52)$ \\
\hline$\widehat{\beta_{1}}$ (Dep. Admin.) & $-4,20(-6,26 ;-2,16)$ & $-4,12(-6,16 ;-2,11)$ & $-4,02(-6,07 ;-1,95)$ \\
\hline$\widehat{\beta_{2}}$ (Localização) & - & $-5,49(-11,05 ; 0,01)$ & $-5,07(-10,77 ; 0,56)$ \\
\hline$\widehat{\beta_{3}}($ Turno) & $0,86(-1,05 ; 2,65)$ & - & $0,91(-0,97 ; 2,75)$ \\
\hline$\widehat{\beta_{4}}(\mathrm{Q} 001)$ & $-14,58(-15,94 ;-13,24)$ & $-14,60(-15,97 ;-13,23)$ & $-14,60(-15,99 ;-13,21)$ \\
\hline$\beta_{5}(\mathrm{Q} 004)$ & $2,40(-0,22 ; 5,00)$ & $2,42(-0,22 ; 5,10)$ & - \\
\hline$\hat{\beta}_{6}(\mathrm{Q} 019)$ & $2,93(1,37 ; 4,57)$ & $2,96(1,34 ; 4,56)$ & $3,06(1,43 ; 4,68)$ \\
\hline$\beta_{7}(\mathrm{Q} 023)$ & $3,31(1,71 ; 4,93)$ & $3,36(1,71 ; 4,99)$ & $3,36(1,74 ; 5,03)$ \\
\hline$\beta_{8}(\mathrm{Q} 049)$ & $-9,93(-11,95 ;-7,92)$ & $-9,95(-11,93 ;-7,93)$ & $-10,96(-12,66 ;-9,25)$ \\
\hline$\beta_{9}$ (Nota Port.) & $0,63(0,61 ; 0,64)$ & $0,63(0,61 ; 0,65)$ & $0,63(0,62 ; 0,65)$ \\
\hline$\widehat{\sigma_{\varepsilon}}$ & $32,23(32,76 ; 32,72)$ & $32,24(32,76 ; 33,72)$ & $33,26(32,79 ; 33,74)$ \\
\hline$\widehat{\sigma_{v 0}}$ & $2,42(0,11 ; 6,35)$ & $2,33(0,10 ; 6,22)$ & $2,59(0,12 ; 6,61)$ \\
\hline$\widehat{\sigma_{v 1}}$ & $3,24(0,17 ; 7,40)$ & $3,16(0,15 ; 7,25)$ & $3,21(0,17 ; 7,58)$ \\
\hline$\widehat{\sigma_{v 2}}$ & - & $2,44(0,09 ; 6,42)$ & $2,80(0,14 ; 6,87)$ \\
\hline$\widehat{\sigma_{v 3}}$ & $2,07(0,07 ; 5,65)$ & & $2,15(0,09 ; 5,70)$ \\
\hline$\widehat{\sigma_{v 4}}$ & $1,95(0,10 ; 4,94)$ & $1,88(0,08 ; 4,87)$ & $1,96(0,09 ; 4,95)$ \\
\hline$\widehat{\sigma_{v 5}}$ & $4,20(0,33 ; 7,72)$ & $4,62(0,54 ; 8,09)$ & 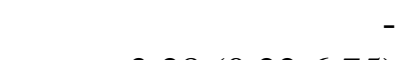 \\
\hline$\widehat{\sigma_{v 6}}$ & $3,16(0,19 ; 6,59)$ & $3,30(0,22 ; 6,77)$ & $3,28(0,22 ; 6,75)$ \\
\hline$\widehat{\sigma_{v 7}}$ & $1,67(0,07 ; 4,35)$ & $1,71(0,07 ; 4,60)$ & $1,71(0,07 ; 4,52)$ \\
\hline$\widehat{\sigma_{v 8}}$ & $3,73(0,20 ; 7,81)$ & $3,67(0,20 ; 7,65)$ & $4,04(0,26 ; 7,99)$ \\
\hline$\widehat{\sigma_{v 9}}$ & $0,03(0,01 ; 0,04)$ & $0,02(0,00 ; 0,04)$ & $0,03(0,01 ; 0,04)$ \\
\hline
\end{tabular}

do verdadeiro número de parâmetros, ocasionando assim discrepâncias como por exemplo, o número efetivo de parâmetros negativo.

Analisamos com mais detalhes o Modelo 4. Na Figura 10 temos o gráfico da densidade $a$ posteriori dos parâmetros, bem como da variância dos erros e dos componentes de variância desse modelo, na Figura 11, temos os histogramas da densidade a posteriori simulada via MCMC com dinâmica hamiltoniana dos parâmetros do modelo, na Figura 12 vemos o desenvolvimento da cadeia de 20.000 iterações, observe que não há padrões que possam indicar falta de convergências.

Observando a Figura 10 e a Figura 11, os parâmetros aparentemente tem distribuições simétricas, assim como a variância dos erros, já os componentes de variância notamos que eles tem distribuição assimétrica à direita.

Observando as estimativas do modelo bayesiano 4 na Tabela 26, podemos notar que há indícios que o aluno declaram ser do sexo feminino e ter sido reprovado influencia de maneira negativa no desempenho do aluno em matemática, fixando as outras covariáveis como sendo zero. Por outro lado, os alunos cujos pais são mais escolarizados tendem a ter um desempenho mais elevado em matemática, destaca-se ainda que apesar do modelo 4 for o escolhido por alguns 
Tabela 26 - Examinando as estimativas dos parâmetros, intervalos de credibilidade dos modelos 4,5 e 6 descritos na Tabela 15.

\begin{tabular}{lrrr}
\hline & Modelo 4 & Modelo 5 & Modelo 6 \\
\hline Parâmetro & média (I.C.) & média (I.C.) & média (I.C.) \\
\hline$\widehat{\beta_{0}}$ (Intercepto) & $102,33(97,62 ; 106,93)$ & $103,69(99,43 ; 108,05)$ & $109,03(102,33 ; 115,73)$ \\
$\widehat{\beta_{1}}$ (Dep. Admin.) & $-4,16(-6,22 ;-2,12)$ & $-4,07(-6,13 ;-2,04)$ & $-3,96(-6,00 ;-1,90)$ \\
$\widehat{\beta_{2}}$ (Localização) & - & - & $-4,96(-10,56 ; 0,68)$ \\
$\widehat{\beta_{3}}$ (Turno) & - & $0,83(-1,01 ; 2,69)$ & - \\
$\widehat{\beta_{4}}($ Q001) & $-14,59(-15,92 ;-13,23)$ & $-14,59(-15,97 ;-13,24)$ & $-14,60(-15,94 ;-13,23)$ \\
$\widehat{\beta_{5}}($ Q004) & $2,41(-0,21 ; 4,98)$ & - & - \\
$\widehat{\beta_{6}}(\mathrm{Q} 019)$ & $2,94(1,34 ; 4,51)$ & $3,04(1,44 ; 4,68)$ & $3,05(1,40 ; 4,71)$ \\
$\widehat{\beta_{7}}(\mathrm{Q} 023)$ & $3,32(1,67 ; 5,00)$ & $3,31(1,74 ; 4,90)$ & $3,38(1,72 ; 5,03)$ \\
$\widehat{\beta_{8}}(\mathrm{Q} 049)$ & $-9,94(-11,95 ;-7,97)$ & $-10,94(-12,67 ;-9,28)$ & $-10,96(-12,69 ;-9,27)$ \\
$\widehat{\beta_{9}}($ Nota Port.) & $0,63(0,61 ; 0,64)$ & $0,63(0,62 ; 0,65)$ & $0,63(0,62 ; 0,65)$ \\
$\widehat{\sigma_{\varepsilon}}$ & $32,25(32,76 ; 32,73)$ & $33,26(32,79 ; 33,76)$ & $33,26(32,79 ; 33,74)$ \\
$\widehat{\sigma_{v 0}}$ & $2,35(0,10 ; 6,36)$ & $2,70(0,12 ; 7,39)$ & $2,68(0,12 ; 6,96)$ \\
$\widehat{\sigma_{v 1}}$ & $3,50(0,17 ; 7,69)$ & $3,66(0,17 ; 8,05)$ & $3,63(0,16 ; 8,09)$ \\
$\widehat{\sigma_{v 2}}$ & - & - & $2,84(0,12 ; 7,16)$ \\
$\widehat{\sigma_{v 3}}$ & - & $2,19(0,10 ; 5,59)$ & \\
$\widehat{\sigma_{v 4}}$ & $1,90(0,08 ; 4,84)$ & $1,93(0,08 ; 4,89)$ & $1,92(0,07 ; 5,03)$ \\
$\widehat{\sigma_{v 5}}$ & $4,09(0,23 ; 7,59)$ & - & - \\
$\widehat{\sigma_{v 6}}$ & $3,10(0,19 ; 6,59)$ & $3,17(0,18 ; 6,65)$ & $3,24(0,20 ; 6,71)$ \\
$\widehat{\sigma_{v 7}}$ & $1,69(0,07 ; 4,47)$ & $1,69(0,06 ; 4,61)$ & $1,75(0,07 ; 4,68)$ \\
$\widehat{\sigma_{v 8}}$ & $3,72(0,21 ; 7,69)$ & $3,85(0,21 ; 7,93)$ & $4,09(0,25 ; 8,06)$ \\
$\widehat{\sigma_{v 9}}$ & $0,03(0,01 ; 0,04)$ & $0,03(0,02 ; 0,04)$ & $0,03(0,01 ; 0,04)$ \\
\hline
\end{tabular}

dos critérios de informação, o intervalo com $95 \%$ de credibilidade para o parâmetro associado a covariável que identifica a distorção idade série contêm o zero.

\subsection{Seleção de Variáveis}

Nesta seção realizamos seleção de variáveis, ressaltamos que ao contrário de seleção de modelos, onde é feito a comparação do modelo completo com o modelo reduzido (sem algumas das covariáveis utilizadas anteriormente), utilizamos o modelo completo e daí extraímos os preditores que não são significativos, ou seja, dentre todas as variáveis explicativas disponíveis, devemos encontrar um subconjunto de variáveis importantes para o modelo.

Consideramos modelos de regressão multinível com dois níveis, com efeito aleatório de escola, cuja variável resposta é a proficiência em matemática, que conforme foi visto anteriormente, há indícios de que é aderente a uma distribuição normal. O objetivo aqui é utilizar o algoritmo glmmLasso que descrevemos no capítulo 4 e realizar seleção de variáveis num contexto educacional. Para tanto consideramos todas as variáveis que são provenientes do questionário dos alunos e também as variáveis dependência administrativa, localização, turno, nota de 
Tabela 27 - Examinando as estimativas dos parâmetros, intervalos de credibilidade do modelo 7 descritos na Tabela 15.

\begin{tabular}{lr}
\hline & Modelo 7 \\
\hline Parâmetro & média (I.C.) \\
\hline$\widehat{\beta_{0}}$ (Intercepto) & $104,24(100,16 ; 108,36)$ \\
$\widehat{\beta_{1}}$ (Dep. Admin.) & $-3,99(-6,07 ;-1,89)$ \\
$\widehat{\beta_{2}}$ (Localização) & - \\
$\widehat{\beta_{3}}$ (Turno) & - \\
$\widehat{\beta_{4}}(\mathrm{Q} 001)$ & $-14,59(-15,94 ;-13,25)$ \\
$\widehat{\beta_{5}}(\mathrm{Q} 004)$ & - \\
$\widehat{\beta_{6}}(\mathrm{Q} 019)$ & $3,04(1,42 ; 4,70)$ \\
$\widehat{\beta_{7}}(\mathrm{Q} 023)$ & $3,32(1,74 ; 4,92)$ \\
$\widehat{\beta_{8}}(\mathrm{Q} 049)$ & $-10,97(-12,68 ;-9,25)$ \\
$\widehat{\beta_{9}}($ Nota Port.) & $0,63(0,61 ; 0,65)$ \\
$\widehat{\sigma_{\varepsilon}}$ & $33,26(32,78 ; 33,74)$ \\
$\widehat{\sigma_{v 0}}$ & $2,81(0,13 ; 6,82)$ \\
$\widehat{\sigma_{v 1}}$ & $4,40(0,40 ; 8,62)$ \\
$\widehat{\sigma_{v 2}}$ & \\
$\widehat{\widehat{\sigma_{v 3}}}$ & \\
$\widehat{\sigma_{v 4}}$ & \\
$\widehat{\sigma_{v 5}}$ & $1,92(0,08 ; 4,93)$ \\
$\widehat{\sigma_{v 6}}$ & \\
$\widehat{\widehat{\sigma_{v 7}}}$ & \\
$\widehat{\sigma_{v 8}}$ & $3,17(0,20 ; 6,62)$ \\
$\widehat{\sigma_{v 9}}$ & $1,72(0,07 ; 4,52)$ \\
\hline & $4,16(0,30 ; 8,05)$ \\
& $0,03(0,02 ; 0,04)$ \\
\hline
\end{tabular}

Tabela 28 - Comparação dos modelos com interceptos e inclinações aleatórias, utilizando os critérios looic, WAIC, DIC,EAIC e EBIC.

\begin{tabular}{crrrrr}
\hline & EAIC & EBIC & WAIC & looic & DIC \\
\hline Modelo (6.16) & 102765,6 & 102917,9 & 103112,1 & 103113,9 & -431541 \\
Modelo 1 & $\mathbf{1 0 2 7 6 0}$ & 102897,8 & 103110,9 & 103112,7 & $-600863,2$ \\
Modelo 2 & 102763,9 & 102901,7 & 103110,9 & 103112,7 & $-613839,8$ \\
Modelo 3 & 102903 & 103040,9 & 103242,9 & 103244,6 & $-559262,6$ \\
Modelo 4 & 102761 & $\mathbf{1 0 2 8 8 4 , 3}$ & $\mathbf{1 0 3 1 0 8 , 6}$ & $\mathbf{1 0 3 1 1 0 , 4}$ & -38513777 \\
Modelo 5 & 102899,6 & 103022,9 & 103240,5 & 103242,2 & -38676171 \\
Modelo 6 & 102901,6 & 103024,9 & 103241,9 & 103243,6 & $\mathbf{- 3 8 7 0 0 9 1 8}$ \\
Modelo 7 & 102894,9 & 103003,7 & 103237,7 & 103239,4 & $-633529,9$ \\
\hline
\end{tabular}

matemática da escola, nota de português da escola, taxa de participação da escola, número de alunos presentes por escola, número de alunos matriculados por escola e proficiência em língua portuguesa. Ressaltamos ainda que as variáveis contínuas usadas nesse procedimento foram centralizadas. Mais detalhes a respeito das covariáveis que são utilizadas pode ser encontrado no apêndice $\mathrm{A}$.

O primeiro passo é encontrar o $\lambda$ ótimo, para tanto realizamos simulações computacionais 


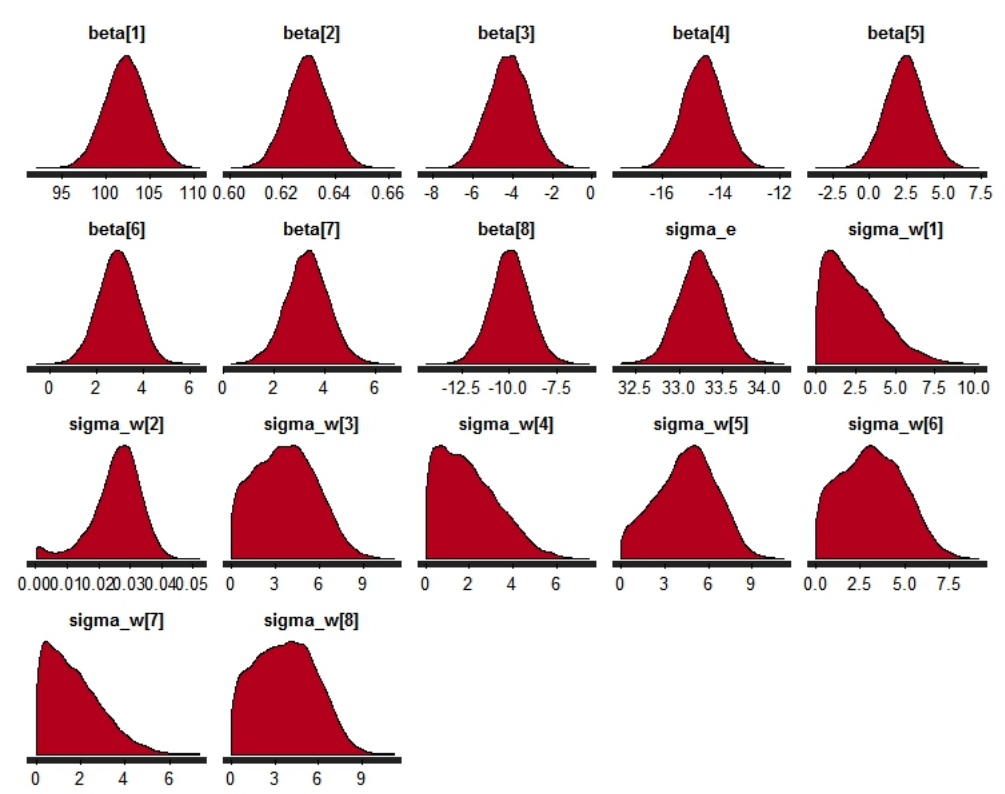

Figura 10 - Gráfico da função densidade marginal a posteriori dos parâmetros do Modelo 4.

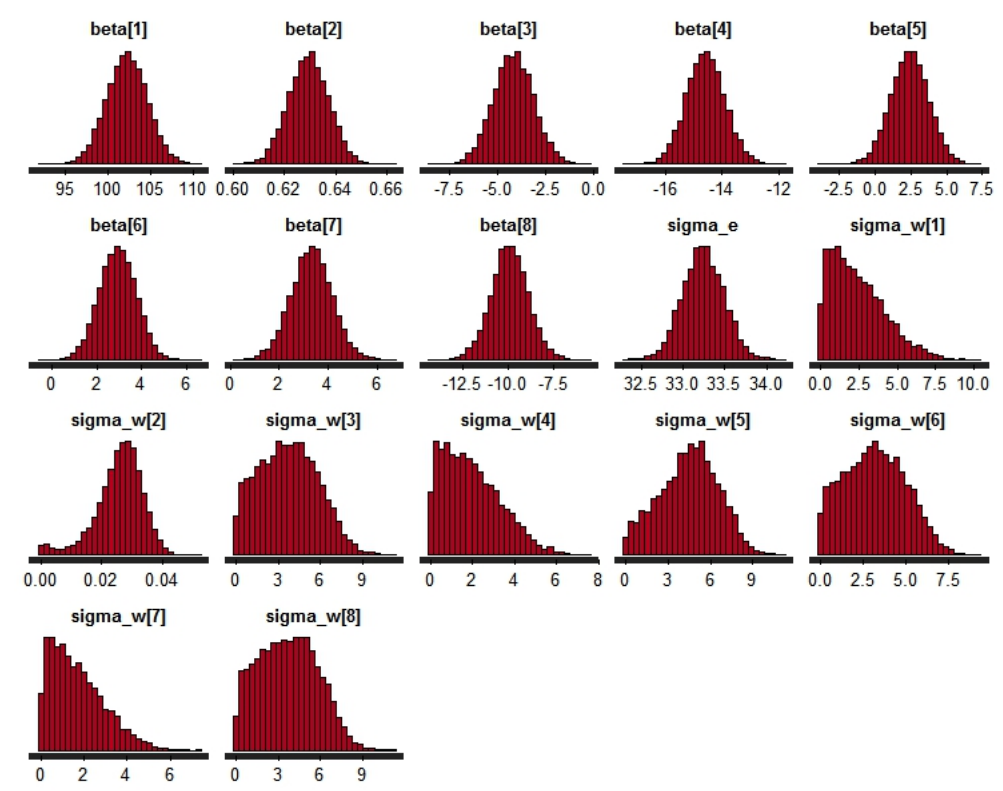

Figura 11 - Histogramas da densidade a posteriori simulada via MCMC com dinâmica hamiltoniana dos parâmetros do modelo 4 .

comparando os modelos estimados e seus respectivos $B I C$, foi gerado um conjunto de 21 valores para $\lambda$ variando de 0 até 1000 . Constatamos que para $\lambda=450$ foi estimado o modelo com o menor $B I C(-3403,94)$ e na Figura 13 temos o gráfico dos valores do BIC para os $\lambda$ citados anteriormente.

Na Tabela 29 temos o modelo estimado via escore de Fisher, apenas com as covariáveis selecionadas. Observe que 34 preditores foram selecionados, vemos ainda como fatores que influenciam positivamente a proficiência em matemática são: mãe alfabetizada, leitura de livros 


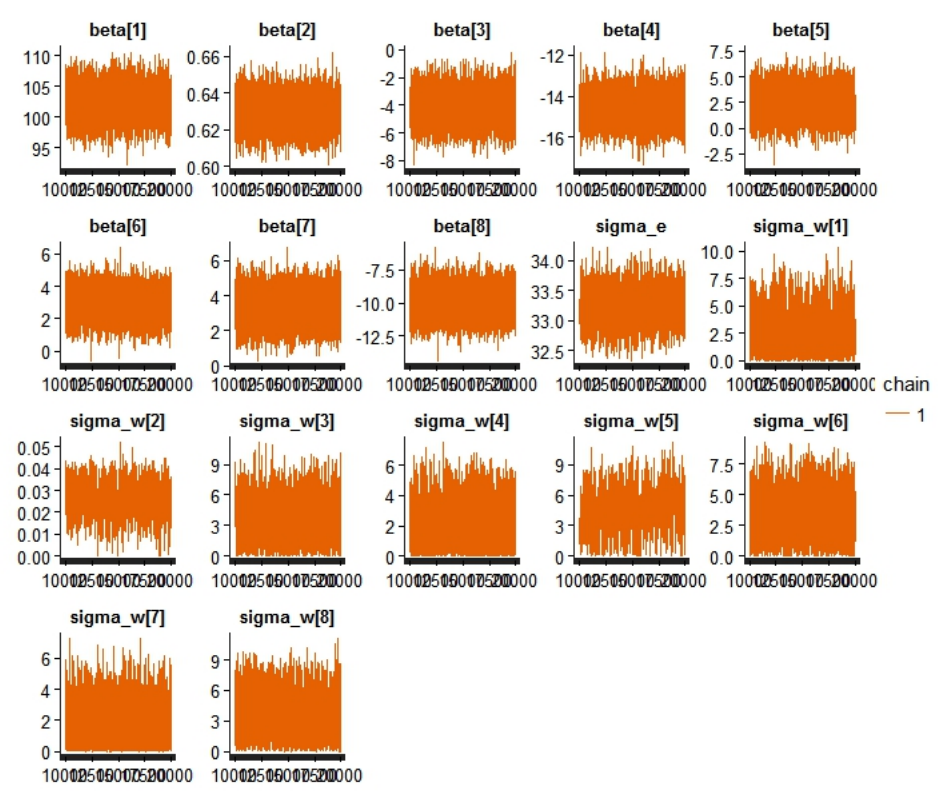

Figura 12 - Desenvolvimento do processo MCMC durante as 20.000 iterações para cada um dos parâmetros.

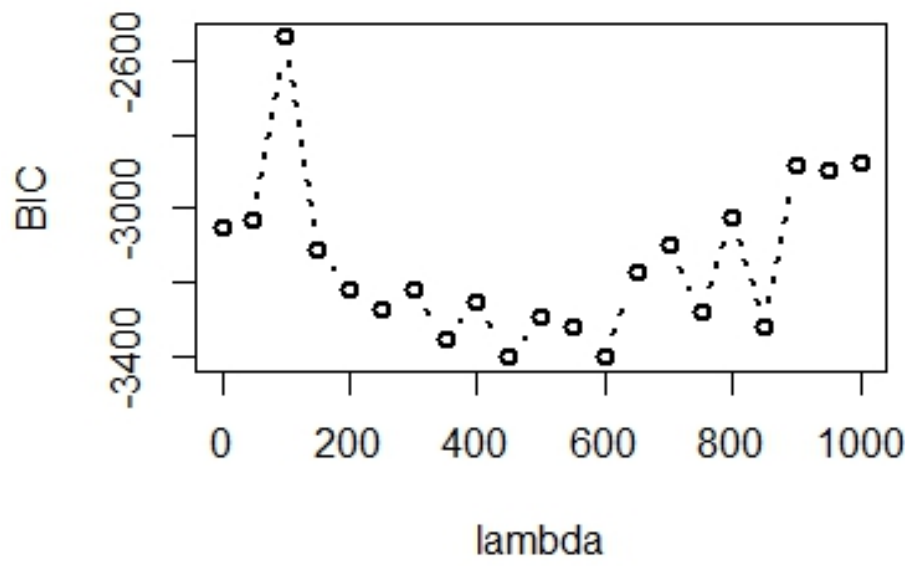

Figura 13 - Gráfico dos BIC versus $\lambda$, para 21 valores de $\lambda$ tomados entre 0 e 1000 .

com alta frequência por parte do aluno, tempo gasto com recreação em dia de aula, aluno gostar de matemática, o desempenho em matemática global da escola e o desempenho em língua portuguesa do aluno. Por outro lado podemos destacar como fatores que influenciam negativamente a proficiência em matemática são: o aluno declarar ser do sexo feminino, o aluno já ter sido reprovado e gostar de língua portuguesa. 
Tabela 29 - Resultados referentes ao algoritmo glmmLasso com as covariáveis descritas anteriormente, para $\lambda=450$, foi selecionado no total 34 variáveis explicativas.

\begin{tabular}{|c|c|c|}
\hline Variáveis Explicativas & Estimativa & Valor $\mathrm{p}$ \\
\hline \multicolumn{3}{|l|}{ Efeito fixo } \\
\hline Intercepto & $-0,582$ & $<0,001$ \\
\hline Q001 (1: Sexo Feminino) & $-0,257$ & $<0,001$ \\
\hline Q002: Amarelo & 0,154 & 0,067 \\
\hline Q002: Branco & 0,149 & $<0,001$ \\
\hline Q002: Indígena & 0,019 & 0,856 \\
\hline Q002: Pardo & 0,134 & 0,038 \\
\hline Q002: Preto & 0,072 & 0,601 \\
\hline Q002: Não Sei & - & - \\
\hline Q004 (1: aluno está na série ideal) & 0,052 & 0,294 \\
\hline Q012 (1: tem carro em casa) & $-0,000$ & 0,973 \\
\hline Q013 (1: tem computador em casa) & 0,054 & 0,080 \\
\hline Q019 (1: mãe com ensino superior ou mais) & 0,036 & 0,192 \\
\hline Q020 (1: mãe alfabetizada) & 0,143 & 0,022 \\
\hline Q022 (1: aluno mora com o pai) & $-0,002$ & 0,923 \\
\hline Q023 (1: pai com ensino superior ou mais) & 0,042 & 0,141 \\
\hline Q024 (1: pai alfabetizado) & 0,044 & 0,328 \\
\hline Q026 (1: alta frequência dos pais nas reuniões escolares) & 0,029 & 0,255 \\
\hline Q030 (1: há incentivo dos pais para que os alunos não faltem) & 0,154 & 0,152 \\
\hline Q033 (1: leitura de livros com alta frequência) & 0,057 & 0,053 \\
\hline Q037 (1: alta frequência de leitura de revistas comportamentais) & $-0,065$ & 0,013 \\
\hline Q038 (1: leitura de sites de internet com alta frequência) & 0,001 & 0,955 \\
\hline Q040 (1: ir ao cinema em alta frequência) & $-0,070$ & 0,021 \\
\hline Q041 (1: ver apresentações teatrais em alta frequência) & $-0,058$ & 0,354 \\
\hline Q042 (1: ver shows musicais ou de dança em alta frequência) & $-0,041$ & 0,343 \\
\hline Q043 (1: participar de festas comunitárias em alta frequência) & $-0,049$ & 0,105 \\
\hline $\begin{array}{l}\text { Q044 (1: alunos gasta muito tempo com recreação em dia de } \\
\text { aula) }\end{array}$ & 0,072 & 0,012 \\
\hline Q046 (1: aluno trabalha fora de casa) & 0,012 & 0,696 \\
\hline Q047 (1: ingressou na escola antes da $1^{\mathrm{a}}$ serie) & $-0,029$ & 0,391 \\
\hline Q049 (1: aluno já foi reprovado) & $-0,151$ & $<0,001$ \\
\hline Q050 (1: aluno já abandonou a escola) & 0,010 & 0,882 \\
\hline Q051 (1: aluno gosta de estudar Língua Portuguesa) & $-0,180$ & $<0,001$ \\
\hline $\begin{array}{l}\text { Q052 (1: aluno faz o dever de casa de Língua Portuguesa } \\
\text { com alta frequência) }\end{array}$ & 0,021 & 0,716 \\
\hline Q054 (1: aluno gosta de estudar Matemática) & 0,308 & $<0,001$ \\
\hline $\begin{array}{l}\text { Q055 (1: aluno faz o dever de casa de Matemática com alta } \\
\text { frequência) }\end{array}$ & 0,084 & 0,094 \\
\hline $\begin{array}{l}\text { Q056 (1: professor corrige o dever de casa de Matemática com } \\
\text { alta frequência) }\end{array}$ & 0,034 & 0,610 \\
\hline MEDIA_MT & 0,321 & $<0,001$ \\
\hline MEDIA_LP & $-0,191$ & $<0,001$ \\
\hline TAXA_PARTICIPACAO & $-0,004$ & 0,723 \\
\hline PROFICIENCIA_LP_SAEB & 0,579 & $<0,001$ \\
\hline DEPENDENCIA_ADM (1: Estadual) & $-0,030$ & 0,272 \\
\hline \multicolumn{3}{|l|}{ Efeito aleatório } \\
\hline Desvio Padrão(Intercepto da Escola) & 0,041 & \\
\hline
\end{tabular}


CAPÍTULO

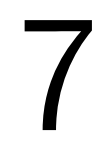

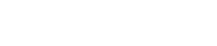

\section{DISCUSSÃO E PROPOSTAS FUTURAS}

O presente trabalho tem como objetivo principal construir modelos de regressão multinível tendo como variável resposta o desempenho escolar dos estudantes do nono ano do ensino fundamental do Estado de São Paulo na PROVA BRASIL 2011 em matemática. O uso de modelos multiníveis com dois níveis se justificam pelo fato de que há uma porção significativa da variabilidade dos dados que é explicada por escolas. Nosso intuito foi identificar quais variáveis explicativas afetam o desempenho dos estudantes em matemática. É importante destacar que ao apontarmos essas variáveis, damos um grande passo para compreender o que influencia no bom ou no mau desempenho do estudante e a partir daí, entender o funcionamento do sistema educacional paulista.

Nossa análise se dividiu em seleção de modelos e seleção de variáveis. Quando falamos em seleção de variáveis o método utilizado foi o Lasso, desenvolvido inicialmente para modelos de regressão linear simples e depois aperfeiçoado para ser utilizado em modelos lineares generalizados mistos (multiníveis com dois níveis), considerando resposta normal e função de ligação identidade. Constatamos uma diminuição de aproximadamente $45 \%$ dos preditores, contudo deve-se ressaltar que após a execução do algoritmo do gradiente ascendente, são obtidas as estimativas dos parâmetros utilizando um procedimento de escore de Fisher, e nesse caso verificamos que vários dos preditores selecionados via Lasso não são significativos se utilizarmos um teste t com 5\% de significância. Assim podemos afirmar que os fatores que influenciam positivamente a proficiência em matemática dos alunos da rede pública paulista são: grau de instrução da mãe, frequência de leitura de livros por parte dos alunos, tempo gasto com recreação em dia de aula, o aluno declarou gostar de matemática, o desempenho em matemática global da escola e o desempenho em língua portuguesa do aluno. Por outro lado, podemos destacar como fatores que influenciam negativamente a proficiência em matemática: o aluno declara ser do sexo feminino, o aluno já ter sido reprovado e gostar de língua portuguesa.

Com relação à seleção de modelos, dividimos nossa análise entre enfoque clássico e 
enfoque bayesiano. Na modelagem clássica utilizamos para selecionar modelos três critérios de informação: AIC, AICc e BIC. No fim os três critérios utilizados foram favoráveis à seleção do modelo de regressão multinível com intercepto aleatório para região, modelo esse em que as covariáveis turno, localização e idade (mede a distorção idade e série) são não significativas. Baseado em todas as configurações existentes relativas à extração ou não das covariáveis citadas acima, ajustamos mais sete modelos e aplicamos novamente os critérios de seleção e daí notamos que o BIC optou pelo modelo onde é feita a exclusão das três covariáveis, por outro lado o AIC e AICc selecionou o modelo onde apenas a variável explicativa turno é excluída. Como o modelo selecionado pelo AIC e AICc contem variáveis explicativas não significativas se utilizarmos um teste t com 5\% de significância, o que não ocorre com o modelo selecionado pelo BIC, que possui todas os preditores significativos, foi realizado ainda um breve estudo de simulação para o caso frequentista, onde foi constatado que para grande amostras e muitos preditores o critério BIC é mais eficiente que o AIC e o AICc. Sendo assim, sugerimos a utilização do BIC como critério de seleção de modelos, onde a abordagem for de modelos de regressão multiníveis com resposta normal.

Na modelagem bayesiana utilizamos as mesmas covariáveis da parte clássica. Os critérios de informação que empregamos para comparação desses modelos foram: WAIC, looic, DIC, EAIC e EBIC. Primeiramente ajustamos três modelos bayesianos: um com efeitos fixos apenas, outro com intercepto aleatório e por último um com intercepto e inclinações aleatórias. Ressaltamos que os efeitos aleatórios são de escola.

Depois de ajustados esses três primeiros modelos constatamos que os cinco critérios são favoráveis à seleção do modelo com intercepto e inclinações aleatórias para escola. Analisando os intervalos de credibilidade desses modelos, concluímos que os intervalos de credibilidade para localização, turno e distorção idade-série contêm o zero, evidenciando assim que esses preditores podem ou não fazer parte do modelo. Logo se faz necessário ajustar mais sete modelos levando em consideração todas as configurações possíveis com essas três covariáveis. Feito isso e calculado os critérios de informação, concluímos que em três dos cinco critérios (WAIC, Looic e EBIC), o modelo sem os preditores localização e turno é o melhor, contudo o intervalo de credibilidade para o coeficiente da covariável distorção idade-série contêm o zero.

De uma forma geral, sugerimos a utilização do critério de informação WAIC, para seleção de modelos de regressão multinível, pois ao contrário das outras medidas de informação, é invariante a parametrização, insensível ao tamanho amostral e também computacionalmente eficiente, além do mais sua construção é feita totalmente numa abordagem bayesiana, pois se baseia na função $\log$ a posteriori preditiva.

Para trabalhos futuros podem-se testar outros preditores, sejam eles já existentes na amostra dos dados, ou até mesmo outro construído via técnicas de análise multivariada e a partir daí é possível realizar também: 
- a extensão de suposições de distribuição de probabilidade para componentes aleatórios;

- análise de diagnóstico;

- estudos de simulação mais aprofundados.

Ressaltamos que a base de dados em questão nos fornece uma grande quantidade de análises possíveis a serem realizadas além daquelas que aqui apresentamos, inclusive outras questões práticas do contexto educacional em análise podem ser respondidas, uma das mais importantes que consideramos é encontrar quais são os preditores que são significativos para a covariável reprovação, bem como a analisar as covariáveis provenientes do questionário de professor, diretor e da escola são significativas para o desempenho do aluno em matemática. Devido à alta correlação entre a proficiência em matemática e proficiência em língua portuguesa é possível o ajuste de modelos de regressão multivariados.

No contexto prático abordado neste trabalho há uma imensa quantidade de preditores (mais de 500), por isso é esperado que métodos de seleção de modelos sejam mais eficazes neste caso, pois para estimar todos os modelos possíveis e calcular os seus respectivos critérios de informação seria muito trabalhoso e ainda demandaria muito tempo. Futuramente outros métodos de seleção de modelos podem ser testados, dentre os mais importantes podemos destacar: Regressão Ridge, Adaptative Lasso e Lasso Bayesiano.

Como já foi dito anteriormente, a educação é uma das demandas mais desafiadoras em nossa sociedade atual, por isso, pesquisas com dados educacionais são de vital importância. Tais pesquisas fornecem subsídios para diagnósticos e reformulações de políticas educacionais, fornecem ainda ferramentas para que o docente em sala de aula possa reformular sua prática pedagógica e assim contribuir mais incisivamente para a evolução do aluno no processo de ensino e aprendizagem. 

AKAIKE, H. Information theory and an extension of the maximum likelihood principle. In: Selected Papers of Hirotugu Akaike. [S.1.]: Springer, 1998. p. 199-213. Citado nas páginas 25,43 e 44.

ANDRADE, R. J. de; SOARES, J. F. O efeito da escola básica brasileira. Estudos em avaliação educacional, v. 19, n. 41, p. 379-406, 2008. Citado na página 25.

BATES, D.; MÄCHLER, M.; BOLKER, B.; WALKER, S. Fitting linear mixed-effects models using lme4. Journal of Statistical Software, v. 67, n. 1, p. 1-48, 2015. Citado nas páginas 62 e 163.

BATES, D. M. Ime4: Mixed-effects modeling with R. [S.1.]: Springer New York, 2010. Citado na página 39.

BERGAMO, G. C. Aplicação de modelos multiníveis na análise de dados de medidas repetidas no tempo. Dissertação (Mestrado) - Universidade de São Paulo, 2002. Citado na página 25.

BLIESE, P. Multilevel Modeling in R (2.2)-A Brief Introduction to R, the multilevel package and the nlme package. [S.1.]: October, 2006. Citado na página 39.

BOLKER, B.; TEAM, R. bbmle: Tools for general maximum likelihood estimation. R package version 0.9, v. 5, 2010. Citado na página 163.

BRESLOW, N. E.; CLAYTON, D. G. Approximate inference in generalized linear mixed models. Journal of the American statistical Association, Taylor \& Francis Group, v. 88, n. 421, p. 9-25, 1993. Citado na página 52.

BROOKS, S.; SMITH, J.; VEHTARI, A.; PLUMMER, M.; STONE, M.; ROBERT, C.; TITTERINGTON, D.; NELDER, J.; ATKINSON, A.; DAWID, A.; LAWSON, A.; CLARK, A.; BERNARDO, J.; SAHU, S.; RICHARDSON, S.; GREEN, P.; BURNHAM, K.; DEIORIO, M.; ROBERT, C.; DRAPER, D.; GELFAND, A.; TREVISANI, M.; HODGES, J.; LEE, Y.; De Luna, X.; MENG, X. Discussion on the paper by Spiegelhalter, Best, Carlin and Van der Linde. Journal of the Royal Statistical Society. Series B: Statistical Methodology, Wiley-Blackwell, v. 64, n. 4, p. 616-639, 2002. ISSN 1369-7412. Citado na página 49.

CARLIM, B.; LOUIS, T. Bayes and empirical bayes methods for data analysis essays on item response theory. Chapman and Hall, New York, 2001. Citado na página 50.

CASELLA, G.; BERGER, R. L. Statistical inference. [S.1.]: Duxbury Pacific Grove, CA, 2002. v. 2. Citado na página 39.

CASTRO, C. S. Aplicação de Modelos Multinível para o Estudo da Sinistralidade no Retalho Alimentar. Dissertação (Mestrado) - Faculdade de Ciências da Universidade do Porto, 2015. Citado nas páginas 23 e 62. 
EMILIANO, P. C. Fundamentos e aplicações dos critérios de Informação: akaike e bayesiano. Dissertação (Mestrado), 2009. Citado nas páginas 43 e 76.

EMILIANO, P. C. Critérios de Informaçao: Como eles se comportam em diferentes modelos. Tese (Doutorado) — Universidade Federal de Lavras, 2013. C Citado na página 26.

GELMAN, A.; HILL, J. Data analysis using regression and multilevel/hierarchical models. [S.1.]: Cambridge university press, 2006. Citado nas páginas 25, 40, 41, 42, 46, 62 e 82.

GOLDSTEIN, H. Multilevel mixed linear model analysis using iterative generalized least squares. Biometrika, v. 73, n. 1, p. 43-56, 1986. Citado nas páginas 23 e 62.

GONÇALVES, F. d. O.; FRANÇA, M. T. A. Qualidade educacional nos municípios nordestinos: Evidências a partir do prova brasil 2005. Planejamento e Políticas Públicas, n. 40, 2013. Citado nas páginas 29 e 30.

GROLL, A.; TUTZ, G. Variable selection for generalized linear mixed models by 1 1-penalized estimation. Statistics and Computing, Springer, v. 24, n. 2, p. 137-154, 2014. Citado nas páginas 50 e 51.

KUZNETSOVA, A.; BROCKHOFF, P. B.; CHRISTENSEN, R. H. B. Package 'lmertest'. R package version, v. 2, 2015. Citado na página 163.

LAROS, J. A.; MARCIANO, J. L. P.; ANDRADE, J. M. de. Fatores que afetam o desempenho na prova de matemática do saeb: Um estudo multinível. Avaliaçao Psicologica: Interamerican Journal of Psychological Assessment, Instituto Brasileiro de Avaliação Psicológica (IBAP), v. 9, n. 2, p. 173-186, 2010. Citado nas páginas 25, 29, 30 e 61.

MICRODADOS. 2011. <http://portal.inep.gov.br/basica-levantamentos-acessar>. Accessed: 2016-03-15. Citado nas páginas 28 e 61.

MISSÃO, É. C. M. Uma revisão do fator de Bayes com aplicação à modelos com misturas. Dissertação (Mestrado), 2010. Citado na página 45.

MOREIRA, K. d. S. G.; JACINTO, P. de A. Determinantes da proficiência em matemática no rio grande do sul: Uma análise a partir de modelos hierárquicos. PPGE/PUCRS, 2013. Citado na página 25.

NATIS, L. Modelos lineares hierárquicos. Dissertação (Mestrado) — Instituto de Matemática e Estatística, 2000. Citado na página 25.

NATIS, L. Modelos hierárquicos lineares. Estudos em avaliação educacional, n. 23, p. 3-29, 2013. Citado nas páginas 25, 29, 30 e 62.

NEAL, R. M. et al. Mcmc using hamiltonian dynamics. Handbook of Markov Chain Monte Carlo, v. 2, p. 113-162, 2011. Citado nas páginas 79, 165 e 166.

OSIO, M. M. G. Análise de modelos de regressão multiníveis simétricos. Dissertação (Mestrado) - Instituto de Ciências Matemáticas e de Computação, 2013. Citado nas páginas 24, 25, 39 e 62.

PATTERSON, H. D.; THOMPSON, R. Recovery of inter-block information when block sizes are unequal. Biometrika, Biometrika Trust, v. 58, n. 3, p. 545-554, 1971. Citado na página 39. 
PESQUISA. 2011. <https://www.educacao.mg.gov.br/images/documentos/Pesquisa\%20sobre\% 20a\%20Qualidade\%20do\%20Ensino\%20nas\%20Escolas\%20Estaduais\%20de\%20MG.pdf>. Accessed: 2016-08-07. Citado na página 30.

PINHEIRO, J.; BATES, D.; DEBROY, S.; SARKAR, D.; R Core Team. nlme: Linear and Nonlinear Mixed Effects Models. [S.1.], 2017. R package version 3.1-131. Disponível em: $<$ https://CRAN.R-project.org/package=nlme>. Citado na página 163.

RUSSO, C. M.; AOKI, R.; PAULA, G. A. Assessment of variance components in nonlinear mixed-effects elliptical models. Test, Springer, p. 1-27, 2012. Citado na página 40.

SANTOS, L. S. G. dos. Fatores associados ao sucesso escolar em matemática: um estudo comparativo entre duas escolas públicas do DF a partir dos dados da prova brasil. 2013. Citado na página 25.

SCHWARZ, G. et al. Estimating the dimension of a model. The annals of statistics, Institute of Mathematical Statistics, v. 6, n. 2, p. 461-464, 1978. Citado nas páginas 43 e 45.

SEARLE, S. R. et al. Biometrics unit technical reports: Number bu-1256-m: On mixed models, reml and blup. 1994. Citado na página 25.

SILVA, N. N. d. Análise probabilística: um curso introdutório. 18. ed. [S.1.]: Edusp, 1998. Citado na página 30.

SORENSEN, T.; VASISHTH, S. Bayesian linear mixed models using stan: a tutorial for psychologists, linguists, and cognitive scientists. arXiv preprint arXiv:1506.06201, 2015. Citado na página 79.

SPIEGELHALTER, D. J.; BEST, N. G.; CARLIN, B. P.; LINDE, A. V. D. Bayesian measures of model complexity and fit. Journal of the Royal Statistical Society: Series B (Statistical Methodology), Wiley Online Library, v. 64, n. 4, p. 583-639, 2002. Citado nas páginas 45, 46 e 47.

SPIEGELHALTER, D. J.; BEST, N. G.; CARLIN, B. P.; LINDE, A. The deviance information criterion: 12 years on. Journal of the Royal Statistical Society: Series B (Statistical Methodology), Wiley Online Library, v. 76, n. 3, p. 485-493, 2014. Citado nas páginas 45 e 82.

SUGIURA, N. Further analysts of the data by akaike's information criterion and the finite corrections: Further analysts of the data by akaike's. Communications in Statistics-Theory and Methods, Taylor \& Francis, v. 7, n. 1, p. 13-26, 1978. Citado nas páginas 43 e 45.

SULLIVAN, L. M.; DUKES, K. A.; LOSINA, E. Tutorial in biostatistics. an introduction to hierarchical linear modelling. Stat Med, v. 18, n. 7, p. 855-888, 1999. Citado nas páginas 39 e 40 .

TIBSHIRANI, R. Regression shrinkage and selection via the lasso. Journal of the Royal Statistical Society. Series B (Methodological), te, p. 267-288, 1996. Citado nas páginas 25, 26,50 e 62.

VEHTARI, A.; GELMAN, A.; GABRY, J. Practical bayesian model evaluation using leave-oneout cross-validation and waic. Statistics and Computing, Springer, p. 1-20, 2016. Citado nas páginas 47,48 e 49. 
WATANABE, S. Asymptotic equivalence of bayes cross validation and widely applicable information criterion in singular learning theory. Journal of Machine Learning Research, v. 11, n. Dec, p. 3571-3594, 2010. Citado nas páginas 46 e 47.

WEAKLIEM, D. L. A critique of the bayesian information criterion for model selection. Sociological Methods \& Research, Sage Publications, v. 27, n. 3, p. 359-397, 1999. Citado nas páginas 25 e 62 . 
APÊNDICE

A

BANCO DE DADOS

Neste apêndice apresentamos a sumarização dos dados em sua forma original, como pode ser visto na Tabela 30. Nesta tabela temos o código original das covariáveis, o código em que cada covariável foi realocada, nome da variável, enunciado referente, tipo e o valor-p associado ao teste t de significância individual. Após o procedimento de amostragem descrito no capítulo 2, algumas covariáveis foram dicotomizadas, na Tabela 31, vemos como foi codificado as variáveis explicativas com mais de uma categoria e a partir daí foram dicotomizadas. $\mathrm{Na}$ Tabela 32 destacamos as variáveis que foram dicotomizadas, sua categorias, o código que essas categorias assumiram e sua frequência amostral.

Tabela 30 - Descrição do banco de dados geral.

\begin{tabular}{|c|c|c|c|c|c|}
\hline $\begin{array}{l}\text { Código } \\
\text { original }\end{array}$ & $\begin{array}{c}\text { Código } \\
\text { na base } \\
\text { de dados }\end{array}$ & $\begin{array}{c}\text { Nome da } \\
\text { variável }\end{array}$ & Enunciado & $\begin{array}{l}\text { Tipo de } \\
\text { variável }\end{array}$ & valor $\mathbf{p}$ \\
\hline MEDIA_LP & MEDIA_LP & $\begin{array}{c}\text { Nota média dos } \\
\text { participantes em } \\
\text { Língua Portuguesa } \\
\text { na escola }\end{array}$ & & Contínua & $<2.10^{-16}$ \\
\hline MEDIA_MT & MEDIA_MT & $\begin{array}{c}\text { Nota média dos } \\
\text { participantes em } \\
\text { matemática na } \\
\text { escola }\end{array}$ & & Contínua & $<2.10^{-16}$ \\
\hline TAXA_PARTICIPACAO & TAXA_PARTICIPACAO & $\begin{array}{c}\text { Taxa de } \\
\text { participação dos } \\
\text { estudantes da } \\
\text { escola }\end{array}$ & & Contínua & $<2.10^{-16}$ \\
\hline NU_PRESENTES & NU_PRESENTES & $\begin{array}{c}\text { Número de } \\
\text { presentes }\end{array}$ & & Contínua & $<2.10^{-16}$ \\
\hline NU_MATRICULADOS_CENSO & NU_MATRICULADOS_CENSO & $\begin{array}{c}\text { Número de } \\
\text { matriculados na } \\
\text { escola }\end{array}$ & & Contínua & $<2.10^{-16}$ \\
\hline PROFICIENCIA_LP_SAEB & PROFICIENCIA_LP_SAEB & $\begin{array}{l}\text { Proficiência } \\
\text { em língua } \\
\text { portuguesa no } \\
\text { SAEB }\end{array}$ & & Contínua & $<2.10^{-16}$ \\
\hline ID_DEPENDENCIA_ADM & DEPENDENCIA_ADM & $\begin{array}{c}\text { Dependência } \\
\text { administrativa } \\
\text { da escola }\end{array}$ & & $\begin{array}{r}\text { Categórica } \\
\text { nominal }\end{array}$ & $<2.10^{-16}$ \\
\hline ID_LOCALIZACAO & LOCALIZACAO & Localização da escola & & $\begin{array}{c}\text { Categórica } \\
\text { nominal }\end{array}$ & 0,205 \\
\hline
\end{tabular}




\begin{tabular}{|c|c|c|c|c|c|}
\hline $\begin{array}{l}\text { Código } \\
\text { original }\end{array}$ & $\begin{array}{c}\text { Código } \\
\text { na base } \\
\text { de dados }\end{array}$ & $\begin{array}{r}\text { Nome da } \\
\text { variável }\end{array}$ & Enunciado & $\begin{array}{l}\text { Tipo de } \\
\text { variável }\end{array}$ & valor $\mathbf{p}$ \\
\hline TX_RESP_Q032 & Q032 & Jornais & Você lê: Jornais & $\begin{array}{c}\text { categórica } \\
\text { nominal }\end{array}$ & $<2.10^{-16}$ \\
\hline TX_RESP_Q033 & Q033 & Livros em geral & Você lê: Livros em geral & $\begin{array}{c}\text { categórica } \\
\text { nominal }\end{array}$ & $<2.10^{-16}$ \\
\hline TX_RESP_Q034 & Q034 & $\begin{array}{l}\text { Livros de literatura } \\
\text { infanto-juvenil }\end{array}$ & $\begin{array}{l}\text { Você lê: Livros de literatura } \\
\text { infanto-juvenil }\end{array}$ & $\begin{array}{c}\text { categórica } \\
\text { nominal }\end{array}$ & $<2.10^{-16}$ \\
\hline TX_RESP_Q035 & Q035 & Revistas em geral & Você lê: Revistas em geral quadrinhos & $\begin{array}{c}\text { categórica } \\
\text { nominal }\end{array}$ & $<2.10^{-16}$ \\
\hline TX_RESP_Q036 & Q036 & Revistas em quadrinhos & Você lê: Revistas em quadrinhos & $\begin{array}{c}\text { categórica } \\
\text { nominal }\end{array}$ & $<2.10^{-16}$ \\
\hline TX_RESP_Q037 & Q037 & $\begin{array}{c}\text { Revistas sobre } \\
\text { comportamento, } \\
\text { celebridades, esporte e } \\
\text { TV }\end{array}$ & $\begin{array}{l}\text { Você lê: Revistas sobre comportamento, } \\
\text { celebridades, esporte e TV }\end{array}$ & $\begin{array}{c}\text { categórica } \\
\text { nominal }\end{array}$ & $<2.10^{-16}$ \\
\hline TX_RESP_Q038 & Q038 & Internet & Você lê: Sites da internet & $\begin{array}{c}\text { categórica } \\
\text { nominal }\end{array}$ & $<2.10^{-16}$ \\
\hline TX_RESP_Q039 & Q039 & Biblioteca & Você Costuma: Frequentar bibliotecas & $\begin{array}{c}\text { categórica } \\
\text { nominal }\end{array}$ & $<2.10^{-16}$ \\
\hline TX_RESP_Q040 & Q040 & Cinema & Você Costuma: Ir ao cinema. & $\begin{array}{c}\text { categórica } \\
\text { nominal }\end{array}$ & $<2.10^{-16}$ \\
\hline TX_RESP_Q041 & Q041 & Apresentações Teatrais & Você Costuma: Ver apresentações teatrais & $\begin{array}{c}\text { categórica } \\
\text { nominal }\end{array}$ & $<2.10^{-16}$ \\
\hline TX_RESP_Q042 & Q042 & Apresentações Teatrais & $\begin{array}{c}\text { Você Costuma: Ver apresentações } \\
\text { musicais ou de dança }\end{array}$ & $\begin{array}{c}\text { categórica } \\
\text { nominal }\end{array}$ & $<2.10^{-16}$ \\
\hline TX_RESP_Q043 & Q043 & $\begin{array}{l}\text { Festas abertas à } \\
\text { comunidade }\end{array}$ & $\begin{array}{l}\text { Você Costuma: Participar de festas } \\
\text { abertas à comunidade }\end{array}$ & $\begin{array}{c}\text { categórica } \\
\text { nominal }\end{array}$ & $<2.10^{-16}$ \\
\hline TX_RESP_Q044 & Q044 & Lazer & $\begin{array}{c}\text { Em dia de aula, quanto tempo você gasta } \\
\text { assistindo à TV, navegando na internet } \\
\text { ou jogando jogos eletrônicos? }\end{array}$ & $\begin{array}{c}\text { categórica } \\
\text { nominal }\end{array}$ & $<2.10^{-16}$ \\
\hline TX_RESP_Q045 & Q045 & Trabalhos domésticos & $\begin{array}{l}\text { Em dias de aula, quanto tempo você } \\
\text { gasta fazendo trabalhos domésticos? }\end{array}$ & $\begin{array}{c}\text { categórica } \\
\text { nominal }\end{array}$ & $<2.10^{-16}$ \\
\hline TX_RESP_Q046 & Q046 & Trabalho fora de casa & Você trabalha fora de casa? & $\begin{array}{c}\text { categórica } \\
\text { nominal }\end{array}$ & $<2.10^{-16}$ \\
\hline TX_RESP_Q047 & Q047 & Entrada na escola & Quando você entrou na escola? & $\begin{array}{c}\text { categórica } \\
\text { nominal }\end{array}$ & $<2.10^{-16}$ \\
\hline TX_RESP_Q048 & Q048 & $\begin{array}{c}\text { Tipo de escola desde a } \\
\text { quinta série }\end{array}$ & $\begin{array}{l}\text { Desde a quinta série em que tipo de } \\
\text { escola você estudou? }\end{array}$ & $\begin{array}{c}\text { categórica } \\
\text { nominal }\end{array}$ & $<2.10^{-16}$ \\
\hline TX_RESP_Q049 & Q049 & Reprovas & Você já foi reprovado? & $\begin{array}{c}\text { categórica } \\
\text { nominal }\end{array}$ & $<2.10^{-16}$ \\
\hline TX_RESP_Q050 & Q050 & Abandono Escolar & $\begin{array}{l}\text { Você já abandonou a escola durante o } \\
\text { período de aulas e ficou fora da escola } \\
\text { o resto do ano? }\end{array}$ & $\begin{array}{c}\text { categórica } \\
\text { nominal }\end{array}$ & $<2.10^{-16}$ \\
\hline TX_RESP_Q051 & Q051 & Língua Portuguesa & Você gosta de estudar língua portuguesa? & $\begin{array}{c}\text { categórica } \\
\text { nominal }\end{array}$ & $<2.10^{-16}$ \\
\hline TX_RESP_Q052 & Q052 & Dever de casa de L.P. & $\begin{array}{c}\text { Você faz o dever de casa de língua } \\
\text { portuguesa? }\end{array}$ & $\begin{array}{c}\text { categórica } \\
\text { nominal }\end{array}$ & $<2.10^{-16}$ \\
\hline TX_RESP_Q053 & Q053 & $\begin{array}{l}\text { Correção do dever de } \\
\text { casa de L.P. }\end{array}$ & $\begin{array}{c}\text { O professor corrige o dever de casa de } \\
\text { língua portuguesa? }\end{array}$ & $\begin{array}{c}\text { categórica } \\
\text { nominal }\end{array}$ & $<2.10^{-16}$ \\
\hline TX_RESP_Q054 & Q054 & Matemática & Você gosta de estudar matemática? & $\begin{array}{c}\text { categórica } \\
\text { nominal }\end{array}$ & $<2.10^{-16}$ \\
\hline TX_RESP_Q055 & Q055 & $\begin{array}{l}\text { Dever de casa de } \\
\text { matemática }\end{array}$ & Você faz o dever de casa de matemática? & $\begin{array}{c}\text { categórica } \\
\text { nominal }\end{array}$ & $<2.10^{-16}$ \\
\hline TX_RESP_Q056 & Q056 & $\begin{array}{l}\text { Correção do dever de } \\
\text { casa de matemática }\end{array}$ & $\begin{array}{l}\text { O professor corrige o dever de casa de } \\
\text { matemática? }\end{array}$ & $\begin{array}{c}\text { categórica } \\
\text { nominal }\end{array}$ & $<2.10^{-16}$ \\
\hline TX_RESP_Q057 & Q057 & Sala de Leitura & $\begin{array}{l}\text { Você utiliza a biblioteca ou sala de } \\
\text { leitura da sua escola? }\end{array}$ & $\begin{array}{c}\text { categórica } \\
\text { nominal }\end{array}$ & $<2.10^{-16}$ \\
\hline TX_RESP_Q058 & Q058 & $\begin{array}{l}\text { Pretensão ao terminar } \\
9^{\circ} \text { ano }\end{array}$ & $\begin{array}{l}\text { Quando você terminar o } 9^{\circ} \text { ano }\left(8^{\mathrm{a}}\right. \\
\text { série), você pretende: }\end{array}$ & $\begin{array}{c}\text { categórica } \\
\text { nominal }\end{array}$ & $<2.10^{-16}$ \\
\hline TX_RESP_Q001 & E001 & Telhado & $\begin{array}{l}\text { Avalie o estado de conservação dos } \\
\text { itens e equipamentos do prédio - telhado }\end{array}$ & $\begin{array}{c}\text { categórica } \\
\text { nominal }\end{array}$ & $7,08.10^{-14}$ \\
\hline TX_RESP_Q002 & E002 & Paredes & $\begin{array}{l}\text { Avalie o estado de conservação dos } \\
\text { itens e equipamentos do prédio-paredes }\end{array}$ & $\begin{array}{c}\text { categórica } \\
\text { nominal }\end{array}$ & $<2.10^{-16}$ \\
\hline TX_RESP_Q003 & E003 & Piso & $\begin{array}{l}\text { Avalie o estado de conservação dos } \\
\text { itens e equipamentos do prédio-piso }\end{array}$ & $\begin{array}{c}\text { categórica } \\
\text { nominal }\end{array}$ & $<2.10^{-16}$ \\
\hline TX_RESP_Q004 & E004 & Entrada do prédio & $\begin{array}{c}\text { Avalie o estado de conservação dos } \\
\text { itens e equipamentos do prédio-entrada } \\
\text { do prédio }\end{array}$ & $\begin{array}{c}\text { categórica } \\
\text { nominal }\end{array}$ & $<2.10^{-16}$ \\
\hline TX_RESP_Q005 & E005 & Pátio & $\begin{array}{l}\text { Avalie o estado de conservação dos } \\
\text { itens e equipamentos do prédio-pátio }\end{array}$ & $\begin{array}{c}\text { categórica } \\
\text { nominal }\end{array}$ & $<2.10^{-16}$ \\
\hline
\end{tabular}




\begin{tabular}{|c|c|c|c|c|c|}
\hline $\begin{array}{l}\text { Código } \\
\text { original }\end{array}$ & $\begin{array}{c}\text { Código } \\
\text { na base } \\
\text { de dados }\end{array}$ & $\begin{array}{r}\text { Nome da } \\
\text { variável }\end{array}$ & Enunciado & $\begin{array}{l}\text { Tipo de } \\
\text { variável }\end{array}$ & valor $p$ \\
\hline TX_RESP_Q006 & E006 & Corredores & $\begin{array}{c}\text { Avalie o estado de conservação dos } \\
\text { itens e equipamentos do prédio- } \\
\text { corredores }\end{array}$ & $\begin{array}{c}\text { categórica } \\
\text { nominal }\end{array}$ & $<2.10^{-16}$ \\
\hline TX_RESP_Q007 & E007 & Salas de aula & $\begin{array}{c}\text { Avalie o estado de conservação dos } \\
\text { itens e equipamentos do prédio-salas de } \\
\text { aula }\end{array}$ & $\begin{array}{c}\text { categórica } \\
\text { nominal }\end{array}$ & $<2.10^{-16}$ \\
\hline TX_RESP_Q008 & E008 & Portas & $\begin{array}{l}\text { Avalie o estado de conservação dos } \\
\text { itens e equipamentos do prédio-portas }\end{array}$ & $\begin{array}{c}\text { categórica } \\
\text { nominal }\end{array}$ & $<2.10^{-16}$ \\
\hline TX_RESP_Q009 & E009 & Janelas & $\begin{array}{l}\text { Avalie o estado de conservação dos } \\
\text { itens e equipamentos do prédio-janelas }\end{array}$ & $\begin{array}{c}\text { categórica } \\
\text { nominal }\end{array}$ & $<2.10^{-16}$ \\
\hline TX_RESP_Q010 & E010 & Banheiros & $\begin{array}{l}\text { Avalie o estado de conservação dos } \\
\text { itens e equipamentos do prédio-banheiros }\end{array}$ & $\begin{array}{c}\text { categórica } \\
\text { nominal }\end{array}$ & $<2.10^{-16}$ \\
\hline TX_RESP_Q011 & E011 & Cozinha & $\begin{array}{l}\text { Avalie o estado de conservação dos } \\
\text { itens e equipamentos do prédio-cozinha }\end{array}$ & $\begin{array}{c}\text { categórica } \\
\text { nominal }\end{array}$ & 0,000519 \\
\hline TX_RESP_Q012 & E012 & Instalações hidráulicas & $\begin{array}{c}\text { Avalie o estado de conservação dos } \\
\text { itens e equipamentos do prédio - } \\
\text { instalações hidráulicas }\end{array}$ & $\begin{array}{c}\text { categórica } \\
\text { nominal }\end{array}$ & $<2.10^{-16}$ \\
\hline TX_RESP_Q013 & E013 & Instalações elétricas & $\begin{array}{c}\text { Avalie o estado de conservação dos } \\
\text { itens e equipamentos do prédio- } \\
\text { instalações elétricas }\end{array}$ & $\begin{array}{c}\text { categórica } \\
\text { nominal }\end{array}$ & $<2.10^{-16}$ \\
\hline TX_RESP_Q014 & E014 & $\begin{array}{l}\text { Iluminação de sala de } \\
\text { aula }\end{array}$ & $\begin{array}{l}\text { Avalie os seguintes aspectos em relação } \\
\text { às salas de aula: (considere sim quando } \\
\text { mais de } 50 \% \text { das salas de aula } \\
\text { apresentarem o aspecto questionado) - } \\
\text { são iluminadas? }\end{array}$ & $\begin{array}{c}\text { categórica } \\
\text { nominal }\end{array}$ & $<2.10^{-16}$ \\
\hline TX_RESP_Q015 & E015 & $\begin{array}{l}\text { Ventilação de sala de } \\
\text { aula }\end{array}$ & $\begin{array}{l}\text { Avalie os seguintes aspectos em relação } \\
\text { às salas de aula: (considere sim quando } \\
\text { mais de } 50 \% \text { das salas de aula } \\
\text { apresentarem o aspecto questionado) - } \\
\text { são arejadas? }\end{array}$ & $\begin{array}{c}\text { categórica } \\
\text { nominal }\end{array}$ & $7,73.10^{-11}$ \\
\hline TX_RESP_Q016 & E016 & $\begin{array}{l}\text { Ventilação de sala de } \\
\text { aula }\end{array}$ & $\begin{array}{l}\text { Avalie os seguintes aspectos em relação } \\
\text { à segurança da escola e dos alunos: há } \\
\text { muros, grades ou cercas em condições de } \\
\text { garantir a segurança dos alunos? (caso } \\
\text { existam buracos ou aberturas que } \\
\text { permitam o acesso de estranhos, } \\
\text { responder não) }\end{array}$ & $\begin{array}{c}\text { categórica } \\
\text { nominal }\end{array}$ & $<2.10^{-16}$ \\
\hline TX_RESP_Q017 & E017 & Fluxo de alunos & $\begin{array}{l}\text { Avalie os seguintes aspectos em relação } \\
\text { à segurança da escola e dos alunos: há } \\
\text { controle de entrada e saída de alunos? }\end{array}$ & $\begin{array}{c}\text { categórica } \\
\text { nominal }\end{array}$ & $5,36.10^{-12}$ \\
\hline TX_RESP_Q018 & E018 & $\begin{array}{c}\text { Fluxo de pessoas } \\
\text { estranhas }\end{array}$ & $\begin{array}{c}\text { Avalie os seguintes aspectos em relação } \\
\text { à segurança da escola e dos alunos: há } \\
\text { controle de entrada de pessoas } \\
\text { estranhas na escola? }\end{array}$ & $\begin{array}{c}\text { categórica } \\
\text { nominal }\end{array}$ & $<2.10^{-16}$ \\
\hline TX_RESP_Q019 & E019 & $\begin{array}{c}\text { Portões de acesso à } \\
\text { parte externa da escola }\end{array}$ & $\begin{array}{l}\text { Avalie os seguintes aspectos em relação } \\
\text { à segurança da escola e dos alunos: os } \\
\text { portões que dão acesso à parte externa } \\
\text { permanecem trancados durante o horário } \\
\text { de funcionamento da escola? }\end{array}$ & $\begin{array}{c}\text { categórica } \\
\text { nominal }\end{array}$ & 0,000703 \\
\hline TX_RESP_Q020 & E020 & $\begin{array}{c}\text { Segurança no período } \\
\text { diurno }\end{array}$ & $\begin{array}{l}\text { Avalie os seguintes aspectos em relação } \\
\text { à segurança da escola e dos alunos: há } \\
\text { algum tipo de vigilância para o período } \\
\text { diurno? }\end{array}$ & $\begin{array}{c}\text { categórica } \\
\text { nominal }\end{array}$ & $<2.10^{-16}$ \\
\hline TX_RESP_Q021 & E021 & $\begin{array}{c}\text { Segurança no período } \\
\text { noturno }\end{array}$ & $\begin{array}{l}\text { Avalie os seguintes aspectos em relação } \\
\text { à segurança da escola e dos alunos: há } \\
\text { algum tipo de vigilância para o período } \\
\text { noturno? }\end{array}$ & $\begin{array}{c}\text { categórica } \\
\text { nominal }\end{array}$ & $<2.10^{-16}$ \\
\hline TX_RESP_Q022 & E022 & $\begin{array}{l}\text { Segurança nos fins de } \\
\text { semana }\end{array}$ & $\begin{array}{l}\text { Avalie os seguintes aspectos em relação } \\
\text { à segurança da escola e dos alunos: há } \\
\text { algum tipo de vigilância para os finais } \\
\text { de semana e feriados? }\end{array}$ & $\begin{array}{c}\text { categórica } \\
\text { nominal }\end{array}$ & $<2.10^{-16}$ \\
\hline TX_RESP_Q023 & E023 & $\begin{array}{l}\text { Policiamento anti - } \\
\text { furtos }\end{array}$ & $\begin{array}{l}\text { Avalie os seguintes aspectos em relação } \\
\text { à segurança da escola e dos alunos: há } \\
\text { algum esquema de policiamento para } \\
\text { inibição de furtos, roubos e outras } \\
\text { formas de violência? }\end{array}$ & $\begin{array}{c}\text { categórica } \\
\text { nominal }\end{array}$ & 0,0418 \\
\hline TX_RESP_Q024 & E024 & $\begin{array}{l}\text { Policiamento anti - } \\
\text { drogas dentro da escola }\end{array}$ & $\begin{array}{l}\text { Avalie os seguintes aspectos em relação } \\
\text { à segurança da escola e dos alunos: há } \\
\text { algum esquema de policiamento para } \\
\text { inibição de tráfico de tóxicos/ drogas } \\
\text { dentro da escola? }\end{array}$ & $\begin{array}{c}\text { categórica } \\
\text { nominal }\end{array}$ & $4,37.10^{-6}$ \\
\hline
\end{tabular}




\begin{tabular}{|c|c|c|c|c|c|}
\hline $\begin{array}{l}\text { Código } \\
\text { original }\end{array}$ & $\begin{array}{c}\text { Código } \\
\text { na base } \\
\text { de dados }\end{array}$ & $\begin{array}{l}\text { Nome da } \\
\text { variável }\end{array}$ & Enunciado & $\begin{array}{l}\text { Tipo de } \\
\text { variável }\end{array}$ & valor $p$ \\
\hline TX_RESP_Q025 & E025 & $\begin{array}{c}\text { Policiamento anti - } \\
\text { drogas nas imediações } \\
\text { escola }\end{array}$ & $\begin{array}{l}\text { Avalie os seguintes aspectos em relação } \\
\text { à segurança da escola e dos alunos: há } \\
\text { algum esquema de policiamento para } \\
\text { inibição de tráfico de tóxicos/ drogas } \\
\text { nas imediações da escola? }\end{array}$ & $\begin{array}{c}\text { categórica } \\
\text { nominal }\end{array}$ & $<2.10^{-16}$ \\
\hline TX_RESP_Q026 & E026 & $\begin{array}{c}\text { Proteção contra } \\
\text { incêndio }\end{array}$ & $\begin{array}{l}\text { Avalie os seguintes aspectos em relação } \\
\text { à segurança da escola e dos alunos: a } \\
\text { escola possui algum sistema de proteção } \\
\text { contra incêndio (alarme de fumaça e } \\
\text { temperatura, extintores contra incêndio } \\
\text { dentro do prazo de validade, mangueira, } \\
\text { etc.)? }\end{array}$ & $\begin{array}{c}\text { categórica } \\
\text { nominal }\end{array}$ & $<2.10^{-16}$ \\
\hline TX_RESP_Q027 & E027 & $\begin{array}{c}\text { Proteção para } \\
\text { equipamentos de alto } \\
\text { custo }\end{array}$ & $\begin{array}{c}\text { Avalie os seguintes aspectos em relação } \\
\text { à segurança da escola e dos alunos: as } \\
\text { salas onde são guardados os } \\
\text { equipamentos mais caros (computadores, } \\
\text { projetores, televisão, vídeo etc.) } \\
\text { Possuem dispositivos para serem } \\
\text { trancados (cadeados, grades, travas, } \\
\text { trancas, etc.)? }\end{array}$ & $\begin{array}{c}\text { categórica } \\
\text { nominal }\end{array}$ & 0,561 \\
\hline TX_RESP_Q028 & E028 & Depredação & $\begin{array}{l}\text { Avalie os seguintes aspectos em relação } \\
\text { à segurança da escola e dos alunos: a } \\
\text { escola apresenta sinais de depredação } \\
\text { (vidros, portas e janelas quebradas, } \\
\text { lâmpadas estouradas etc.)? }\end{array}$ & $\begin{array}{c}\text { categórica } \\
\text { nominal }\end{array}$ & $<2.10^{-16}$ \\
\hline TX_RESP_Q029 & E029 & Iluminação externa & $\begin{array}{c}\text { Avalie os seguintes aspectos em relação } \\
\text { à segurança da escola e dos alunos: há } \\
\text { uma boa iluminação do lado de fora da } \\
\text { escola? }\end{array}$ & categórica & $<2.10^{-16}$ \\
\hline TX_RESP_Q030 & E030 & $\begin{array}{l}\text { Segurança nas } \\
\text { imediações }\end{array}$ & $\begin{array}{l}\text { Avalie os seguintes aspectos em relação } \\
\text { à segurança da escola e dos alunos: a } \\
\text { escola adota alguma medida de segurança } \\
\text { para proteger os alunos nas suas } \\
\text { imediações? }\end{array}$ & $\begin{array}{c}\text { categórica } \\
\text { nominal }\end{array}$ & $<2.10^{-16}$ \\
\hline TX_RESP_Q031 & E031 & Computadores escolares & $\begin{array}{l}\text { Indique se nesta escola existem ou não } \\
\text { os recursos apontados e quais são suas } \\
\text { condições de uso. Computadores para uso } \\
\text { dos alunos. }\end{array}$ & $\begin{array}{c}\text { categórica } \\
\text { nominal }\end{array}$ & $<2.10^{-16}$ \\
\hline TX_RESP_Q032 & E032 & Internet da escola & $\begin{array}{l}\text { Indique se nesta escola existem ou não } \\
\text { os recursos apontados e quais são suas } \\
\text { condições de uso. Acesso à internet } \\
\text { para uso dos alunos. }\end{array}$ & $\begin{array}{c}\text { categórica } \\
\text { nominal }\end{array}$ & $<2.10^{-16}$ \\
\hline TX_RESP_Q033 & E033 & $\begin{array}{l}\text { Computadores para } \\
\text { professores }\end{array}$ & $\begin{array}{c}\text { Indique se nesta escola existem ou não } \\
\text { os recursos apontados e quais são suas } \\
\text { condições de uso. Computadores para uso } \\
\text { dos professores. }\end{array}$ & $\begin{array}{c}\text { categórica } \\
\text { nominal }\end{array}$ & $<2.10^{-16}$ \\
\hline TX_RESP_Q034 & E034 & $\begin{array}{c}\text { Internet para } \\
\text { professores }\end{array}$ & $\begin{array}{l}\text { Indique se nesta escola existem ou não } \\
\text { os recursos apontados e quais são suas } \\
\text { condições de uso. Acesso à internet } \\
\text { para uso dos professores. }\end{array}$ & $\begin{array}{c}\text { categórica } \\
\text { nominal }\end{array}$ & $<2.10^{-16}$ \\
\hline TX_RESP_Q035 & E035 & $\begin{array}{l}\text { Computadores } \\
\text { administrativos }\end{array}$ & $\begin{array}{l}\text { Indique se nesta escola existem ou não } \\
\text { os recursos apontados e quais são suas } \\
\text { condições de uso. Computadores } \\
\text { exclusivamente para o uso administrativo. }\end{array}$ & $\begin{array}{c}\text { categórica } \\
\text { nominal }\end{array}$ & $<2.10^{-16}$ \\
\hline TX_RESP_Q036 & E036 & Mídias educativas & $\begin{array}{c}\text { Indique se nesta escola existem ou não } \\
\text { os recursos apontados e quais são suas } \\
\text { condições de uso. Fitas de vídeo ou DVD } \\
\text { (educativas). }\end{array}$ & $\begin{array}{c}\text { categórica } \\
\text { nominal }\end{array}$ & $<2.10^{-16}$ \\
\hline TX_RESP_Q037 & E037 & Mídias de lazer & $\begin{array}{c}\text { Indique se nesta escola existem ou não } \\
\text { os recursos apontados e quais são suas } \\
\text { condições de uso. Fitas de vídeo ou DVD } \\
\text { (lazer). }\end{array}$ & $\begin{array}{c}\text { categórica } \\
\text { nominal }\end{array}$ & $<2.10^{-16}$ \\
\hline TX_RESP_Q038 & E038 & Máquina copiadora & $\begin{array}{l}\text { Indique se nesta escola existem ou não } \\
\text { os recursos apontados e quais são suas } \\
\text { condições de uso. Máquina copiadora. }\end{array}$ & $\begin{array}{c}\text { categórica } \\
\text { nominal }\end{array}$ & $<2.10^{-16}$ \\
\hline TX_RESP_Q039 & E039 & Impressora & $\begin{array}{l}\text { Indique se nesta escola existem ou não } \\
\text { os recursos apontados e quais são suas } \\
\text { condições de uso. Impressora. }\end{array}$ & $\begin{array}{c}\text { categórica } \\
\text { nominal }\end{array}$ & $<2.10^{-16}$ \\
\hline TX_RESP_Q040 & E040 & Retroprojetor & $\begin{array}{l}\text { Indique se nesta escola existem ou não } \\
\text { os recursos apontados e quais são suas } \\
\text { condições de uso. Retroprojetor. }\end{array}$ & $\begin{array}{c}\text { categórica } \\
\text { nominal }\end{array}$ & $<2.10^{-16}$ \\
\hline
\end{tabular}




\begin{tabular}{|c|c|c|c|c|c|}
\hline $\begin{array}{l}\text { Código } \\
\text { original }\end{array}$ & $\begin{array}{c}\text { Código } \\
\text { na base } \\
\text { de dados }\end{array}$ & $\begin{array}{r}\text { Nome da } \\
\text { variável }\end{array}$ & Enunciado & $\begin{array}{l}\text { Tipo de } \\
\text { variável }\end{array}$ & valor $p$ \\
\hline TX_RESP_Q041 & E041 & Projetor de slides & $\begin{array}{c}\text { Indique se nesta escola existem ou não } \\
\text { os recursos apontados e quais são suas } \\
\text { condições de uso. Projetor de slides. }\end{array}$ & $\begin{array}{c}\text { categórica } \\
\text { nominal }\end{array}$ & $<2.10^{-16}$ \\
\hline TX_RESP_Q042 & E042 & $\begin{array}{l}\text { Videocassete ou DVD } \\
\text { escolar }\end{array}$ & $\begin{array}{l}\text { Indique se nesta escola existem ou não } \\
\text { os recursos apontados e quais são suas } \\
\text { condições de uso. Videocassete ou DVD. }\end{array}$ & $\begin{array}{c}\text { categórica } \\
\text { nominal }\end{array}$ & $<2.10^{-16}$ \\
\hline TX_RESP_Q043 & E043 & Televisão & $\begin{array}{c}\text { Indique se nesta escola existem ou não } \\
\text { os recursos apontados e quais são suas } \\
\text { condições de uso. Televisão. }\end{array}$ & $\begin{array}{c}\text { categórica } \\
\text { nominal }\end{array}$ & $<2.10^{-16}$ \\
\hline TX_RESP_Q044 & E044 & Mimeógrafo & $\begin{array}{l}\text { Indique se nesta escola existem ou não } \\
\text { os recursos apontados e quais são suas } \\
\text { condições de uso. Mimeógrafo. }\end{array}$ & $\begin{array}{c}\text { categórica } \\
\text { nominal }\end{array}$ & $<2.10^{-16}$ \\
\hline TX_RESP_Q045 & E045 & Câmera fotográfica & $\begin{array}{l}\text { Indique se nesta escola existem ou não } \\
\text { os recursos apontados e quais são suas } \\
\text { condições de uso. Câmera fotográfica. }\end{array}$ & $\begin{array}{c}\text { categórica } \\
\text { nominal }\end{array}$ & $<2.10^{-16}$ \\
\hline TX_RESP_Q046 & E046 & Antena parabólica & $\begin{array}{l}\text { Indique se nesta escola existem ou não } \\
\text { os recursos apontados e quais são suas } \\
\text { condições de uso. Antena parabólica. }\end{array}$ & $\begin{array}{c}\text { categórica } \\
\text { nominal }\end{array}$ & $<2.10^{-16}$ \\
\hline TX_RESP_Q047 & E047 & Linha telefônica & $\begin{array}{l}\text { Indique se nesta escola existem ou não } \\
\text { os recursos apontados e quais são suas } \\
\text { condições de uso. Linha telefônica. }\end{array}$ & $\begin{array}{c}\text { categórica } \\
\text { nominal }\end{array}$ & $<2.10^{-16}$ \\
\hline TX_RESP_Q048 & E048 & Fax & $\begin{array}{c}\text { Indique se nesta escola existem ou não } \\
\text { os recursos apontados e quais são suas } \\
\text { condições de uso. Aparelho de fax. }\end{array}$ & $\begin{array}{c}\text { categórica } \\
\text { nominal }\end{array}$ & $<2.10^{-16}$ \\
\hline TX_RESP_Q049 & E049 & Aparelho de som & $\begin{array}{l}\text { Indique se nesta escola existem ou não } \\
\text { os recursos apontados e quais são suas } \\
\text { condições de uso. Aparelho de som. }\end{array}$ & $\begin{array}{c}\text { categórica } \\
\text { nominal }\end{array}$ & $<2.10^{-16}$ \\
\hline TX_RESP_Q050 & E050 & Biblioteca & $\begin{array}{c}\text { Indique se nesta escola existem ou não } \\
\text { os recursos apontados e quais são suas } \\
\text { condições de uso. Biblioteca. }\end{array}$ & $\begin{array}{c}\text { categórica } \\
\text { nominal }\end{array}$ & $<2.10^{-16}$ \\
\hline TX_RESP_Q051 & E051 & Quadra de esportes & $\begin{array}{l}\text { Indique se nesta escola existem ou não } \\
\text { os recursos apontados e quais são suas } \\
\text { condições de uso. Quadra de esportes. }\end{array}$ & $\begin{array}{c}\text { categórica } \\
\text { nominal }\end{array}$ & $<2.10^{-16}$ \\
\hline TX_RESP_Q052 & E052 & Laboratório & $\begin{array}{c}\text { Indique se nesta escola existem ou não } \\
\text { os recursos apontados e quais são suas } \\
\text { condições de uso. Laboratório. }\end{array}$ & $\begin{array}{c}\text { categórica } \\
\text { nominal }\end{array}$ & $<2.10^{-16}$ \\
\hline TX_RESP_Q053 & E053 & Auditório & $\begin{array}{c}\text { Indique se nesta escola existem ou não } \\
\text { os recursos apontados e quais são suas } \\
\text { condições de uso. Auditório. }\end{array}$ & $\begin{array}{c}\text { categórica } \\
\text { nominal }\end{array}$ & $<2.10^{-16}$ \\
\hline TX_RESP_Q054 & E054 & Sala de música & $\begin{array}{c}\text { Indique se nesta escola existem ou não } \\
\text { os recursos apontados e quais são suas } \\
\text { condições de uso. Sala para atividades } \\
\text { de música. }\end{array}$ & $\begin{array}{c}\text { categórica } \\
\text { nominal }\end{array}$ & $<2.10^{-16}$ \\
\hline TX_RESP_Q055 & E055 & Sala de artes plásticas & $\begin{array}{l}\text { Indique se nesta escola existem ou não } \\
\text { os recursos apontados e quais são suas } \\
\text { condições de uso. Sala para atividades } \\
\text { de artes plásticas. }\end{array}$ & $\begin{array}{c}\text { categórica } \\
\text { nominal }\end{array}$ & $<2.10^{-16}$ \\
\hline TX_RESP_Q056 & E056 & Sala de leitura & $\begin{array}{c}\text { Indique se nesta escola existem ou não } \\
\text { os recursos apontados e quais são suas } \\
\text { condições de uso. Sala de leitura. }\end{array}$ & $\begin{array}{c}\text { categórica } \\
\text { nominal }\end{array}$ & $<2.10^{-16}$ \\
\hline TX_RESP_Q057 & E057 & $\begin{array}{l}\text { Acervo da sala de } \\
\text { leitura }\end{array}$ & $\begin{array}{l}\text { Em relação à biblioteca ou sala de } \\
\text { leitura: possui acervo diversificado } \\
\text { que desperte o interesse dos alunos. }\end{array}$ & $\begin{array}{c}\text { categórica } \\
\text { nominal }\end{array}$ & $<2.10^{-16}$ \\
\hline TX_RESP_Q058 & E058 & $\begin{array}{c}\text { Brinquedoteca da sala } \\
\text { de leitura } \\
\end{array}$ & $\begin{array}{c}\text { Em relação à biblioteca ou sala de } \\
\text { leitura: possui brinquedoteca. }\end{array}$ & $\begin{array}{c}\text { categórica } \\
\text { nominal }\end{array}$ & $3,2.10^{-8}$ \\
\hline TX_RESP_Q059 & E059 & $\begin{array}{l}\text { Sala de estudos } \\
\text { coletivos }\end{array}$ & $\begin{array}{c}\text { Em relação à biblioteca ou sala de } \\
\text { leitura: possui espaço para estudos } \\
\text { coletivos. }\end{array}$ & $\begin{array}{c}\text { categórica } \\
\text { nominal }\end{array}$ & $<2.10^{-16}$ \\
\hline TX_RESP_Q060 & E060 & Empréstimo de livros & $\begin{array}{c}\text { Em relação à biblioteca ou sala de } \\
\text { leitura: os livros podem ser manuseados } \\
\text { e emprestados. }\end{array}$ & $\begin{array}{c}\text { categórica } \\
\text { nominal }\end{array}$ & $<2.10^{-16}$ \\
\hline TX_RESP_Q061 & E061 & $\begin{array}{l}\text { Comunidade na sala de } \\
\text { leitura }\end{array}$ & $\begin{array}{l}\text { Em relação à biblioteca ou sala de } \\
\text { leitura: a comunidade pode utilizar o } \\
\text { espaço e os livros. }\end{array}$ & $\begin{array}{c}\text { categórica } \\
\text { nominal }\end{array}$ & $<2.10^{-16}$ \\
\hline TX_RESP_Q062 & E062 & $\begin{array}{c}\text { Climatização da sala de } \\
\text { leitura }\end{array}$ & $\begin{array}{c}\text { Em relação à biblioteca ou sala de } \\
\text { leitura: o espaço é arejado e bem } \\
\text { iluminado. }\end{array}$ & $\begin{array}{c}\text { categórica } \\
\text { nominal }\end{array}$ & 0,00363 \\
\hline TX_RESP_Q063 & E063 & $\begin{array}{c}\text { Responsável pela sala } \\
\text { de leitura }\end{array}$ & $\begin{array}{c}\text { Em relação à biblioteca ou sala de } \\
\text { leitura: existe uma pessoa responsável } \\
\text { pelo atendimento na biblioteca ou na } \\
\text { sala de leitura? }\end{array}$ & $\begin{array}{c}\text { categórica } \\
\text { nominal }\end{array}$ & $<2.10^{-16}$ \\
\hline
\end{tabular}




\begin{tabular}{|c|c|c|c|c|c|}
\hline $\begin{array}{l}\text { Código } \\
\text { original }\end{array}$ & $\begin{array}{c}\text { Código } \\
\text { na base } \\
\text { de dados } \\
\end{array}$ & $\begin{array}{l}\text { Nome da } \\
\text { variável }\end{array}$ & Enunciado & $\begin{array}{l}\text { Tipo de } \\
\text { variável }\end{array}$ & valor $\mathbf{p}$ \\
\hline TX_RESP_Q064 & E064 & $\begin{array}{l}\text { Retirada de livros por } \\
\text { alunos }\end{array}$ & $\begin{array}{c}\text { Os usuários da biblioteca (ou sala de } \\
\text { leitura) levam livros para casa? Os } \\
\text { alunos. }\end{array}$ & categórica & $<2.10^{-16}$ \\
\hline TX_RESP_Q065 & E065 & $\begin{array}{l}\text { Retirada de livros por } \\
\text { professores }\end{array}$ & $\begin{array}{c}\text { Os usuários da biblioteca (ou sala de } \\
\text { leitura) levam livros para casa? Os } \\
\text { professores. }\end{array}$ & $\begin{array}{c}\text { categórica } \\
\text { nominal }\end{array}$ & $<2.10^{-16}$ \\
\hline TX_RESP_Q066 & E066 & $\begin{array}{l}\text { Retirada de livros pela } \\
\text { comunidade }\end{array}$ & $\begin{array}{c}\text { Os usuários da biblioteca (ou sala de } \\
\text { leitura) levam livros para casa? Os } \\
\text { membros da comunidade. }\end{array}$ & $\begin{array}{c}\text { categórica } \\
\text { nominal }\end{array}$ & $<2.10^{-16}$ \\
\hline TX_RESP_Q001 & D001 & Sexo do diretor & Sexo & $\begin{array}{c}\text { categórica } \\
\text { nominal }\end{array}$ & $<2.10^{-16}$ \\
\hline TX_RESP_Q002 & D002 & Idade do diretor & Idade & $\begin{array}{c}\text { categórica } \\
\text { nominal }\end{array}$ & $<2.10^{-16}$ \\
\hline TX_RESP_Q003 & D003 & Raça do diretor & Como você se considera? & $\begin{array}{c}\text { categórica } \\
\text { nominal }\end{array}$ & $<2.10^{-16}$ \\
\hline TX_RESP_Q004 & D004 & Escolaridade do diretor & $\begin{array}{l}\text { Qual o seu nível de escolaridade (até a } \\
\text { graduação). }\end{array}$ & $\begin{array}{c}\text { categórica } \\
\text { nominal }\end{array}$ & $<2.10^{-16}$ \\
\hline TX_RESP_Q005 & D005 & Tempo de escolaridade & $\begin{array}{l}\text { Há quantos anos você obteve o nível de } \\
\text { escolaridade assinalado anteriormente? }\end{array}$ & $\begin{array}{c}\text { categórica } \\
\text { nominal }\end{array}$ & $<2.10^{-16}$ \\
\hline TX_RESP_Q006 & D006 & $\begin{array}{c}\text { Tipo de instituição } \\
\text { onde obteve seu título } \\
\text { profissional }\end{array}$ & $\begin{array}{l}\text { Em que tipo de instituição você fez o } \\
\text { curso superior? Se você estudou em mais } \\
\text { de uma instituição, assinale aquela em } \\
\text { que obteve seu título profissional. }\end{array}$ & $\begin{array}{c}\text { categórica } \\
\text { nominal }\end{array}$ & $<2.10^{-16}$ \\
\hline TX_RESP_Q007 & D007 & $\begin{array}{c}\text { Natureza da instituição } \\
\text { onde obteve seu título } \\
\text { profissional }\end{array}$ & Qual era a natureza dessa instituição? & $\begin{array}{c}\text { categórica } \\
\text { nominal }\end{array}$ & $<2.10^{-16}$ \\
\hline TX_RESP_Q008 & D008 & $\begin{array}{l}\text { Forma de realização do } \\
\text { curso superior }\end{array}$ & $\begin{array}{l}\text { De que forma você realizou o curso } \\
\text { superior? }\end{array}$ & $\begin{array}{c}\text { categórica } \\
\text { nominal }\end{array}$ & $<2.10^{-16}$ \\
\hline TX_RESP_Q009 & D009 & $\begin{array}{l}\text { Modalidade da pós - } \\
\text { graduação }\end{array}$ & $\begin{array}{l}\text { Indique a modalidade de cursos de } \\
\text { pós-graduação de mais alta titulação } \\
\text { que você possui. }\end{array}$ & $\begin{array}{c}\text { categórica } \\
\text { nominal }\end{array}$ & $<2.10^{-16}$ \\
\hline TX_RESP_Q010 & D010 & $\begin{array}{l}\text { Temática da pós - } \\
\text { graduação }\end{array}$ & $\begin{array}{c}\text { Indique qual a área temática do curso } \\
\text { de pós-graduação de mais alta } \\
\text { titulação que você possui. }\end{array}$ & $\begin{array}{c}\text { categórica } \\
\text { nominal }\end{array}$ & $<2.10^{-16}$ \\
\hline TX_RESP_Q011 & D011 & Formação Continuada & $\begin{array}{l}\text { Você participou de alguma atividade de } \\
\text { formação continuada (atualização, } \\
\text { treinamento, capacitação, etc.) nos } \\
\text { últimos dois anos? }\end{array}$ & $\begin{array}{c}\text { categórica } \\
\text { nominal }\end{array}$ & $<2.10^{-16}$ \\
\hline TX_RESP_Q012 & D012 & $\begin{array}{l}\text { Carga horária da } \\
\text { atividade mais relevante }\end{array}$ & $\begin{array}{l}\text { Qual a carga horária da atividade mais } \\
\text { relevante da qual você participou? }\end{array}$ & $\begin{array}{c}\text { categórica } \\
\text { nominal }\end{array}$ & $1,71.10^{-11}$ \\
\hline TX_RESP_Q013 & D013 & $\begin{array}{l}\text { Aplicação da formação } \\
\text { continuada }\end{array}$ & $\begin{array}{c}\text { Você utiliza os conhecimentos } \\
\text { adquiridos nas atividades de formação } \\
\text { continuada de que você participou? }\end{array}$ & $\begin{array}{c}\text { categórica } \\
\text { nominal }\end{array}$ & $1,08 \cdot 10^{-15}$ \\
\hline TX_RESP_Q014 & D014 & Salário bruto do diretor & $\begin{array}{l}\text { Qual é aproximadamente o seu salário } \\
\text { bruto como diretor(a), com adicionais, } \\
\text { se houver? (preencha os espaços com o } \\
\text { valor e, abaixo de cada algarismo, } \\
\text { marque o campo correspondente.) }\end{array}$ & $\begin{array}{c}\text { categórica } \\
\text { nominal }\end{array}$ & $<2.10^{-16}$ \\
\hline TX_RESP_Q015 & D015 & $\begin{array}{l}\text { Renda familiar bruta do } \\
\text { diretor }\end{array}$ & $\begin{array}{l}\text { Qual é aproximadamente sua renda } \\
\text { familiar bruta? (preencha os espaços } \\
\text { com o valor e, abaixo de cada } \\
\text { algarismo, marque o campo } \\
\text { correspondente.) }\end{array}$ & $\begin{array}{c}\text { categórica } \\
\text { nominal }\end{array}$ & $<2.10^{-16}$ \\
\hline TX_RESP_Q016 & D016 & Atividade extraescolar & $\begin{array}{c}\text { Além da direção desta escola, você } \\
\text { exerce outra atividade que contribui } \\
\text { para sua renda pessoal? }\end{array}$ & $\begin{array}{c}\text { categórica } \\
\text { nominal }\end{array}$ & $<2.10^{-16}$ \\
\hline TX_RESP_Q017 & D017 & $\begin{array}{l}\text { Tempo de trabalho na } \\
\text { educação }\end{array}$ & $\begin{array}{l}\text { Há quantos anos você trabalha em } \\
\text { educação? }\end{array}$ & $\begin{array}{c}\text { categórica } \\
\text { nominal }\end{array}$ & $<2.10^{-16}$ \\
\hline TX_RESP_Q018 & D018 & Tempo de como direção & $\begin{array}{l}\text { Há quantos anos você exerce funções de } \\
\text { direção? }\end{array}$ & $\begin{array}{c}\text { categórica } \\
\text { nominal }\end{array}$ & $<2.10^{-16}$ \\
\hline TX_RESP_Q019 & D019 & $\begin{array}{c}\text { Tempo como direção } \\
\text { desta escola }\end{array}$ & $\begin{array}{l}\text { Há quantos anos você é diretor(a) } \\
\text { desta escola? }\end{array}$ & $\begin{array}{c}\text { categórica } \\
\text { nominal }\end{array}$ & $<2.10^{-16}$ \\
\hline TX_RESP_Q020 & D020 & $\begin{array}{l}\text { Carga horária nesta } \\
\text { escola }\end{array}$ & $\begin{array}{l}\text { Qual é a sua carga horária de trabalho } \\
\text { nesta escola? }\end{array}$ & $\begin{array}{c}\text { categórica } \\
\text { nominal }\end{array}$ & $<2.10^{-16}$ \\
\hline TX_RESP_Q021 & D021 & $\begin{array}{l}\text { Forma que assumiu a } \\
\text { direção }\end{array}$ & $\begin{array}{l}\text { Você assumiu a direção desta escola } \\
\text { por: }\end{array}$ & $\begin{array}{c}\text { categórica } \\
\text { nominal }\end{array}$ & $<2.10^{-16}$ \\
\hline TX_RESP_Q022 & D022 & $\begin{array}{l}\text { Promoção de formação } \\
\text { continuada }\end{array}$ & $\begin{array}{l}\text { Você promoveu alguma atividade de } \\
\text { formação continuada (atualização, } \\
\text { treinamento, capacitação, etc.) Nesta } \\
\text { escola? }\end{array}$ & $\begin{array}{c}\text { categórica } \\
\text { nominal }\end{array}$ & $4,55.10^{-10}$ \\
\hline
\end{tabular}




\begin{tabular}{|c|c|c|c|c|c|}
\hline $\begin{array}{l}\text { Código } \\
\text { original }\end{array}$ & $\begin{array}{l}\text { Código } \\
\text { na base } \\
\text { de dados }\end{array}$ & $\begin{array}{r}\text { Nome da } \\
\text { variável }\end{array}$ & Enunciado & $\begin{array}{l}\text { Tipo de } \\
\text { variável }\end{array}$ & valor $\mathbf{p}$ \\
\hline TX_RESP_Q023 & D023 & $\begin{array}{c}\text { Proporção de } \\
\text { professores que } \\
\text { participaram das } \\
\text { atividades de formação }\end{array}$ & $\begin{array}{l}\text { Qual foi à proporção de docentes da } \\
\text { sua escola que participou das } \\
\text { atividades de formação continuada } \\
\text { promovidas por você nos últimos dois } \\
\text { anos? }\end{array}$ & $\begin{array}{c}\text { categórica } \\
\text { nominal }\end{array}$ & $<2.10^{-16}$ \\
\hline TX_RESP_Q024 & D024 & $\begin{array}{l}\text { Números de reunião de } \\
\text { conselho de escola }\end{array}$ & $\begin{array}{l}\text { Conselho de escola é um colegiado } \\
\text { constituído por representantes da } \\
\text { escola e da comunidade que tem como } \\
\text { objetivo acompanhar as atividades } \\
\text { escolares. Neste ano, quantas vezes o } \\
\text { conselho desta escola se reuniu? }\end{array}$ & $\begin{array}{c}\text { categórica } \\
\text { nominal }\end{array}$ & $<2.10^{-16}$ \\
\hline TX_RESP_Q025 & D025 & $\begin{array}{l}\text { Professores no } \\
\text { conselho de escola }\end{array}$ & $\begin{array}{l}\text { O conselho de escola é composto por } \\
\text { professores. (marque sim ou não em } \\
\text { cada linha) }\end{array}$ & $\begin{array}{c}\text { categórica } \\
\text { nominal }\end{array}$ & $3,25.10^{-9}$ \\
\hline TX_RESP_Q026 & D026 & $\begin{array}{c}\text { Alunos no } \\
\text { conselho de escola }\end{array}$ & $\begin{array}{l}\text { O conselho de escola é composto por } \\
\text { alunos. (marque sim ou não em cada } \\
\text { linha) }\end{array}$ & $\begin{array}{c}\text { categórica } \\
\text { nominal }\end{array}$ & $<2.10^{-16}$ \\
\hline TX_RESP_Q027 & D027 & $\begin{array}{l}\text { Funcionários no } \\
\text { conselho de escola }\end{array}$ & $\begin{array}{l}\text { O conselho de escola é composto por } \\
\text { funcionários. (marque sim ou não em } \\
\text { cada linha) }\end{array}$ & $\begin{array}{c}\text { categórica } \\
\text { nominal }\end{array}$ & $7,72.10^{-7}$ \\
\hline TX_RESP_Q028 & D028 & $\begin{array}{l}\text { Pais no conselho de } \\
\text { escola }\end{array}$ & $\begin{array}{l}\text { O conselho de escola é composto por } \\
\text { pais. (marque sim ou não em cada linha) }\end{array}$ & $\begin{array}{c}\text { categórica } \\
\text { nominal }\end{array}$ & $2,04 \cdot 10^{-7}$ \\
\hline TX_RESP_Q029 & D029 & Conselho de classe & $\begin{array}{l}\text { Conselho de classe é um órgão formado } \\
\text { por todos os professores que lecionam } \\
\text { em cada turma/série. Neste ano, } \\
\text { quantas vezes se reuniram os conselhos } \\
\text { de classe desta escola? }\end{array}$ & $\begin{array}{c}\text { categórica } \\
\text { nominal }\end{array}$ & $<2.10^{-16}$ \\
\hline TX_RESP_Q030 & D030 & Projeto Pedagógico & $\begin{array}{l}\text { Quanto ao projeto pedagógico desta } \\
\text { escola neste ano (marque apenas uma } \\
\text { opção) }\end{array}$ & $\begin{array}{c}\text { categórica } \\
\text { nominal }\end{array}$ & $<2.10^{-16}$ \\
\hline TX_RESP_Q031 & D031 & $\begin{array}{l}\text { Critério Admissão } \\
\text { Escolar }\end{array}$ & $\begin{array}{c}\text { Qual é o critério para a admissão de } \\
\text { alunos nesta escola? }\end{array}$ & $\begin{array}{c}\text { categórica } \\
\text { nominal }\end{array}$ & $<2.10^{-16}$ \\
\hline TX_RESP_Q032 & D032 & Oferta de vagas escolar & $\begin{array}{c}\text { Neste ano letivo, como foi a situação } \\
\text { da oferta de vagas nesta escola? } \\
\text { (marque apenas uma alternativa.) }\end{array}$ & $\begin{array}{c}\text { categórica } \\
\text { nominal }\end{array}$ & $<2.10^{-16}$ \\
\hline TX_RESP_Q033 & D033 & $\begin{array}{l}\text { Critério de composição } \\
\text { de turmas }\end{array}$ & $\begin{array}{l}\text { Qual o critério utilizado para formação } \\
\text { das turmas nesta escola? }\end{array}$ & $\begin{array}{c}\text { categórica } \\
\text { nominal }\end{array}$ & $<2.10^{-16}$ \\
\hline TX_RESP_Q034 & D034 & $\begin{array}{l}\text { Atribuição de turmas } \\
\text { ensino fundamental I }\end{array}$ & $\begin{array}{l}\text { Neste ano, qual foi o critério mais } \\
\text { importante para a atribuição das turmas } \\
\text { de } 1 .^{\mathrm{a}} \text { a } 4 .^{\mathrm{a}} \text { séries do ensino } \\
\text { fundamental aos professores? }\end{array}$ & $\begin{array}{c}\text { categórica } \\
\text { nominal }\end{array}$ & $<2.10^{-16}$ \\
\hline TX_RESP_Q035 & D035 & Professores estáveis & $\begin{array}{l}\text { Qual é o percentual de professores com } \\
\text { vínculo estável nesta escola? }\end{array}$ & $\begin{array}{c}\text { categórica } \\
\text { nominal }\end{array}$ & $<2.10^{-16}$ \\
\hline TX_RESP_Q036 & D036 & Taxas de abandono & $\begin{array}{l}\text { Nesta escola, há algum programa de } \\
\text { redução das taxas de abandono? }\end{array}$ & $\begin{array}{c}\text { categórica } \\
\text { nominal }\end{array}$ & $<2.10^{-16}$ \\
\hline TX_RESP_Q037 & D037 & Taxas de reprova & $\begin{array}{l}\text { Nesta escola, há algum programa de } \\
\text { redução das taxas de reprovação? }\end{array}$ & $\begin{array}{c}\text { categórica } \\
\text { nominal }\end{array}$ & $<2.10^{-16}$ \\
\hline TX_RESP_Q038 & D038 & $\begin{array}{l}\text { Política anti - faltas } \\
\text { dos alunos feita pelos } \\
\text { professores }\end{array}$ & $\begin{array}{l}\text { Para evitar que os alunos faltem às } \\
\text { aulas, os professores falam com os } \\
\text { alunos. }\end{array}$ & $\begin{array}{c}\text { categórica } \\
\text { nominal }\end{array}$ & $5,66.10^{-5}$ \\
\hline TX_RESP_Q039 & D039 & $\begin{array}{c}\text { Comunicação com os pais } \\
\text { por causa das faltas } \\
\text { dos alunos }\end{array}$ & $\begin{array}{l}\text { Para evitar que os alunos faltem às } \\
\text { aulas, os pais/responsáveis são } \\
\text { avisados por comunicação escrita. }\end{array}$ & $\begin{array}{c}\text { categórica } \\
\text { nominal }\end{array}$ & $4,32 \cdot 10^{-6}$ \\
\hline TX_RESP_Q040 & D040 & $\begin{array}{l}\text { Conversa com os pais } \\
\text { por causa das faltas } \\
\text { dos alunos em reunião }\end{array}$ & $\begin{array}{c}\text { Para evitar que os alunos faltem às } \\
\text { aulas, os pais/responsáveis são } \\
\text { chamados à escola para conversar sobre } \\
\text { o assunto em reunião de pais. }\end{array}$ & $\begin{array}{c}\text { categórica } \\
\text { nominal }\end{array}$ & $<2.10^{-16}$ \\
\hline TX_RESP_Q041 & D041 & $\begin{array}{c}\text { Conversa com os pais } \\
\text { por causa das faltas } \\
\text { dos alunos } \\
\text { individualmente }\end{array}$ & $\begin{array}{c}\text { Para evitar que os alunos faltem às } \\
\text { aulas, os pais/responsáveis são } \\
\text { chamados à escola para conversar sobre } \\
\text { o assunto individualmente. }\end{array}$ & $\begin{array}{c}\text { categórica } \\
\text { nominal }\end{array}$ & $3,33.10^{-10}$ \\
\hline TX_RESP_Q042 & D042 & Visita aos alunos & $\begin{array}{c}\text { Para evitar que os alunos faltem às } \\
\text { aulas, a escola envia alguém à casa do } \\
\text { aluno. }\end{array}$ & $\begin{array}{c}\text { categórica } \\
\text { nominal }\end{array}$ & $2,86 \cdot 10^{-13}$ \\
\hline TX_RESP_Q043 & D043 & Reforço escolar & $\begin{array}{c}\text { Esta escola desenvolve, regularmente, } \\
\text { algum programa de apoio ou reforço de } \\
\text { aprendizagem para os alunos (monitoria, } \\
\text { aula de reforço etc.) }\end{array}$ & $\begin{array}{c}\text { categórica } \\
\text { nominal }\end{array}$ & $8,32 \cdot 10^{-14}$ \\
\hline
\end{tabular}




\begin{tabular}{|c|c|c|c|c|c|}
\hline $\begin{array}{l}\text { Código } \\
\text { original }\end{array}$ & $\begin{array}{c}\text { Código } \\
\text { na base } \\
\text { de dados }\end{array}$ & $\begin{array}{r}\text { Nome da } \\
\text { variável }\end{array}$ & Enunciado & $\begin{array}{l}\text { Tipo de } \\
\text { variável }\end{array}$ & valor $\mathbf{p}$ \\
\hline TX_RESP_Q044 & D044 & $\begin{array}{l}\text { Cultura afro - } \\
\text { brasileira }\end{array}$ & $\begin{array}{l}\text { Você tem conhecimento do conteúdo da } \\
\text { lei } 11.645 \text { de } 2008 \text { que determina a } \\
\text { obrigatoriedade do estudo da temática } \\
\text { "história e cultura afro-brasileira e } \\
\text { indígena"nos estabelecimentos de } \\
\text { ensino do país? }\end{array}$ & $\begin{array}{c}\text { categórica } \\
\text { nominal }\end{array}$ & $1,87.10^{-9}$ \\
\hline TX_RESP_Q045 & D045 & $\begin{array}{l}\text { Atividades de cultura } \\
\text { afro - brasileira }\end{array}$ & $\begin{array}{l}\text { Neste ano, foram desenvolvidas } \\
\text { atividades para atender o determinado } \\
\text { pela lei } 11.645 \text { de } 2008 \text { nesta escola? }\end{array}$ & $\begin{array}{c}\text { categórica } \\
\text { nominal }\end{array}$ & $<2.10^{-16}$ \\
\hline TX_RESP_Q046 & D046 & $\begin{array}{l}\text { Recursos financeiros } \\
\text { para merenda escolar }\end{array}$ & $\begin{array}{l}\text { Em relação à merenda escolar, como você } \\
\text { considera recursos financeiros. }\end{array}$ & $\begin{array}{c}\text { categórica } \\
\text { nominal }\end{array}$ & $3,34 \cdot 10^{-16}$ \\
\hline TX_RESP_Q047 & D047 & $\begin{array}{l}\text { Quantidade de merenda } \\
\text { escolar }\end{array}$ & $\begin{array}{l}\text { Em relação à merenda escolar, como você } \\
\text { considera quantidade de alimentos. }\end{array}$ & $\begin{array}{c}\text { categórica } \\
\text { nominal }\end{array}$ & $1,56.10^{-14}$ \\
\hline TX_RESP_Q049 & D049 & $\begin{array}{l}\text { Variedade da merenda } \\
\text { escolar }\end{array}$ & $\begin{array}{l}\text { Em relação à merenda escolar, como você } \\
\text { considera variedade do cardápio. }\end{array}$ & $\begin{array}{c}\text { categórica } \\
\text { nominal }\end{array}$ & $<2.10^{-16}$ \\
\hline TX_RESP_Q050 & D050 & $\begin{array}{l}\text { Conservação da merenda } \\
\text { escolar }\end{array}$ & $\begin{array}{l}\text { Em relação à merenda escolar, como você } \\
\text { considera armazenamento e conservação. }\end{array}$ & $\begin{array}{c}\text { categórica } \\
\text { nominal }\end{array}$ & $<2.10^{-16}$ \\
\hline TX_RESP_Q051 & D051 & Cozinha escolar & $\begin{array}{l}\text { Em relação à merenda escolar, como você } \\
\text { considera espaço físico para cozinhar. }\end{array}$ & $\begin{array}{c}\text { categórica } \\
\text { nominal }\end{array}$ & $<2.10^{-16}$ \\
\hline TX_RESP_Q052 & D052 & $\begin{array}{l}\text { Higiene da merenda } \\
\text { escolar }\end{array}$ & $\begin{array}{l}\text { Em relação à merenda escolar, como você } \\
\text { considera higiene. }\end{array}$ & $\begin{array}{c}\text { categórica } \\
\text { nominal }\end{array}$ & $<2.10^{-16}$ \\
\hline TX_RESP_Q053 & D053 & Merendeira & $\begin{array}{l}\text { Em relação à merenda escolar, como você } \\
\text { considera disponibilidade de pessoal. }\end{array}$ & $\begin{array}{c}\text { categórica } \\
\text { nominal }\end{array}$ & $<2.10^{-16}$ \\
\hline TX_RESP_Q054 & D054 & Qualificação: Merendeira & $\begin{array}{l}\text { Em relação à merenda escolar, como você } \\
\text { considera qualificação do pessoal. }\end{array}$ & $\begin{array}{c}\text { categórica } \\
\text { nominal }\end{array}$ & $<2.10^{-16}$ \\
\hline TX_RESP_Q056 & D056 & Falta de professores & $\begin{array}{l}\text { As perguntas de } 55 \text { a } 64 \text { apresentam } \\
\text { alguns problemas que podem ocorrer nas } \\
\text { escolas. Responda se cada um deles } \\
\text { ocorreu ou não neste ano. Caso tenha } \\
\text { ocorrido, assinale se foi ou não um } \\
\text { problema grave, dificultando o } \\
\text { funcionamento da escola. (marque apenas } \\
\text { uma opção em cada linha.) Ocorreu na } \\
\text { escola inexistência de professores para } \\
\text { algumas disciplinas ou séries? }\end{array}$ & $\begin{array}{c}\text { categórica } \\
\text { nominal }\end{array}$ & $<2.10^{-16}$ \\
\hline TX_RESP_Q057 & D057 & $\begin{array}{l}\text { Falta de pessoal } \\
\text { administrativo }\end{array}$ & $\begin{array}{l}\text { As perguntas de } 55 \text { a } 64 \text { apresentam } \\
\text { alguns problemas que podem ocorrer nas } \\
\text { escolas. Responda se cada um deles } \\
\text { ocorreu ou não neste ano. Caso tenha } \\
\text { ocorrido, assinale se foi ou não um } \\
\text { problema grave, dificultando o } \\
\text { funcionamento da escola. (marque apenas } \\
\text { uma opção em cada linha.) Ocorreu na } \\
\text { escola carência de pessoal } \\
\text { administrativo? }\end{array}$ & $\begin{array}{c}\text { categórica } \\
\text { nominal }\end{array}$ & $<2.10^{-16}$ \\
\hline
\end{tabular}




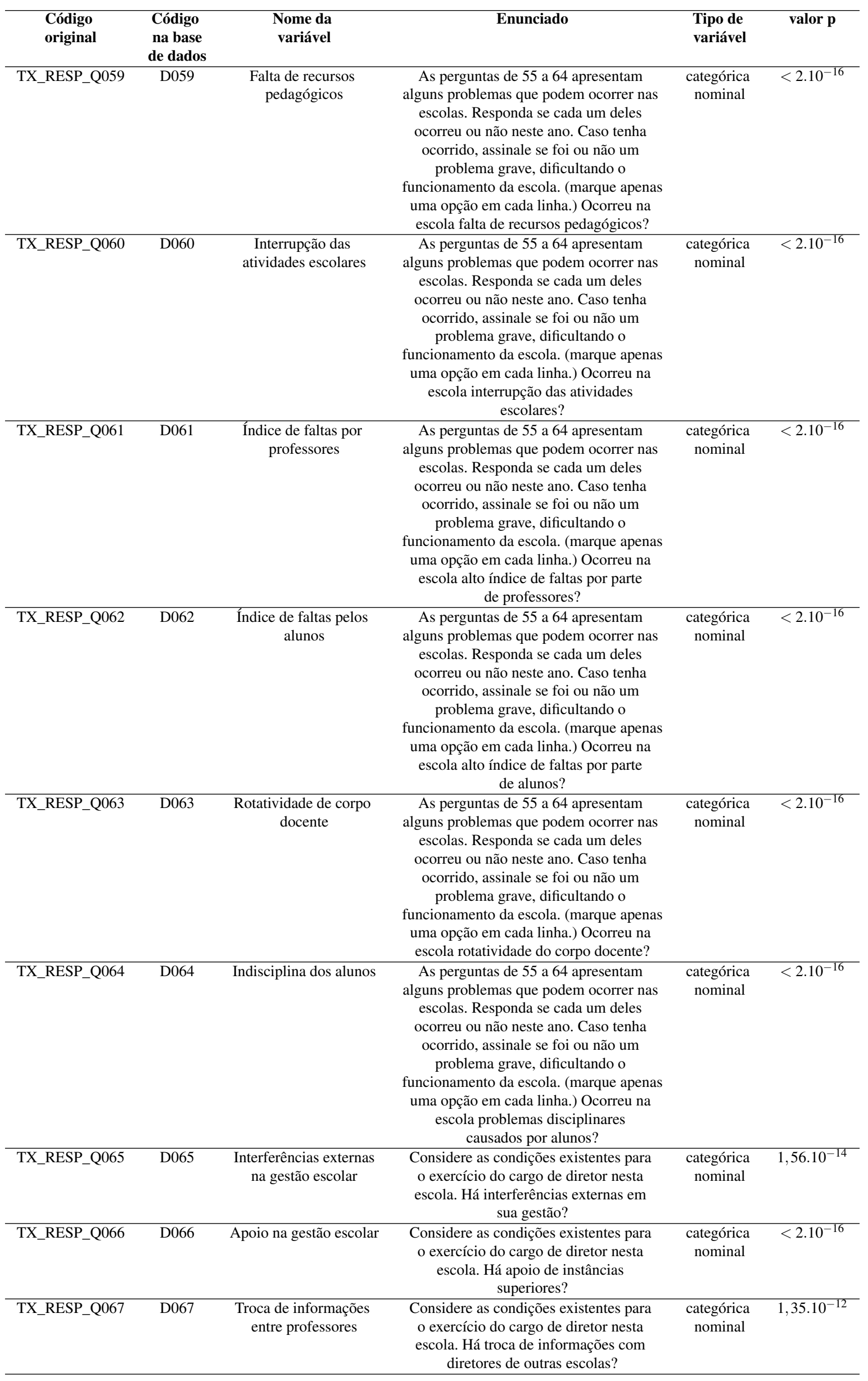




\begin{tabular}{|c|c|c|c|c|c|}
\hline $\begin{array}{l}\text { Código } \\
\text { original }\end{array}$ & $\begin{array}{c}\text { Código } \\
\text { na base } \\
\text { de dados }\end{array}$ & $\begin{array}{r}\text { Nome da } \\
\text { variável }\end{array}$ & Enunciado & $\begin{array}{l}\text { Tipo de } \\
\text { variável }\end{array}$ & valor $p$ \\
\hline TX_RESP_Q068 & D068 & $\begin{array}{l}\text { Apoio da comunidade na } \\
\text { gestão escolar }\end{array}$ & $\begin{array}{c}\text { Considere as condições existentes para } \\
\text { o exercício do cargo de diretor nesta } \\
\text { escola. Há apoio da comunidade à sua } \\
\text { gestão? }\end{array}$ & $\begin{array}{c}\text { categórica } \\
\text { nominal }\end{array}$ & $<2.10^{-16}$ \\
\hline TX_RESP_Q069 & D069 & $\begin{array}{l}\text { Pavimentação asfáltica } \\
\text { próximo à escola }\end{array}$ & $\begin{array}{l}\text { As perguntas de } 69 \text { a } 113 \text { referem-se às } \\
\text { condições de acessibilidade. Nas } \\
\text { imediações ou na frente da escola, as } \\
\text { calçadas possuem pavimento regular, } \\
\text { plano, sem buracos ou degraus? }\end{array}$ & $\begin{array}{c}\text { categórica } \\
\text { nominal }\end{array}$ & $<2.10^{-16}$ \\
\hline TX_RESP_Q070 & D070 & $\begin{array}{l}\text { Largura da calçada } \\
\text { próximo à escola }\end{array}$ & $\begin{array}{c}\text { As perguntas de } 69 \text { a } 113 \text { referem-se às } \\
\text { condições de acessibilidade. Nas } \\
\text { imediações ou na frente da escola, as } \\
\text { calçadas possuem largura mínima de } 1,20 \\
\text { m? }\end{array}$ & $\begin{array}{c}\text { categórica } \\
\text { nominal }\end{array}$ & $<2.10^{-16}$ \\
\hline TX_RESP_Q072 & D072 & $\begin{array}{l}\text { Semáforos próximo à } \\
\text { escola }\end{array}$ & $\begin{array}{l}\text { As perguntas de } 69 \text { a } 113 \text { referem-se às } \\
\text { condições de acessibilidade. Nas } \\
\text { imediações ou na frente da escola: há } \\
\text { semáforos para pedestres? }\end{array}$ & $\begin{array}{c}\text { categórica } \\
\text { nominal }\end{array}$ & $<2.10^{-16}$ \\
\hline TX_RESP_Q073 & D073 & $\begin{array}{l}\text { Semáforos sonoros } \\
\text { próximo à escola }\end{array}$ & $\begin{array}{l}\text { As perguntas de } 69 \text { a } 113 \text { referem-se às } \\
\text { condições de acessibilidade. Nas } \\
\text { imediações ou na frente da escola: o } \\
\text { semáforo é sonoro? }\end{array}$ & $\begin{array}{c}\text { categórica } \\
\text { nominal }\end{array}$ & $3.10^{-12}$ \\
\hline TX_RESP_Q075 & D075 & $\begin{array}{c}\text { Rampas de Travessia } \\
\text { próximo à escola }\end{array}$ & $\begin{array}{c}\text { As perguntas de } 69 \text { a } 113 \text { referem-se às } \\
\text { condições de acessibilidade. Nas } \\
\text { imediações ou na frente da escola: as } \\
\text { calçadas são rebaixadas com rampas dos } \\
\text { dois lados da rua no trecho da travessia? }\end{array}$ & $\begin{array}{c}\text { categórica } \\
\text { nominal }\end{array}$ & $<2.10^{-16}$ \\
\hline TX_RESP_Q076 & D076 & $\begin{array}{l}\text { Vagas em estacionamento } \\
\text { para deficientes } \\
\text { próximo à escola }\end{array}$ & $\begin{array}{l}\text { As perguntas de } 69 \text { a } 113 \text { referem-se às } \\
\text { condições de acessibilidade. Nas } \\
\text { imediações ou na frente da escola: há } \\
\text { vagas sinalizadas para veículos para } \\
\text { pessoas com deficiência? }\end{array}$ & $\begin{array}{c}\text { categórica } \\
\text { nominal }\end{array}$ & $<2.10^{-16}$ \\
\hline TX_RESP_Q077 & D077 & Acesso à escola & $\begin{array}{l}\text { As perguntas de } 69 \text { a } 113 \text { referem-se às } \\
\text { condições de acessibilidade. Nas } \\
\text { imediações ou na frente da escola: o } \\
\text { portão de acesso de pedestres à escola } \\
\text { é separado da entrada de carros? }\end{array}$ & $\begin{array}{c}\text { categórica } \\
\text { nominal }\end{array}$ & $<2.10^{-16}$ \\
\hline TX_RESP_Q078 & D078 & Acesso à escola & $\begin{array}{l}\text { As perguntas de } 69 \text { a } 113 \text { referem-se às } \\
\text { condições de acessibilidade. Nas } \\
\text { imediações ou na frente da escola: o } \\
\text { portão de acesso tem largura mínima de } \\
\qquad 80 \mathrm{~cm} \text { ? }\end{array}$ & $\begin{array}{c}\text { categórica } \\
\text { nominal }\end{array}$ & $<2.10^{-16}$ \\
\hline TX_RESP_Q079 & D079 & Entrada principal & $\begin{array}{l}\text { As perguntas de } 69 \text { a } 113 \text { referem-se às } \\
\text { condições de acessibilidade. No } \\
\text { interior da escola, na entrada } \\
\text { principal e nas circulações internas: } \\
\text { os corredores e as calçadas tem largura } \\
\text { mínima de } 1,20 \mathrm{~cm} \text { ? }\end{array}$ & $\begin{array}{c}\text { categórica } \\
\text { nominal }\end{array}$ & $<2.10^{-16}$ \\
\hline
\end{tabular}




\begin{tabular}{|c|c|c|c|c|c|}
\hline $\begin{array}{l}\text { Código } \\
\text { original }\end{array}$ & $\begin{array}{c}\text { Código } \\
\text { na base } \\
\text { de dados }\end{array}$ & $\begin{array}{l}\text { Nome da } \\
\text { variável }\end{array}$ & Enunciado & $\begin{array}{l}\text { Tipo de } \\
\text { variável }\end{array}$ & valor $\mathbf{p}$ \\
\hline TX_RESP_Q081 & D081 & Piso interno & $\begin{array}{l}\text { As perguntas de } 69 \text { a } 113 \text { referem-se às } \\
\text { condições de acessibilidade. No } \\
\text { interior da escola, na entrada } \\
\text { principal e nas circulações internas: o } \\
\text { piso é plano, sem degraus e sem } \\
\text { desníveis superiores a } 1,5 \mathrm{~cm} ?\end{array}$ & $\begin{array}{c}\text { categórica } \\
\text { nominal }\end{array}$ & $8,71.10^{-16}$ \\
\hline TX_RESP_Q082 & D082 & Rampas interna & $\begin{array}{c}\text { As perguntas de } 69 \text { a } 113 \text { referem-se às } \\
\text { condições de acessibilidade. No } \\
\text { interior da escola, na entrada } \\
\text { principal e nas circulações internas: } \\
\text { há rampas? }\end{array}$ & $\begin{array}{c}\text { categórica } \\
\text { nominal }\end{array}$ & $<2.10^{-16}$ \\
\hline TX_RESP_Q083 & D083 & Rampas interna & $\begin{array}{l}\text { As perguntas de } 69 \text { a } 113 \text { referem-se às } \\
\text { condições de acessibilidade. No } \\
\text { interior da escola, na entrada } \\
\text { principal e nas circulações internas: } \\
\text { as rampas têm largura mínima de } 80 \mathrm{~cm} \text { ? }\end{array}$ & $\begin{array}{c}\text { categórica } \\
\text { nominal }\end{array}$ & $<2.10^{-16}$ \\
\hline TX_RESP_Q084 & D084 & $\begin{array}{l}\text { Rampas internas com } \\
\text { corrimão }\end{array}$ & $\begin{array}{l}\text { As perguntas de } 69 \text { a } 113 \text { referem-se às } \\
\text { condições de acessibilidade. No } \\
\text { interior da escola, na entrada } \\
\text { principal e nas circulações internas: } \\
\text { há rampas com corrimão dos dois lados? }\end{array}$ & $\begin{array}{c}\text { categórica } \\
\text { nominal }\end{array}$ & $<2.10^{-16}$ \\
\hline TX_RESP_Q085 & D085 & $\begin{array}{l}\text { Escadas internas com } \\
\text { corrimão }\end{array}$ & $\begin{array}{l}\text { As perguntas de } 69 \text { a } 113 \text { referem-se às } \\
\text { condições de acessibilidade. No interior } \\
\text { da escola, na entrada principal e nas } \\
\text { circulações internas: as escadas têm } \\
\text { corrimãos dos dois lados? }\end{array}$ & $\begin{array}{c}\text { categórica } \\
\text { nominal }\end{array}$ & $<2.10^{-16}$ \\
\hline TX_RESP_Q086 & D086 & $\begin{array}{l}\text { Escadas internas com } \\
\text { corrimão }\end{array}$ & $\begin{array}{l}\text { As perguntas de } 69 \text { a } 113 \text { referem-se às } \\
\text { condições de acessibilidade. No } \\
\text { interior da escola, na entrada } \\
\text { principal e nas circulações internas: } \\
\text { elevadores ou plataformas elevatórias? }\end{array}$ & $\begin{array}{c}\text { categórica } \\
\text { nominal }\end{array}$ & $<2.10^{-16}$ \\
\hline TX_RESP_Q087 & D087 & Soleiras das portas & $\begin{array}{l}\text { As perguntas de } 69 \text { a } 113 \text { referem-se às } \\
\text { condições de acessibilidade. Nas salas } \\
\text { de aula, na administração, na } \\
\text { biblioteca e outros ambientes: nas } \\
\text { portas, há soleiras niveladas com o } \\
\text { piso do corredor, pequenas rampas ou } \\
\text { degraus de no máximo } 1,5 \mathrm{~cm} \text { ? }\end{array}$ & $\begin{array}{c}\text { categórica } \\
\text { nominal }\end{array}$ & $<2.10^{-16}$ \\
\hline TX_RESP_Q088 & D088 & largura das portas & $\begin{array}{c}\text { As perguntas de } 69 \text { a } 113 \text { referem-se às } \\
\text { condições de acessibilidade. Nas salas } \\
\text { de aula, na administração, na } \\
\text { biblioteca e outros ambientes: as } \\
\text { portas de entrada possuem largura } \\
\text { mínima de } 80 \mathrm{~cm} \text { ? }\end{array}$ & $\begin{array}{c}\text { categórica } \\
\text { nominal }\end{array}$ & $4,35.10^{-8}$ \\
\hline TX_RESP_Q089 & D089 & Maçanetas das portas & $\begin{array}{l}\text { As perguntas de } 69 \text { a } 113 \text { referem-se às } \\
\text { condições de acessibilidade. Nas salas } \\
\text { de aula, na administração, na } \\
\text { biblioteca e outros ambientes: as } \\
\text { maçanetas são de alavanca? }\end{array}$ & $\begin{array}{c}\text { categórica } \\
\text { nominal }\end{array}$ & $<2.10^{-16}$ \\
\hline TX_RESP_Q090 & D090 & Sinalização em braile & $\begin{array}{l}\text { As perguntas de } 69 \text { a } 113 \text { referem-se às } \\
\text { condições de acessibilidade. Nas salas } \\
\text { de aula, na administração, na } \\
\text { biblioteca e outros ambientes: há algum } \\
\text { tipo de sinalização em braile nos } \\
\text { ambientes? }\end{array}$ & $\begin{array}{c}\text { categórica } \\
\text { nominal }\end{array}$ & $3,62 \cdot 10^{-9}$ \\
\hline TX_RESP_Q091 & D091 & $\begin{array}{c}\text { Banheiro para } \\
\text { deficientes }\end{array}$ & $\begin{array}{l}\text { As perguntas de } 69 \text { a } 113 \text { referem-se às } \\
\text { condições de acessibilidade. Os } \\
\text { banheiros: há pelo menos um sanitário } \\
\text { adequado a pessoas com deficiência? }\end{array}$ & $\begin{array}{c}\text { categórica } \\
\text { nominal }\end{array}$ & $<2.10^{-16}$ \\
\hline TX_RESP_Q092 & D092 & $\begin{array}{l}\text { Banheiro para pessoas } \\
\text { deficientes para cada } \\
\text { sexo }\end{array}$ & $\begin{array}{l}\text { As perguntas de } 69 \text { a } 113 \text { referem-se às } \\
\text { condições de acessibilidade. Os } \\
\text { banheiros: há pelo menos um sanitário } \\
\text { adequado a pessoas com deficiência para } \\
\text { cada sexo? }\end{array}$ & $\begin{array}{c}\text { categórica } \\
\text { nominal }\end{array}$ & $<2.10^{-16}$ \\
\hline TX_RESP_Q093 & D093 & $\begin{array}{l}\text { Largura das portas dos } \\
\text { banheiros }\end{array}$ & $\begin{array}{c}\text { As perguntas de } 69 \text { a } 113 \text { referem-se às } \\
\text { condições de acessibilidade. Os } \\
\text { banheiros: as portas possuem largura } \\
\text { mínima de } 80 \mathrm{~cm} ?\end{array}$ & $\begin{array}{c}\text { categórica } \\
\text { nominal }\end{array}$ & $2,77 \cdot 10^{-7}$ \\
\hline TX_RESP_Q094 & D094 & $\begin{array}{l}\text { Direção de abertura das } \\
\text { portas dos banheiros }\end{array}$ & $\begin{array}{l}\text { As perguntas de } 69 \text { a } 113 \text { referem-se às } \\
\text { condições de acessibilidade. Os } \\
\text { banheiros: há banheiros ou mictórios } \\
\text { com portas que abrem para fora? }\end{array}$ & $\begin{array}{c}\text { categórica } \\
\text { nominal }\end{array}$ & $3,92 \cdot 10^{-9}$ \\
\hline
\end{tabular}




\begin{tabular}{|c|c|c|c|c|c|}
\hline $\begin{array}{l}\text { Código } \\
\text { original }\end{array}$ & $\begin{array}{c}\text { Código } \\
\text { na base } \\
\text { de dados }\end{array}$ & $\begin{array}{l}\text { Nome da } \\
\text { variável }\end{array}$ & Enunciado & $\begin{array}{l}\text { Tipo de } \\
\text { variável }\end{array}$ & valor $\mathbf{p}$ \\
\hline TX_RESP_Q095 & D095 & $\begin{array}{l}\text { Maçaneta das portas dos } \\
\text { banheiros }\end{array}$ & $\begin{array}{l}\text { As perguntas de } 69 \text { a } 113 \text { referem-se às } \\
\text { condições de acessibilidade. Os } \\
\text { banheiros: as maçanetas são de alavanca? }\end{array}$ & $\begin{array}{c}\text { categórica } \\
\text { nominal }\end{array}$ & $<2.10^{-16}$ \\
\hline TX_RESP_Q096 & D096 & $\begin{array}{c}\text { Cadeira de rodas nos } \\
\text { banheiros }\end{array}$ & $\begin{array}{l}\text { As perguntas de } 69 \text { a } 113 \text { referem-se às } \\
\text { condições de acessibilidade. Os } \\
\text { banheiros: há espaço para cadeiras de } \\
\text { rodas e para transferência de pelo } \\
\text { menos } 80 \mathrm{~cm} ?\end{array}$ & $\begin{array}{c}\text { categórica } \\
\text { nominal }\end{array}$ & $<2.10^{-16}$ \\
\hline TX_RESP_Q097 & D097 & $\begin{array}{l}\text { Barras de apoio nos } \\
\text { banheiros }\end{array}$ & $\begin{array}{l}\text { As perguntas de } 69 \text { a } 113 \text { referem-se às } \\
\text { condições de acessibilidade. Os } \\
\text { banheiros: há barras de apoio fixadas } \\
\text { nas paredes de fundo e na lateral do } \\
\text { vaso sanitário? }\end{array}$ & $\begin{array}{c}\text { categórica } \\
\text { nominal }\end{array}$ & $4,63.10^{-14}$ \\
\hline TX_RESP_Q098 & D098 & $\begin{array}{l}\text { Torneira da pia dos } \\
\text { banheiros }\end{array}$ & $\begin{array}{l}\text { As perguntas de } 69 \text { a } 113 \text { referem-se às } \\
\text { condições de acessibilidade. Os } \\
\text { banheiros: há pia com torneira com } \\
\text { acionamento por alavanca, pressão ou } \\
\text { cruzeta (em cruz)? }\end{array}$ & $\begin{array}{c}\text { categórica } \\
\text { nominal }\end{array}$ & $<2.10^{-16}$ \\
\hline TX_RESP_Q099 & D099 & Pia dos banheiros & $\begin{array}{l}\text { As perguntas de } 69 \text { a } 113 \text { referem-se às } \\
\text { condições de acessibilidade. Os } \\
\text { banheiros: há pia com altura entre } 78 \text { e } \\
80 \mathrm{~cm} \text { e com vão inferior livre com } \\
\text { altura de } 73 \mathrm{~cm} ?\end{array}$ & $\begin{array}{c}\text { categórica } \\
\text { nominal }\end{array}$ & $2,12 \cdot 10^{-8}$ \\
\hline TX_RESP_Q100 & D100 & Atendimento Educacional & $\begin{array}{l}\text { As perguntas de } 69 \text { a } 113 \text { referem-se às } \\
\text { condições de acessibilidade. A escola } \\
\text { possui: sala de recursos } \\
\text { multifuncionais para atendimento } \\
\text { educacional especializado (aee)? }\end{array}$ & $\begin{array}{c}\text { categórica } \\
\text { nominal }\end{array}$ & $<2.10^{-16}$ \\
\hline TX_RESP_Q101 & D101 & Materiais didáticos & $\begin{array}{l}\text { As perguntas de } 69 \text { a } 113 \text { referem-se às } \\
\text { condições de acessibilidade. A escola } \\
\text { possui: materiais didáticos e } \\
\text { paradidáticos acessíveis? (braile, } \\
\text { caracteres ampliados, libras, texturas, } \\
\text { contrastes etc). }\end{array}$ & $\begin{array}{c}\text { categórica } \\
\text { nominal }\end{array}$ & $<2.10^{-16}$ \\
\hline TX_RESP_Q102 & D102 & Recursos ópticos & $\begin{array}{l}\text { As perguntas de } 69 \text { a } 113 \text { referem-se às } \\
\text { condições de acessibilidade. A escola } \\
\text { possui: recursos ópticos? (ex: lupa, } \\
\text { telelupa, telescópio, lentes especiais, } \\
\text { etc.) }\end{array}$ & $\begin{array}{c}\text { categórica } \\
\text { nominal }\end{array}$ & $<2.10^{-16}$ \\
\hline TX_RESP_Q103 & D103 & Recursos não ópticos & $\begin{array}{l}\text { As perguntas de } 69 \text { a } 113 \text { referem-se às } \\
\text { condições de acessibilidade. A escola } \\
\text { possui: recursos não ópticos? (ex: } \\
\text { celofane amarelo, livro falado, } \\
\text { material impresso com tipos maiores, } \\
\text { tábua de apoio para leitura, lápis e } \\
\text { canetas especiais, guia de leitura etc.) }\end{array}$ & $\begin{array}{c}\text { categórica } \\
\text { nominal }\end{array}$ & $<2.10^{-16}$ \\
\hline TX_RESP_Q104 & D104 & Soroban & $\begin{array}{c}\text { As perguntas de } 69 \text { a } 113 \text { referem-se às } \\
\text { condições de acessibilidade. A escola } \\
\text { possui: soroban? }\end{array}$ & $\begin{array}{c}\text { categórica } \\
\text { nominal }\end{array}$ & $<2.10^{-16}$ \\
\hline TX_RESP_Q105 & D105 & Reglete e punção & $\begin{array}{l}\text { As perguntas de } 69 \text { a } 113 \text { referem-se às } \\
\text { condições de acessibilidade. A escola } \\
\text { possui: reglete e punção? }\end{array}$ & $\begin{array}{c}\text { categórica } \\
\text { nominal }\end{array}$ & $<2.10^{-16}$ \\
\hline TX_RESP_Q106 & D106 & Calculadora sonora & $\begin{array}{l}\text { As perguntas de } 69 \text { a } 113 \text { referem-se às } \\
\text { condições de acessibilidade. A escola } \\
\text { possui: calculadora sonora? }\end{array}$ & $\begin{array}{c}\text { categórica } \\
\text { nominal }\end{array}$ & $5,03.10^{-12}$ \\
\hline TX_RESP_Q107 & D107 & $\begin{array}{c}\text { Calculadora para } \\
\text { pessoas com baixa visão }\end{array}$ & $\begin{array}{c}\text { As perguntas de } 69 \text { a } 113 \text { referem-se às } \\
\text { condições de acessibilidade. A escola } \\
\text { possui: calculadora para pessoas de } \\
\text { baixa visão? }\end{array}$ & $\begin{array}{c}\text { categórica } \\
\text { nominal }\end{array}$ & $<2.10^{-16}$ \\
\hline TX_RESP_Q108 & D108 & Máquina perkins & $\begin{array}{l}\text { As perguntas de } 69 \text { a } 113 \text { referem-se às } \\
\text { condições de acessibilidade. A escola } \\
\text { possui: máquina perkins? (máquina de } \\
\text { escrever em braile) }\end{array}$ & $\begin{array}{c}\text { categórica } \\
\text { nominal }\end{array}$ & $<2.10^{-16}$ \\
\hline TX_RESP_Q109 & D109 & Software leitor de tela & $\begin{array}{c}\text { As perguntas de } 69 \text { a } 113 \text { referem-se às } \\
\text { condições de acessibilidade. A escola } \\
\text { possui: computador com software leitor } \\
\text { de tela? }\end{array}$ & $\begin{array}{c}\text { categórica } \\
\text { nominal }\end{array}$ & $<2.10^{-16}$ \\
\hline TX_RESP_Q110 & D110 & $\begin{array}{c}\text { Software de comunicação } \\
\text { alternativa }\end{array}$ & $\begin{array}{l}\text { As perguntas de } 69 \text { a } 113 \text { referem-se às } \\
\text { condições de acessibilidade. A escola } \\
\text { possui: software de comunicação } \\
\text { alternativa aumentativa (caa)? }\end{array}$ & $\begin{array}{c}\text { categórica } \\
\text { nominal }\end{array}$ & $<2.10^{-16}$ \\
\hline
\end{tabular}




\begin{tabular}{|c|c|c|c|c|c|}
\hline $\begin{array}{l}\text { Código } \\
\text { original }\end{array}$ & $\begin{array}{c}\text { Código } \\
\text { na base } \\
\text { de dados }\end{array}$ & $\begin{array}{r}\text { Nome da } \\
\text { variável }\end{array}$ & Enunciado & $\begin{array}{l}\text { Tipo de } \\
\text { variável }\end{array}$ & valor $\mathbf{p}$ \\
\hline TX_RESP_Q111 & D111 & $\begin{array}{l}\text { Mesas e cadeiras para } \\
\text { cadeirantes }\end{array}$ & $\begin{array}{l}\text { As perguntas de } 69 \text { a } 113 \text { referem-se às } \\
\text { condições de acessibilidade. A escola } \\
\text { possui: mesas e cadeiras acessíveis } \\
\text { para pessoas em cadeiras de rodas? }\end{array}$ & $\begin{array}{c}\text { categórica } \\
\text { nominal }\end{array}$ & $<2.10^{-16}$ \\
\hline TX_RESP_Q112 & D112 & $\begin{array}{c}\text { Quadro negro que } \\
\text { permita o alcance de } \\
\text { cadeirantes }\end{array}$ & $\begin{array}{l}\text { As perguntas de } 69 \text { a } 113 \text { referem-se às } \\
\text { condições de acessibilidade. A escola } \\
\text { possui: quadro negro (ou branco) sem } \\
\text { degraus com altura que permita seu } \\
\text { alcance por pessoa em cadeira de rodas? }\end{array}$ & $\begin{array}{c}\text { categórica } \\
\text { nominal }\end{array}$ & $<2.10^{-16}$ \\
\hline TX_RESP_Q113 & D113 & $\begin{array}{l}\text { Bebedouros para } \\
\text { deficientes }\end{array}$ & $\begin{array}{l}\text { As perguntas de } 69 \text { a } 113 \text { referem-se às } \\
\text { condições de acessibilidade. A escola } \\
\text { possui: bebedouros que permitem a } \\
\text { aproximação frontal de pessoas em } \\
\text { cadeiras de rodas? }\end{array}$ & $\begin{array}{c}\text { categórica } \\
\text { nominal }\end{array}$ & $<2.10^{-16}$ \\
\hline TX_RESP_Q114 & D114 & Atividades esportivas & $\begin{array}{c}\text { Que atividades extracurriculares são } \\
\text { desenvolvidas regularmente com os } \\
\text { alunos nesta escola? Esportivas. }\end{array}$ & $\begin{array}{c}\text { categórica } \\
\text { nominal }\end{array}$ & $<2.10^{-16}$ \\
\hline TX_RESP_Q115 & D115 & Atividades artísticas & $\begin{array}{l}\text { Que atividades extracurriculares são } \\
\text { desenvolvidas regularmente com os } \\
\text { alunos nesta escola? Artísticas (música } \\
\text {, teatro, trabalhos artesanais). }\end{array}$ & $\begin{array}{c}\text { categórica } \\
\text { nominal }\end{array}$ & $<2.10^{-16}$ \\
\hline TX_RESP_Q116 & D116 & Atividades comunitárias & $\begin{array}{c}\text { Os espaços desta escola são utilizados } \\
\text { para atividades comunitárias? }\end{array}$ & $\begin{array}{c}\text { categórica } \\
\text { nominal }\end{array}$ & $<2.10^{-16}$ \\
\hline TX_RESP_Q117 & D117 & $\begin{array}{l}\text { Atividades comunitárias } \\
\text { com recursos da escola }\end{array}$ & $\begin{array}{c}\text { Neste ano, ocorreram nesta escola } \\
\text { eventos da comunidade usando } \\
\text { instalações, equipamentos ou recursos } \\
\text { da escola? }\end{array}$ & $\begin{array}{c}\text { categórica } \\
\text { nominal }\end{array}$ & $9,62.10^{-6}$ \\
\hline TX_RESP_Q118 & D118 & $\begin{array}{l}\text { Atividades comunitárias } \\
\text { realizados por terceiros }\end{array}$ & $\begin{array}{l}\text { Neste ano, ocorreram nesta escola } \\
\text { eventos de terceiros realizados na } \\
\text { escola e abertos para a comunidade } \\
\text { (shows, teatro, palestras)? }\end{array}$ & $\begin{array}{c}\text { categórica } \\
\text { nominal }\end{array}$ & $<2.10^{-16}$ \\
\hline TX_RESP_Q119 & D119 & $\begin{array}{l}\text { Eventos á comunidade } \\
\text { externa }\end{array}$ & $\begin{array}{l}\text { Neste ano, ocorreram nesta escola } \\
\text { eventos da escola e destinados à } \\
\text { comunidade externa (cursos, práticas } \\
\text { esportivas, palestras)? }\end{array}$ & $\begin{array}{c}\text { categórica } \\
\text { nominal }\end{array}$ & 0,078 \\
\hline TX_RESP_Q120 & D120 & $\begin{array}{c}\text { Campanhas de } \\
\text { solidariedade }\end{array}$ & $\begin{array}{c}\text { Neste ano, ocorreram nesta escola } \\
\text { campanhas de solidariedade promovidas } \\
\text { pela escola? }\end{array}$ & $\begin{array}{c}\text { categórica } \\
\text { nominal }\end{array}$ & $<2.10^{-16}$ \\
\hline TX_RESP_Q121 & D121 & $\begin{array}{l}\text { Campanhas de } \\
\text { solidariedade da } \\
\text { comunidade }\end{array}$ & $\begin{array}{l}\text { Neste ano, ocorreram nesta escola } \\
\text { campanhas de solidariedade propostas } \\
\text { pela comunidade, envolvendo a escola? }\end{array}$ & $\begin{array}{c}\text { categórica } \\
\text { nominal }\end{array}$ & $<2.10^{-16}$ \\
\hline TX_RESP_Q122 & D122 & Hortas, pomar, jardins & $\begin{array}{c}\text { Neste ano, ocorreram nesta escola } \\
\text { comunidade colaborando na manutenção } \\
\text { de hortas, pomar, jardins? }\end{array}$ & $\begin{array}{c}\text { categórica } \\
\text { nominal }\end{array}$ & $3,02.10^{-6}$ \\
\hline TX_RESP_Q123 & D123 & Mutirão de limpeza & $\begin{array}{c}\text { Neste ano, ocorreram nesta escola } \\
\text { comunidade participando em mutirão para } \\
\text { limpeza da escola? }\end{array}$ & $\begin{array}{c}\text { categórica } \\
\text { nominal }\end{array}$ & $<2.10^{-16}$ \\
\hline TX_RESP_Q124 & D124 & Mutirão de manutenção & $\begin{array}{c}\text { Neste ano, ocorreram nesta escola } \\
\text { comunidade participando em mutirão para } \\
\text { manutenção da estrutura física da } \\
\text { escola? }\end{array}$ & $\begin{array}{c}\text { categórica } \\
\text { nominal }\end{array}$ & $9,66.10^{-9}$ \\
\hline TX_RESP_Q125 & D125 & Financiamento Federal & $\begin{array}{l}\text { Esta escola recebe apoio financeiro de } \\
\text { programa de financiamento do governo } \\
\text { federal? }\end{array}$ & $\begin{array}{c}\text { categórica } \\
\text { nominal }\end{array}$ & $2,26.10^{-12}$ \\
\hline TX_RESP_Q126 & D126 & Financiamento estadual & $\begin{array}{c}\text { Esta escola recebe apoio financeiro de } \\
\text { programa de financiamento do governo } \\
\text { estadual? }\end{array}$ & $\begin{array}{c}\text { categórica } \\
\text { nominal }\end{array}$ & $<2.10^{-16}$ \\
\hline TX_RESP_Q127 & D127 & Financiamento municipal & $\begin{array}{c}\text { Esta escola recebe apoio financeiro de } \\
\text { programa de financiamento do governo } \\
\text { municipal? }\end{array}$ & $\begin{array}{c}\text { categórica } \\
\text { nominal }\end{array}$ & $<2.10^{-16}$ \\
\hline TX_RESP_Q128 & D128 & Livros didáticos & $\begin{array}{c}\text { Quem escolheu os livros didáticos } \\
\text { utilizados nesta escola? }\end{array}$ & $\begin{array}{c}\text { categórica } \\
\text { nominal }\end{array}$ & $<2.10^{-16}$ \\
\hline TX_RESP_Q129 & D129 & $\begin{array}{l}\text { Época que os livros } \\
\text { didáticos chegaram }\end{array}$ & $\begin{array}{c}\text { Neste ano, ocorreram as seguintes } \\
\text { situações: os livros chegaram a tempo } \\
\text { hábil para o início das aulas. }\end{array}$ & $\begin{array}{c}\text { categórica } \\
\text { nominal }\end{array}$ & $<2.10^{-16}$ \\
\hline TX_RESP_Q130 & D130 & $\begin{array}{l}\text { Faltaram livros } \\
\text { didáticos }\end{array}$ & $\begin{array}{c}\text { Neste ano, ocorreram as seguintes } \\
\text { situações: faltaram livros para os } \\
\text { alunos. }\end{array}$ & $\begin{array}{c}\text { categórica } \\
\text { nominal }\end{array}$ & $<2.10^{-16}$ \\
\hline TX_RESP_Q131 & D131 & $\begin{array}{c}\text { Sobraram livros } \\
\text { didáticos }\end{array}$ & $\begin{array}{c}\text { Neste ano, ocorreram as seguintes } \\
\text { situações: sobraram livros. }\end{array}$ & $\begin{array}{c}\text { categórica } \\
\text { nominal }\end{array}$ & $<2.10^{-16}$ \\
\hline TX_RESP_Q132 & D132 & $\begin{array}{l}\text { Recebimento dos livros } \\
\text { didáticos }\end{array}$ & $\begin{array}{c}\text { Neste ano, ocorreram as seguintes } \\
\text { situações: os livros escolhidos foram } \\
\text { os recebidos. }\end{array}$ & $\begin{array}{c}\text { categórica } \\
\text { nominal }\end{array}$ & $<2.10^{-16}$ \\
\hline
\end{tabular}




\begin{tabular}{|c|c|c|c|c|c|}
\hline $\begin{array}{l}\text { Código } \\
\text { original }\end{array}$ & $\begin{array}{c}\text { Código } \\
\text { na base } \\
\text { de dados }\end{array}$ & $\begin{array}{r}\text { Nome da } \\
\text { variável }\end{array}$ & Enunciado & $\begin{array}{l}\text { Tipo de } \\
\text { variável }\end{array}$ & valor $\mathbf{p}$ \\
\hline TX_RESP_Q133 & D133 & $\begin{array}{c}\text { Atentado á vida de } \\
\text { professores(estranho à } \\
\text { escola) }\end{array}$ & $\begin{array}{l}\text { Neste ano, aconteceram os seguintes } \\
\text { fatos nesta escola: atentado à vida de } \\
\text { professores ou funcionários dentro da } \\
\text { escola. Agente causador externo } \\
\text { (estranho à escola) }\end{array}$ & $\begin{array}{c}\text { categórica } \\
\text { nominal }\end{array}$ & $<2.10^{-16}$ \\
\hline TX_RESP_Q134 & D134 & $\begin{array}{c}\text { Atentado á vida de } \\
\text { alunos(estranho à } \\
\text { escola) }\end{array}$ & $\begin{array}{l}\text { Neste ano, aconteceram os seguintes } \\
\text { fatos nesta escola: atentado à vida de } \\
\text { alunos dentro da escola. agente } \\
\text { causador externo (estranho à escola) }\end{array}$ & $\begin{array}{c}\text { categórica } \\
\text { nominal }\end{array}$ & $<2.10^{-16}$ \\
\hline TX_RESP_Q135 & D135 & $\begin{array}{c}\text { Furto aos professores } \\
\text { ou funcionários } \\
\text { (estranho a escola) }\end{array}$ & $\begin{array}{l}\text { Neste ano, aconteceram os seguintes } \\
\text { fatos nesta escola: furto a professores } \\
\text { ou funcionários dentro da escola. } \\
\text { Agente causador externo (estranho à } \\
\text { escola) }\end{array}$ & $\begin{array}{c}\text { categórica } \\
\text { nominal }\end{array}$ & $<2.10^{-16}$ \\
\hline TX_RESP_Q136 & D136 & $\begin{array}{l}\text { Furto aos alunos } \\
\text { (estranho a escola) }\end{array}$ & $\begin{array}{l}\text { Neste ano, aconteceram os seguintes } \\
\text { fatos nesta escola: furto a alunos } \\
\text { dentro da escola. Agente causador } \\
\text { externo (estranho à escola) }\end{array}$ & $\begin{array}{c}\text { categórica } \\
\text { nominal }\end{array}$ & $<2.10^{-16}$ \\
\hline TX_RESP_Q137 & D137 & $\begin{array}{l}\text { Roubo(com uso de } \\
\text { violência)aos } \\
\text { professores }\end{array}$ & $\begin{array}{l}\text { Neste ano, aconteceram os seguintes } \\
\text { fatos nesta escola: roubo (com uso de } \\
\text { violência) a professores ou } \\
\text { funcionários dentro da escola. Agente } \\
\text { causador externo (estranho à escola) }\end{array}$ & $\begin{array}{c}\text { categórica } \\
\text { nominal }\end{array}$ & $<2.10^{-16}$ \\
\hline TX_RESP_Q138 & D138 & $\begin{array}{l}\text { Roubo(com uso de } \\
\text { violência)aos alunos }\end{array}$ & $\begin{array}{l}\text { Neste ano, aconteceram os seguintes } \\
\text { fatos nesta escola: roubo (com uso de } \\
\text { violência) a alunos dentro da escola. } \\
\text { Agente causador externo (estranho à } \\
\text { escola) }\end{array}$ & $\begin{array}{c}\text { categórica } \\
\text { nominal }\end{array}$ & $6,39 \cdot 10^{-8}$ \\
\hline TX_RESP_Q139 & D139 & Furtos de equipamentos & $\begin{array}{l}\text { Neste ano, aconteceram os seguintes } \\
\text { fatos nesta escola: furto de } \\
\text { equipamentos e materiais didáticos ou } \\
\text { pedagógicos da escola. Agente causador } \\
\text { externo (estranho à escola) }\end{array}$ & $\begin{array}{c}\text { categórica } \\
\text { nominal }\end{array}$ & $<2.10^{-16}$ \\
\hline TX_RESP_Q140 & D140 & Roubos de equipamentos & $\begin{array}{l}\text { Neste ano, aconteceram os seguintes } \\
\text { fatos nesta escola: roubo (com uso de } \\
\text { violência) de equipamentos e materiais } \\
\text { didáticos ou pedagógicos da escola. } \\
\text { Agente causador externo (estranho à } \\
\text { escola) }\end{array}$ & $\begin{array}{c}\text { categórica } \\
\text { nominal }\end{array}$ & $<2.10^{-16}$ \\
\hline TX_RESP_Q141 & D141 & $\begin{array}{l}\text { Quebra intencional } \\
\text { de equipamentos } \\
\text { (estranho à escola) }\end{array}$ & $\begin{array}{c}\text { Neste ano, aconteceram os seguintes } \\
\text { fatos nesta escola: quebra intencional } \\
\text { de equipamento. Agente causador externo } \\
\text { (estranho à escola) }\end{array}$ & $\begin{array}{c}\text { categórica } \\
\text { nominal }\end{array}$ & $<2.10^{-16}$ \\
\hline TX_RESP_Q142 & D142 & $\begin{array}{l}\text { Pichações externas } \\
\text { (estranho à escola) }\end{array}$ & $\begin{array}{l}\text { Neste ano, aconteceram os seguintes } \\
\text { fatos nesta escola: pichação de muros } \\
\text { ou paredes das dependências externas da } \\
\text { escola. Agente causador externo } \\
\text { (estranho à escola) }\end{array}$ & $\begin{array}{c}\text { categórica } \\
\text { nominal }\end{array}$ & $<2.10^{-16}$ \\
\hline TX_RESP_Q143 & D143 & $\begin{array}{l}\text { Depredações externas } \\
\text { (estranho à escola) }\end{array}$ & $\begin{array}{l}\text { Neste ano, aconteceram os seguintes } \\
\text { fatos nesta escola: depredação das } \\
\text { dependências externas da escola. Agente } \\
\text { causador externo (estranho à escola) }\end{array}$ & $\begin{array}{c}\text { categórica } \\
\text { nominal }\end{array}$ & $<2.10^{-16}$ \\
\hline TX_RESP_Q144 & D144 & $\begin{array}{c}\text { Sujeira nas } \\
\text { dependências externas } \\
\text { (estranho à escola) }\end{array}$ & $\begin{array}{l}\text { Neste ano, aconteceram os seguintes } \\
\text { fatos nesta escola: sujeira nas } \\
\text { dependências externas da escola. Agente } \\
\text { causador externo (estranho à escola) }\end{array}$ & $\begin{array}{c}\text { categórica } \\
\text { nominal }\end{array}$ & $<2.10^{-16}$ \\
\hline TX_RESP_Q145 & D145 & $\begin{array}{c}\text { Sujeira nas } \\
\text { dependências internas } \\
\text { (estranho à escola) }\end{array}$ & $\begin{array}{l}\text { Neste ano, aconteceram os seguintes } \\
\text { fatos nesta escola: sujeira nas } \\
\text { dependências internas da escola. Agente } \\
\text { causador externo (estranho à escola) }\end{array}$ & $\begin{array}{c}\text { categórica } \\
\text { nominal }\end{array}$ & $<2.10^{-16}$ \\
\hline TX_RESP_Q146 & D146 & $\begin{array}{c}\text { Pichações nas } \\
\text { dependências internas } \\
\text { (estranho à escola) }\end{array}$ & $\begin{array}{l}\text { Neste ano, aconteceram os seguintes } \\
\text { fatos nesta escola: pichação de muros } \\
\text { ou paredes das dependências internas da } \\
\text { escola. Agente causador externo } \\
\text { (estranho à escola) }\end{array}$ & $\begin{array}{c}\text { categórica } \\
\text { nominal }\end{array}$ & $<2.10^{-16}$ \\
\hline TX_RESP_Q147 & D147 & $\begin{array}{c}\text { Depredação nas } \\
\text { dependências internas } \\
\text { (estranho à escola) }\end{array}$ & $\begin{array}{l}\text { Neste ano, aconteceram os seguintes } \\
\text { fatos nesta escola: depredação das } \\
\text { dependências internas da escola. Agente } \\
\text { causador externo (estranho à escola) }\end{array}$ & $\begin{array}{c}\text { categórica } \\
\text { nominal }\end{array}$ & $<2.10^{-16}$ \\
\hline TX_RESP_Q148 & D148 & $\begin{array}{l}\text { Depredação de banheiros } \\
\text { (estranho à escola) }\end{array}$ & $\begin{array}{l}\text { Neste ano, aconteceram os seguintes } \\
\text { fatos nesta escola: depredação de } \\
\text { banheiros. Agente causador externo } \\
\text { (estranho à escola) }\end{array}$ & $\begin{array}{c}\text { categórica } \\
\text { nominal }\end{array}$ & $<2.10^{-16}$ \\
\hline
\end{tabular}




\begin{tabular}{|c|c|c|c|c|c|}
\hline $\begin{array}{l}\text { Código } \\
\text { original }\end{array}$ & $\begin{array}{c}\text { Código } \\
\text { na base } \\
\text { de dados }\end{array}$ & $\begin{array}{r}\text { Nome da } \\
\text { variável }\end{array}$ & Enunciado & $\begin{array}{l}\text { Tipo de } \\
\text { variável }\end{array}$ & valor $p$ \\
\hline TX_RESP_Q149 & D149 & $\begin{array}{l}\text { Bebidas alcoólicas } \\
\text { (estranho à escola) }\end{array}$ & $\begin{array}{l}\text { Neste ano, aconteceram os seguintes } \\
\text { fatos nesta escola: consumo de bebidas } \\
\text { alcoólicas nas dependências da escola. } \\
\text { Agente causador externo (estranho à } \\
\text { escola) }\end{array}$ & $\begin{array}{c}\text { categórica } \\
\text { nominal }\end{array}$ & $<2.10^{-16}$ \\
\hline TX_RESP_Q150 & D150 & $\begin{array}{c}\text { Consumo de drogas } \\
\text { (estranho à escola) }\end{array}$ & $\begin{array}{l}\text { Neste ano, aconteceram os seguintes } \\
\text { fatos nesta escola: consumo de drogas } \\
\text { nas dependências da escola. Agente } \\
\text { causador externo (estranho à escola) }\end{array}$ & $\begin{array}{c}\text { categórica } \\
\text { nominal }\end{array}$ & $<2.10^{-16}$ \\
\hline TX_RESP_Q151 & D151 & $\begin{array}{l}\text { Consumo de drogas nas } \\
\text { proximidades da escola } \\
\text { (estranho à escola) }\end{array}$ & $\begin{array}{l}\text { Neste ano, aconteceram os seguintes } \\
\text { fatos nesta escola: consumo de drogas } \\
\text { nas proximidades da escola. Agente } \\
\text { causador externo (estranho à escola) }\end{array}$ & $\begin{array}{c}\text { categórica } \\
\text { nominal }\end{array}$ & $<2.10^{-16}$ \\
\hline TX_RESP_Q152 & D152 & $\begin{array}{l}\text { Tráfico de drogas nas } \\
\text { dependências da escola } \\
\text { (estranho à escola) }\end{array}$ & $\begin{array}{l}\text { Neste ano, aconteceram os seguintes } \\
\text { fatos nesta escola: tráfico de drogas } \\
\text { nas dependências da escola. Agente } \\
\text { causador externo (estranho à escola) }\end{array}$ & $\begin{array}{c}\text { categórica } \\
\text { nominal }\end{array}$ & $<2.10^{-16}$ \\
\hline TX_RESP_Q153 & D153 & $\begin{array}{l}\text { Tráfico de drogas nas } \\
\text { proximidades da escola } \\
\text { (estranho à escola) }\end{array}$ & $\begin{array}{l}\text { Neste ano, aconteceram os seguintes } \\
\text { fatos nesta escola: tráfico de drogas } \\
\text { nas proximidades da escola. Agente } \\
\text { causador externo (estranho à escola) }\end{array}$ & $\begin{array}{c}\text { categórica } \\
\text { nominal }\end{array}$ & $<2.10^{-16}$ \\
\hline TX_RESP_Q154 & D154 & $\begin{array}{c}\text { Atentado à vida de } \\
\text { professores dentro da } \\
\text { escola(interno à escola) }\end{array}$ & $\begin{array}{l}\text { Neste ano, aconteceram os seguintes } \\
\text { fatos nesta escola: atentado à vida de } \\
\text { professores ou funcionários dentro da } \\
\text { escola. Agente causador interno (da } \\
\text { própria escola) }\end{array}$ & $\begin{array}{c}\text { categórica } \\
\text { nominal }\end{array}$ & $<2.10^{-16}$ \\
\hline TX_RESP_Q155 & D155 & $\begin{array}{l}\text { Atentado à vida de } \\
\text { alunos dentro da escola } \\
\text { (interno à escola) }\end{array}$ & $\begin{array}{l}\text { Neste ano, aconteceram os seguintes } \\
\text { fatos nesta escola: atentado à vida de } \\
\text { alunos dentro da escola. Agente } \\
\text { causador interno (da própria escola) }\end{array}$ & $\begin{array}{c}\text { categórica } \\
\text { nominal }\end{array}$ & $<2.10^{-16}$ \\
\hline TX_RESP_Q156 & D156 & $\begin{array}{l}\text { Furto aos professores } \\
\text { dentro da escola } \\
\text { (interno à escola) }\end{array}$ & $\begin{array}{l}\text { Neste ano, aconteceram os seguintes } \\
\text { fatos nesta escola: furto a professores } \\
\text { ou funcionários dentro da escola. } \\
\text { Agente causador interno (da própria } \\
\text { escola) }\end{array}$ & $\begin{array}{c}\text { categórica } \\
\text { nominal }\end{array}$ & $<2.10^{-16}$ \\
\hline TX_RESP_Q157 & D157 & $\begin{array}{l}\text { Furto aos alunos } \\
\text { dentro da escola } \\
\text { (interno à escola) }\end{array}$ & $\begin{array}{l}\text { Neste ano, aconteceram os seguintes } \\
\text { fatos nesta escola: furto a alunos } \\
\text { dentro da escola. Agente causador } \\
\text { interno (da própria escola) } \\
\end{array}$ & $\begin{array}{c}\text { categórica } \\
\text { nominal }\end{array}$ & $<2.10^{-16}$ \\
\hline TX_RESP_Q158 & D158 & $\begin{array}{l}\text { Roubo aos professores } \\
\quad \text { (interno à escola) }\end{array}$ & $\begin{array}{l}\text { Neste ano, aconteceram os seguintes } \\
\text { fatos nesta escola: roubo (com uso de } \\
\text { violência) a professores Agente } \\
\text { causador interno }\end{array}$ & $\begin{array}{c}\text { categórica } \\
\text { nominal }\end{array}$ & $<2.10^{-16}$ \\
\hline TX_RESP_Q159 & D159 & $\begin{array}{r}\text { Roubo aos alunos } \\
\text { (interno à escola) }\end{array}$ & $\begin{array}{l}\text { Neste ano, aconteceram os seguintes } \\
\text { fatos nesta escola: roubo (com uso de } \\
\text { violência) a alunos dentro da escola. } \\
\text { Agente causador interno (da própria } \\
\text { escola) }\end{array}$ & $\begin{array}{c}\text { categórica } \\
\text { nominal }\end{array}$ & $<2.10^{-16}$ \\
\hline TX_RESP_Q160 & D160 & $\begin{array}{l}\text { Furto de equipamentos } \\
\text { (interno à escola) }\end{array}$ & $\begin{array}{l}\text { Neste ano, aconteceram os seguintes } \\
\text { fatos nesta escola: furto de } \\
\text { equipamentos e materiais didáticos ou } \\
\text { pedagógicos da escola. Agente causador } \\
\text { interno (da própria escola) }\end{array}$ & $\begin{array}{c}\text { categórica } \\
\text { nominal }\end{array}$ & $<2.10^{-16}$ \\
\hline TX_RESP_Q161 & D161 & $\begin{array}{l}\text { Roubo de equipamentos } \\
\text { (interno à escola) }\end{array}$ & $\begin{array}{c}\text { Neste ano, aconteceram os seguintes } \\
\text { fatos nesta escola: roubo (com uso de } \\
\text { violência) de equipamentos e materiais } \\
\text { didáticos ou pedagógicos da escola. } \\
\text { Agente causador interno (da própria } \\
\text { escola) }\end{array}$ & $\begin{array}{c}\text { categórica } \\
\text { nominal }\end{array}$ & $<2.10^{-16}$ \\
\hline TX_RESP_Q162 & D162 & $\begin{array}{l}\text { Quebra intencional de } \\
\text { equipamentos } \\
\text { (interno à escola) }\end{array}$ & $\begin{array}{c}\text { Neste ano, aconteceram os seguintes } \\
\text { fatos nesta escola: quebra intencional } \\
\text { de equipamento. Agente causador interno } \\
\text { (da própria escola) }\end{array}$ & $\begin{array}{c}\text { categórica } \\
\text { nominal }\end{array}$ & $<2.10^{-16}$ \\
\hline TX_RESP_Q163 & D163 & $\begin{array}{l}\text { Pichação de muros } \\
\text { externos } \\
\text { (interno à escola) }\end{array}$ & $\begin{array}{l}\text { Neste ano, aconteceram os seguintes } \\
\text { fatos nesta escola: pichação de muros } \\
\text { ou paredes das dependências externas da } \\
\text { escola. Agente causador interno (da } \\
\text { própria escola) }\end{array}$ & $\begin{array}{c}\text { categórica } \\
\text { nominal }\end{array}$ & $<2.10^{-16}$ \\
\hline TX_RESP_Q164 & D164 & $\begin{array}{l}\text { Depredação de áreas } \\
\text { externos } \\
\text { (interno à escola) }\end{array}$ & $\begin{array}{l}\text { Neste ano, aconteceram os seguintes } \\
\text { fatos nesta escola: depredação das } \\
\text { dependências externas da escola. } \\
\text { Agente causador interno (da própria } \\
\text { escola) }\end{array}$ & $\begin{array}{c}\text { categórica } \\
\text { nominal }\end{array}$ & $<2.10^{-16}$ \\
\hline
\end{tabular}




\begin{tabular}{|c|c|c|c|c|c|}
\hline $\begin{array}{l}\text { Código } \\
\text { original }\end{array}$ & $\begin{array}{c}\text { Código } \\
\text { na base } \\
\text { de dados }\end{array}$ & $\begin{array}{r}\text { Nome da } \\
\text { variável }\end{array}$ & Enunciado & $\begin{array}{l}\text { Tipo de } \\
\text { variável }\end{array}$ & valor $\mathbf{p}$ \\
\hline TX_RESP_Q165 & D165 & $\begin{array}{l}\text { Sujeira nas áreas } \\
\text { externas } \\
\text { (interno à escola) }\end{array}$ & $\begin{array}{l}\text { Neste ano, aconteceram os seguintes } \\
\text { fatos nesta escola: sujeira nas } \\
\text { dependências externas da escola. Agente } \\
\text { causador interno (da própria escola) }\end{array}$ & $\begin{array}{c}\text { categórica } \\
\text { nominal }\end{array}$ & $<2.10^{-16}$ \\
\hline TX_RESP_Q166 & D166 & $\begin{array}{l}\text { Sujeira nas áreas } \\
\text { internas } \\
\text { (interno à escola) }\end{array}$ & $\begin{array}{l}\text { Neste ano, aconteceram os seguintes } \\
\text { fatos nesta escola: sujeira nas } \\
\text { dependências internas da escola. Agente } \\
\text { causador interno (da própria escola) }\end{array}$ & $\begin{array}{c}\text { categórica } \\
\text { nominal }\end{array}$ & $<2.10^{-16}$ \\
\hline TX_RESP_Q167 & D167 & $\begin{array}{l}\text { Pichação nas áreas } \\
\text { internas } \\
\text { (interno à escola) }\end{array}$ & $\begin{array}{c}\text { Neste ano, aconteceram os seguintes } \\
\text { fatos nesta escola: pichação de muros } \\
\text { ou paredes das dependências internas da } \\
\text { escola. Agente causador interno (da } \\
\text { própria escola) }\end{array}$ & $\begin{array}{c}\text { categórica } \\
\text { nominal }\end{array}$ & $<2.10^{-16}$ \\
\hline TX_RESP_Q168 & D168 & $\begin{array}{l}\text { Depredação nas } \\
\text { dependências internas } \\
\text { (interno à escola) }\end{array}$ & $\begin{array}{l}\text { Neste ano, aconteceram os seguintes } \\
\text { fatos nesta escola: depredação das } \\
\text { dependências internas da escola. Agente } \\
\text { causador interno (da própria escola) }\end{array}$ & $\begin{array}{c}\text { categórica } \\
\text { nominal }\end{array}$ & $<2.10^{-16}$ \\
\hline TX_RESP_Q169 & D169 & $\begin{array}{c}\text { Depredação de banheiros } \\
\text { nas dependências } \\
\text { internas (interno à } \\
\text { escola) }\end{array}$ & $\begin{array}{c}\text { Neste ano, aconteceram os seguintes } \\
\text { fatos nesta escola: depredação de } \\
\text { banheiros. Agente causador interno (da } \\
\text { própria escola) }\end{array}$ & $\begin{array}{c}\text { categórica } \\
\text { nominal }\end{array}$ & $<2.10^{-16}$ \\
\hline TX_RESP_Q170 & D170 & $\begin{array}{l}\text { Consumo de bebidas } \\
\text { alcoólicas nas } \\
\text { dependências internas } \\
\text { (interno à escola) }\end{array}$ & $\begin{array}{l}\text { Neste ano, aconteceram os seguintes } \\
\text { fatos nesta escola: consumo de bebidas } \\
\text { alcoólicas nas dependências da escola. } \\
\text { Agente causador interno (da própria } \\
\text { escola) }\end{array}$ & $\begin{array}{c}\text { categórica } \\
\text { nominal }\end{array}$ & $<2.10^{-16}$ \\
\hline TX_RESP_Q171 & D171 & $\begin{array}{l}\text { Consumo de drogas nas } \\
\text { dependências internas } \\
\text { (interno à escola) }\end{array}$ & $\begin{array}{l}\text { Neste ano, aconteceram os seguintes } \\
\text { fatos nesta escola: consumo de drogas } \\
\text { nas dependências da escola. Agente } \\
\text { causador interno (da própria escola) }\end{array}$ & $\begin{array}{c}\text { categórica } \\
\text { nominal }\end{array}$ & $<2.10^{-16}$ \\
\hline TX_RESP_Q172 & D172 & $\begin{array}{l}\text { Consumo de drogas nas } \\
\text { proximidades da escola } \\
\text { (interno à escola) }\end{array}$ & $\begin{array}{l}\text { Neste ano, aconteceram os seguintes } \\
\text { fatos nesta escola: consumo de drogas } \\
\text { nas proximidades da escola. Agente } \\
\text { causador interno (da própria escola) }\end{array}$ & $\begin{array}{c}\text { categórica } \\
\text { nominal }\end{array}$ & $<2.10^{-16}$ \\
\hline TX_RESP_Q173 & D173 & $\begin{array}{l}\text { Tráficos de drogas nas } \\
\text { dependências da escola } \\
\text { (interno à escola) }\end{array}$ & $\begin{array}{l}\text { Neste ano, aconteceram os seguintes } \\
\text { fatos nesta escola: tráfico de drogas } \\
\text { nas dependências da escola. Agente } \\
\text { causador interno (da própria escola) }\end{array}$ & $\begin{array}{c}\text { categórica } \\
\text { nominal }\end{array}$ & $<2.10^{-16}$ \\
\hline TX_RESP_Q174 & D174 & $\begin{array}{l}\text { Tráfico de drogas nas } \\
\text { proximidades da escola } \\
\text { (interno à escola) }\end{array}$ & $\begin{array}{l}\text { Neste ano, aconteceram os seguintes } \\
\text { fatos nesta escola: tráfico de drogas } \\
\text { nas proximidades da escola. Agente } \\
\text { causador interno (da própria escola) }\end{array}$ & $\begin{array}{c}\text { categórica } \\
\text { nominal }\end{array}$ & $<2.10^{-16}$ \\
\hline TX_RESP_Q175 & D175 & Porte de arma de fogo & $\begin{array}{c}\text { Neste ano, os seguintes eventos fizeram } \\
\text { ou não parte do cotidiano desta escola: } \\
\text { membros da comunidade escolar portando } \\
\text { arma de fogo. }\end{array}$ & $\begin{array}{c}\text { categórica } \\
\text { nominal }\end{array}$ & $<2.10^{-16}$ \\
\hline TX_RESP_Q176 & D176 & Porte de arma branca & $\begin{array}{l}\text { Neste ano, os seguintes eventos fizeram } \\
\text { ou não parte do cotidiano desta escola: } \\
\text { membros da comunidade escolar portando } \\
\text { arma branca (faca, canivete, estilete, } \\
\text { etc.). }\end{array}$ & $\begin{array}{c}\text { categórica } \\
\text { nominal }\end{array}$ & $<2.10^{-16}$ \\
\hline TX_RESP_Q177 & D177 & $\begin{array}{c}\text { Ação de gangues na área } \\
\text { externa a escola }\end{array}$ & $\begin{array}{c}\text { Neste ano, os seguintes eventos fizeram } \\
\text { ou não parte do cotidiano desta escola: } \\
\text { ação de gangues nas dependências } \\
\text { externas da escola. }\end{array}$ & $\begin{array}{c}\text { categórica } \\
\text { nominal }\end{array}$ & $<2.10^{-16}$ \\
\hline TX_RESP_Q178 & D178 & $\begin{array}{l}\text { Ação de gangues na área } \\
\text { interna a escola }\end{array}$ & $\begin{array}{l}\text { Neste ano, os seguintes eventos fizeram } \\
\text { ou não parte do cotidiano desta escola: } \\
\text { ação de gangues nas dependências } \\
\text { internas da escola. }\end{array}$ & $\begin{array}{c}\text { categórica } \\
\text { nominal }\end{array}$ & $<2.10^{-16}$ \\
\hline TX_RESP_Q179 & D179 & $\begin{array}{l}\text { Agressão verbal aos } \\
\text { professores por alunos }\end{array}$ & $\begin{array}{l}\text { Neste ano, houve agressão verbal a } \\
\text { professores. Quem foi o agressor? Aluno }\end{array}$ & $\begin{array}{c}\text { categórica } \\
\text { nominal }\end{array}$ & $<2.10^{-16}$ \\
\hline TX_RESP_Q180 & D180 & $\begin{array}{l}\text { Agressão física aos } \\
\text { professores por alunos }\end{array}$ & $\begin{array}{l}\text { Neste ano, houve agressão física a } \\
\text { professores. Quem foi o agressor? Aluno }\end{array}$ & $\begin{array}{c}\text { categórica } \\
\text { nominal }\end{array}$ & $<2.10^{-16}$ \\
\hline TX_RESP_Q181 & D181 & $\begin{array}{l}\text { Agressão verbal aos } \\
\text { alunos por alunos }\end{array}$ & $\begin{array}{l}\text { Neste ano, houve agressão verbal a } \\
\text { alunos. Quem foi o agressor? Aluno }\end{array}$ & $\begin{array}{c}\text { categórica } \\
\text { nominal }\end{array}$ & $<2.10^{-16}$ \\
\hline TX_RESP_Q182 & D182 & $\begin{array}{c}\text { Agressão física aos } \\
\text { alunos por alunos }\end{array}$ & $\begin{array}{l}\text { Neste ano, houve agressão física a } \\
\text { alunos. Quem foi o agressor? Aluno }\end{array}$ & $\begin{array}{c}\text { categórica } \\
\text { nominal }\end{array}$ & $<2.10^{-16}$ \\
\hline TX_RESP_Q183 & D183 & $\begin{array}{l}\text { Agressão verbal aos } \\
\text { funcionários por alunos }\end{array}$ & $\begin{array}{l}\text { Neste ano, houve agressão verbal a } \\
\text { funcionários. Quem foi o agressor? } \\
\text { Aluno }\end{array}$ & $\begin{array}{c}\text { categórica } \\
\text { nominal }\end{array}$ & $<2.10^{-16}$ \\
\hline TX_RESP_Q184 & D184 & $\begin{array}{l}\text { Agressão física aos } \\
\text { funcionários por alunos }\end{array}$ & $\begin{array}{c}\text { Neste ano, houve agressão física a } \\
\text { funcionários. Quem foi o agressor? } \\
\text { Aluno }\end{array}$ & $\begin{array}{c}\text { categórica } \\
\text { nominal }\end{array}$ & $<2.10^{-16}$ \\
\hline
\end{tabular}




\begin{tabular}{|c|c|c|c|c|c|}
\hline $\begin{array}{l}\text { Código } \\
\text { original }\end{array}$ & $\begin{array}{l}\text { Código } \\
\text { na base } \\
\text { de dados }\end{array}$ & $\begin{array}{r}\text { Nome da } \\
\text { variável }\end{array}$ & Enunciado & $\begin{array}{l}\text { Tipo de } \\
\text { variável }\end{array}$ & valor $p$ \\
\hline TX_RESP_Q185 & D185 & $\begin{array}{l}\text { Agressão verbal aos } \\
\text { professores por } \\
\text { professores }\end{array}$ & $\begin{array}{l}\text { Neste ano, houve agressão verbal a } \\
\text { professores. Quem foi o agressor? } \\
\text { Professor }\end{array}$ & $\begin{array}{c}\text { categórica } \\
\text { nominal }\end{array}$ & $<2.10^{-16}$ \\
\hline TX_RESP_Q186 & D186 & $\begin{array}{l}\text { Agressão física aos } \\
\text { professores por } \\
\text { professores }\end{array}$ & $\begin{array}{l}\text { Neste ano, houve agressão física a } \\
\text { professores. Quem foi o agressor? } \\
\text { Professor }\end{array}$ & $\begin{array}{c}\text { categórica } \\
\text { nominal }\end{array}$ & $<2.10^{-16}$ \\
\hline TX_RESP_Q187 & D187 & $\begin{array}{l}\text { Agressão verbal aos } \\
\text { alunos por professores }\end{array}$ & $\begin{array}{l}\text { Neste ano, houve agressão verbal a } \\
\text { alunos. Quem foi o agressor? Professor }\end{array}$ & $\begin{array}{c}\text { categórica } \\
\text { nominal }\end{array}$ & $<2.10^{-16}$ \\
\hline TX_RESP_Q188 & D188 & $\begin{array}{l}\text { Agressão física aos } \\
\text { alunos por professores }\end{array}$ & $\begin{array}{l}\text { Neste ano, houve agressão física a } \\
\text { alunos. Quem foi o agressor? Professor }\end{array}$ & $\begin{array}{c}\text { categórica } \\
\text { nominal }\end{array}$ & $<2.10^{-16}$ \\
\hline TX_RESP_Q189 & D189 & $\begin{array}{l}\text { Agressão verbal aos } \\
\text { funcionários por } \\
\text { professores }\end{array}$ & $\begin{array}{l}\text { Neste ano, houve agressão verbal a } \\
\text { funcionários. Quem foi o agressor? } \\
\text { Professor }\end{array}$ & $\begin{array}{c}\text { categórica } \\
\text { nominal }\end{array}$ & $<2.10^{-16}$ \\
\hline TX_RESP_Q190 & D190 & $\begin{array}{l}\text { Agressão física aos } \\
\text { funcionários por } \\
\text { professores }\end{array}$ & $\begin{array}{l}\text { Neste ano, houve agressão física a } \\
\text { funcionários. Quem foi o agressor? } \\
\text { Professor }\end{array}$ & $\begin{array}{c}\text { categórica } \\
\text { nominal }\end{array}$ & $<2.10^{-16}$ \\
\hline TX_RESP_Q191 & D191 & $\begin{array}{l}\text { Agressão verbal aos } \\
\text { professores por } \\
\text { funcionários }\end{array}$ & $\begin{array}{c}\text { Neste ano, houve agressão verbal a } \\
\text { professores. Quem foi o agressor? } \\
\text { Funcionário }\end{array}$ & $\begin{array}{c}\text { categórica } \\
\text { nominal }\end{array}$ & $<2.10^{-16}$ \\
\hline TX_RESP_Q192 & D192 & $\begin{array}{l}\text { Agressão física aos } \\
\text { professores por } \\
\text { funcionários }\end{array}$ & $\begin{array}{c}\text { Neste ano, houve agressão física a } \\
\text { professores. Quem foi o agressor? } \\
\text { Funcionário }\end{array}$ & $\begin{array}{c}\text { categórica } \\
\text { nominal }\end{array}$ & $6,02 \cdot 10^{-14}$ \\
\hline TX_RESP_Q193 & D193 & $\begin{array}{l}\text { Agressão verbal aos } \\
\text { alunos por funcionários }\end{array}$ & $\begin{array}{l}\text { Neste ano, houve agressão verbal a } \\
\text { alunos. Quem foi o agressor? Funcionário }\end{array}$ & $\begin{array}{c}\text { categórica } \\
\text { nominal }\end{array}$ & $<2.10^{-16}$ \\
\hline TX_RESP_Q194 & D194 & $\begin{array}{l}\text { Agressão física aos } \\
\text { alunos por funcionários }\end{array}$ & $\begin{array}{l}\text { Neste ano, houve agressão física a } \\
\text { alunos. Quem foi o agressor? Funcionário }\end{array}$ & $\begin{array}{c}\text { categórica } \\
\text { nominal }\end{array}$ & $<2.10^{-16}$ \\
\hline TX_RESP_Q195 & D195 & $\begin{array}{l}\text { Agressão verbal aos } \\
\text { funcionários por } \\
\text { funcionários }\end{array}$ & $\begin{array}{l}\text { Neste ano, houve agressão verbal a } \\
\text { funcionários. Quem foi o agressor? } \\
\text { Funcionário }\end{array}$ & $\begin{array}{c}\text { categórica } \\
\text { nominal }\end{array}$ & $<2.10^{-16}$ \\
\hline TX_RESP_Q196 & D196 & $\begin{array}{l}\text { Agressão física aos } \\
\text { funcionários por } \\
\text { funcionários }\end{array}$ & $\begin{array}{c}\text { Neste ano, houve agressão física a } \\
\text { funcionários. Quem foi o agressor? } \\
\text { Funcionário }\end{array}$ & $\begin{array}{c}\text { categórica } \\
\text { nominal }\end{array}$ & $7,53 \cdot 10^{-16}$ \\
\hline TX_RESP_Q197 & D197 & Projetos sobre violência & $\begin{array}{l}\text { Nesta escola há projetos nas seguintes } \\
\text { temáticas violência. }\end{array}$ & $\begin{array}{c}\text { categórica } \\
\text { nominal }\end{array}$ & $6,01.10^{-16}$ \\
\hline TX_RESP_Q198 & D198 & Projetos sobre drogas & $\begin{array}{l}\text { Nesta escola há projetos nas seguintes } \\
\text { temáticas uso abusivo de drogas. }\end{array}$ & $\begin{array}{c}\text { categórica } \\
\text { nominal }\end{array}$ & $<2.10^{-16}$ \\
\hline TX_RESP_Q199 & D199 & Projetos sobre racismo & $\begin{array}{c}\text { Nesta escola há projetos nas seguintes } \\
\text { temáticas racismo. }\end{array}$ & $\begin{array}{c}\text { categórica } \\
\text { nominal }\end{array}$ & $<2.10^{-16}$ \\
\hline TX_RESP_Q200 & D200 & Projetos sobre machismo & $\begin{array}{l}\text { Nesta escola há projetos nas seguintes } \\
\text { temáticas machismo e homofobia. }\end{array}$ & $\begin{array}{c}\text { categórica } \\
\text { nominal }\end{array}$ & $<2.10^{-16}$ \\
\hline TX_RESP_Q201 & D201 & Projetos sobre bullying & $\begin{array}{l}\text { Nesta escola há projetos nas seguintes } \\
\text { temáticas bullying. }\end{array}$ & $\begin{array}{c}\text { categórica } \\
\text { nominal }\end{array}$ & $<2.10^{-16}$ \\
\hline TX_RESP_Q202 & D202 & $\begin{array}{l}\text { Projetos sobre } \\
\text { sexualidade }\end{array}$ & $\begin{array}{c}\text { Nesta escola há projetos nas seguintes } \\
\text { temáticas sexualidade e gravidez na } \\
\text { adolescência. }\end{array}$ & $\begin{array}{c}\text { categórica } \\
\text { nominal }\end{array}$ & $<2.10^{-16}$ \\
\hline TX_RESP_Q203 & D203 & $\begin{array}{c}\text { Projetos sobre } \\
\text { desigualdades sociais }\end{array}$ & $\begin{array}{l}\text { Nesta escola há projetos nas seguintes } \\
\text { temáticas desigualdades sociais. }\end{array}$ & $\begin{array}{c}\text { categórica } \\
\text { nominal }\end{array}$ & $<2.10^{-16}$ \\
\hline TX_RESP_Q204 & D204 & $\begin{array}{l}\text { Projetos sobre } \\
\text { conflitos religiosos }\end{array}$ & $\begin{array}{l}\text { Nesta escola há projetos nas seguintes } \\
\text { temáticas conflitos religiosos. }\end{array}$ & $\begin{array}{c}\text { categórica } \\
\text { nominal }\end{array}$ & $<2.10^{-16}$ \\
\hline TX_RESP_Q205 & D205 & $\begin{array}{l}\text { Projetos sobre } \\
\text { meio ambiente }\end{array}$ & $\begin{array}{l}\text { Nesta escola há projetos nas seguintes } \\
\text { temáticas meio ambiente. }\end{array}$ & $\begin{array}{c}\text { categórica } \\
\text { nominal }\end{array}$ & $<2.10^{-16}$ \\
\hline TX_RESP_Q206 & D206 & $\begin{array}{l}\text { Músicas religiosas ou } \\
\text { orações }\end{array}$ & $\begin{array}{l}\text { Nesta escola há costume de se fazer } \\
\text { oração ou cantar músicas religiosas (na } \\
\text { entrada, antes do lanche, etc). }\end{array}$ & $\begin{array}{c}\text { categórica } \\
\text { nominal }\end{array}$ & $<2.10^{-16}$ \\
\hline TX_RESP_Q207 & D207 & Símbolos religioso & $\begin{array}{l}\text { Nesta escola há objetos, imagens, frases } \\
\text { ou símbolos de teor religioso. }\end{array}$ & $\begin{array}{c}\text { categórica } \\
\text { nominal }\end{array}$ & $<2.10^{-16}$ \\
\hline TX_RESP_Q208 & D208 & Ensino religioso & Nesta escola há aula de ensino religioso. & $\begin{array}{c}\text { categórica } \\
\text { nominal }\end{array}$ & $<2.10^{-16}$ \\
\hline TX_RESP_Q209 & D209 & $\begin{array}{l}\text { Alternativas ao ensino } \\
\text { religioso }\end{array}$ & $\begin{array}{l}\text { Nesta escola há atividades alternativas } \\
\text { para os estudantes que não queiram } \\
\text { participar das aulas de ensino religioso. }\end{array}$ & $\begin{array}{c}\text { categórica } \\
\text { nominal }\end{array}$ & $<2.10^{-16}$ \\
\hline TX_RESP_Q210 & D210 & $\begin{array}{l}\text { Obrigatoriedade do } \\
\text { ensino religioso }\end{array}$ & $\begin{array}{l}\text { Nesta escola, o ensino religioso (se não } \\
\text { houver ensino religioso deixe as } \\
\text { próximas questões em branco): é de } \\
\text { presença obrigatória. }\end{array}$ & $\begin{array}{c}\text { categórica } \\
\text { nominal }\end{array}$ & 0,0079 \\
\hline TX_RESP_Q211 & D211 & $\begin{array}{l}\text { Caráter do ensino } \\
\text { religioso }\end{array}$ & $\begin{array}{l}\text { Nesta escola, o ensino religioso (se não } \\
\text { houver ensino religioso deixe as } \\
\text { próximas questões em branco): é de } \\
\text { caráter confessional (segundo uma } \\
\text { religião específica). }\end{array}$ & $\begin{array}{c}\text { categórica } \\
\text { nominal }\end{array}$ & $1,32 \cdot 10^{-7}$ \\
\hline
\end{tabular}




\begin{tabular}{|c|c|c|c|c|c|}
\hline $\begin{array}{l}\text { Código } \\
\text { original }\end{array}$ & $\begin{array}{l}\text { Código } \\
\text { na base } \\
\text { de dados }\end{array}$ & $\begin{array}{r}\text { Nome da } \\
\text { variável }\end{array}$ & Enunciado & $\begin{array}{l}\text { Tipo de } \\
\text { variável }\end{array}$ & valor $\mathbf{p}$ \\
\hline TX_RESP_Q212 & D212 & $\begin{array}{l}\text { Diversidade do ensino } \\
\text { religioso }\end{array}$ & $\begin{array}{l}\text { Nesta escola, o ensino religioso (se não } \\
\text { houver ensino religioso deixe as } \\
\text { próximas questões em branco): contempla } \\
\text { a diversidade religiosa. }\end{array}$ & $\begin{array}{c}\text { categórica } \\
\text { nominal }\end{array}$ & $3,82.10^{-8}$ \\
\hline TX_RESP_Q001 & P001 & Sexo do professor & Sexo & $\begin{array}{c}\text { categórica } \\
\text { nominal }\end{array}$ & $<2.10^{-16}$ \\
\hline TX_RESP_Q002 & P002 & Idade do professor & Idade & $\begin{array}{c}\text { categórica } \\
\text { nominal }\end{array}$ & $<2.10^{-16}$ \\
\hline TX_RESP_Q003 & P003 & Raça do professor & Como você se considera? & $\begin{array}{c}\text { categórica } \\
\text { nominal }\end{array}$ & $<2.10^{-16}$ \\
\hline TX_RESP_Q004 & P004 & $\begin{array}{l}\text { Escolaridade do } \\
\text { professor }\end{array}$ & $\begin{array}{c}\text { Qual o seu nível de escolaridade (Até a } \\
\text { Graduação). Caso Marque A, B ou C, passe } \\
\text { para questão } 11\end{array}$ & $\begin{array}{c}\text { categórica } \\
\text { nominal }\end{array}$ & $<2.10^{-16}$ \\
\hline TX_RESP_Q005 & P005 & $\begin{array}{c}\text { Tempo de escolaridade } \\
\text { do professor }\end{array}$ & $\begin{array}{l}\text { Há Quantos anos você obteve o nível de } \\
\text { escolaridade assinalado anteriormente? }\end{array}$ & $\begin{array}{c}\text { categórica } \\
\text { nominal }\end{array}$ & $<2.10^{-16}$ \\
\hline TX_RESP_Q006 & P006 & $\begin{array}{l}\text { Tipo de instituição } \\
\text { onde o professor obteve } \\
\text { seu título profissional }\end{array}$ & $\begin{array}{l}\text { Em que tipo de instituição você fez o } \\
\text { curso superior? Se você estudou em mais } \\
\text { de uma instituição, assinale aquela em } \\
\text { que obteve o seu título profissional. }\end{array}$ & $\begin{array}{c}\text { categórica } \\
\text { nominal }\end{array}$ & $<2.10^{-16}$ \\
\hline TX_RESP_Q007 & P007 & $\begin{array}{l}\text { Natureza da instituição } \\
\text { onde o professor obteve } \\
\text { seu título profissional }\end{array}$ & Qual era a natureza dessa instituição? & $\begin{array}{c}\text { categórica } \\
\text { nominal }\end{array}$ & $<2.10^{-16}$ \\
\hline TX_RESP_Q008 & P008 & $\begin{array}{c}\text { Forma de realização do } \\
\text { curso superior pelo } \\
\text { professor }\end{array}$ & $\begin{array}{c}\text { De que forma você realizou o curso } \\
\text { superior? }\end{array}$ & $\begin{array}{c}\text { categórica } \\
\text { nominal }\end{array}$ & $<2.10^{-16}$ \\
\hline TX_RESP_Q009 & P009 & $\begin{array}{l}\text { Modalidade da pós - } \\
\text { graduação do professor }\end{array}$ & $\begin{array}{c}\text { Indique a modalidade de cursos de } \\
\text { pós-graduação de mais alta titulação que } \\
\text { você possui. }\end{array}$ & $\begin{array}{c}\text { categórica } \\
\text { nominal }\end{array}$ & $<2.10^{-16}$ \\
\hline TX_RESP_Q010 & P010 & $\begin{array}{l}\text { Temática da pós - } \\
\text { graduação do professor }\end{array}$ & $\begin{array}{c}\text { Indique qual a área temática do curso de } \\
\text { pós-graduação de mais alta titulação que } \\
\text { você possui. }\end{array}$ & $\begin{array}{c}\text { categórica } \\
\text { nominal }\end{array}$ & $<2.10^{-16}$ \\
\hline TX_RESP_Q011 & P011 & $\begin{array}{l}\text { Formação continuada do } \\
\text { professor }\end{array}$ & $\begin{array}{l}\text { Você participou de alguma atividade de } \\
\text { formação continuada (atualização, } \\
\text { treinamento, capacitação nos últimos } \\
\text { dois anos?etc.) }\end{array}$ & $\begin{array}{c}\text { categórica } \\
\text { nominal }\end{array}$ & $<2.10^{-16}$ \\
\hline TX_RESP_Q012 & P012 & $\begin{array}{l}\text { Carga horária da } \\
\text { atividade mais } \\
\text { relevante do professor }\end{array}$ & $\begin{array}{l}\text { Qual a carga horária da atividade mais } \\
\text { relevante da qual você participou? }\end{array}$ & $\begin{array}{c}\text { categórica } \\
\text { nominal }\end{array}$ & $<2.10^{-16}$ \\
\hline TX_RESP_Q013 & P013 & $\begin{array}{l}\text { Aplicação da formação } \\
\text { continuada pelo } \\
\text { professor }\end{array}$ & $\begin{array}{l}\text { Você utiliza os conhecimentos adquiridos } \\
\text { nas atividades de formação continuada } \\
\text { para a melhoria de sua prática em sala } \\
\text { de aula? }\end{array}$ & $\begin{array}{c}\text { categórica } \\
\text { nominal }\end{array}$ & $<2.10^{-16}$ \\
\hline TX_RESP_Q014 & P014 & $\begin{array}{l}\text { Salário bruto do } \\
\text { professor na escola }\end{array}$ & $\begin{array}{l}\text { Nesta escola, qual, aproximadamente, o } \\
\text { seu salário bruto? (com adicionais, se } \\
\text { houver) (preencha os espaços com o valor } \\
\text { e marque, na folha de respostas, os } \\
\text { campos correspondentes a cada algarismo.) }\end{array}$ & $\begin{array}{c}\text { categórica } \\
\text { nominal }\end{array}$ & $<2.10^{-16}$ \\
\hline TX_RESP_Q015 & $\mathrm{P} 015$ & $\begin{array}{l}\text { Atividade de renda } \\
\text { complementar do } \\
\text { professor }\end{array}$ & $\begin{array}{l}\text { Além da atividade como docente nesta } \\
\text { escola, você exerce outra atividade que } \\
\text { contribui para sua renda pessoal? }\end{array}$ & $\begin{array}{c}\text { categórica } \\
\text { nominal }\end{array}$ & $<2.10^{-16}$ \\
\hline TX_RESP_Q016 & P016 & $\begin{array}{l}\text { Salário bruto do } \\
\text { professor }\end{array}$ & $\begin{array}{l}\text { Qual é, aproximadamente, seu salário } \\
\text { bruto (com adicionais, se houver) como } \\
\text { professor(a)? (soma de tudo o que você } \\
\text { ganha como professor(a)) (preencha os } \\
\text { espaços com o valor e marque, na folha } \\
\text { de respostas, os campos correspondentes } \\
\text { a cada algarismo.) }\end{array}$ & $\begin{array}{c}\text { categórica } \\
\text { nominal }\end{array}$ & $<2.10^{-16}$ \\
\hline TX_RESP_Q017 & P017 & $\begin{array}{l}\text { Tempo de trabalho na } \\
\text { educação do professor }\end{array}$ & Há quantos anos você leciona? & $\begin{array}{c}\text { categórica } \\
\text { nominal }\end{array}$ & $<2.10^{-16}$ \\
\hline TX_RESP_Q018 & P018 & $\begin{array}{c}\text { Tempo como professor } \\
\text { desta escola }\end{array}$ & $\begin{array}{l}\text { Há quantos anos você trabalha nesta } \\
\text { escola? }\end{array}$ & $\begin{array}{c}\text { categórica } \\
\text { nominal }\end{array}$ & $<2.10^{-16}$ \\
\hline TX_RESP_Q019 & P019 & $\begin{array}{c}\text { Tempo como professor } \\
\text { desta série }\end{array}$ & $\begin{array}{l}\text { Há quantos anos você ministra aulas para } \\
\text { alunos das série desta turma? }\end{array}$ & $\begin{array}{c}\text { categórica } \\
\text { nominal }\end{array}$ & $<2.10^{-16}$ \\
\hline TX_RESP_Q020 & P020 & $\begin{array}{c}\text { Carga horária semanal } \\
\text { do professor nesta } \\
\text { escola }\end{array}$ & $\begin{array}{c}\text { Nesta escola, qual a sua carga horária } \\
\text { semanal? (considere a carga horária } \\
\text { contratual: horas-aula mais horas para } \\
\text { atividades, se houver.) }\end{array}$ & $\begin{array}{c}\text { categórica } \\
\text { nominal }\end{array}$ & $<2.10^{-16}$ \\
\hline TX_RESP_Q021 & $\mathrm{P} 021$ & $\begin{array}{l}\text { Número de escolas que o } \\
\text { professor trabalha }\end{array}$ & $\begin{array}{c}\text { Em quantas escolas você trabalha? (caso } \\
\text { marque a alternativa a, passe para a } \\
\text { questão 23) }\end{array}$ & $\begin{array}{c}\text { categórica } \\
\text { nominal }\end{array}$ & $4,48 \cdot 10^{-16}$ \\
\hline TX_RESP_Q022 & P022 & $\begin{array}{l}\text { Horas - aulas semanais } \\
\text { pelo professor }\end{array}$ & $\begin{array}{c}\text { Ao todo, quantas horas-aula você } \\
\text { ministra por semana? (não considere } \\
\text { aulas particulares) }\end{array}$ & $\begin{array}{c}\text { categórica } \\
\text { nominal }\end{array}$ & $<2.10^{-16}$ \\
\hline
\end{tabular}




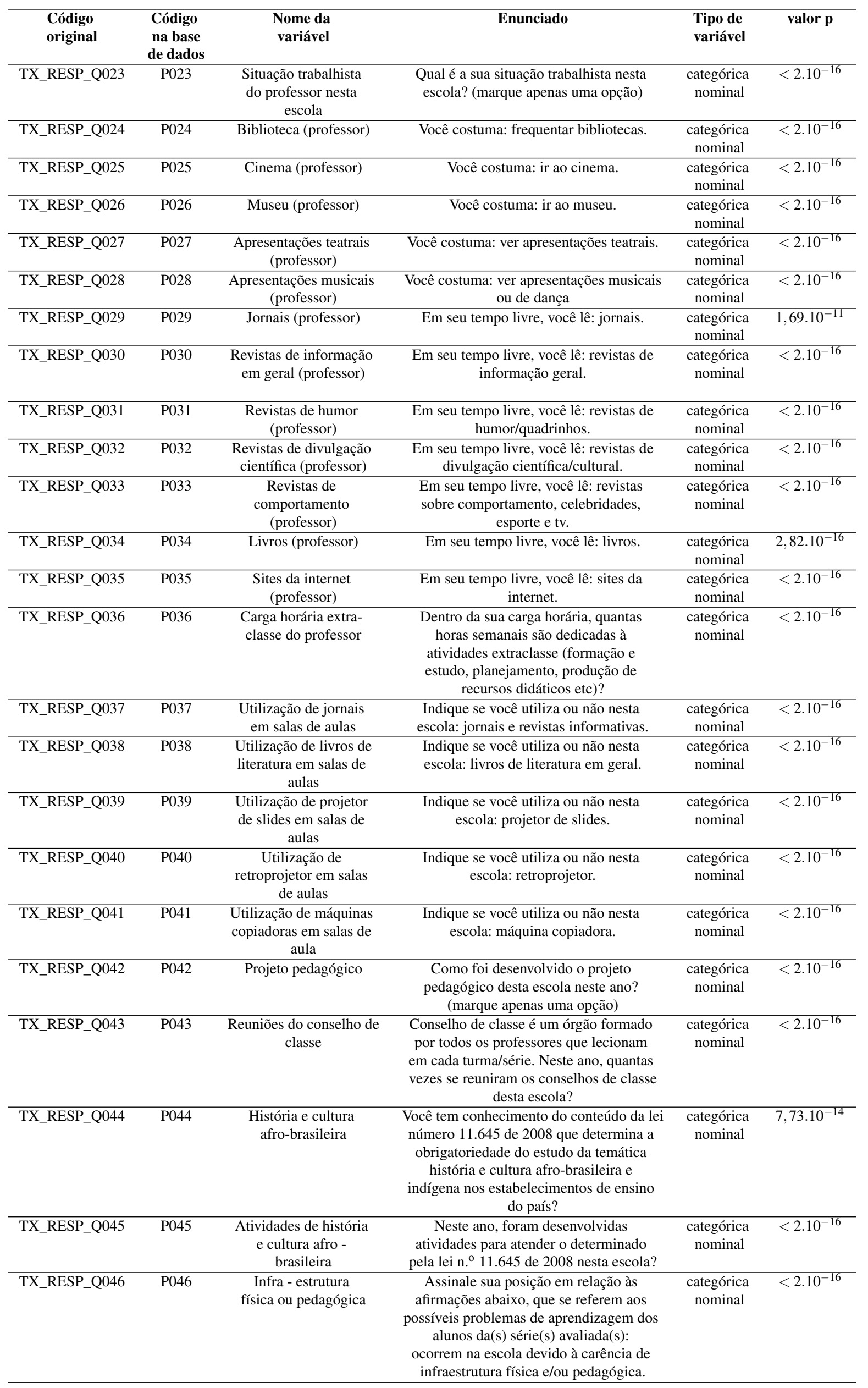




\begin{tabular}{|c|c|c|c|c|c|}
\hline $\begin{array}{l}\text { Código } \\
\text { original }\end{array}$ & $\begin{array}{c}\text { Código } \\
\text { na base } \\
\text { de dados }\end{array}$ & $\begin{array}{r}\text { Nome da } \\
\text { variável }\end{array}$ & Enunciado & $\begin{array}{l}\text { Tipo de } \\
\text { variável }\end{array}$ & valor $\mathbf{p}$ \\
\hline TX_RESP_Q047 & P047 & $\begin{array}{c}\text { Insegurança física da } \\
\text { escola }\end{array}$ & $\begin{array}{c}\text { Assinale sua posição em relação às } \\
\text { afirmações abaixo, que se referem aos } \\
\text { possíveis problemas de aprendizagem dos } \\
\text { alunos da(s) série(s) avaliada(s): são } \\
\text { decorrentes do ambiente de insegurança } \\
\text { física da escola. }\end{array}$ & $\begin{array}{c}\text { categórica } \\
\text { nominal }\end{array}$ & $<2.10^{-16}$ \\
\hline TX_RESP_Q048 & P048 & $\begin{array}{l}\text { Desenvolvimento das } \\
\text { capacidades intelectuais }\end{array}$ & $\begin{array}{c}\text { Assinale sua posição em relação às } \\
\text { afirmações abaixo, que se referem aos } \\
\text { possíveis problemas de aprendizagem dos } \\
\text { alunos da(s) série(s) avaliada(s): } \\
\text { ocorrem na escola por oferecer poucas } \\
\text { oportunidades de desenvolvimento das } \\
\text { capacidades intelectuais do aluno. }\end{array}$ & $\begin{array}{c}\text { categórica } \\
\text { nominal }\end{array}$ & $<2.10^{-16}$ \\
\hline TX_RESP_Q049 & P049 & $\begin{array}{l}\text { Dificuldades dos alunos } \\
\text { relacionada aos } \\
\text { conteúdos curriculares }\end{array}$ & $\begin{array}{c}\text { Assinale sua posição em relação às } \\
\text { afirmações abaixo, que se referem aos } \\
\text { possíveis problemas de aprendizagem dos } \\
\text { avaliada(s): estão relacionados aos } \\
\text { conteúdos curriculares, que são } \\
\text { inadequados às necessidades dos alunos. }\end{array}$ & $\begin{array}{c}\text { categórica } \\
\text { nominal }\end{array}$ & $<2.10^{-16}$ \\
\hline TX_RESP_Q050 & P050 & $\begin{array}{l}\text { Dificuldades dos alunos } \\
\text { relacionada ao não } \\
\text { cumprimento do conteúdo } \\
\text { curricular. }\end{array}$ & $\begin{array}{l}\text { Assinale sua posição em relação às } \\
\text { afirmações abaixo, que se referem aos } \\
\text { possíveis problemas de aprendizagem dos } \\
\text { alunos da(s) série(s) avaliada(s): estão } \\
\text { relacionados ao não cumprimento do } \\
\text { conteúdo curricular. }\end{array}$ & $\begin{array}{c}\text { categórica } \\
\text { nominal }\end{array}$ & $3,36.10^{-14}$ \\
\hline TX_RESP_Q051 & P051 & $\begin{array}{l}\text { Dificuldades dos alunos } \\
\text { relacionada à } \\
\text { sobrecarga de trabalho } \\
\text { dos professores. }\end{array}$ & $\begin{array}{l}\text { Assinale sua posição em relação às } \\
\text { afirmações abaixo, que se referem aos } \\
\text { possíveis problemas de aprendizagem dos } \\
\text { alunos da(s) série(s) avaliada(s): } \\
\text { relacionam-se à sobrecarga de trabalho } \\
\text { do(as) professores(as), dificultando o } \\
\text { planejamento e o preparo das aulas. }\end{array}$ & $\begin{array}{c}\text { categórica } \\
\text { nominal }\end{array}$ & $5,68 \cdot 10^{-14}$ \\
\hline TX_RESP_Q052 & P052 & $\begin{array}{l}\text { Dificuldades dos alunos } \\
\text { relacionada ao baixo } \\
\text { salário dos professores }\end{array}$ & $\begin{array}{c}\text { Assinale sua posição em relação às } \\
\text { afirmações abaixo, que se referem aos } \\
\text { possíveis problemas de aprendizagem dos } \\
\text { alunos da(s) série(s) avaliada(s): } \\
\text { ocorrem devido ao baixo salário dos } \\
\text { insatisfação e desestímulo para a } \\
\text { atividade docente. }\end{array}$ & $\begin{array}{c}\text { categórica } \\
\text { nominal }\end{array}$ & $<2.10^{-16}$ \\
\hline TX_RESP_Q053 & P053 & $\begin{array}{l}\text { Dificuldades dos alunos } \\
\text { relacionada são devido } \\
\text { ao meio que vive }\end{array}$ & $\begin{array}{l}\text { Assinale sua posição em relação às } \\
\text { afirmações abaixo, que se referem aos } \\
\text { possíveis problemas de aprendizagem dos } \\
\text { alunos da(s) série(s) avaliada(s): são } \\
\text { decorrentes do meio em que o aluno vive. }\end{array}$ & $\begin{array}{c}\text { categórica } \\
\text { nominal }\end{array}$ & $<2.10^{-16}$ \\
\hline TX_RESP_Q054 & P054 & $\begin{array}{l}\text { Dificuldades dos alunos } \\
\text { relacionada são devido } \\
\text { ao meio cultural dos } \\
\quad \text { pais do aluno }\end{array}$ & $\begin{array}{c}\text { Assinale sua posição em relação às } \\
\text { afirmações abaixo, que se referem aos } \\
\text { possíveis problemas de aprendizagem dos } \\
\text { alunos da(s) série(s) avaliada(s): são } \\
\text { decorrentes do nível cultural dos pais } \\
\text { dos alunos. }\end{array}$ & $\begin{array}{c}\text { categórica } \\
\text { nominal }\end{array}$ & $<2.10^{-16}$ \\
\hline TX_RESP_Q055 & P055 & $\begin{array}{l}\text { Dificuldades dos alunos } \\
\text { relacionada à falta de } \\
\text { acompanhamento familiar }\end{array}$ & $\begin{array}{l}\text { Assinale sua posição em relação às } \\
\text { afirmações abaixo, que se referem aos } \\
\text { possíveis problemas de aprendizagem dos } \\
\text { alunos da(s) série(s) avaliada(s): estão } \\
\text { relacionadas à falta de assistência e } \\
\text { acompanhamento da família nos deveres de } \\
\text { casa e pesquisas dos alunos. }\end{array}$ & $\begin{array}{c}\text { categórica } \\
\text { nominal }\end{array}$ & $<2.10^{-16}$ \\
\hline TX_RESP_Q056 & P056 & $\begin{array}{l}\text { Dificuldades dos alunos } \\
\text { relacionada à falta de } \\
\text { aptidão do aluno }\end{array}$ & $\begin{array}{c}\text { Assinale sua posição em relação às } \\
\text { afirmações abaixo, que se referem aos } \\
\text { possíveis problemas de aprendizagem dos } \\
\text { alunos da(s) série(s) avaliada(s): } \\
\text { ocorrem devido à falta de aptidão e } \\
\text { habilidades do aluno. }\end{array}$ & $\begin{array}{c}\text { categórica } \\
\text { nominal }\end{array}$ & $<2.10^{-16}$ \\
\hline TX_RESP_Q057 & P057 & $\begin{array}{l}\text { Dificuldades dos alunos } \\
\text { relacionada à baixa } \\
\text { autoestima do aluno }\end{array}$ & $\begin{array}{l}\text { Assinale sua posição em relação às } \\
\text { afirmações abaixo, que se referem aos } \\
\text { possíveis problemas de aprendizagem dos } \\
\text { alunos da(s) série(s) avaliada(s): estão } \\
\text { vinculados à baixa autoestima dos alunos. }\end{array}$ & $\begin{array}{c}\text { categórica } \\
\text { nominal }\end{array}$ & $<2.10^{-16}$ \\
\hline TX_RESP_Q058 & P058 & $\begin{array}{l}\text { Dificuldades dos alunos } \\
\text { relacionada à falta } \\
\text { de esforço do aluno }\end{array}$ & $\begin{array}{c}\text { Assinale sua posição em relação às } \\
\text { afirmações abaixo, que se referem aos } \\
\text { possíveis problemas de aprendizagem dos } \\
\text { alunos da(s) série(s) avaliada(s): } \\
\text { ocorrem devido ao desinteresse e falta } \\
\text { de esforço do aluno. }\end{array}$ & $\begin{array}{c}\text { categórica } \\
\text { nominal }\end{array}$ & $1,39.10^{-8}$ \\
\hline
\end{tabular}




\begin{tabular}{|c|c|c|c|c|c|}
\hline $\begin{array}{l}\text { Código } \\
\text { original }\end{array}$ & $\begin{array}{c}\text { Código } \\
\text { na base } \\
\text { de dados }\end{array}$ & $\begin{array}{r}\text { Nome da } \\
\text { variável }\end{array}$ & Enunciado & $\begin{array}{l}\text { Tipo de } \\
\text { variável }\end{array}$ & valor $\mathbf{p}$ \\
\hline TX_RESP_Q059 & P059 & $\begin{array}{l}\text { Dificuldades dos alunos } \\
\text { relacionada à } \\
\text { indisciplina do aluno }\end{array}$ & $\begin{array}{c}\text { Assinale sua posição em relação às } \\
\text { afirmações abaixo, que se referem aos } \\
\text { possíveis problemas de aprendizagem dos } \\
\text { alunos da(s) série(s) avaliada(s): são } \\
\text { decorrentes da indisciplina dos alunos } \\
\text { em sala de aula. }\end{array}$ & $\begin{array}{c}\text { categórica } \\
\text { nominal }\end{array}$ & $<2.10^{-16}$ \\
\hline TX_RESP_Q060 & P060 & $\begin{array}{l}\text { Motivação do diretor ao } \\
\text { trabalho do professor }\end{array}$ & $\begin{array}{l}\text { Os itens de } 60 \text { a } 74 \text { apresentam algumas } \\
\text { afirmações. Indique seu grau de } \\
\text { concordância/discordância com cada uma } \\
\text { delas. (marque apenas uma opção em cada } \\
\text { linha.): ao(a) diretor(a) me anima e me } \\
\text { motiva para o trabalho. }\end{array}$ & $\begin{array}{c}\text { categórica } \\
\text { nominal }\end{array}$ & $<2.10^{-16}$ \\
\hline TX_RESP_Q061 & P061 & Confiança no diretor & $\begin{array}{l}\text { Os itens de } 60 \text { a } 74 \text { apresentam algumas } \\
\text { afirmações. Indique seu grau de } \\
\text { concordância/discordância com cada uma } \\
\text { delas. (marque apenas uma opção em cada } \\
\text { linha.): tenho plena confiança no(a) } \\
\text { diretor(a) como profissional. }\end{array}$ & $\begin{array}{c}\text { categórica } \\
\text { nominal }\end{array}$ & $<2.10^{-16}$ \\
\hline TX_RESP_Q062 & P062 & $\begin{array}{l}\text { Comprometimento do } \\
\text { professor }\end{array}$ & $\begin{array}{l}\text { Os itens de } 60 \text { a } 74 \text { apresentam algumas } \\
\text { afirmações. Indique seu grau de } \\
\text { concordância/discordância com cada uma } \\
\text { delas. (marque apenas uma opção em cada } \\
\text { linha.): o(a) diretor(a) consegue que os } \\
\text { professores se comprometam com a escola. }\end{array}$ & $\begin{array}{c}\text { categórica } \\
\text { nominal }\end{array}$ & $<2.10^{-16}$ \\
\hline TX_RESP_Q063 & P063 & $\begin{array}{c}\text { Estimulo às atividades } \\
\text { inovadoras }\end{array}$ & $\begin{array}{l}\text { Os itens de } 60 \text { a } 74 \text { apresentam algumas } \\
\text { afirmações. Indique seu grau de } \\
\text { concordância/discordância com cada uma } \\
\text { delas. (marque apenas uma opção em cada } \\
\text { linha.): o(a) diretor(a) estimula as } \\
\text { atividades inovadoras. }\end{array}$ & $\begin{array}{c}\text { categórica } \\
\text { nominal }\end{array}$ & $<2.10^{-16}$ \\
\hline TX_RESP_Q064 & P064 & $\begin{array}{c}\text { Atenção do diretor à } \\
\text { aprendizagem dos alunos }\end{array}$ & $\begin{array}{l}\text { Os itens de } 60 \text { a } 74 \text { apresentam algumas } \\
\text { afirmações. Indique seu grau de } \\
\text { concordância/discordância com cada uma } \\
\text { delas. (marque apenas uma opção em cada } \\
\text { linha.): o(a) diretor(a) dá atenção } \\
\text { especial a aspectos relacionados com a } \\
\text { aprendizagem dos alunos. }\end{array}$ & $\begin{array}{c}\text { categórica } \\
\text { nominal }\end{array}$ & $<2.10^{-16}$ \\
\hline TX_RESP_Q065 & P065 & $\begin{array}{l}\text { Atenção do diretor às } \\
\text { normas administrativas }\end{array}$ & $\begin{array}{l}\text { Os itens de } 60 \text { a } 74 \text { apresentam algumas } \\
\text { afirmações. Indique seu grau de } \\
\text { concordância/discordância com cada uma } \\
\text { delas. (marque apenas uma opção em cada } \\
\text { linha.): o(a) diretor(a) dá atenção } \\
\text { especial a aspectos relacionados com as } \\
\text { normas administrativas. }\end{array}$ & $\begin{array}{c}\text { categórica } \\
\text { nominal }\end{array}$ & $<2.10^{-16}$ \\
\hline TX_RESP_Q066 & P066 & $\begin{array}{l}\text { Atenção do diretor às } \\
\text { manutenção da escola }\end{array}$ & $\begin{array}{l}\text { Os itens de } 60 \text { a } 74 \text { apresentam algumas } \\
\text { afirmações. Indique seu grau de } \\
\text { concordância/discordância com cada uma } \\
\text { delas. (marque apenas uma opção em cada } \\
\text { linha.): o(a) diretor(a) dá atenção } \\
\text { especial a aspectos relacionados com a } \\
\text { manutenção da escola. }\end{array}$ & $\begin{array}{c}\text { categórica } \\
\text { nominal }\end{array}$ & $<2.10^{-16}$ \\
\hline TX_RESP_Q067 & P067 & $\begin{array}{c}\text { Respeito do diretor ao } \\
\text { professor }\end{array}$ & $\begin{array}{l}\text { Os itens de } 60 \text { a } 74 \text { apresentam algumas } \\
\text { afirmações. Indique seu grau de } \\
\text { concordância/discordância com cada uma } \\
\text { delas. (marque apenas uma opção em cada } \\
\text { linha.): sinto-me respeitado(a) pelo(a) } \\
\text { diretor(a). }\end{array}$ & $\begin{array}{c}\text { categórica } \\
\text { nominal }\end{array}$ & $<2.10^{-16}$ \\
\hline TX_RESP_Q068 & P068 & $\begin{array}{l}\text { Respeito ao diretor } \\
\text { pelo professor }\end{array}$ & $\begin{array}{l}\text { Os itens de } 60 \text { a } 74 \text { apresentam algumas } \\
\text { afirmações. Indique seu grau de } \\
\text { concordância/discordância com cada uma } \\
\text { delas. (marque apenas uma opção em cada } \\
\text { linha.): respeito o(a) diretor(a). }\end{array}$ & $\begin{array}{c}\text { categórica } \\
\text { nominal }\end{array}$ & $<2.10^{-16}$ \\
\hline TX_RESP_Q069 & P069 & $\begin{array}{c}\text { Participação das } \\
\text { decisões relacionadas à } \\
\text { escola pelo professor }\end{array}$ & $\begin{array}{l}\text { Os itens de } 60 \text { a } 74 \text { apresentam algumas } \\
\text { afirmações. Indique seu grau de } \\
\text { concordância/discordância com cada uma } \\
\text { delas. (marque apenas uma opção em cada } \\
\text { linha.): participo das decisões } \\
\text { relacionadas com o meu trabalho. }\end{array}$ & $\begin{array}{c}\text { categórica } \\
\text { nominal }\end{array}$ & $<2.10^{-16}$ \\
\hline TX_RESP_Q070 & $\mathrm{P} 070$ & $\begin{array}{c}\text { Professores leva em } \\
\text { consideração minhas } \\
\text { ideias. }\end{array}$ & $\begin{array}{l}\text { Os itens de } 60 \text { a } 74 \text { apresentam algumas } \\
\text { afirmações. Indique seu grau de } \\
\text { concordância/discordância com cada uma } \\
\text { delas. (marque apenas uma opção em cada } \\
\text { linha.): a equipe de professores leva em } \\
\text { consideração minhas ideias. }\end{array}$ & $\begin{array}{c}\text { categórica } \\
\text { nominal }\end{array}$ & $<2.10^{-16}$ \\
\hline
\end{tabular}




\begin{tabular}{|c|c|c|c|c|c|}
\hline $\begin{array}{l}\text { Código } \\
\text { original }\end{array}$ & $\begin{array}{l}\text { Código } \\
\text { na base } \\
\text { de dados }\end{array}$ & $\begin{array}{l}\text { Nome da } \\
\text { variável }\end{array}$ & Enunciado & $\begin{array}{l}\text { Tipo de } \\
\text { variável }\end{array}$ & valor $\mathbf{p}$ \\
\hline TX_RESP_Q071 & P071 & $\begin{array}{l}\text { Eu levo em consideração } \\
\text { as ideias de outros } \\
\text { colegas. }\end{array}$ & $\begin{array}{l}\text { Os itens de } 60 \text { a } 74 \text { apresentam algumas } \\
\text { afirmações. Indique seu grau de } \\
\text { concordância/discordância com cada uma } \\
\text { delas. (marque apenas uma opção em cada } \\
\text { linha.): eu levo em consideração as } \\
\text { ideias de outros colegas. }\end{array}$ & $\begin{array}{c}\text { categórica } \\
\text { nominal }\end{array}$ & $<2.10^{-16}$ \\
\hline TX_RESP_Q072 & P072 & $\begin{array}{c}\text { Interação entre os } \\
\text { professores }\end{array}$ & $\begin{array}{l}\text { Os itens de } 60 \text { a } 74 \text { apresentam algumas } \\
\text { afirmações. Indique seu grau de } \\
\text { concordância/discordância com cada uma } \\
\text { delas. (marque apenas uma opção em cada } \\
\text { linha.): o ensino que a escola oferece } \\
\text { aos alunos é muito influenciado pela } \\
\text { troca de ideias entre os professores. }\end{array}$ & $\begin{array}{c}\text { categórica } \\
\text { nominal }\end{array}$ & $<2.10^{-16}$ \\
\hline TX_RESP_Q073 & P073 & $\begin{array}{l}\text { Interação entre os } \\
\text { conteúdos das } \\
\text { disciplinas }\end{array}$ & $\begin{array}{l}\text { Os itens de } 60 \text { a } 74 \text { apresentam algumas } \\
\text { afirmações. Indique seu grau de } \\
\text { concordância/discordância com cada uma } \\
\text { delas. (marque apenas uma opção em cada } \\
\text { linha.): os professores desta escola } \\
\text { procuram coordenar o conteúdo das } \\
\text { disciplinas entre as diferentes séries. }\end{array}$ & $\begin{array}{c}\text { categórica } \\
\text { nominal }\end{array}$ & $<2.10^{-16}$ \\
\hline TX_RESP_Q074 & P074 & $\begin{array}{c}\text { Colaboração entre os } \\
\text { membros da comunidade } \\
\text { escolar }\end{array}$ & $\begin{array}{l}\text { Os itens de } 60 \text { a } 74 \text { apresentam algumas } \\
\text { afirmações. Indique seu grau de } \\
\text { concordância/discordância com cada uma } \\
\text { delas. (marque apenas uma opção em cada } \\
\text { linha.): o diretor, os professores e os } \\
\text { demais membros da equipe da escola } \\
\text { colaboram para fazer esta escola } \\
\text { funcionar bem. }\end{array}$ & $\begin{array}{l}\text { categórica } \\
\text { nominal }\end{array}$ & $<2.10^{-16}$ \\
\hline TX_RESP_Q075 & P075 & $\begin{array}{l}\text { Carência de recursos } \\
\text { financeiros }\end{array}$ & $\begin{array}{c}\text { As perguntas de } 75 \text { a } 82 \text { apresentam } \\
\text { alguns problemas que podem ocorrer nas } \\
\text { escolas. Responda se cada um deles } \\
\text { ocorreu ou não neste ano. Caso tenha } \\
\text { ocorrido, assinale se foi ou não um } \\
\text { problema grave, dificultando o } \\
\text { funcionamento da escola. (marque apenas } \\
\text { uma opção em cada linha.) Ocorreu na } \\
\text { escola: insuficiência de recursos } \\
\text { financeiros? }\end{array}$ & $\begin{array}{c}\text { categórica } \\
\text { nominal }\end{array}$ & $<2.10^{-16}$ \\
\hline TX_RESP_Q076 & P076 & Falta de professores & $\begin{array}{l}\text { As perguntas de } 75 \text { a } 82 \text { apresentam } \\
\text { alguns problemas que podem ocorrer nas } \\
\text { escolas. Responda se cada um deles } \\
\text { ocorreu ou não neste ano. Caso tenha } \\
\text { ocorrido, assinale se foi ou não um } \\
\text { problema grave, dificultando o } \\
\text { funcionamento da escola. (marque apenas } \\
\text { uma opção em cada linha.) Ocorreu na } \\
\text { escola: inexistência de professores } \\
\text { para algumas disciplinas ou séries? }\end{array}$ & $\begin{array}{c}\text { categórica } \\
\text { nominal }\end{array}$ & $<2.10^{-16}$ \\
\hline TX_RESP_Q077 & P077 & $\begin{array}{l}\text { Falta de pessoal } \\
\text { administrativo }\end{array}$ & $\begin{array}{l}\text { As perguntas de } 75 \text { a } 82 \text { apresentam } \\
\text { alguns problemas que podem ocorrer nas } \\
\text { escolas. Responda se cada um deles } \\
\text { ocorreu ou não neste ano. Caso tenha } \\
\text { ocorrido, assinale se foi ou não um } \\
\text { problema grave, dificultando o } \\
\text { funcionamento da escola. (marque apenas } \\
\text { uma opção em cada linha.) Ocorreu na } \\
\text { escola: carência de pessoal } \\
\text { administrativo? }\end{array}$ & $\begin{array}{c}\text { categórica } \\
\text { nominal }\end{array}$ & $<2.10^{-16}$ \\
\hline TX_RESP_Q078 & P078 & $\begin{array}{l}\text { Falta de apoio } \\
\text { pedagógico }\end{array}$ & $\begin{array}{l}\text { As perguntas de } 75 \text { a } 82 \text { apresentam } \\
\text { alguns problemas que podem ocorrer nas } \\
\text { escolas. Responda se cada um deles } \\
\text { ocorreu ou não neste ano. Caso tenha } \\
\text { ocorrido, assinale se foi ou não um } \\
\text { problema grave, dificultando o } \\
\text { funcionamento da escola. (marque apenas } \\
\text { uma opção em cada linha.) Ocorreu na } \\
\text { escola: carência de pessoal de apoio } \\
\text { pedagógico (coordenador, supervisor, } \\
\text { orientador educacional)? }\end{array}$ & $\begin{array}{c}\text { categórica } \\
\text { nominal }\end{array}$ & $<2.10^{-16}$ \\
\hline
\end{tabular}




\begin{tabular}{|c|c|c|c|c|c|}
\hline $\begin{array}{l}\text { Código } \\
\text { original }\end{array}$ & $\begin{array}{c}\text { Código } \\
\text { na base } \\
\text { de dados }\end{array}$ & $\begin{array}{r}\text { Nome da } \\
\text { variável }\end{array}$ & Enunciado & $\begin{array}{l}\text { Tipo de } \\
\text { variável }\end{array}$ & valor $\mathbf{p}$ \\
\hline TX_RESP_Q079 & P079 & $\begin{array}{c}\text { Falta de recurso } \\
\text { pedagógico }\end{array}$ & $\begin{array}{l}\text { As perguntas de } 75 \text { a } 82 \text { apresentam } \\
\text { alguns problemas que podem ocorrer nas } \\
\text { escolas. Responda se cada um deles } \\
\text { ocorreu ou não neste ano. Caso tenha } \\
\text { ocorrido, assinale se foi ou não um } \\
\text { problema grave, dificultando o } \\
\text { funcionamento da escola. (marque apenas } \\
\text { uma opção em cada linha.) Ocorreu na } \\
\text { escola: falta de recursos pedagógicos? }\end{array}$ & $\begin{array}{c}\text { categórica } \\
\text { nominal }\end{array}$ & $<2.10^{-16}$ \\
\hline TX_RESP_Q080 & P080 & $\begin{array}{c}\text { Índice de falta dos } \\
\text { professores }\end{array}$ & $\begin{array}{c}\text { As perguntas de } 75 \text { a } 82 \text { apresentam } \\
\text { alguns problemas que podem ocorrer nas } \\
\text { escolas. Responda se cada um deles } \\
\text { ocorreu ou não neste ano. Caso tenha } \\
\text { ocorrido, assinale se foi ou não um } \\
\text { problema grave, dificultando o } \\
\text { funcionamento da escola. (marque apenas } \\
\text { uma opção em cada linha.) Ocorreu na } \\
\text { escola: alto índice de faltas por parte } \\
\text { dos professores? }\end{array}$ & $\begin{array}{c}\text { categórica } \\
\text { nominal }\end{array}$ & $<2.10^{-16}$ \\
\hline TX_RESP_Q081 & P081 & $\begin{array}{c}\text { Índice de falta dos } \\
\text { alunos }\end{array}$ & $\begin{array}{c}\text { As perguntas de } 75 \text { a } 82 \text { apresentam } \\
\text { alguns problemas que podem ocorrer nas } \\
\text { escolas. Responda se cada um deles } \\
\text { ocorreu ou não neste ano. Caso tenha } \\
\text { ocorrido, assinale se foi ou não um } \\
\text { problema grave, dificultando o } \\
\text { funcionamento da escola. (marque apenas } \\
\text { uma opção em cada linha.) Ocorreu na } \\
\text { escola: alto índice de faltas por parte } \\
\text { dos alunos? }\end{array}$ & $\begin{array}{c}\text { categórica } \\
\text { nominal }\end{array}$ & $<2.10^{-16}$ \\
\hline TX_RESP_Q082 & P082 & $\begin{array}{l}\text { Indisciplinas dos } \\
\text { alunos }\end{array}$ & $\begin{array}{c}\text { As perguntas de } 75 \text { a } 82 \text { apresentam } \\
\text { alguns problemas que podem ocorrer nas } \\
\text { escolas. Responda se cada um deles } \\
\text { ocorreu ou não neste ano. Caso tenha } \\
\text { ocorrido, assinale se foi ou não um } \\
\text { problema grave, dificultando o } \\
\text { funcionamento da escola. (marque apenas } \\
\text { uma opção em cada linha.) Ocorreu na } \\
\text { escola: problemas disciplinares causados } \\
\text { pelos alunos? }\end{array}$ & $\begin{array}{c}\text { categórica } \\
\text { nominal }\end{array}$ & $<2.10^{-16}$ \\
\hline TX_RESP_Q083 & P083 & $\begin{array}{l}\text { Agressão verbal a } \\
\text { professores feita por } \\
\text { alunos }\end{array}$ & $\begin{array}{l}\text { Sobre os fatos listados abaixo, diga se } \\
\text { eles aconteceram ou não este ano nesta } \\
\text { escola. (agressor: aluno): agressão } \\
\text { verbal a professores. }\end{array}$ & $\begin{array}{c}\text { categórica } \\
\text { nominal }\end{array}$ & $<2.10^{-16}$ \\
\hline TX_RESP_Q084 & P084 & $\begin{array}{l}\text { Agressão física aos } \\
\text { professores feita por } \\
\text { alunos }\end{array}$ & $\begin{array}{l}\text { Sobre os fatos listados abaixo, diga se } \\
\text { eles aconteceram ou não este ano nesta } \\
\text { escola. (agressor: aluno): agressão } \\
\text { física a professores. }\end{array}$ & $\begin{array}{c}\text { categórica } \\
\text { nominal }\end{array}$ & $<2.10^{-16}$ \\
\hline TX_RESP_Q085 & P085 & $\begin{array}{l}\text { Agressão verbal aos } \\
\text { alunos feitas por alunos }\end{array}$ & $\begin{array}{l}\text { Sobre os fatos listados abaixo, diga se } \\
\text { eles aconteceram ou não este ano nesta } \\
\text { escola. (agressor: aluno): agressão } \\
\text { verbal a alunos. }\end{array}$ & $\begin{array}{c}\text { categórica } \\
\text { nominal }\end{array}$ & $1,51.10^{-12}$ \\
\hline TX_RESP_Q086 & P086 & $\begin{array}{c}\text { Agressão física aos } \\
\text { alunos feita por alunos }\end{array}$ & $\begin{array}{l}\text { Sobre os fatos listados abaixo, diga se } \\
\text { eles aconteceram ou não este ano nesta } \\
\text { escola. (agressor: aluno): agressão } \\
\text { física a alunos. }\end{array}$ & $\begin{array}{c}\text { categórica } \\
\text { nominal }\end{array}$ & $<2.10^{-16}$ \\
\hline TX_RESP_Q087 & P087 & $\begin{array}{l}\text { Agressão verbal aos } \\
\text { funcionários feita por } \\
\text { alunos }\end{array}$ & $\begin{array}{l}\text { Sobre os fatos listados abaixo, diga se } \\
\text { eles aconteceram ou não este ano nesta } \\
\text { escola. (agressor: aluno): agressão } \\
\text { verbal a funcionários. }\end{array}$ & $\begin{array}{c}\text { categórica } \\
\text { nominal }\end{array}$ & $<2.10^{-16}$ \\
\hline TX_RESP_Q088 & P088 & $\begin{array}{l}\text { Agressão física aos } \\
\text { funcionários feitos por } \\
\text { alunos }\end{array}$ & $\begin{array}{l}\text { Sobre os fatos listados abaixo, diga se } \\
\text { eles aconteceram ou não este ano nesta } \\
\text { escola. (agressor: aluno): agressão } \\
\text { física a funcionários. }\end{array}$ & $\begin{array}{c}\text { categórica } \\
\text { nominal }\end{array}$ & $<2.10^{-16}$ \\
\hline TX_RESP_Q089 & P089 & $\begin{array}{l}\text { Agressão verbal aos } \\
\text { professores feito por } \\
\text { professores }\end{array}$ & $\begin{array}{l}\text { Sobre os fatos listados abaixo, diga se } \\
\text { eles aconteceram ou não este dano nesta } \\
\text { escola. (agressor: professor): agressão } \\
\text { verbal a professores. }\end{array}$ & $\begin{array}{c}\text { categórica } \\
\text { nominal }\end{array}$ & $<2.10^{-16}$ \\
\hline TX_RESP_Q090 & P090 & $\begin{array}{l}\text { Agressão física aos } \\
\text { professores feito por } \\
\text { professores }\end{array}$ & $\begin{array}{l}\text { Sobre os fatos listados abaixo, diga se } \\
\text { eles aconteceram ou não este ano nesta } \\
\text { escola. (agressor: professor): agressão } \\
\text { física a professores. }\end{array}$ & $\begin{array}{c}\text { categórica } \\
\text { nominal }\end{array}$ & $<2.10^{-16}$ \\
\hline
\end{tabular}




\begin{tabular}{|c|c|c|c|c|c|}
\hline $\begin{array}{l}\text { Código } \\
\text { original }\end{array}$ & $\begin{array}{c}\text { Código } \\
\text { na base } \\
\text { de dados }\end{array}$ & $\begin{array}{r}\text { Nome da } \\
\text { variável }\end{array}$ & Enunciado & $\begin{array}{l}\text { Tipo de } \\
\text { variável }\end{array}$ & valor $\mathbf{p}$ \\
\hline TX_RESP_Q091 & P091 & $\begin{array}{l}\text { Agressão verbal aos } \\
\text { alunos por professor }\end{array}$ & $\begin{array}{c}\text { Sobre os fatos listados abaixo, diga se } \\
\text { eles aconteceram ou não este banho nesta } \\
\text { escola. (agressor: professor): agressão } \\
\text { verbal a alunos. }\end{array}$ & $\begin{array}{c}\text { categórica } \\
\text { nominal }\end{array}$ & $<2.10^{-16}$ \\
\hline TX_RESP_Q092 & P092 & $\begin{array}{l}\text { Agressão física aos } \\
\text { alunos feita por } \\
\text { professor }\end{array}$ & $\begin{array}{l}\text { Sobre os fatos listados abaixo, diga se } \\
\text { eles aconteceram ou não este ano nesta } \\
\text { escola. (agressor: professor): agressão } \\
\text { física a alunos. }\end{array}$ & $\begin{array}{c}\text { categórica } \\
\text { nominal }\end{array}$ & $<2.10^{-16}$ \\
\hline TX_RESP_Q093 & P093 & $\begin{array}{l}\text { Agressão verbal aos } \\
\text { funcionários feita por } \\
\text { professor }\end{array}$ & $\begin{array}{l}\text { Sobre os fatos listados abaixo, diga se } \\
\text { eles aconteceram ou não este ano nesta } \\
\text { escola. (agressor: professor): agressão } \\
\text { verbal a funcionários. }\end{array}$ & $\begin{array}{c}\text { categórica } \\
\text { nominal }\end{array}$ & $<2.10^{-16}$ \\
\hline TX_RESP_Q094 & P094 & $\begin{array}{l}\text { Agressão física aos } \\
\text { funcionários feita por } \\
\text { professor }\end{array}$ & $\begin{array}{l}\text { Sobre os fatos listados abaixo, diga se } \\
\text { eles aconteceram ou não este ano nesta } \\
\text { escola. (agressor: professor): agressão } \\
\text { física a funcionários. }\end{array}$ & $\begin{array}{c}\text { categórica } \\
\text { nominal }\end{array}$ & $<2.10^{-16}$ \\
\hline TX_RESP_Q095 & P095 & $\begin{array}{l}\text { Agressão verbal aos } \\
\text { professores feita por } \\
\quad \text { funcionários }\end{array}$ & $\begin{array}{l}\text { Agressão verbal a professores. Sobre os } \\
\text { fatos listados abaixo, diga se eles } \\
\text { aconteceram ou não este ano nesta } \\
\text { escola. (agressor: funcionário): }\end{array}$ & $\begin{array}{c}\text { categórica } \\
\text { nominal }\end{array}$ & $<2.10^{-16}$ \\
\hline TX_RESP_Q096 & P096 & $\begin{array}{l}\text { Agressão física aos } \\
\text { professores feita por } \\
\quad \text { funcionários }\end{array}$ & $\begin{array}{l}\text { Agressão física a professores. Sobre os } \\
\text { fatos listados abaixo, diga se eles } \\
\text { aconteceram ou não este ano nesta } \\
\text { escola. (agressor: funcionário): }\end{array}$ & $\begin{array}{c}\text { categórica } \\
\text { nominal }\end{array}$ & $<2.10^{-16}$ \\
\hline TX_RESP_Q097 & P097 & $\begin{array}{l}\text { Agressão verbal aos } \\
\text { alunos feita por } \\
\text { funcionários }\end{array}$ & $\begin{array}{l}\text { Agressão verbal a alunos. Sobre os fatos } \\
\text { listados abaixo, diga se eles } \\
\text { aconteceram ou não este ano nesta } \\
\text { escola. (agressor: funcionário): }\end{array}$ & $\begin{array}{c}\text { categórica } \\
\text { nominal }\end{array}$ & $<2.10^{-16}$ \\
\hline TX_RESP_Q098 & P098 & $\begin{array}{l}\text { Agressão física aos } \\
\text { alunos feita por } \\
\text { funcionários }\end{array}$ & $\begin{array}{l}\text { Agressão física a alunos. Sobre os fatos } \\
\text { listados abaixo, diga se eles } \\
\text { aconteceram ou não este ano nesta } \\
\text { escola. (agressor: funcionário): }\end{array}$ & $\begin{array}{c}\text { categórica } \\
\text { nominal }\end{array}$ & $<2.10^{-16}$ \\
\hline TX_RESP_Q099 & P099 & $\begin{array}{l}\text { Agressão verbal aos } \\
\text { funcionários feita por } \\
\text { funcionários }\end{array}$ & $\begin{array}{l}\text { Agressão verbal a funcionários. Sobre os } \\
\text { fatos listados abaixo, diga se eles } \\
\text { aconteceram ou não este ano nesta } \\
\text { escola. (agressor: funcionário): }\end{array}$ & $\begin{array}{c}\text { categórica } \\
\text { nominal }\end{array}$ & $<2.10^{-16}$ \\
\hline TX_RESP_Q100 & P100 & $\begin{array}{l}\text { Agressão física aos } \\
\text { funcionários feita por } \\
\text { funcionários }\end{array}$ & $\begin{array}{l}\text { Agressão física a funcionários. Sobre os } \\
\text { fatos listados abaixo, diga se eles } \\
\text { aconteceram ou não este ano nesta } \\
\text { escola. (agressor: funcionário): }\end{array}$ & $\begin{array}{c}\text { categórica } \\
\text { nominal }\end{array}$ & $<2.10^{-16}$ \\
\hline TX_RESP_Q101 & P101 & Atentado à vida & $\begin{array}{c}\text { Sobre os fatos listados abaixo, diga se } \\
\text { eles aconteceram ou não este ano, nesta } \\
\text { escola: você foi vítima de atentado à } \\
\text { vida? }\end{array}$ & $\begin{array}{c}\text { categórica } \\
\text { nominal }\end{array}$ & $<2.10^{-16}$ \\
\hline TX_RESP_Q102 & P102 & $\begin{array}{l}\text { Ameaças à vida feita } \\
\text { por alunos }\end{array}$ & $\begin{array}{l}\text { Sobre os fatos listados abaixo, diga se } \\
\text { eles aconteceram ou não este ano, nesta } \\
\text { escola: você foi ameaçado por algum } \\
\text { aluno? }\end{array}$ & $\begin{array}{c}\text { categórica } \\
\text { nominal }\end{array}$ & $<2.10^{-16}$ \\
\hline TX_RESP_Q103 & P103 & $\begin{array}{l}\text { Agressão verbal por } \\
\text { algum aluno }\end{array}$ & $\begin{array}{c}\text { Sobre os fatos listados abaixo, diga se } \\
\text { eles aconteceram ou não este ano, nesta } \\
\text { escola: você foi agredido verbalmente } \\
\text { por algum aluno? }\end{array}$ & $\begin{array}{c}\text { categórica } \\
\text { nominal }\end{array}$ & $<2.10^{-16}$ \\
\hline TX_RESP_Q104 & P104 & $\begin{array}{l}\text { Agressão física por } \\
\text { algum aluno }\end{array}$ & $\begin{array}{l}\text { Sobre os fatos listados abaixo, diga se } \\
\text { eles aconteceram ou não este ano, nesta } \\
\text { escola: você foi agredido fisicamente } \\
\text { por algum aluno? }\end{array}$ & $\begin{array}{c}\text { categórica } \\
\text { nominal }\end{array}$ & $<2.10^{-16}$ \\
\hline TX_RESP_Q105 & P105 & Furto aos professores & $\begin{array}{l}\text { Sobre os fatos listados abaixo, diga se } \\
\text { eles aconteceram ou não este ano, nesta } \\
\text { escola: você foi vítima de furto? }\end{array}$ & $\begin{array}{c}\text { categórica } \\
\text { nominal }\end{array}$ & $<2.10^{-16}$ \\
\hline TX_RESP_Q106 & P106 & Roubo aos professores & $\begin{array}{l}\text { Sobre os fatos listados abaixo, diga se } \\
\text { eles aconteceram ou não este ano, nesta } \\
\text { escola: você foi vítima de roubo (com } \\
\text { uso de violência)? }\end{array}$ & $\begin{array}{c}\text { categórica } \\
\text { nominal }\end{array}$ & $<2.10^{-16}$ \\
\hline TX_RESP_Q107 & P107 & Bebida alcoólicas & $\begin{array}{l}\text { Sobre os fatos listados abaixo, diga se } \\
\text { eles aconteceram ou não este ano, nesta } \\
\text { escola: alunos frequentaram as suas } \\
\text { aulas sob efeito de bebida alcoólica? }\end{array}$ & $\begin{array}{c}\text { categórica } \\
\text { nominal }\end{array}$ & $<2.10^{-16}$ \\
\hline TX_RESP_Q108 & P108 & Drogas ilícitas & $\begin{array}{l}\text { Sobre os fatos listados abaixo, diga se } \\
\text { eles aconteceram ou não este ano, nesta } \\
\text { escola: alunos frequentaram as suas } \\
\text { aulas sob efeito de drogas ilícitas? }\end{array}$ & $\begin{array}{c}\text { categórica } \\
\text { nominal }\end{array}$ & $<2.10^{-16}$ \\
\hline
\end{tabular}




\begin{tabular}{|c|c|c|c|c|c|}
\hline $\begin{array}{l}\text { Código } \\
\text { original }\end{array}$ & $\begin{array}{c}\text { Código } \\
\text { na base } \\
\text { de dados }\end{array}$ & $\begin{array}{r}\text { Nome da } \\
\text { variável }\end{array}$ & Enunciado & $\begin{array}{l}\text { Tipo de } \\
\text { variável }\end{array}$ & valor $\mathbf{p}$ \\
\hline TX_RESP_Q109 & P109 & Porte de arma branca & $\begin{array}{l}\text { Sobre os fatos listados abaixo, diga se } \\
\text { eles aconteceram ou não este ano, nesta } \\
\text { escola: alunos frequentaram as suas } \\
\text { aulas portando arma branca (facas, } \\
\text { canivetes, etc.)? }\end{array}$ & $\begin{array}{c}\text { categórica } \\
\text { nominal }\end{array}$ & $<2.10^{-16}$ \\
\hline TX_RESP_Q110 & P110 & Porte de arma de fogo & $\begin{array}{l}\text { Sobre os fatos listados abaixo, diga se } \\
\text { eles aconteceram ou não este ano, nesta } \\
\text { escola: alunos frequentaram as suas } \\
\text { aulas portando arma de fogo? }\end{array}$ & $\begin{array}{c}\text { categórica } \\
\text { nominal }\end{array}$ & $<2.10^{-16}$ \\
\hline TX_RESP_Q111 & P111 & Prova Brasil de 2009 & $\begin{array}{c}\text { A sua escola participou da Prova Brasil } \\
\text { de } 2009 ?\end{array}$ & $\begin{array}{c}\text { categórica } \\
\text { nominal }\end{array}$ & $<2.10^{-16}$ \\
\hline TX_RESP_Q112 & P112 & $\begin{array}{l}\text { Conhecimento dos } \\
\text { resultados do SAEB da } \\
\text { sua escola }\end{array}$ & $\begin{array}{l}\text { Você conhece os resultados do sistema de } \\
\text { avaliação da educação básica, SAEB: da } \\
\text { sua escola? }\end{array}$ & $\begin{array}{c}\text { categórica } \\
\text { nominal }\end{array}$ & $<2.10^{-16}$ \\
\hline TX_RESP_Q113 & P113 & $\begin{array}{l}\text { Conhecimento dos } \\
\text { resultados do SAEB do } \\
\text { seu município }\end{array}$ & $\begin{array}{l}\text { Você conhece os resultados do sistema de } \\
\text { avaliação da educação básica, SAEB: do } \\
\text { seu município? }\end{array}$ & $\begin{array}{c}\text { categórica } \\
\text { nominal }\end{array}$ & $<2.10^{-16}$ \\
\hline TX_RESP_Q114 & P114 & $\begin{array}{l}\text { Conhecimento dos } \\
\text { resultados do SAEB do } \\
\text { seu estado }\end{array}$ & $\begin{array}{l}\text { Você conhece os resultados do sistema de } \\
\text { avaliação da educação básica, SAEB: do } \\
\text { seu estado? }\end{array}$ & $\begin{array}{c}\text { categórica } \\
\text { nominal }\end{array}$ & $<2.10^{-16}$ \\
\hline TX_RESP_Q115 & P115 & $\begin{array}{c}\text { Utilização de } \\
\text { computadores pelos } \\
\text { professores em sala de } \\
\text { aula }\end{array}$ & $\begin{array}{l}\text { Indique se você utiliza ou não nesta } \\
\text { turma: (marque apenas uma opção em cada } \\
\text { linha.): computadores. }\end{array}$ & $\begin{array}{c}\text { categórica } \\
\text { nominal }\end{array}$ & $<2.10^{-16}$ \\
\hline TX_RESP_Q116 & P116 & $\begin{array}{c}\text { Utilização de } \\
\text { internet pelos } \\
\text { professores em sala de } \\
\text { aula } \\
\end{array}$ & $\begin{array}{c}\text { Indique se você utiliza ou não nesta } \\
\text { turma: (marque apenas uma opção em cada } \\
\text { linha.): internet. }\end{array}$ & $\begin{array}{c}\text { categórica } \\
\text { nominal }\end{array}$ & $<2.10^{-16}$ \\
\hline TX_RESP_Q117 & P117 & $\begin{array}{l}\text { Utilização de fitas de } \\
\text { vídeo ou DVD pelos } \\
\text { professores em sala de } \\
\text { aula }\end{array}$ & $\begin{array}{l}\text { Indique se você utiliza ou não nesta } \\
\text { turma: (marque apenas uma opção em cada } \\
\text { linha.): fitas de vídeo ou DVD. }\end{array}$ & $\begin{array}{c}\text { categórica } \\
\text { nominal }\end{array}$ & $<2.10^{-16}$ \\
\hline TX_RESP_Q118 & P118 & $\begin{array}{l}\text { Utilização de jornais e } \\
\text { revistas pelos } \\
\text { professores em sala de } \\
\text { aula }\end{array}$ & $\begin{array}{l}\text { Indique se você utiliza ou não nesta } \\
\text { turma: (marque apenas uma opção em cada } \\
\text { linha.): jornais e revistas informativas. }\end{array}$ & $\begin{array}{c}\text { categórica } \\
\text { nominal }\end{array}$ & $<2.10^{-16}$ \\
\hline TX_RESP_Q119 & P119 & $\begin{array}{l}\text { Utilização de revistas } \\
\text { em quadrinhos pelos } \\
\text { professores em sala de } \\
\text { aula } \\
\end{array}$ & $\begin{array}{l}\text { Indique se você utiliza ou não nesta } \\
\text { turma: (marque apenas uma opção em cada } \\
\text { linha.): revistas em quadrinhos. }\end{array}$ & $\begin{array}{c}\text { categórica } \\
\text { nominal }\end{array}$ & $<2.10^{-16}$ \\
\hline TX_RESP_Q120 & $\mathrm{P} 120$ & $\begin{array}{l}\text { Utilização de livros } \\
\text { didáticos pelos } \\
\text { professores em sala de } \\
\text { aula }\end{array}$ & $\begin{array}{l}\text { Indique se você utiliza ou não nesta } \\
\text { turma: (marque apenas uma opção em cada } \\
\text { linha.): livros didáticos. }\end{array}$ & $\begin{array}{c}\text { categórica } \\
\text { nominal }\end{array}$ & $<2.10^{-16}$ \\
\hline TX_RESP_Q121 & P121 & $\begin{array}{l}\text { Quantidade de conteúdos } \\
\text { curriculares cumpridas } \\
\text { pelo professor }\end{array}$ & $\begin{array}{c}\text { Quanto dos conteúdos previstos você } \\
\text { conseguiu desenvolver com os alunos } \\
\text { desta turma, neste ano? }\end{array}$ & $\begin{array}{c}\text { categórica } \\
\text { nominal }\end{array}$ & $<2.10^{-16}$ \\
\hline TX_RESP_Q122 & P122 & $\begin{array}{l}\text { Perspectiva de } \\
\text { conclusão do Ensino } \\
\text { Fundamental I }\end{array}$ & $\begin{array}{c}\text { Quantos dos alunos desta turma você acha } \\
\text { que: concluirão os anos iniciais do } \\
\text { ensino fundamental }\left(4 .^{\mathrm{a}} \text { série } / 5 .^{\circ} \text { ano }\right) ?\end{array}$ & $\begin{array}{c}\text { categórica } \\
\text { nominal }\end{array}$ & $<2.10^{-16}$ \\
\hline TX_RESP_Q123 & P123 & $\begin{array}{c}\text { Perspectiva de } \\
\text { conclusão do Ensino } \\
\text { Fundamental II }\end{array}$ & $\begin{array}{l}\text { Quantos dos alunos desta turma você acha } \\
\text { que: concluirão o ensino fundamental } \\
\left(8 .^{\mathrm{a}} \text { série } / 9 .^{\circ} \text { ano }\right) ?\end{array}$ & $\begin{array}{c}\text { categórica } \\
\text { nominal }\end{array}$ & $<2.10^{-16}$ \\
\hline TX_RESP_Q124 & P124 & $\begin{array}{c}\text { Perspectiva de } \\
\text { conclusão do Ensino } \\
\text { Médio }\end{array}$ & $\begin{array}{l}\text { Quantos dos alunos desta turma você acha } \\
\text { que: concluirão o ensino médio? }\end{array}$ & $\begin{array}{c}\text { categórica } \\
\text { nominal }\end{array}$ & $<2.10^{-16}$ \\
\hline TX_RESP_Q125 & $\mathrm{P} 125$ & $\begin{array}{c}\text { Perspectiva de } \\
\text { ingresso nas } \\
\text { universidades }\end{array}$ & $\begin{array}{c}\text { Quantos dos alunos desta turma você acha } \\
\text { que: entrarão para a universidade? }\end{array}$ & $\begin{array}{c}\text { categórica } \\
\text { nominal }\end{array}$ & $<2.10^{-16}$ \\
\hline TX_RESP_Q126 & P126 & $\begin{array}{c}\text { Porte de livros } \\
\text { didáticos pelos alunos }\end{array}$ & $\begin{array}{c}\text { Os alunos desta turma têm livros } \\
\text { didáticos? }\end{array}$ & $\begin{array}{c}\text { categórica } \\
\text { nominal }\end{array}$ & $<2.10^{-16}$ \\
\hline TX_RESP_Q127 & P127 & $\begin{array}{l}\text { Recebimento de livros } \\
\text { didáticos pelos alunos }\end{array}$ & $\begin{array}{c}\text { Os alunos desta turma receberam o livro } \\
\text { didático no início do ano letivo? }\end{array}$ & $\begin{array}{c}\text { categórica } \\
\text { nominal }\end{array}$ & $<2.10^{-16}$ \\
\hline TX_RESP_Q128 & P128 & $\begin{array}{l}\text { Escolha e recebimento } \\
\text { de livros didáticos }\end{array}$ & $\begin{array}{l}\text { O livro didático escolhido foi o } \\
\text { recebido? }\end{array}$ & $\begin{array}{c}\text { categórica } \\
\text { nominal }\end{array}$ & $<2.10^{-16}$ \\
\hline TX_RESP_Q129 & P129 & $\begin{array}{l}\text { Qualidade do livros } \\
\text { didáticos desta turma }\end{array}$ & $\begin{array}{l}\text { Como você considera o(s) livro(s) } \\
\text { didático(s) utilizado(s) por você na(s) } \\
\text { disciplina(s) que ministra nesta turma? }\end{array}$ & $\begin{array}{c}\text { categórica } \\
\text { nominal }\end{array}$ & $<2.10^{-16}$ \\
\hline TX_RESP_Q130 & P130 & $\begin{array}{c}\text { Guia de livros } \\
\text { didáticos do MEC }\end{array}$ & $\begin{array}{c}\text { Na escolha do livro didático utilizado } \\
\text { nesta turma em que você leciona, foi } \\
\text { consultado o "guia de livros didáticos" } \\
\text { da SEB/MEC? }\end{array}$ & $\begin{array}{c}\text { categórica } \\
\text { nominal }\end{array}$ & $4,31 \cdot 10^{-15}$ \\
\hline
\end{tabular}




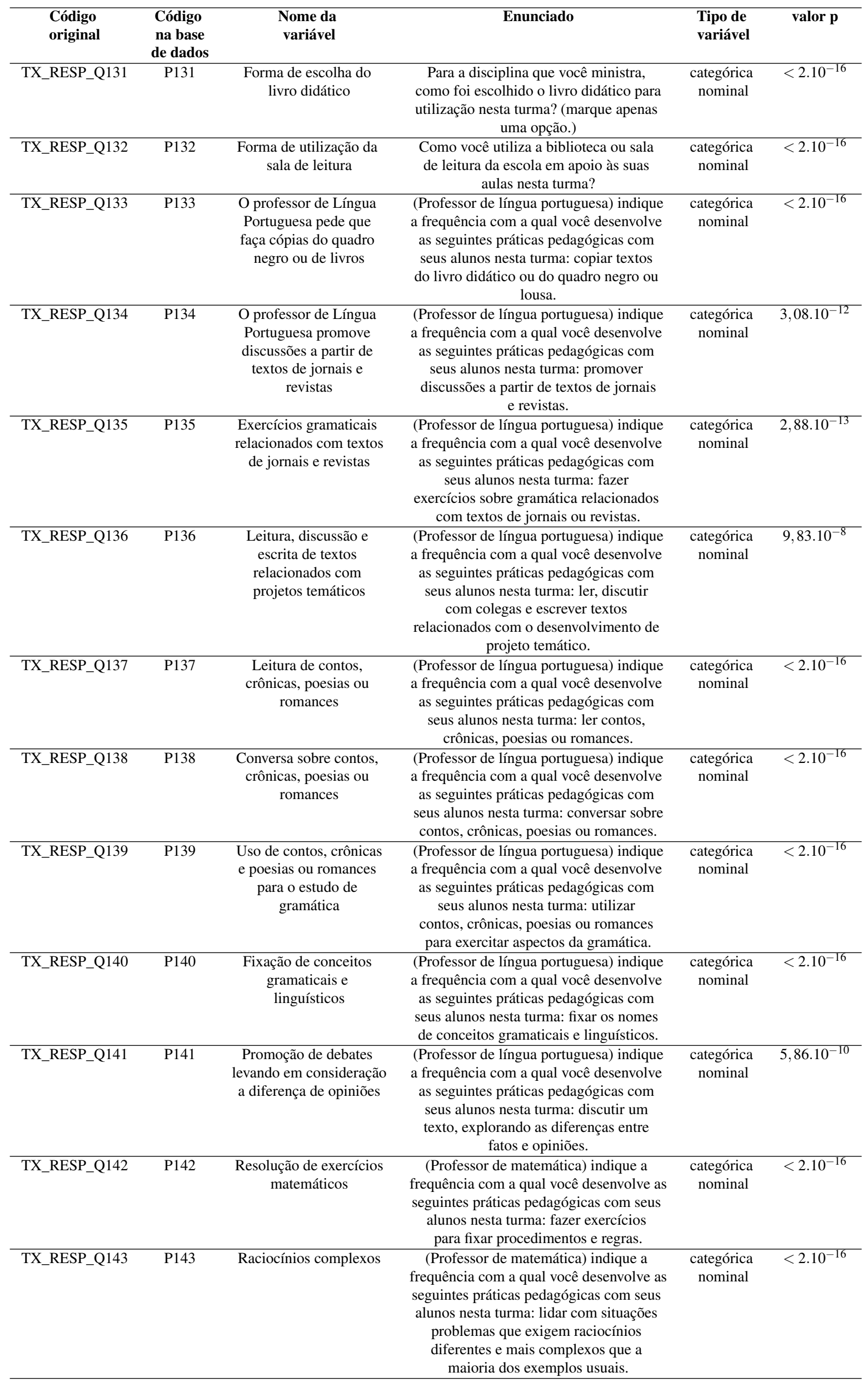




\begin{tabular}{|c|c|c|c|c|c|}
\hline $\begin{array}{l}\text { Código } \\
\text { original }\end{array}$ & $\begin{array}{c}\text { Código } \\
\text { na base } \\
\text { de dados }\end{array}$ & $\begin{array}{r}\text { Nome da } \\
\text { variável }\end{array}$ & Enunciado & $\begin{array}{l}\text { Tipo de } \\
\text { variável }\end{array}$ & valor $\mathbf{p}$ \\
\hline TX_RESP_Q144 & P144 & $\begin{array}{l}\text { Análise de soluções de } \\
\text { problemas }\end{array}$ & $\begin{array}{c}\text { (Professor de matemática) indique a } \\
\text { frequência com a qual você desenvolve as } \\
\text { seguintes práticas pedagógicas com seus } \\
\text { alunos nesta turma: falar sobre suas } \\
\text { soluções, discutindo os caminhos usados } \\
\text { para encontrá-las. }\end{array}$ & $\begin{array}{c}\text { categórica } \\
\text { nominal }\end{array}$ & $<2.10^{-16}$ \\
\hline TX_RESP_Q145 & P145 & $\begin{array}{c}\text { Fixação de regras } \\
\text { matemáticas }\end{array}$ & $\begin{array}{c}\text { (Professor de matemática) indique a } \\
\text { frequência com a qual você desenvolve as } \\
\text { seguintes práticas pedagógicas com seus } \\
\text { alunos nesta turma: gravar as regras que } \\
\text { permitem obter as respostas certas dos } \\
\text { cálculos e problemas. }\end{array}$ & $\begin{array}{c}\text { categórica } \\
\text { nominal }\end{array}$ & $<2.10^{-16}$ \\
\hline TX_RESP_Q146 & P146 & $\begin{array}{l}\text { Contextualização dos } \\
\text { temas de jornais e } \\
\text { revistas em matemática }\end{array}$ & $\begin{array}{c}\text { (Professor de matemática) indique a } \\
\text { frequência com a qual você desenvolve as } \\
\text { seguintes práticas pedagógicas com seus } \\
\text { alunos nesta turma: lidar com temas que } \\
\text { aparecem em jornais e/ou revistas, } \\
\text { discutindo a relação dos temas com a } \\
\text { matemática. }\end{array}$ & $\begin{array}{c}\text { categórica } \\
\text { nominal }\end{array}$ & $<2.10^{-16}$ \\
\hline TX_RESP_Q147 & P147 & $\begin{array}{c}\text { Interpretação de } \\
\text { resultados obtidos em } \\
\text { resolução de problemas }\end{array}$ & $\begin{array}{l}\text { (Professor de matemática) indique a } \\
\text { frequência com a qual você desenvolve as } \\
\text { seguintes práticas pedagógicas com seus } \\
\text { alunos nesta turma: interpretar } \\
\text { resultados numéricos obtidos para dar } \\
\text { uma resposta adequada ao problema. }\end{array}$ & $\begin{array}{c}\text { categórica } \\
\text { nominal }\end{array}$ & $<2.10^{-16}$ \\
\hline TX_RESP_Q148 & P148 & $\begin{array}{l}\text { Temas matemáticos de } \\
\text { interesse dos alunos }\end{array}$ & $\begin{array}{l}\text { (Professor de matemática) indique a } \\
\text { frequência com a qual você desenvolve as } \\
\text { seguintes práticas pedagógicas com seus } \\
\text { alunos nesta turma: lidar com situações } \\
\text { que lhes sejam familiares e que } \\
\text { apresentem temas de interesse dos alunos. }\end{array}$ & $\begin{array}{c}\text { categórica } \\
\text { nominal }\end{array}$ & $7,71 \cdot 10^{-10}$ \\
\hline TX_RESP_Q149 & P149 & $\begin{array}{c}\text { Exploração de } \\
\text { diferentes métodos de } \\
\text { resolução de problemas }\end{array}$ & $\begin{array}{l}\text { (Professor de matemática) indique a } \\
\text { frequência com a qual você desenvolve as } \\
\text { seguintes práticas pedagógicas com seus } \\
\text { alunos nesta turma: experimentar } \\
\text { diferentes modos de resolver um problema } \\
\text { ou de efetuar um cálculo. }\end{array}$ & $\begin{array}{c}\text { categórica } \\
\text { nominal }\end{array}$ & $<2.10^{-16}$ \\
\hline TX_RESP_Q150 & P150 & $\begin{array}{l}\text { Precisão de execução de } \\
\text { cálculos }\end{array}$ & $\begin{array}{l}\text { (Professor de matemática) indique a } \\
\text { frequência com a qual você desenvolve as } \\
\text { seguintes práticas pedagógicas com seus } \\
\text { alunos nesta turma: aprimorar a precisão } \\
\text { e a velocidade de execução de cálculos. }\end{array}$ & $\begin{array}{c}\text { categórica } \\
\text { nominal }\end{array}$ & $<2.10^{-16}$ \\
\hline TX_RESP_Q151 & P151 & $\begin{array}{c}\text { Táticas de resolução } \\
\text { de problemas }\end{array}$ & $\begin{array}{l}\text { (Professor de matemática) indique a } \\
\text { frequência com a qual você desenvolve as } \\
\text { seguintes práticas pedagógicas com seus } \\
\text { alunos nesta turma: experimentar } \\
\text { diferentes ações (coletar informações, } \\
\text { recortar, analisar, explorar, discutir, } \\
\text { manipular, etc.) Para resolver problemas. }\end{array}$ & $\begin{array}{c}\text { categórica } \\
\text { nominal }\end{array}$ & $3,39.10^{-10}$ \\
\hline TX_RESP_Q152 & $\mathrm{P} 152$ & $\begin{array}{c}\text { Análise crítica de } \\
\text { resultados matemáticos }\end{array}$ & $\begin{array}{l}\text { (Professor de matemática) indique a } \\
\text { frequência com a qual você desenvolve as } \\
\text { seguintes práticas pedagógicas com seus } \\
\text { alunos nesta turma: incentivar e } \\
\text { estimular o aluno a analisar } \\
\text { criticamente se os resultados obtidos na } \\
\text { resolução de um problema são plausíveis. }\end{array}$ & $\begin{array}{c}\text { categórica } \\
\text { nominal }\end{array}$ & $<2.10^{-16}$ \\
\hline PESO & PESO & PESO & & Contínua & $<2.10^{-16}$ \\
\hline ID_TURNO & TURNO & Turno da turma & & $\begin{array}{c}\text { Categórica } \\
\text { nominal }\end{array}$ & $<2.10^{-16}$ \\
\hline
\end{tabular}


Tabela 31 - Codificação das variáveis

\begin{tabular}{|c|c|c|c|}
\hline Questão & Questão & Alternativa & Código \\
\hline \multirow[t]{2}{*}{ Q001 } & Sexo & $\mathrm{A}$ & 0 \\
\hline & & $\mathrm{B}$ & 1 \\
\hline \multirow[t]{8}{*}{ Q004 } & Em que ano você nasceu? & $\mathrm{A}$ & 8 \\
\hline & & B & 7 \\
\hline & & $\mathrm{C}$ & 6 \\
\hline & & $\mathrm{D}$ & 5 \\
\hline & & $\mathrm{E}$ & 4 \\
\hline & & $\mathrm{F}$ & 3 \\
\hline & & G & 2 \\
\hline & & $\mathrm{H}$ & 1 \\
\hline \multirow[t]{4}{*}{ Q005 } & Na sua casa tem televisão em cores? & $\mathrm{D}$ & 1 \\
\hline & & A & 2 \\
\hline & & B & 3 \\
\hline & & $\mathrm{C}$ & 4 \\
\hline \multirow[t]{4}{*}{ Q006 } & Na sua casa tem rádio? & $\mathrm{D}$ & 1 \\
\hline & & A & 2 \\
\hline & & B & 3 \\
\hline & & $\mathrm{C}$ & 4 \\
\hline \multirow[t]{2}{*}{ Q007 } & Na sua casa tem videocassete ou DVD? & $\mathrm{B}$ & 1 \\
\hline & & A & 2 \\
\hline \multirow[t]{3}{*}{ Q008 } & Na sua casa tem geladeira? & $\mathrm{C}$ & 1 \\
\hline & & A & 2 \\
\hline & & $\mathrm{B}$ & 3 \\
\hline \multirow[t]{3}{*}{ Q009 } & Na sua casa tem freezer junto à geladeira? & $\mathrm{C}$ & 1 \\
\hline & & $\mathrm{B}$ & 2 \\
\hline & & A & 3 \\
\hline \multirow[t]{3}{*}{ Q010 } & Na sua casa tem freezer separado da geladeira? & $\mathrm{C}$ & 1 \\
\hline & & B & 2 \\
\hline & & A & 3 \\
\hline \multirow[t]{2}{*}{ Q011 } & Na sua casa tem máquina de lavar roupas? & $\mathrm{B}$ & 1 \\
\hline & & A & 2 \\
\hline \multirow[t]{4}{*}{ Q012 } & Na sua casa tem carro? & $\mathrm{D}$ & 1 \\
\hline & & A & 2 \\
\hline & & B & 3 \\
\hline & & $\mathrm{C}$ & 4 \\
\hline \multirow[t]{3}{*}{ Q013 } & Na sua casa tem computador? & $\mathrm{C}$ & 1 \\
\hline & & B & 2 \\
\hline & & A & 3 \\
\hline Q014 & Dentro da sua casa tem banheiro? & $\mathrm{E}$ & 1 \\
\hline & & A & 2 \\
\hline & & $\mathrm{B}$ & 3 \\
\hline & & $\mathrm{C}$ & 4 \\
\hline & & $\mathrm{D}$ & 5 \\
\hline Q015 & Na sua casa trabalha alguma empregada doméstica? & $\mathrm{D}$ & 1 \\
\hline & & A & 2 \\
\hline & & $\mathrm{B}$ & 3 \\
\hline & & $\mathrm{C}$ & 4 \\
\hline Q016 & Na sua casa tem quartos para dormir? & $\mathrm{E}$ & 1 \\
\hline & & A & 2 \\
\hline & & B & 3 \\
\hline & & $\mathrm{C}$ & 4 \\
\hline & & $\mathrm{D}$ & 5 \\
\hline Q017 & Quantas pessoas moram com você? & $\mathrm{A}$ & 1 \\
\hline & & $\mathrm{B}$ & 2 \\
\hline & & $\mathrm{C}$ & 3 \\
\hline & & $\mathrm{D}$ & 4 \\
\hline & & $\mathrm{E}$ & 5 \\
\hline & & $\mathrm{F}$ & 6 \\
\hline & & G & 7 \\
\hline Q018 & Você mora com sua mãe? & $\mathrm{B}$ & 1 \\
\hline & & $\mathrm{C}$ & 2 \\
\hline & & A & 3 \\
\hline Q019 & Até que série sua mãe ou a mulher responsável por você estudou? & G & 1 \\
\hline & & A & 2 \\
\hline & & B & 3 \\
\hline & & $\mathrm{C}$ & 4 \\
\hline & & $\mathrm{D}$ & 5 \\
\hline & & $\mathrm{E}$ & 6 \\
\hline & & $\mathrm{F}$ & 7 \\
\hline Q020 & Sua mãe ou mulher responsável por você sabe ler e escrever? & $\mathrm{C}$ & 1 \\
\hline & & $\mathrm{B}$ & 2 \\
\hline & & A & 3 \\
\hline
\end{tabular}




\begin{tabular}{|c|c|c|c|}
\hline Questão & Questão & Alternativa & Código \\
\hline \multirow[t]{2}{*}{ Q021 } & Você vê sua mãe ou mulher responsável por você lendo? & B & 1 \\
\hline & & A & 2 \\
\hline \multirow[t]{3}{*}{ Q022 } & Você mora com seu pai? & B & 1 \\
\hline & & $\mathrm{C}$ & 2 \\
\hline & & A & 3 \\
\hline \multirow[t]{7}{*}{ Q023 } & Até que série seu pai ou o homem responsável por você estudou? & G & 1 \\
\hline & & A & 2 \\
\hline & & B & 3 \\
\hline & & $\mathrm{C}$ & 4 \\
\hline & & D & 5 \\
\hline & & E & 6 \\
\hline & & $\mathrm{F}$ & 7 \\
\hline \multirow[t]{3}{*}{ Q024 } & Seu pai ou homem responsável por você sabe ler e escrever? & $\mathrm{C}$ & 1 \\
\hline & & B & 2 \\
\hline & & A & 3 \\
\hline \multirow[t]{2}{*}{ Q025 } & Você vê o seu pai ou homem responsável por você lendo? & B & 1 \\
\hline & & A & 2 \\
\hline \multirow[t]{3}{*}{ Q026 } & Com que frequência seus pais ou responsáveis vão á reunião de pais? & $\mathrm{C}$ & 1 \\
\hline & & B & 2 \\
\hline & & A & 3 \\
\hline \multirow[t]{2}{*}{ Q027 } & Seus pais ou responsáveis incentivam você a estudar? & B & 1 \\
\hline & & A & 2 \\
\hline \multirow[t]{2}{*}{ Q028 } & Seus pais ou responsáveis incentivam você a fazer o dever de casa e os trabalhos da escola? & B & 1 \\
\hline & & A & 2 \\
\hline \multirow[t]{2}{*}{ Q029 } & Seus pais ou responsáveis incentivam você a ler? & $\bar{B}$ & 1 \\
\hline & & A & 2 \\
\hline Q030 & Seus pais ou responsáveis incentivam você a ir à escola e não faltar ás aulas? & B & 1 \\
\hline & & A & 2 \\
\hline Q031 & Seus pais ou responsáveis conversam com você sobre o que acontece na escola? & B & 1 \\
\hline & & A & 2 \\
\hline Q032 & Você lê: Jornais & $\mathrm{C}$ & 1 \\
\hline & & B & 2 \\
\hline & & A & 3 \\
\hline Q033 & Você lê: Livros em geral & $\mathrm{C}$ & 1 \\
\hline & & B & 2 \\
\hline & & A & 3 \\
\hline Q034 & Você lê: Livros de literatura infanto-juvenil. & A & 3 \\
\hline & & B & 2 \\
\hline & & $\mathrm{C}$ & 1 \\
\hline Q035 & Você lê: Revistas em geral. & A & 3 \\
\hline & & B & 2 \\
\hline & & $\mathrm{C}$ & 1 \\
\hline Q036 & Você lê: Revistas em quadrinhos. & A & 3 \\
\hline & & B & 2 \\
\hline & & $\mathrm{C}$ & 1 \\
\hline Q037 & Você lê: Revistas sobre comportamento, celebridades, esporte e TV. & A & 3 \\
\hline & & B & 2 \\
\hline & & $\mathrm{C}$ & 1 \\
\hline Q038 & Você lê: Sites da internet. & A & 3 \\
\hline & & B & 2 \\
\hline & & $\mathrm{C}$ & 1 \\
\hline Q039 & Você Costuma: Frequentar bibliotecas. & A & 3 \\
\hline & & B & 2 \\
\hline & & $\mathrm{C}$ & 1 \\
\hline Q040 & Você Costuma: Ir ao cinema. & A & 3 \\
\hline & & B & 2 \\
\hline & & $\mathrm{C}$ & 1 \\
\hline Q041 & Você Costuma: Ver apresentações teatrais. & A & 3 \\
\hline & & B & 2 \\
\hline & & $\mathrm{C}$ & 1 \\
\hline Q042 & Você Costuma: Ver apresentações musicais ou de dança. & A & 3 \\
\hline & & B & 2 \\
\hline & & $\mathrm{C}$ & 1 \\
\hline Q043 & Você Costuma: Participar de festas abertas à comunidade. & A & 3 \\
\hline & & B & 2 \\
\hline & & $\mathrm{C}$ & 1 \\
\hline Q044 & Em dia de aula, quanto tempo você gasta assistindo à TV, navegando na internet ou jogando jogos & A & 1 \\
\hline & eletrônicos? & B & 2 \\
\hline & & $\mathrm{C}$ & 3 \\
\hline & & $\mathrm{D}$ & 4 \\
\hline Q045 & Em dias de aula, quanto tempo você gasta fazendo trabalhos domésticos? & A & 2 \\
\hline & & B & 3 \\
\hline & & $\mathrm{C}$ & 4 \\
\hline & & $\mathrm{D}$ & 5 \\
\hline & & E & 1 \\
\hline
\end{tabular}




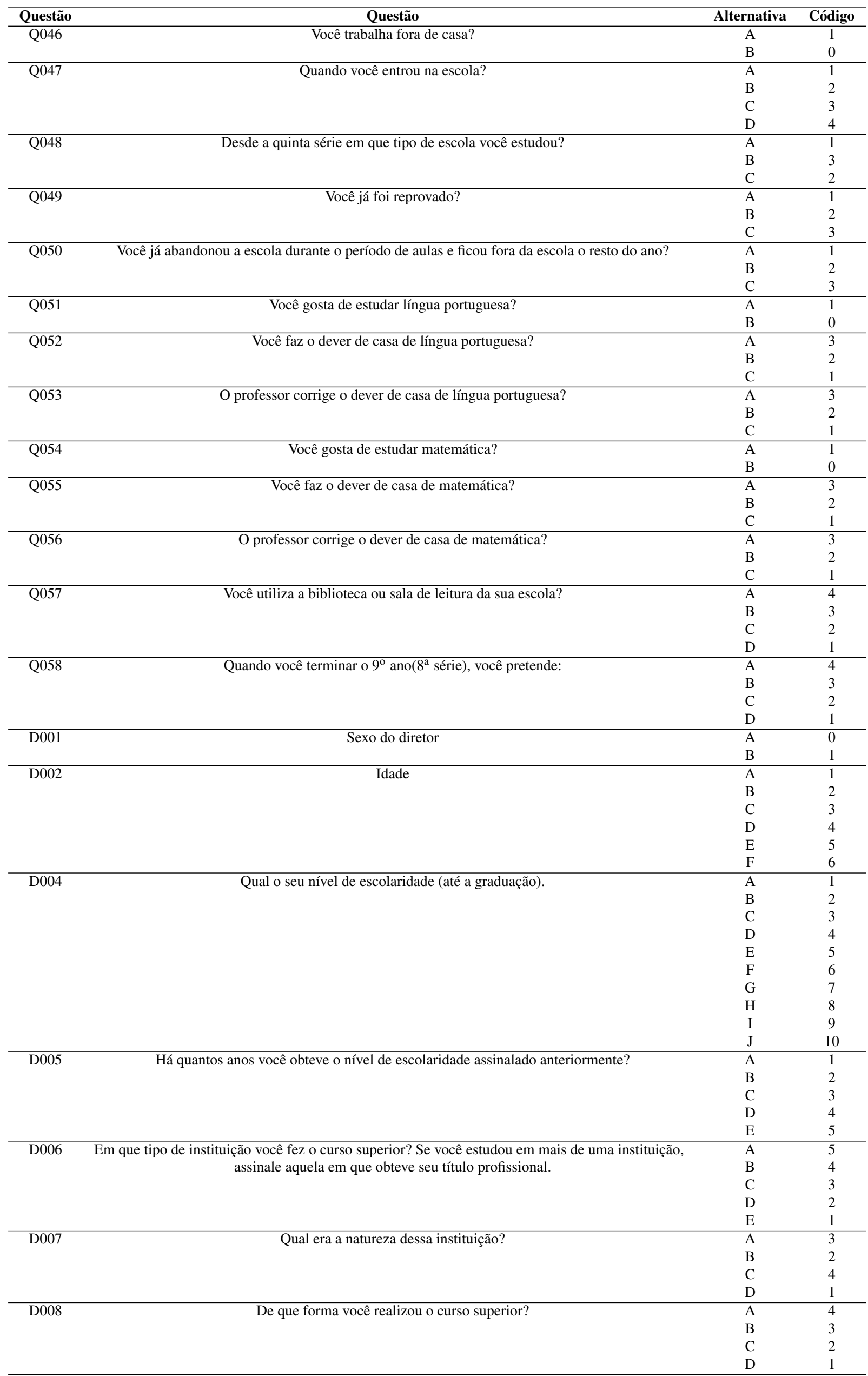




\begin{tabular}{|c|c|c|c|}
\hline Questão & Questão & Alternativa & Código \\
\hline \multirow[t]{5}{*}{ D009 } & Indique a modalidade de cursos de pós-graduação de mais alta titulação que você possui. & $\mathrm{A}$ & 2 \\
\hline & & $\mathrm{B}$ & 3 \\
\hline & & $\mathrm{C}$ & 4 \\
\hline & & $\mathrm{D}$ & 5 \\
\hline & & $\mathrm{E}$ & 1 \\
\hline \multirow[t]{5}{*}{ D010 } & Indique qual a área temática do curso de pós-graduação de mais alta titulação que você possui. & A & 5 \\
\hline & & $\mathrm{B}$ & 4 \\
\hline & & $\mathrm{C}$ & 3 \\
\hline & & $\mathrm{D}$ & 2 \\
\hline & & $\mathrm{E}$ & 1 \\
\hline \multirow[t]{2}{*}{ D011 } & Você participou de alguma atividade de formação continuada (atualização, treinamento, capacitação & A & 1 \\
\hline & nos últimos dois anos?etc.) & $\mathrm{B}$ & 0 \\
\hline \multirow[t]{4}{*}{ D012 } & Qual a carga horária da atividade mais relevante da qual você participou? & A & 1 \\
\hline & & B & 2 \\
\hline & & $\mathrm{C}$ & 3 \\
\hline & & $\mathrm{D}$ & 4 \\
\hline \multirow[t]{4}{*}{ D013 } & Você utiliza os conhecimentos adquiridos nas atividades de formação continuada de que você & A & 4 \\
\hline & participou? & B & 3 \\
\hline & & $\mathrm{C}$ & 2 \\
\hline & & $\mathrm{D}$ & 1 \\
\hline \multirow[t]{11}{*}{ D014 } & Qual é aproximadamente o seu salário bruto como diretor(a), com adicionais, se houver? (preencha & A & 1 \\
\hline & os espaços com o valor e, abaixo de cada algarismo, marque o campo & B & 2 \\
\hline & & $\mathrm{C}$ & 3 \\
\hline & & $\mathrm{D}$ & 4 \\
\hline & & $\mathrm{E}$ & 5 \\
\hline & & $\mathrm{F}$ & 6 \\
\hline & & $\mathrm{G}$ & 7 \\
\hline & & $\mathrm{H}$ & 8 \\
\hline & & I & 9 \\
\hline & & $\mathrm{J}$ & 10 \\
\hline & & $\mathrm{K}$ & 11 \\
\hline \multirow[t]{11}{*}{ D015 } & Qual é aproximadamente sua renda familiar bruta? (preencha os espaços com o valor e, abaixo de & A & 1 \\
\hline & cada algarismo, marque o campo correspondente.) & $\mathrm{B}$ & 2 \\
\hline & & $\mathrm{C}$ & 3 \\
\hline & & $\mathrm{D}$ & 4 \\
\hline & & $\mathrm{E}$ & 5 \\
\hline & & $\mathrm{F}$ & 6 \\
\hline & & G & 7 \\
\hline & & $\mathrm{H}$ & 8 \\
\hline & & I & 9 \\
\hline & & $\mathrm{J}$ & 10 \\
\hline & & $\mathrm{K}$ & 11 \\
\hline \multirow[t]{3}{*}{ D016 } & Além da direção desta escola, você exerce outra atividade que contribui para sua renda pessoal? & A & 3 \\
\hline & & B & 2 \\
\hline & & $\mathrm{C}$ & 1 \\
\hline \multirow[t]{8}{*}{ D017 } & Há quantos anos você trabalha em educação? & A & 1 \\
\hline & & B & 2 \\
\hline & & $\mathrm{C}$ & 3 \\
\hline & & $\mathrm{D}$ & 4 \\
\hline & & $\mathrm{E}$ & 5 \\
\hline & & $\mathrm{F}$ & 6 \\
\hline & & $\mathrm{G}$ & 7 \\
\hline & & $\mathrm{H}$ & 8 \\
\hline D018 & Há quantos anos você exerce funções de direção? & A & 1 \\
\hline & & $\mathrm{B}$ & 2 \\
\hline & & $\mathrm{C}$ & 3 \\
\hline & & $\mathrm{D}$ & 4 \\
\hline & & $\mathrm{E}$ & 5 \\
\hline & & $\mathrm{F}$ & 6 \\
\hline & & $\mathrm{G}$ & 7 \\
\hline & & $\mathrm{H}$ & 8 \\
\hline D019 & Há quantos anos você é diretor(a) desta escola? & A & 1 \\
\hline & & $\mathrm{B}$ & 2 \\
\hline & & $\mathrm{C}$ & 3 \\
\hline & & $\mathrm{D}$ & 4 \\
\hline & & $\mathrm{E}$ & 5 \\
\hline & & $\mathrm{F}$ & 6 \\
\hline & & $\mathrm{G}$ & 7 \\
\hline & & $\mathrm{H}$ & 8 \\
\hline D020 & Qual é a sua carga horária de trabalho nesta escola? & A & 1 \\
\hline & & B & 2 \\
\hline & & $\mathrm{C}$ & 3 \\
\hline & & $\mathrm{D}$ & 4 \\
\hline D022 & Você promoveu alguma atividade de formação continuada (atualização, treinamento, capacitação & A & 1 \\
\hline & etc.) Nesta escola? & $\mathrm{B}$ & 0 \\
\hline
\end{tabular}




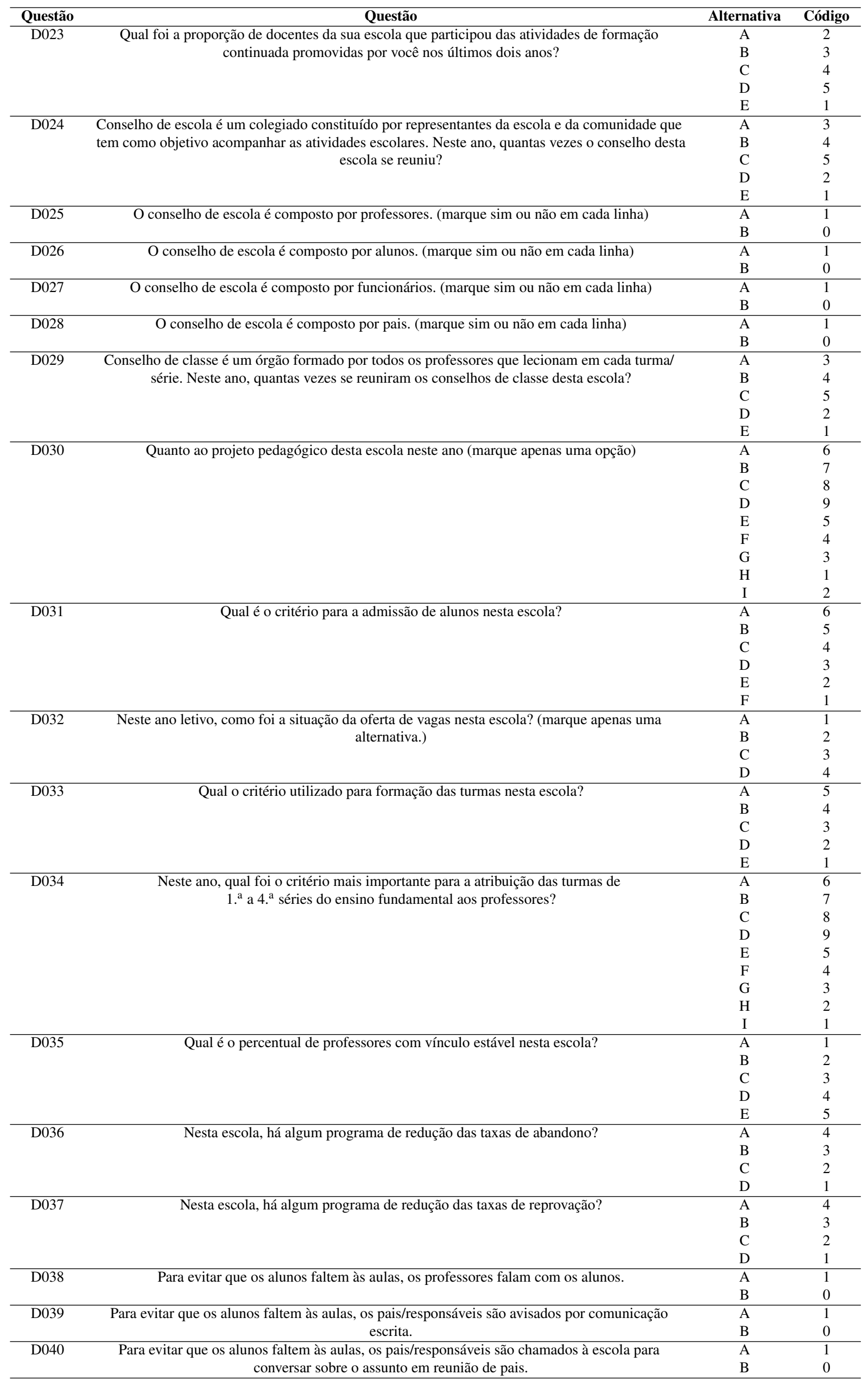




\begin{tabular}{|c|c|c|c|}
\hline Questão & Questão & Alternativa & Código \\
\hline \multirow[t]{2}{*}{ D041 } & Para evitar que os alunos faltem às aulas, os pais/responsáveis são chamados à escola para & A & 1 \\
\hline & conversar sobre o assunto individualmente. & $\mathrm{B}$ & 0 \\
\hline \multirow[t]{2}{*}{ D042 } & Para evitar que os alunos faltem às aulas, a escola envia alguém à casa do aluno. & A & 1 \\
\hline & & $\mathrm{B}$ & 0 \\
\hline \multirow[t]{2}{*}{ D043 } & Esta escola desenvolve, regularmente, algum programa de apoio ou reforço de aprendizagem para & A & 1 \\
\hline & os alunos (monitoria, aula de reforço etc.)? & $\mathrm{B}$ & 0 \\
\hline \multirow[t]{2}{*}{ D044 } & Você tem conhecimento do conteúdo da lei 11.645 de 2008 que determina a obrigatoriedade do & A & 1 \\
\hline & $\begin{array}{c}\text { estudo da temática "história e cultura afro-brasileira e indígena"nos estabelecimentos de } \\
\text { ensino do país? }\end{array}$ & B & 0 \\
\hline \multirow[t]{3}{*}{ D045 } & Neste ano, foram desenvolvidas atividades para atender o determinado pela lei 11.645 de & A & 3 \\
\hline & 2008 nesta escola? & $\mathrm{B}$ & 2 \\
\hline & & $\mathrm{C}$ & 1 \\
\hline \multirow[t]{5}{*}{ D046 } & Em relação à merenda escolar, como você considera recursos financeiros. & A & 1 \\
\hline & & B & 2 \\
\hline & & $\mathrm{C}$ & 3 \\
\hline & & $\mathrm{D}$ & 4 \\
\hline & & $\mathrm{E}$ & 5 \\
\hline \multirow[t]{5}{*}{ D047 } & Em relação à merenda escolar, como você considera quantidade de alimentos. & $\mathrm{A}$ & 1 \\
\hline & & B & 2 \\
\hline & & $\mathrm{C}$ & 3 \\
\hline & & $\mathrm{D}$ & 4 \\
\hline & & $\mathrm{E}$ & 5 \\
\hline \multirow[t]{5}{*}{ D048 } & Em relação à merenda escolar, como você considera qualidade dos alimentos. & A & 1 \\
\hline & & $\mathrm{B}$ & 2 \\
\hline & & $\mathrm{C}$ & 3 \\
\hline & & $\mathrm{D}$ & 4 \\
\hline & & $\mathrm{E}$ & 5 \\
\hline \multirow[t]{5}{*}{ D049 } & Em relação à merenda escolar, como você considera variedade do cardápio. & A & 1 \\
\hline & & B & 2 \\
\hline & & $\mathrm{C}$ & 3 \\
\hline & & $\mathrm{D}$ & 4 \\
\hline & & $\mathrm{E}$ & 5 \\
\hline \multirow[t]{5}{*}{ D050 } & Em relação à merenda escolar, como você considera armazenamento e & A & 1 \\
\hline & conservação. & B & 2 \\
\hline & & $\mathrm{C}$ & 3 \\
\hline & & $\mathrm{D}$ & 4 \\
\hline & & $\mathrm{E}$ & 5 \\
\hline \multirow[t]{5}{*}{ D051 } & Em relação à merenda escolar, como você considera espaço físico para & $\mathrm{A}$ & 1 \\
\hline & cozinhar. & $\mathrm{B}$ & 2 \\
\hline & & $\mathrm{C}$ & 3 \\
\hline & & $\mathrm{D}$ & 4 \\
\hline & & $\mathrm{E}$ & 5 \\
\hline \multirow[t]{5}{*}{ D052 } & Em relação à merenda escolar, como você considera higiene. & A & 1 \\
\hline & & $\mathrm{B}$ & 2 \\
\hline & & $\mathrm{C}$ & 3 \\
\hline & & $\mathrm{D}$ & 4 \\
\hline & & $\mathrm{E}$ & 5 \\
\hline D053 & Em relação à merenda escolar, como você considera disponibilidade de & A & 1 \\
\hline & pessoal. & B & 2 \\
\hline & & $\mathrm{C}$ & 3 \\
\hline & & $\mathrm{D}$ & 4 \\
\hline & & $\mathrm{E}$ & 5 \\
\hline D054 & Em relação à merenda escolar, como você considera qualificação do pessoal. & A & 1 \\
\hline & & B & 2 \\
\hline & & $\mathrm{C}$ & 3 \\
\hline & & $\mathrm{D}$ & 4 \\
\hline & & $\mathrm{E}$ & 5 \\
\hline D055 & As perguntas de 55 a 64 apresentam alguns problemas que podem ocorrer nas & A & 3 \\
\hline & escolas. Responda se cada um deles ocorreu ou não neste ano. Caso tenha & $\mathrm{B}$ & 2 \\
\hline & ocorrido, assinale se foi ou não um problema grave, dificultando o & $\mathrm{C}$ & 1 \\
\hline & funcionamento da escola. (marque apenas uma opção em cada linha.) Ocorreu & & \\
\hline & na escola insuficiência de recursos financeiros? & & \\
\hline D056 & As perguntas de 55 a 64 apresentam alguns problemas que podem ocorrer nas & A & 3 \\
\hline & escolas. Responda se cada um deles ocorreu ou não neste ano. Caso tenha & B & 2 \\
\hline & ocorrido, assinale se foi ou não um problema grave, dificultando o & $\mathrm{C}$ & 1 \\
\hline & funcionamento da escola. (marque apenas uma opção em cada linha.) Ocorreu & & \\
\hline & na escola inexistência de professores para algumas disciplinas ou séries? & & \\
\hline D057 & As perguntas de 55 a 64 apresentam alguns problemas que podem ocorrer nas & A & 3 \\
\hline & escolas. Responda se cada um deles ocorreu ou não neste ano. Caso tenha & $\mathrm{B}$ & 2 \\
\hline & ocorrido, assinale se foi ou não um problema grave, dificultando o & $\mathrm{C}$ & 1 \\
\hline & $\begin{array}{l}\text { funcionamento da escola. (marque apenas uma opção em cada linha.) Ocorreu } \\
\text { na escola carência de pessoal administrativo? }\end{array}$ & & \\
\hline
\end{tabular}




\begin{tabular}{|c|c|c|c|}
\hline Questão & Questão & Alternativa & Código \\
\hline D058 & $\begin{array}{l}\text { As perguntas de } 55 \text { a } 64 \text { apresentam alguns problemas que podem ocorrer nas } \\
\text { escolas. Responda se cada um deles ocorreu ou não neste ano. Caso tenha } \\
\text { ocorrido, assinale se foi ou não um problema grave, dificultando o } \\
\text { funcionamento da escola.(marque apenas uma opção em cada linha.) Ocorreu } \\
\text { na escola carência de pessoal de apoio pedagógico (coordenador, } \\
\text { supervisor, orientador educacional)? }\end{array}$ & $\begin{array}{l}\text { A } \\
\text { B } \\
\text { C }\end{array}$ & $\begin{array}{l}3 \\
2 \\
1\end{array}$ \\
\hline D059 & $\begin{array}{l}\text { As perguntas de } 55 \text { a } 64 \text { apresentam alguns problemas que podem ocorrer nas } \\
\text { escolas. Responda se cada um deles ocorreu ou não neste ano. Caso tenha } \\
\text { ocorrido, assinale se foi ou não um problema grave, dificultando o } \\
\text { funcionamento da escola.(marque apenas uma opção em cada linha.) Ocorreu } \\
\text { na escola falta de recursos pedagógicos? }\end{array}$ & $\begin{array}{l}\text { A } \\
\text { B } \\
\text { C }\end{array}$ & $\begin{array}{l}3 \\
2 \\
1\end{array}$ \\
\hline D060 & $\begin{array}{l}\text { As perguntas de } 55 \text { a } 64 \text { apresentam alguns problemas que podem ocorrer nas } \\
\text { escolas. Responda se cada um deles ocorreu ou não neste ano. Caso tenha } \\
\text { ocorrido, assinale se foi ou não um problema grave, dificultando o } \\
\text { funcionamento da escola.(marque apenas uma opção em cada linha.) Ocorreu } \\
\text { na escola interrupção das atividades escolares? }\end{array}$ & $\begin{array}{l}\text { A } \\
\text { B } \\
\text { C }\end{array}$ & $\begin{array}{l}3 \\
2 \\
1\end{array}$ \\
\hline D061 & $\begin{array}{l}\text { As perguntas de } 55 \text { a } 64 \text { apresentam alguns problemas que podem ocorrer nas } \\
\text { escolas. Responda se cada um deles ocorreu ou não neste ano. Caso tenha } \\
\text { ocorrido, assinale se foi ou não um problema grave, dificultando o } \\
\text { funcionamento da escola.(marque apenas uma opção em cada linha.) Ocorreu } \\
\text { na escola alto índice de faltas por parte de professores? }\end{array}$ & $\begin{array}{l}\text { A } \\
\text { B } \\
\text { C }\end{array}$ & $\begin{array}{l}3 \\
2 \\
1\end{array}$ \\
\hline D062 & $\begin{array}{l}\text { As perguntas de } 55 \text { a } 64 \text { apresentam alguns problemas que podem ocorrer nas } \\
\text { escolas. Responda se cada um deles ocorreu ou não neste ano. Caso tenha } \\
\text { ocorrido, assinale se foi ou não um problema grave, dificultando o } \\
\text { funcionamento da escola.(marque apenas uma opção em cada linha.) Ocorreu } \\
\text { na escola alto índice de faltas por parte de alunos? }\end{array}$ & $\begin{array}{l}\text { A } \\
\text { B } \\
\text { C }\end{array}$ & $\begin{array}{l}3 \\
2 \\
1\end{array}$ \\
\hline D063 & $\begin{array}{l}\text { As perguntas de } 55 \text { a } 64 \text { apresentam alguns problemas que podem ocorrer nas } \\
\text { escolas. Responda se cada um deles ocorreu ou não neste ano. Caso tenha } \\
\text { ocorrido, assinale se foi ou não um problema grave, dificultando o } \\
\text { funcionamento da escola.(marque apenas uma opção em cada linha.) Ocorreu } \\
\text { na escola rotatividade do corpo docente? }\end{array}$ & $\begin{array}{l}\text { A } \\
\text { B } \\
\text { C }\end{array}$ & $\begin{array}{l}3 \\
2 \\
1\end{array}$ \\
\hline D064 & $\begin{array}{l}\text { As perguntas de } 55 \text { a } 64 \text { apresentam alguns problemas que podem ocorrer nas } \\
\text { escolas. Responda se cada um deles ocorreu ou não neste ano. Caso tenha } \\
\text { ocorrido, assinale se foi ou não um problema grave, dificultando o } \\
\text { funcionamento da escola.(marque apenas uma opção em cada linha.) Ocorreu } \\
\text { na escola problemas disciplinares causados por alunos? }\end{array}$ & $\begin{array}{l}\text { A } \\
\text { B } \\
\text { C }\end{array}$ & $\begin{array}{l}3 \\
2 \\
1\end{array}$ \\
\hline D065 & $\begin{array}{l}\text { Considere as condições existentes para o exercício do cargo de diretor } \\
\text { nesta escola. Há interferências externas em sua gestão? }\end{array}$ & $\begin{array}{l}\text { A } \\
\text { B }\end{array}$ & $\begin{array}{l}1 \\
0\end{array}$ \\
\hline D066 & $\begin{array}{c}\text { Considere as condições existentes para o exercício do cargo de diretor } \\
\text { nesta escola. Há apoio de instâncias superiores? }\end{array}$ & $\begin{array}{l}\text { A } \\
\text { B }\end{array}$ & $\begin{array}{l}1 \\
0\end{array}$ \\
\hline D067 & $\begin{array}{l}\text { Considere as condições existentes para o exercício do cargo de diretor } \\
\text { nesta escola. Há troca de informações com diretores de outras escolas? }\end{array}$ & $\begin{array}{l}\mathrm{A} \\
\mathrm{B}\end{array}$ & $\begin{array}{l}1 \\
0\end{array}$ \\
\hline D068 & $\begin{array}{c}\text { Considere as condições existentes para o exercício do cargo de diretor } \\
\text { nesta escola. Há apoio da comunidade à sua gestão? }\end{array}$ & $\begin{array}{l}\text { A } \\
\text { B }\end{array}$ & $\begin{array}{l}1 \\
0\end{array}$ \\
\hline D069 & $\begin{array}{l}\text { As perguntas de } 69 \text { a } 113 \text { referem-se às condições de acessibilidade. Nas } \\
\text { imediações ou na frente da escola, as calçadas possuem pavimento regular, } \\
\text { plano, sem buracos ou degraus? }\end{array}$ & $\begin{array}{l}\text { A } \\
\text { B }\end{array}$ & $\begin{array}{l}1 \\
0\end{array}$ \\
\hline D070 & $\begin{array}{l}\text { As perguntas de } 69 \text { a } 113 \text { referem-se às condições de acessibilidade. Nas } \\
\text { imediações ou na frente da escola, as calçadas possuem largura mínima de } \\
1,20 \mathrm{~m} \text { ? }\end{array}$ & $\begin{array}{l}\text { A } \\
\text { B }\end{array}$ & $\begin{array}{l}1 \\
0\end{array}$ \\
\hline D071 & $\begin{array}{l}\text { As perguntas de } 69 \text { a } 113 \text { referem-se às condições de acessibilidade. Nas } \\
\text { imediações ou na frente da escola, as calçadas garantem uma faixa de } \\
\text { circulação livre de obstáculos com largura mínima de } 80 \mathrm{~cm} \text { ? (obstáculos: } \\
\text { poste, árvore, floreira, orelhão, lixeira, placa de sinalização etc.) }\end{array}$ & $\begin{array}{l}\text { A } \\
\text { B }\end{array}$ & $\begin{array}{l}1 \\
0\end{array}$ \\
\hline D072 & $\begin{array}{l}\text { As perguntas de } 69 \text { a } 113 \text { referem-se às condições de acessibilidade. Nas } \\
\text { imediações ou na frente da escola: há semáforos para pedestres? }\end{array}$ & $\begin{array}{l}\text { A } \\
\text { B }\end{array}$ & $\begin{array}{l}1 \\
0\end{array}$ \\
\hline D073 & $\begin{array}{l}\text { As perguntas de } 69 \text { a } 113 \text { referem-se às condições de acessibilidade. Nas } \\
\text { imediações ou na frente da escola: o semáforo é sonoro? }\end{array}$ & $\begin{array}{l}\text { A } \\
\text { B }\end{array}$ & $\begin{array}{l}1 \\
0\end{array}$ \\
\hline D074 & $\begin{array}{c}\text { As perguntas de } 69 \text { a } 113 \text { referem-se às condições de acessibilidade. Nas } \\
\text { imediações ou na frente da escola: há faixa de travessia (faixa de } \\
\text { pedestres ou faixa de segurança)? }\end{array}$ & $\begin{array}{l}\text { A } \\
\text { B }\end{array}$ & $\begin{array}{l}1 \\
0\end{array}$ \\
\hline D075 & $\begin{array}{l}\text { As perguntas de } 69 \text { a } 113 \text { referem-se às condições de acessibilidade. Nas } \\
\text { imediações ou na frente da escola: as calçadas são rebaixadas com rampas } \\
\text { dos dois lados da rua no trecho da travessia? }\end{array}$ & $\begin{array}{l}\text { A } \\
\text { B }\end{array}$ & $\begin{array}{l}1 \\
0\end{array}$ \\
\hline D076 & $\begin{array}{l}\text { As perguntas de } 69 \text { a } 113 \text { referem-se às condições de acessibilidade. Nas } \\
\text { imediações ou na frente da escola: há vagas sinalizadas para veículos para } \\
\text { pessoas com deficiência? }\end{array}$ & $\begin{array}{l}\text { A } \\
\text { B }\end{array}$ & $\begin{array}{l}1 \\
0\end{array}$ \\
\hline D077 & $\begin{array}{c}\text { As perguntas de } 69 \text { a } 113 \text { referem-se às condições de acessibilidade. Nas } \\
\text { imediações ou na frente da escola: o portão de acesso de pedestres à } \\
\text { escola é separado da entrada de carros? }\end{array}$ & $\begin{array}{l}\text { A } \\
\text { B }\end{array}$ & $\begin{array}{l}1 \\
0\end{array}$ \\
\hline D078 & $\begin{array}{l}\text { As perguntas de } 69 \text { a } 113 \text { referem-se às condições de acessibilidade. Nas } \\
\text { imediações ou na frente da escola: o portão de acesso tem largura mínima } \\
\text { de } 80 \mathrm{~cm} \text { ? }\end{array}$ & $\begin{array}{l}\text { A } \\
\text { B }\end{array}$ & $\begin{array}{l}1 \\
0\end{array}$ \\
\hline
\end{tabular}




\begin{tabular}{|c|c|c|c|}
\hline Questão & Questão & Alternativa & Código \\
\hline D079 & $\begin{array}{c}\text { As perguntas de } 69 \text { a } 113 \text { referem-se às condições de acessibilidade. No } \\
\text { interior da escola, na entrada principal e nas circulações internas: os } \\
\text { corredores e as calçadas tem largura mínima de } 1,20 \mathrm{~cm} \text { ? }\end{array}$ & $\begin{array}{l}\text { A } \\
\text { B }\end{array}$ & $\begin{array}{l}1 \\
0\end{array}$ \\
\hline D080 & $\begin{array}{l}\text { As perguntas de } 69 \text { a } 113 \text { referem-se às condições de acessibilidade. No } \\
\text { interior da escola, na entrada principal e nas circulações internas: há } \\
\text { faixa de circulação livre de obstáculos com largura mínima de } 80 \mathrm{~cm} \text { ? } \\
\text { (obstáculos: extintor de incêndio, vasos, lixeiras, móveis, bebedouros etc.) }\end{array}$ & $\begin{array}{l}\text { A } \\
\text { B }\end{array}$ & $\begin{array}{l}1 \\
0\end{array}$ \\
\hline D081 & $\begin{array}{l}\text { As perguntas de } 69 \text { a } 113 \text { referem-se às condiçóes de acessibilidade. No } \\
\text { interior da escola, na entrada principal e nas circulações internas: o } \\
\text { piso é plano, sem degraus e sem desníveis superiores a } 1,5 \mathrm{~cm} ?\end{array}$ & $\begin{array}{l}\text { A } \\
\text { B }\end{array}$ & $\begin{array}{l}1 \\
0\end{array}$ \\
\hline D082 & $\begin{array}{c}\text { As perguntas de } 69 \text { a } 113 \text { referem-se às condições de acessibilidade. No } \\
\text { interior da escola, na entrada principal e nas circulações internas: há } \\
\text { rampas? }\end{array}$ & $\begin{array}{l}\text { A } \\
\text { B }\end{array}$ & $\begin{array}{l}1 \\
0\end{array}$ \\
\hline D083 & $\begin{array}{c}\text { As perguntas de } 69 \text { a } 113 \text { referem-se às condições de acessibilidade. No } \\
\text { interior da escola, na entrada principal e nas circulações internas: as } \\
\text { rampas têm largura mínima de } 80 \mathrm{~cm} ?\end{array}$ & $\begin{array}{l}\text { A } \\
\text { B }\end{array}$ & $\begin{array}{l}1 \\
0\end{array}$ \\
\hline D084 & $\begin{array}{c}\text { As perguntas de } 69 \text { a } 113 \text { referem-se às condições de acessibilidade. No } \\
\text { interior da escola, na entrada principal e nas circulações internas: há } \\
\text { rampas com corrimão dos dois lados? }\end{array}$ & $\begin{array}{l}\text { A } \\
\text { B } \\
\text { C }\end{array}$ & $\begin{array}{l}3 \\
2 \\
1\end{array}$ \\
\hline D085 & $\begin{array}{c}\text { As perguntas de } 69 \text { a } 113 \text { referem-se às condições de acessibilidade. No } \\
\text { interior da escola, na entrada principal e nas circulações internas: as } \\
\text { escadas têm corrimãos dos dois lados? }\end{array}$ & $\begin{array}{l}\mathrm{A} \\
\mathrm{B} \\
\mathrm{C}\end{array}$ & $\begin{array}{l}3 \\
2 \\
1\end{array}$ \\
\hline D086 & $\begin{array}{c}\text { As perguntas de } 69 \text { a } 113 \text { referem-se às condições de acessibilidade. No } \\
\text { interior da escola, na entrada principal e nas circulações internas: há } \\
\text { elevadores ou plataformas elevatórias? }\end{array}$ & $\begin{array}{l}\text { A } \\
\text { B } \\
\text { C }\end{array}$ & $\begin{array}{l}3 \\
2 \\
1\end{array}$ \\
\hline D087 & $\begin{array}{c}\text { As perguntas de } 69 \text { a } 113 \text { referem-se às condições de acessibilidade. Nas } \\
\text { salas de aula, na administração, na biblioteca e outros ambientes: nas } \\
\text { portas, há soleiras niveladas com o piso do corredor, pequenas rampas ou } \\
\text { degraus de no máximo } 1,5 \mathrm{~cm} \text { ? }\end{array}$ & $\begin{array}{l}\text { A } \\
\text { B }\end{array}$ & $\begin{array}{l}1 \\
0\end{array}$ \\
\hline D088 & $\begin{array}{l}\text { As perguntas de } 69 \text { a } 113 \text { referem-se às condições de acessibilidade. Nas } \\
\text { salas de aula, na administração, na biblioteca e outros ambientes: as } \\
\text { portas de entrada possuem largura mínima de } 80 \mathrm{~cm} \text { ? }\end{array}$ & $\begin{array}{l}\text { A } \\
\text { B }\end{array}$ & $\begin{array}{l}1 \\
0\end{array}$ \\
\hline D089 & $\begin{array}{l}\text { As perguntas de } 69 \text { a } 113 \text { referem-se às condições de acessibilidade. Nas } \\
\text { salas de aula, na administração, na biblioteca e outros ambientes: as } \\
\text { maçanetas são de alavanca? }\end{array}$ & $\begin{array}{l}\text { A } \\
\text { B }\end{array}$ & $\begin{array}{l}1 \\
0\end{array}$ \\
\hline D090 & $\begin{array}{l}\text { As perguntas de } 69 \text { a } 113 \text { referem-se às condições de acessibilidade. Nas } \\
\text { salas de aula, na administração, na biblioteca e outros ambientes: há algum } \\
\text { tipo de sinalização em braile nos ambientes? }\end{array}$ & $\begin{array}{l}\text { A } \\
\text { B }\end{array}$ & $\begin{array}{l}1 \\
0\end{array}$ \\
\hline D091 & $\begin{array}{l}\text { As perguntas de } 69 \text { a } 113 \text { referem-se às condições de acessibilidade. Os } \\
\text { banheiros: há pelo menos um sanitário adequado a pessoas com deficiência? }\end{array}$ & $\begin{array}{l}\text { A } \\
\text { B }\end{array}$ & $\begin{array}{l}1 \\
0\end{array}$ \\
\hline D092 & $\begin{array}{c}\text { As perguntas de } 69 \text { a } 113 \text { referem-se às condições de acessibilidade. Os } \\
\text { banheiros: há pelo menos um sanitário adequado a pessoas com deficiência } \\
\text { para cada sexo? }\end{array}$ & $\begin{array}{l}\text { A } \\
\text { B }\end{array}$ & $\begin{array}{l}1 \\
0\end{array}$ \\
\hline D093 & $\begin{array}{c}\text { As perguntas de } 69 \text { a } 113 \text { referem-se às condições de acessibilidade. Os } \\
\text { banheiros: as portas possuem largura mínima de } 80 \mathrm{~cm} \text { ? }\end{array}$ & $\begin{array}{l}\text { A } \\
\text { B }\end{array}$ & $\begin{array}{l}1 \\
0\end{array}$ \\
\hline D094 & $\begin{array}{l}\text { As perguntas de } 69 \text { a } 113 \text { referem-se às condições de acessibilidade. Os } \\
\text { banheiros: há banheiros ou mictórios com portas que abrem para fora? }\end{array}$ & $\begin{array}{l}\text { A } \\
\text { B }\end{array}$ & $\begin{array}{l}1 \\
0\end{array}$ \\
\hline D095 & $\begin{array}{c}\text { As perguntas de } 69 \text { a } 113 \text { referem-se às condições de acessibilidade. Os } \\
\text { banheiros: as maçanetas são de alavanca? }\end{array}$ & $\begin{array}{l}\text { A } \\
\text { B }\end{array}$ & $\begin{array}{l}1 \\
0\end{array}$ \\
\hline D096 & $\begin{array}{l}\text { As perguntas de } 69 \text { a } 113 \text { referem-se às condições de acessibilidade. Os } \\
\text { banheiros: há espaço para cadeira de rodas e para transferência de pelo } \\
\text { menos } 80 \mathrm{~cm} \text { ? }\end{array}$ & $\begin{array}{l}\text { A } \\
\text { B }\end{array}$ & $\begin{array}{l}1 \\
0\end{array}$ \\
\hline D097 & $\begin{array}{l}\text { As perguntas de } 69 \text { a } 113 \text { referem-se às condições de acessibilidade. Os } \\
\text { banheiros: há barras de apoio fixadas nas paredes de fundo e na lateral do } \\
\text { vaso sanitário? }\end{array}$ & $\begin{array}{l}\text { A } \\
\text { B }\end{array}$ & $\begin{array}{l}1 \\
0\end{array}$ \\
\hline $\bar{D} 098$ & $\begin{array}{c}\text { As perguntas de } 69 \text { a } 113 \text { referem-se às condições de acessibilidade. Os } \\
\text { banheiros: há pia com torneira com acionamento por alavanca, pressão ou } \\
\text { cruzeta (em cruz)? }\end{array}$ & $\begin{array}{l}\text { A } \\
\text { B }\end{array}$ & $\begin{array}{l}1 \\
0\end{array}$ \\
\hline D099 & $\begin{array}{c}\text { As perguntas de } 69 \text { a } 113 \text { referem-se às condições de acessibilidade. Os } \\
\text { banheiros: há pia com altura entre } 78 \text { e } 80 \mathrm{~cm} \text { e com vão inferior livre com } \\
\text { altura de } 73 \mathrm{~cm} \text { ? }\end{array}$ & $\begin{array}{l}\mathrm{A} \\
\mathrm{B}\end{array}$ & $\begin{array}{l}1 \\
0\end{array}$ \\
\hline D100 & $\begin{array}{c}\text { As perguntas de } 69 \text { a } 113 \text { referem-se às condições de acessibilidade. A } \\
\text { escola possui: sala de recursos multifuncionais para atendimento } \\
\text { educacional especializado (aee)? }\end{array}$ & $\begin{array}{l}\mathrm{A} \\
\mathrm{B}\end{array}$ & $\begin{array}{l}1 \\
0\end{array}$ \\
\hline D101 & $\begin{array}{l}\text { As perguntas de } 69 \text { a } 113 \text { referem-se às condições de acessibilidade. A } \\
\text { escola possui: materiais didáticos e paradidáticos acessíveis? (braile, } \\
\text { caracteres ampliados, libras, texturas, contrastes etc). }\end{array}$ & $\begin{array}{l}\mathrm{A} \\
\mathrm{B}\end{array}$ & $\begin{array}{l}1 \\
0\end{array}$ \\
\hline D102 & $\begin{array}{l}\text { As perguntas de } 69 \text { a } 113 \text { referem-se às condições de acessibilidade. A } \\
\text { escola possui: recursos ópticos? (ex: lupa, telelupa, telescópio, lentes } \\
\text { especiais etc.) }\end{array}$ & $\begin{array}{l}\text { A } \\
\text { B }\end{array}$ & $\begin{array}{l}1 \\
0\end{array}$ \\
\hline D103 & $\begin{array}{c}\text { As perguntas de } 69 \text { a } 113 \text { referem-se às condições de acessibilidade. A } \\
\text { escola possui: recursos não ópticos? (ex: celofane amarelo, livro falado, } \\
\text { material impresso com tipos maiores, tábua de apoio para leitura, lápis e } \\
\text { canetas especiais, guia de leitura etc.) }\end{array}$ & $\begin{array}{l}\mathrm{A} \\
\mathrm{B}\end{array}$ & $\begin{array}{l}1 \\
0\end{array}$ \\
\hline
\end{tabular}




\begin{tabular}{|c|c|c|c|}
\hline Questão & Questão & Alternativa & Código \\
\hline \multirow[t]{2}{*}{ D104 } & As perguntas de 69 a 113 referem-se às condições de acessibilidade. A & A & 1 \\
\hline & escola possui: soroban? & $\mathrm{B}$ & 0 \\
\hline \multirow[t]{2}{*}{ D105 } & As perguntas de 69 a 113 referem-se às condições de acessibilidade. A & A & 1 \\
\hline & escola possui: reglete e punção? & $\mathrm{B}$ & 0 \\
\hline \multirow[t]{2}{*}{ D106 } & As perguntas de 69 a 113 referem-se às condições de acessibilidade. A & A & 1 \\
\hline & escola possui: calculadora sonora? & $\mathrm{B}$ & 0 \\
\hline \multirow[t]{2}{*}{ D107 } & As perguntas de 69 a 113 referem-se às condições de acessibilidade. A & A & 1 \\
\hline & escola possui: calculadora para pessoas de baixa visão? & $\mathrm{B}$ & 0 \\
\hline \multirow[t]{2}{*}{ D108 } & As perguntas de 69 a 113 referem-se às condições de acessibilidade. A & A & 1 \\
\hline & escola possui: máquina perkins? (máquina de escrever em braile) & $\mathrm{B}$ & 0 \\
\hline \multirow[t]{2}{*}{ D109 } & As perguntas de 69 a 113 referem-se às condições de acessibilidade. A & A & 1 \\
\hline & escola possui: computador com software leitor de tela? & $\mathrm{B}$ & 0 \\
\hline \multirow[t]{2}{*}{ D110 } & As perguntas de 69 a 113 referem-se às condições de acessibilidade. A & A & 1 \\
\hline & escola possui: software de comunicação alternativa aumentativa (caa)? & $\mathrm{B}$ & 0 \\
\hline \multirow[t]{2}{*}{ D111 } & As perguntas de 69 a 113 referem-se às condições de acessibilidade. A & A & 1 \\
\hline & $\begin{array}{l}\text { escola possui: mesas e cadeiras acessíveis para pessoas em cadeiras de } \\
\text { rodas? }\end{array}$ & B & 0 \\
\hline \multirow[t]{2}{*}{ D112 } & As perguntas de 69 a 113 referem-se às condições de acessibilidade. A & A & 1 \\
\hline & $\begin{array}{l}\text { escola possui: quadro negro (ou branco) sem degraus com altura que permita } \\
\text { seu alcance por pessoa em cadeira de rodas? }\end{array}$ & $\mathrm{B}$ & 0 \\
\hline \multirow[t]{2}{*}{ D113 } & As perguntas de 69 a 113 referem-se às condições de acessibilidade. A & $\mathrm{A}$ & 1 \\
\hline & $\begin{array}{l}\text { escola possui: bebedouros que permitem a aproximação frontal de pessoas em } \\
\text { cadeiras de rodas? }\end{array}$ & $\mathrm{B}$ & 0 \\
\hline \multirow[t]{2}{*}{ D114 } & Que atividades extracurriculares são desenvolvidas regularmente com os & A & 1 \\
\hline & alunos nesta escola? Esportivas. & $\mathrm{B}$ & 0 \\
\hline D115 & Que atividades extracurriculares são desenvolvidas regularmente com os & A & 1 \\
\hline & alunos nesta escola? Artísticas (música, teatro, trabalhos artesanais). & $\mathrm{B}$ & 0 \\
\hline D116 & Os espaços desta escola são utilizados para atividades comunitárias? & $\mathrm{A}$ & 2 \\
\hline & & $\mathrm{B}$ & 3 \\
\hline & & $\mathrm{C}$ & 4 \\
\hline & & $\mathrm{D}$ & 1 \\
\hline D117 & Neste ano, ocorreram nesta escola eventos da comunidade usando instalações, & A & 1 \\
\hline & equipamentos ou recursos da escola? & $\mathrm{B}$ & 0 \\
\hline D118 & Neste ano, ocorreram nesta escola eventos de terceiros realizados na escola & A & 1 \\
\hline & e abertos para a comunidade (shows, teatro, palestras)? & $\mathrm{B}$ & 0 \\
\hline D119 & Neste ano, ocorreram nesta escola eventos da escola e destinados à & A & 1 \\
\hline & comunidade externa (cursos, práticas esportivas, palestras)? & $\mathrm{B}$ & 0 \\
\hline D120 & Neste ano, ocorreram nesta escola campanhas de solidariedade promovidas & A & 1 \\
\hline & pela escola? & $\mathrm{B}$ & 0 \\
\hline D121 & Neste ano, ocorreram nesta escola campanhas de solidariedade propostas pela & A & 1 \\
\hline & comunidade, envolvendo a escola? & $\mathrm{B}$ & 0 \\
\hline D122 & Neste ano, ocorreram nesta escola comunidade colaborando na manutenção de & A & 1 \\
\hline & hortas, pomar, jardins? & $\mathrm{B}$ & 0 \\
\hline D123 & Neste ano, ocorreram nesta escola comunidade participando em mutirão para & A & 1 \\
\hline & limpeza da escola? & $\mathrm{B}$ & 0 \\
\hline D124 & Neste ano, ocorreram nesta escola comunidade participando em mutirão para & A & 1 \\
\hline & manutenção da estrutura física da escola? & $\mathrm{B}$ & 0 \\
\hline D125 & Esta escola recebe apoio financeiro de programa de financiamento do governo & $\mathrm{A}$ & 3 \\
\hline & federal? & $\mathrm{B}$ & 2 \\
\hline & & $\mathrm{C}$ & 1 \\
\hline D126 & Esta escola recebe apoio financeiro de programa de financiamento do governo & A & 3 \\
\hline & estadual? & $\mathrm{B}$ & 2 \\
\hline & & $\mathrm{C}$ & 1 \\
\hline D127 & Esta escola recebe apoio financeiro de programa de financiamento do governo & A & 3 \\
\hline & municipal? & $\mathrm{B}$ & 2 \\
\hline & & $\mathrm{C}$ & 1 \\
\hline D128 & Quem escolheu os livros didáticos utilizados nesta escola? & A & 6 \\
\hline & & $\mathrm{B}$ & 5 \\
\hline & & $\mathrm{C}$ & 4 \\
\hline & & $\mathrm{D}$ & 3 \\
\hline & & $\mathrm{E}$ & 2 \\
\hline & & $\mathrm{F}$ & 1 \\
\hline D129 & Neste ano, ocorreram as seguintes situações: os livros chegaram a tempo & A & 3 \\
\hline & hábil para o início das aulas. & $\mathrm{B}$ & 2 \\
\hline & & $\mathrm{C}$ & 1 \\
\hline D130 & Neste ano, ocorreram as seguintes situações: faltaram livros para os alunos. & A & 3 \\
\hline & & $\mathrm{B}$ & 2 \\
\hline & & $\mathrm{C}$ & 1 \\
\hline D131 & Neste ano, ocorreram as seguintes situações: sobraram livros. & $\mathrm{A}$ & 3 \\
\hline & & $\mathrm{B}$ & 2 \\
\hline & & $\mathrm{C}$ & 1 \\
\hline D132 & Neste ano, ocorreram as seguintes situações: os livros escolhidos foram os & A & 3 \\
\hline & recebidos. & $\mathrm{B}$ & 2 \\
\hline & & $\mathrm{C}$ & 1 \\
\hline
\end{tabular}




\begin{tabular}{|c|c|c|c|}
\hline Questão & Questão & Alternativa & Código \\
\hline \multirow[t]{2}{*}{ D133 } & Neste ano, aconteceram os seguintes fatos nesta escola: atentado à vida de & A & 1 \\
\hline & $\begin{array}{l}\text { professores ou funcionários dentro da escola. Agente causador externo } \\
\text { (estranho a escola) }\end{array}$ & B & 0 \\
\hline \multirow[t]{2}{*}{ D134 } & Neste ano, aconteceram os seguintes fatos nesta escola: atentado à vida de & A & 1 \\
\hline & alunos dentro da escola. Agente causador externo (estranho a escola) & B & 0 \\
\hline \multirow[t]{2}{*}{ D135 } & Neste ano, aconteceram os seguintes fatos nesta escola: furto a professores & A & 1 \\
\hline & ou funcionários dentro da escola. Agente causador externo (estranho a escola) & B & 0 \\
\hline \multirow[t]{2}{*}{ D136 } & Neste ano, aconteceram os seguintes fatos nesta escola: furto a alunos & A & 1 \\
\hline & dentro da escola. Agente causador externo (estranho a escola) & B & 0 \\
\hline \multirow[t]{2}{*}{ D137 } & Neste ano, aconteceram os seguintes fatos nesta escola: roubo (com uso de & A & 1 \\
\hline & $\begin{array}{l}\text { violência) a professores ou funcionários dentro da escola. Agente causador } \\
\text { externo (estranho a escola) }\end{array}$ & B & 0 \\
\hline \multirow[t]{2}{*}{ D138 } & Neste ano, aconteceram os seguintes fatos nesta escola: roubo (com uso de & A & 1 \\
\hline & $\begin{array}{l}\text { violência) a alunos dentro da escola. Agente causador externo (estranho a } \\
\text { escola) }\end{array}$ & B & 0 \\
\hline \multirow[t]{2}{*}{ D139 } & Neste ano, aconteceram os seguintes fatos nesta escola: furto de & A & 1 \\
\hline & $\begin{array}{l}\text { equipamentos e materiais didáticos ou pedagógicos da escola. Agente } \\
\text { causador externo (estranho a escola) }\end{array}$ & B & 0 \\
\hline \multirow[t]{2}{*}{ D140 } & Neste ano, aconteceram os seguintes fatos nesta escola: roubo (com uso de & A & 1 \\
\hline & $\begin{array}{l}\text { violência) de equipamentos e materiais didáticos ou pedagógicos da escola. } \\
\text { Agente causador externo (estranho a escola) }\end{array}$ & B & 0 \\
\hline \multirow[t]{2}{*}{ D141 } & Neste ano, aconteceram os seguintes fatos nesta escola: quebra intencional & A & 1 \\
\hline & de equipamento. Agente causador externo (estranho a escola) & B & 0 \\
\hline \multirow[t]{2}{*}{ D142 } & Neste ano, aconteceram os seguintes fatos nesta escola: pichação de muros & A & 1 \\
\hline & $\begin{array}{l}\text { ou paredes das dependências externas da escola. Agente causador externo } \\
\text { (estranho a escola) }\end{array}$ & B & 0 \\
\hline \multirow[t]{2}{*}{ D143 } & Neste ano, aconteceram os seguintes fatos nesta escola: depredação das & A & 1 \\
\hline & dependências externas da escola. Agente causador externo (estranho a escola) & B & 0 \\
\hline \multirow[t]{2}{*}{ D144 } & Neste ano, aconteceram os seguintes fatos nesta escola: sujeira nas & A & 1 \\
\hline & dependências externas da escola. Agente causador externo (estranho a escola) & B & 0 \\
\hline \multirow[t]{2}{*}{ D145 } & Neste ano, aconteceram os seguintes fatos nesta escola: sujeira nas & A & 1 \\
\hline & dependências internas da escola. Agente causador externo (estranho a escola) & B & 0 \\
\hline \multirow[t]{2}{*}{ D146 } & Neste ano, aconteceram os seguintes fatos nesta escola: pichação de muros & A & 1 \\
\hline & $\begin{array}{l}\text { ou paredes das dependências internas da escola. Agente causador externo } \\
\text { (estranho a escola) }\end{array}$ & B & 0 \\
\hline \multirow[t]{2}{*}{ D147 } & Neste ano, aconteceram os seguintes fatos nesta escola: depredação das & A & 1 \\
\hline & dependências internas da escola. Agente causador externo (estranho a escola) & B & 0 \\
\hline \multirow[t]{2}{*}{ D148 } & Neste ano, aconteceram os seguintes fatos nesta escola: depredação de & A & 1 \\
\hline & banheiros. Agente causador externo (estranho a escola) & B & 0 \\
\hline \multirow[t]{2}{*}{ D149 } & Neste ano, aconteceram os seguintes fatos nesta escola: consumo de bebidas & A & 1 \\
\hline & $\begin{array}{c}\text { alcoólicas nas dependências da escola. Agente causador externo (estranho a } \\
\text { escola) }\end{array}$ & B & 0 \\
\hline D150 & Neste ano, aconteceram os seguintes fatos nesta escola: consumo de drogas & A & 1 \\
\hline & nas dependências da escola. Agente causador externo (estranho a escola) & B & 0 \\
\hline D151 & Neste ano, aconteceram os seguintes fatos nesta escola: consumo de drogas & A & 1 \\
\hline & nas proximidades da escola. Agente causador externo (estranho a escola) & B & 0 \\
\hline D152 & Neste ano, aconteceram os seguintes fatos nesta escola: tráfico de drogas & A & 1 \\
\hline & nas dependências da escola. Agente causador externo (estranho a escola) & B & 0 \\
\hline D153 & Neste ano, aconteceram os seguintes fatos nesta escola: tráfico de drogas & A & 1 \\
\hline & nas proximidades da escola. Agente causador externo (estranho a escola) & B & 0 \\
\hline D154 & Neste ano, aconteceram os seguintes fatos nesta escola: atentado à vida de & A & 1 \\
\hline & $\begin{array}{l}\text { professores ou funcionários dentro da escola. Agente causador interno (da } \\
\text { própria a escola) }\end{array}$ & B & 0 \\
\hline D155 & Neste ano, aconteceram os seguintes fatos nesta escola: atentado à vida de & A & 1 \\
\hline & alunos dentro da escola. Agente causador interno (da própria a escola) & B & 0 \\
\hline D156 & Neste ano, aconteceram os seguintes fatos nesta escola: furto a professores & A & 1 \\
\hline & $\begin{array}{l}\text { ou funcionários dentro da escola. Agente causador interno (da própria a } \\
\text { escola) }\end{array}$ & B & 0 \\
\hline D157 & Neste ano, aconteceram os seguintes fatos nesta escola: furto a alunos & A & 1 \\
\hline & dentro da escola. Agente causador interno (da própria a escola) & B & 0 \\
\hline D158 & Neste ano, aconteceram os seguintes fatos nesta escola: roubo (com uso de & A & 1 \\
\hline & $\begin{array}{l}\text { violência) a professores ou funcionários dentro da escola. Agente causador } \\
\text { interno (da própria a escola) }\end{array}$ & B & 0 \\
\hline D159 & Neste ano, aconteceram os seguintes fatos nesta escola: roubo (com uso de & A & 1 \\
\hline & $\begin{array}{l}\text { violência) a alunos dentro da escola. Agente causador interno (da própria a } \\
\text { escola) }\end{array}$ & B & 0 \\
\hline D160 & Neste ano, aconteceram os seguintes fatos nesta escola: furto de & A & 1 \\
\hline & $\begin{array}{c}\text { equipamentos e materiais didáticos ou pedagógicos da escola. Agente } \\
\text { causador interno (da própria a escola) }\end{array}$ & B & 0 \\
\hline D161 & Neste ano, aconteceram os seguintes fatos nesta escola: roubo (com uso de & $\mathrm{A}$ & 1 \\
\hline & $\begin{array}{l}\text { violência) de equipamentos e materiais didáticos ou pedagógicos da escola. } \\
\text { Agente causador interno (da própria a escola) }\end{array}$ & B & 0 \\
\hline D162 & Neste ano, aconteceram os seguintes fatos nesta escola: quebra intencional & A & 1 \\
\hline & de equipamento. Agente causador interno (da própria a escola) & B & 0 \\
\hline
\end{tabular}




\begin{tabular}{|c|c|c|c|}
\hline Questão & Questão & Alternativa & Código \\
\hline \multirow[t]{2}{*}{ D163 } & Neste ano, aconteceram os seguintes fatos nesta escola: pichação de muros & $\mathrm{A}$ & 1 \\
\hline & $\begin{array}{c}\text { ou paredes das dependências externas da escola. Agente causador interno (da } \\
\text { própria a escola) }\end{array}$ & $\mathrm{B}$ & 0 \\
\hline \multirow[t]{2}{*}{ D164 } & Neste ano, aconteceram os seguintes fatos nesta escola: depredação das & A & 1 \\
\hline & $\begin{array}{c}\text { dependências externas da escola. Agente causador interno (da própria a } \\
\text { escola) }\end{array}$ & $\mathrm{B}$ & 0 \\
\hline \multirow[t]{2}{*}{ D165 } & Neste ano, aconteceram os seguintes fatos nesta escola: sujeira nas & $\mathrm{A}$ & 1 \\
\hline & $\begin{array}{c}\text { dependências externas da escola. Agente causador interno (da própria a } \\
\text { escola) }\end{array}$ & $\mathrm{B}$ & 0 \\
\hline \multirow[t]{2}{*}{ D166 } & Neste ano, aconteceram os seguintes fatos nesta escola: sujeira nas & $\mathrm{A}$ & 1 \\
\hline & $\begin{array}{c}\text { dependências internas da escola. Agente causador interno (da própria a } \\
\text { escola) }\end{array}$ & $\mathrm{B}$ & 0 \\
\hline \multirow[t]{2}{*}{ D167 } & Neste ano, aconteceram os seguintes fatos nesta escola: pichação de muros & $\mathrm{A}$ & 1 \\
\hline & $\begin{array}{l}\text { ou paredes das dependências internas da escola. Agente causador interno (da } \\
\text { própria a escola) }\end{array}$ & $\mathrm{B}$ & 0 \\
\hline \multirow[t]{2}{*}{ D168 } & Neste ano, aconteceram os seguintes fatos nesta escola: depredação das & A & 1 \\
\hline & $\begin{array}{l}\text { dependências internas da escola. Agente causador interno (da própria a } \\
\text { escola) }\end{array}$ & B & 0 \\
\hline \multirow[t]{2}{*}{ D169 } & Neste ano, aconteceram os seguintes fatos nesta escola: depredação de & $\mathrm{A}$ & 1 \\
\hline & banheiros. Agente causador interno (da própria a escola) & $\mathrm{B}$ & 0 \\
\hline \multirow[t]{2}{*}{ D170 } & Neste ano, aconteceram os seguintes fatos nesta escola: consumo de bebidas & $\mathrm{A}$ & 1 \\
\hline & $\begin{array}{l}\text { alcoólicas nas dependências da escola. Agente causador interno (da própria } \\
\text { a escola) }\end{array}$ & $\mathrm{B}$ & 0 \\
\hline \multirow[t]{2}{*}{ D171 } & Neste ano, aconteceram os seguintes fatos nesta escola: consumo de drogas & $\mathrm{A}$ & 1 \\
\hline & nas dependências da escola. Agente causador interno (da própria a escola) & $\mathrm{B}$ & 0 \\
\hline \multirow[t]{2}{*}{ D172 } & Neste ano, aconteceram os seguintes fatos nesta escola: consumo de drogas & A & 1 \\
\hline & nas proximidades da escola. Agente causador interno (da própria a escola) & $\mathrm{B}$ & 0 \\
\hline \multirow[t]{2}{*}{ D173 } & Neste ano, aconteceram os seguintes fatos nesta escola: tráfico de drogas & A & 1 \\
\hline & nas dependências da escola. Agente causador interno (da própria a escola) & $\mathrm{B}$ & 0 \\
\hline \multirow[t]{2}{*}{ D174 } & Neste ano, aconteceram os seguintes fatos nesta escola: tráfico de drogas & A & 1 \\
\hline & nas proximidades da escola. Agente causador interno (da própria a escola) & $\mathrm{B}$ & 0 \\
\hline \multirow{2}{*}{ D175 } & Neste ano, os seguintes eventos fizeram ou não parte do cotidiano desta escola: & A & 1 \\
\hline & membros da comunidade escolar portando arma de fogo. & $\mathrm{B}$ & 0 \\
\hline D176 & Neste ano, os seguintes eventos fizeram ou não parte do cotidiano desta escola: & A & 1 \\
\hline & membros da comunidade escolar portando arma branca (faca, canivete, estilete etc.). & $\mathrm{B}$ & 0 \\
\hline D177 & Neste ano, os seguintes eventos fizeram ou não parte do cotidiano desta escola: & A & 1 \\
\hline & ação de gangues nas dependências externas da escola. & $\mathrm{B}$ & 0 \\
\hline D178 & Neste ano, os seguintes eventos fizeram ou não parte do cotidiano desta escola: & $\mathrm{A}$ & 1 \\
\hline & ação de gangues nas dependências internas da escola. & $\mathrm{B}$ & 0 \\
\hline D179 & Neste ano, houve agressão verbal a professores. Quem foi o agressor? Aluno & A & 1 \\
\hline & & $\mathrm{B}$ & 0 \\
\hline D180 & Neste ano, houve agressão física a professores. Quem foi o agressor? Aluno & $\mathrm{A}$ & 1 \\
\hline & & $\mathrm{B}$ & 0 \\
\hline D181 & Neste ano, houve agressão verbal a alunos. Quem foi o agressor? Aluno & A & 1 \\
\hline & & $\mathrm{B}$ & 0 \\
\hline D182 & Neste ano, houve agressão física a alunos. Quem foi o agressor? Aluno & A & 1 \\
\hline & & $\mathrm{B}$ & 0 \\
\hline D183 & Neste ano, houve agressão verbal a funcionários. Quem foi o agressor? Aluno & A & 1 \\
\hline & & $\mathrm{B}$ & 0 \\
\hline D184 & Neste ano, houve agressão física a funcionários. Quem foi o agressor? Aluno & A & 1 \\
\hline & & $\mathrm{B}$ & 0 \\
\hline D185 & Neste ano, houve agressão verbal a professores. Quem foi o agressor? Professor & A & 1 \\
\hline & & $\mathrm{B}$ & 0 \\
\hline D186 & Neste ano, houve agressão física a professores. Quem foi o agressor? Professor & A & 1 \\
\hline & & $\mathrm{B}$ & 0 \\
\hline D187 & Neste ano, houve agressão verbal a alunos. Quem foi o agressor? Professor & $\mathrm{A}$ & 1 \\
\hline & & $\mathrm{B}$ & 0 \\
\hline D188 & Neste ano, houve agressão física a alunos. Quem foi o agressor? Professor & $\mathrm{A}$ & 1 \\
\hline & & $\mathrm{B}$ & 0 \\
\hline D189 & Neste ano, houve agressão verbal a funcionários. Quem foi o agressor? Professor & $\mathrm{A}$ & 1 \\
\hline & & $\mathrm{B}$ & 0 \\
\hline D190 & Neste ano, houve agressão física a funcionários. Quem foi o agressor? Professor & $\mathrm{A}$ & 1 \\
\hline & & $\mathrm{B}$ & 0 \\
\hline D191 & Neste ano, houve agressão verbal a professores. Quem foi o agressor? Funcionário & A & 1 \\
\hline & & $\mathrm{B}$ & 0 \\
\hline D192 & Neste ano, houve agressão física a professores. Quem foi o agressor? Funcionário & A & 1 \\
\hline & & $\mathrm{B}$ & 0 \\
\hline D193 & Neste ano, houve agressão verbal a alunos. Quem foi o agressor? Funcionário & A & 1 \\
\hline & & $\mathrm{B}$ & 0 \\
\hline D194 & Neste ano, houve agressão física a alunos. Quem foi o agressor? Funcionário & A & 1 \\
\hline & & $\mathrm{B}$ & 0 \\
\hline D195 & Neste ano, houve agressão verbal a funcionários. Quem foi o agressor? Funcionário & A & 1 \\
\hline & & $\mathrm{B}$ & 0 \\
\hline D196 & Neste ano, houve agressão física a funcionários. Quem foi o agressor? Funcionário & A & 1 \\
\hline & & $\mathrm{B}$ & 0 \\
\hline
\end{tabular}




\begin{tabular}{|c|c|c|c|}
\hline Questão & Questão & Alternativa & Código \\
\hline \multirow[t]{2}{*}{ D197 } & Nesta escola há projetos nas seguintes temáticas violência. & A & 1 \\
\hline & & $\mathrm{B}$ & 0 \\
\hline \multirow[t]{2}{*}{ D198 } & Nesta escola há projetos nas seguintes temáticas uso abusivo de drogas. & A & 1 \\
\hline & & $\mathrm{B}$ & 0 \\
\hline \multirow[t]{2}{*}{ D199 } & Nesta escola há projetos nas seguintes temáticas racismo. & A & 1 \\
\hline & & $\mathrm{B}$ & 0 \\
\hline \multirow[t]{2}{*}{ D200 } & Nesta escola há projetos nas seguintes temáticas machismo e homofobia. & A & 1 \\
\hline & & $\mathrm{B}$ & 0 \\
\hline \multirow[t]{2}{*}{ D201 } & Nesta escola há projetos nas seguintes temáticas bullying. & A & 1 \\
\hline & & $\mathrm{B}$ & 0 \\
\hline \multirow[t]{2}{*}{ D202 } & Nesta escola há projetos nas seguintes temáticas sexualidade e gravidez na & A & 1 \\
\hline & adolescência. & $\mathrm{B}$ & 0 \\
\hline \multirow[t]{2}{*}{ D203 } & Nesta escola há projetos nas seguintes temáticas desigualdades sociais. & $\mathrm{A}$ & 1 \\
\hline & & $\mathrm{B}$ & 0 \\
\hline \multirow[t]{2}{*}{ D204 } & Nesta escola há projetos nas seguintes temáticas conflitos religiosos. & $\mathrm{A}$ & 1 \\
\hline & & $\mathrm{B}$ & 0 \\
\hline \multirow[t]{2}{*}{ D205 } & Nesta escola há projetos nas seguintes temáticas meio ambiente. & A & 1 \\
\hline & & $\mathrm{B}$ & 0 \\
\hline \multirow[t]{2}{*}{ D206 } & Nesta escola há costume de se fazer oração ou cantar músicas religiosas (na & A & 1 \\
\hline & entrada, antes do lanche etc). & $\mathrm{B}$ & 0 \\
\hline \multirow[t]{2}{*}{ D207 } & Nesta escola há objetos, imagens, frases ou símbolos de teor religioso. & A & 1 \\
\hline & & $\mathrm{B}$ & 0 \\
\hline D208 & Nesta escola há aula de ensino religioso. & A & 1 \\
\hline & & $\mathrm{B}$ & 0 \\
\hline D209 & Nesta escola há atividades alternativas para os estudantes que não queiram & A & 1 \\
\hline & participar das aulas de ensino religioso. & $\mathrm{B}$ & 0 \\
\hline D210 & Nesta escola, o ensino religioso (se não houver ensino religioso deixe as & A & 1 \\
\hline & próximas questões em branco): é de presença obrigatória. & $\mathrm{B}$ & 0 \\
\hline D211 & Nesta escola, o ensino religioso (se não houver ensino religioso deixe as & A & 1 \\
\hline & $\begin{array}{c}\text { próximas questões em branco): é de caráter confessional (segundo uma religião } \\
\text { específica). }\end{array}$ & B & 0 \\
\hline D212 & Nesta escola, o ensino religioso (se não houver ensino religioso deixe as & A & 1 \\
\hline & próximas questões em branco): contempla a diversidade religiosa. & $\mathrm{B}$ & 0 \\
\hline E001 & Avalie o estado de conservação dos itens e equipamentos do prédio - telhado & $\mathrm{A}$ & 4 \\
\hline & & $\mathrm{B}$ & 3 \\
\hline & & $\mathrm{C}$ & 2 \\
\hline & & $\mathrm{D}$ & 1 \\
\hline E002 & Avalie o estado de conservação dos itens e equipamentos do prédio - paredes & A & 4 \\
\hline & & $\mathrm{B}$ & 3 \\
\hline & & $\mathrm{C}$ & 2 \\
\hline & & $\mathrm{D}$ & 1 \\
\hline E003 & Avalie o estado de conservação dos itens e equipamentos do prédio - piso & A & 4 \\
\hline & & $\mathrm{B}$ & 3 \\
\hline & & $\mathrm{C}$ & 2 \\
\hline & & $\mathrm{D}$ & 1 \\
\hline E004 & Avalie o estado de conservação dos itens e equipamentos do prédio - entrada do & A & 4 \\
\hline & prédio & $\mathrm{B}$ & 3 \\
\hline & & $\mathrm{C}$ & 2 \\
\hline & & $\mathrm{D}$ & 1 \\
\hline E005 & Avalie o estado de conservação dos itens e equipamentos do prédio - pátio & A & 4 \\
\hline & & $\mathrm{B}$ & 3 \\
\hline & & $\mathrm{C}$ & 2 \\
\hline & & $\mathrm{D}$ & 1 \\
\hline E006 & Avalie o estado de conservação dos itens e equipamentos do prédio - corredores & $\mathrm{A}$ & 4 \\
\hline & & $\mathrm{B}$ & 3 \\
\hline & & $\mathrm{C}$ & 2 \\
\hline & & $\mathrm{D}$ & 1 \\
\hline E007 & Avalie o estado de conservação dos itens e equipamentos do prédio - salas de aula & A & 4 \\
\hline & & $\mathrm{B}$ & 3 \\
\hline & & $\mathrm{C}$ & 2 \\
\hline & & $\mathrm{D}$ & 1 \\
\hline E008 & Avalie o estado de conservação dos itens e equipamentos do prédio - portas & A & 4 \\
\hline & & $\mathrm{B}$ & 3 \\
\hline & & $\mathrm{C}$ & 2 \\
\hline & & $\mathrm{D}$ & 1 \\
\hline E009 & Avalie o estado de conservação dos itens e equipamentos do prédio - janelas & A & 4 \\
\hline & & $\mathrm{B}$ & 3 \\
\hline & & $\mathrm{C}$ & 2 \\
\hline & & $\mathrm{D}$ & 1 \\
\hline E010 & Avalie o estado de conservação dos itens e equipamentos do prédio - banheiros & A & 4 \\
\hline & & $\mathrm{B}$ & 3 \\
\hline & & $\mathrm{C}$ & 2 \\
\hline & & $\mathrm{D}$ & 1 \\
\hline
\end{tabular}




\begin{tabular}{|c|c|c|c|}
\hline Questão & Questão & Alternativa & Código \\
\hline \multirow[t]{4}{*}{ E011 } & Avalie o estado de conservação dos itens e equipamentos do prédio - cozinha & A & 4 \\
\hline & & B & 3 \\
\hline & & $\mathrm{C}$ & 2 \\
\hline & & $\mathrm{D}$ & 1 \\
\hline \multirow[t]{4}{*}{ E012 } & Avalie o estado de conservação dos itens e equipamentos do prédio - instalações & $\mathrm{A}$ & 4 \\
\hline & hidráulicas & $\mathrm{B}$ & 3 \\
\hline & & $\mathrm{C}$ & 2 \\
\hline & & $\mathrm{D}$ & 1 \\
\hline \multirow[t]{4}{*}{ E013 } & Avalie o estado de conservação dos itens e equipamentos do prédio - instalações & A & 4 \\
\hline & elétricas & B & 3 \\
\hline & & $\mathrm{C}$ & 2 \\
\hline & & $\mathrm{D}$ & 1 \\
\hline \multirow[t]{2}{*}{ E014 } & Avalie os seguintes aspectos em relação às salas de aula: (considere sim quando mais & A & 1 \\
\hline & de $50 \%$ das salas de aula apresentarem o aspecto questionado) - são iluminadas? & B & 0 \\
\hline \multirow[t]{2}{*}{ E015 } & Avalie os seguintes aspectos em relação às salas de aula: (considere sim quando mais & A & 1 \\
\hline & de $50 \%$ das salas de aula apresentarem o aspecto questionado) - são arejadas? & $\mathrm{B}$ & 0 \\
\hline \multirow[t]{2}{*}{ E016 } & Avalie os seguintes aspectos em relação à segurança da escola e dos alunos: há muros, & A & 1 \\
\hline & $\begin{array}{c}\text { grades ou cercas em condições de garantir a segurança dos alunos? (caso existam } \\
\text { buracos ou aberturas que permitam o acesso de estranhos, responder não) }\end{array}$ & B & 0 \\
\hline \multirow[t]{2}{*}{ E017 } & Avalie os seguintes aspectos em relação à segurança da escola e dos alunos: há & A & 1 \\
\hline & controle de entrada e saída de alunos? & $\mathrm{B}$ & 0 \\
\hline \multirow[t]{2}{*}{ E018 } & Avalie os seguintes aspectos em relação à segurança da escola e dos alunos: há & A & 1 \\
\hline & controle de entrada de pessoas estranhas na escola? & B & 0 \\
\hline \multirow[t]{2}{*}{ E019 } & Avalie os seguintes aspectos em relação à segurança da escola e dos alunos: os portões & A & 1 \\
\hline & $\begin{array}{l}\text { que dão acesso à parte externa permanecem trancados durante o horário de funcionamento } \\
\text { da escola? }\end{array}$ & B & 0 \\
\hline \multirow[t]{2}{*}{ E020 } & Avalie os seguintes aspectos em relação à segurança da escola e dos alunos: há algum & $\mathrm{A}$ & 1 \\
\hline & tipo de vigilância para o período diurno? & $\mathrm{B}$ & 0 \\
\hline \multirow[t]{2}{*}{ E021 } & Avalie os seguintes aspectos em relação à segurança da escola e dos alunos: há algum & A & 1 \\
\hline & tipo de vigilância para o período noturno? & B & 0 \\
\hline \multirow[t]{2}{*}{$\mathrm{E} 022$} & Avalie os seguintes aspectos em relação à segurança da escola e dos alunos: há algum & A & 1 \\
\hline & tipo de vigilância para os finais de semana e feriados? & $\mathrm{B}$ & 0 \\
\hline \multirow[t]{2}{*}{ E023 } & Avalie os seguintes aspectos em relação à segurança da escola e dos alunos: há algum & A & 1 \\
\hline & esquema de policiamento para inibição de furtos, roubos e outras formas de violência? & $\mathrm{B}$ & 0 \\
\hline \multirow[t]{2}{*}{ E024 } & Avalie os seguintes aspectos em relação à segurança da escola e dos alunos: há algum & A & 1 \\
\hline & esquema de policiamento para inibição de tráfico de tóxicos/ drogas dentro da escola? & $\mathrm{B}$ & 0 \\
\hline E025 & Avalie os seguintes aspectos em relação à segurança da escola e dos alunos: há algum & A & 1 \\
\hline & $\begin{array}{c}\text { esquema de policiamento para inibição de tráfico de tóxicos/ drogas nas imediações da } \\
\text { escola? }\end{array}$ & B & 0 \\
\hline E026 & Avalie os seguintes aspectos em relação à segurança da escola e dos alunos: a escola & A & 1 \\
\hline & $\begin{array}{l}\text { possui algum sistema de proteção contra incêndio (alarme de fumaça e temperatura, } \\
\text { extintores contra incêndio dentro do prazo de validade, mangueira, etc.)? }\end{array}$ & $\mathrm{B}$ & 0 \\
\hline E027 & Avalie os seguintes aspectos em relação à segurança da escola e dos alunos: as salas & $\mathrm{A}$ & 1 \\
\hline & $\begin{array}{l}\text { onde são guardados os equipamentos mais caros (computadores, projetores, televisão, } \\
\text { vídeo etc.) Possuem dispositivos para serem trancados(cadeados, grades, travas, trancas } \\
\text { etc.)? }\end{array}$ & $\mathrm{B}$ & 0 \\
\hline E028 & Avalie os seguintes aspectos em relação à segurança da escola e dos alunos: a escola & A & 1 \\
\hline & $\begin{array}{l}\text { apresenta sinais de depredação (vidros, portas e janelas quebradas, lâmpadas estouradas } \\
\text { etc.)? }\end{array}$ & B & 0 \\
\hline E029 & Avalie os seguintes aspectos em relação à segurança da escola e dos alunos: há uma boa & $\mathrm{A}$ & 1 \\
\hline & iluminação do lado de fora da escola? & $\mathrm{B}$ & 0 \\
\hline E030 & Avalie os seguintes aspectos em relação à segurança da escola e dos alunos: a escola & A & 1 \\
\hline & adota alguma medida de segurança para proteger os alunos nas suas imediações? & $\mathrm{B}$ & 0 \\
\hline E031 & Indique se nesta escola existem ou não os recursos apontados e quais são suas condições & A & 4 \\
\hline & de uso. Computadores para uso dos alunos. & $\mathrm{B}$ & 3 \\
\hline & & $\mathrm{C}$ & 2 \\
\hline & & $\mathrm{D}$ & 1 \\
\hline E032 & Indique se nesta escola existem ou não os recursos apontados e quais são suas condições & A & 4 \\
\hline & de uso. Acesso à internet para uso dos alunos. & $\mathrm{B}$ & 3 \\
\hline & & $\mathrm{C}$ & 2 \\
\hline & & $\mathrm{D}$ & 1 \\
\hline E033 & Indique se nesta escola existem ou não os recursos apontados e quais são suas condições & A & 4 \\
\hline & de uso. Computadores para uso dos professores. & $\mathrm{B}$ & 3 \\
\hline & & $\mathrm{C}$ & 2 \\
\hline & & $\mathrm{D}$ & 1 \\
\hline E034 & Indique se nesta escola existem ou não os recursos apontados e quais são suas condições & $\mathrm{A}$ & 4 \\
\hline & de uso. Acesso à internet para uso dos professores. & $\mathrm{B}$ & 3 \\
\hline & & $\mathrm{C}$ & 2 \\
\hline & & $\mathrm{D}$ & 1 \\
\hline E035 & Indique se nesta escola existem ou não os recursos apontados e quais são suas condições & A & 4 \\
\hline & de uso. Computadores exclusivamente para o uso administrativo. & $\mathrm{B}$ & 3 \\
\hline & & $\mathrm{C}$ & 2 \\
\hline & & $\mathrm{D}$ & 1 \\
\hline
\end{tabular}




\begin{tabular}{|c|c|c|c|}
\hline Questão & Questão & Alternativa & Código \\
\hline \multirow[t]{4}{*}{ E036 } & Indique se nesta escola existem ou não os recursos apontados e quais são suas condições & A & 4 \\
\hline & de uso. Fitas de vídeo ou dvd (educativas). & $\mathrm{B}$ & 3 \\
\hline & & $\mathrm{C}$ & 2 \\
\hline & & $\mathrm{D}$ & 1 \\
\hline \multirow[t]{4}{*}{ E037 } & Indique se nesta escola existem ou não os recursos apontados e quais são suas condições & A & 4 \\
\hline & de uso. Fitas de vídeo ou dvd (lazer). & $\mathrm{B}$ & 3 \\
\hline & & $\mathrm{C}$ & 2 \\
\hline & & $\mathrm{D}$ & 1 \\
\hline \multirow[t]{4}{*}{ E038 } & Indique se nesta escola existem ou não os recursos apontados e quais são suas condições & A & 4 \\
\hline & de uso. Máquina copiadora. & $\mathrm{B}$ & 3 \\
\hline & & $\mathrm{C}$ & 2 \\
\hline & & $\mathrm{D}$ & 1 \\
\hline \multirow[t]{4}{*}{ E039 } & Indique se nesta escola existem ou não os recursos apontados e quais são suas condições & A & 4 \\
\hline & de uso. Impressora. & B & 3 \\
\hline & & $\mathrm{C}$ & 2 \\
\hline & & $\mathrm{D}$ & 1 \\
\hline \multirow[t]{4}{*}{ E040 } & Indique se nesta escola existem ou não os recursos apontados e quais são suas condições & A & 4 \\
\hline & de uso. Retroprojetor. & $\mathrm{B}$ & 3 \\
\hline & & $\mathrm{C}$ & 2 \\
\hline & & $\mathrm{D}$ & 1 \\
\hline \multirow[t]{4}{*}{ E041 } & Indique se nesta escola existem ou não os recursos apontados e quais são suas condições & A & 4 \\
\hline & de uso. Projetor de slides. & $\mathrm{B}$ & 3 \\
\hline & & $\mathrm{C}$ & 2 \\
\hline & & $\mathrm{D}$ & 1 \\
\hline \multirow[t]{4}{*}{ E042 } & Indique se nesta escola existem ou não os recursos apontados e quais são suas condições & A & 4 \\
\hline & de uso. Videocassete ou dvd. & $\mathrm{B}$ & 3 \\
\hline & & $\mathrm{C}$ & 2 \\
\hline & & $\mathrm{D}$ & 1 \\
\hline \multirow[t]{4}{*}{ E043 } & Indique se nesta escola existem ou não os recursos apontados e quais são suas condições & A & 4 \\
\hline & de uso. Televisão. & $\mathrm{B}$ & 3 \\
\hline & & $\mathrm{C}$ & 2 \\
\hline & & $\mathrm{D}$ & 1 \\
\hline \multirow[t]{4}{*}{ E044 } & Indique se nesta escola existem ou não os recursos apontados e quais são suas condições & $\mathrm{A}$ & 4 \\
\hline & de uso. Mimeógrafo. & $\mathrm{B}$ & 3 \\
\hline & & $\mathrm{C}$ & 2 \\
\hline & & $\mathrm{D}$ & 1 \\
\hline E045 & Indique se nesta escola existem ou não os recursos apontados e quais são suas condições & A & 4 \\
\hline & de uso. Câmera fotográfica. & $\mathrm{B}$ & 3 \\
\hline & & $\mathrm{C}$ & 2 \\
\hline & & $\mathrm{D}$ & 1 \\
\hline E046 & Indique se nesta escola existem ou não os recursos apontados e quais são suas condições & A & 4 \\
\hline & de uso. Antena parabólica. & $\mathrm{B}$ & 3 \\
\hline & & $\mathrm{C}$ & 2 \\
\hline & & $\mathrm{D}$ & 1 \\
\hline E047 & Indique se nesta escola existem ou não os recursos apontados e quais são suas condições & A & 4 \\
\hline & de uso. Linha telefônica. & $\mathrm{B}$ & 3 \\
\hline & & $\mathrm{C}$ & 2 \\
\hline & & $\mathrm{D}$ & 1 \\
\hline E048 & Indique se nesta escola existem ou não os recursos apontados e quais são suas condições & A & 4 \\
\hline & de uso. Aparelho de fax. & $\mathrm{B}$ & 3 \\
\hline & & $\mathrm{C}$ & 2 \\
\hline & & $\mathrm{D}$ & 1 \\
\hline E049 & Indique se nesta escola existem ou não os recursos apontados e quais são suas condições & A & 4 \\
\hline & de uso. Aparelho de som. & $\mathrm{B}$ & 3 \\
\hline & & $\mathrm{C}$ & 2 \\
\hline & & $\mathrm{D}$ & 1 \\
\hline E050 & Indique se nesta escola existem ou não os recursos apontados e quais são suas condições & A & 4 \\
\hline & de uso. Biblioteca. & $\mathrm{B}$ & 3 \\
\hline & & $\mathrm{C}$ & 2 \\
\hline & & $\mathrm{D}$ & 1 \\
\hline E051 & Indique se nesta escola existem ou não os recursos apontados e quais são suas condições & A & 4 \\
\hline & de uso. Quadra de esportes. & $\mathrm{B}$ & 3 \\
\hline & & $\mathrm{C}$ & 2 \\
\hline & & $\mathrm{D}$ & 1 \\
\hline E052 & Indique se nesta escola existem ou não os recursos apontados e quais são suas condições & A & 4 \\
\hline & de uso. Laboratório. & $\mathrm{B}$ & 3 \\
\hline & & $\mathrm{C}$ & 2 \\
\hline & & $\mathrm{D}$ & 1 \\
\hline E053 & Indique se nesta escola existem ou não os recursos apontados e quais são suas condições & A & 4 \\
\hline & de uso. Auditório. & $\mathrm{B}$ & 3 \\
\hline & & $\mathrm{C}$ & 2 \\
\hline & & $\mathrm{D}$ & 1 \\
\hline E054 & Indique se nesta escola existem ou não os recursos apontados e quais são suas condições & A & 4 \\
\hline & de uso. Sala para atividades de música. & $\mathrm{B}$ & 3 \\
\hline & & $\mathrm{C}$ & 2 \\
\hline & & $\mathrm{D}$ & 1 \\
\hline
\end{tabular}




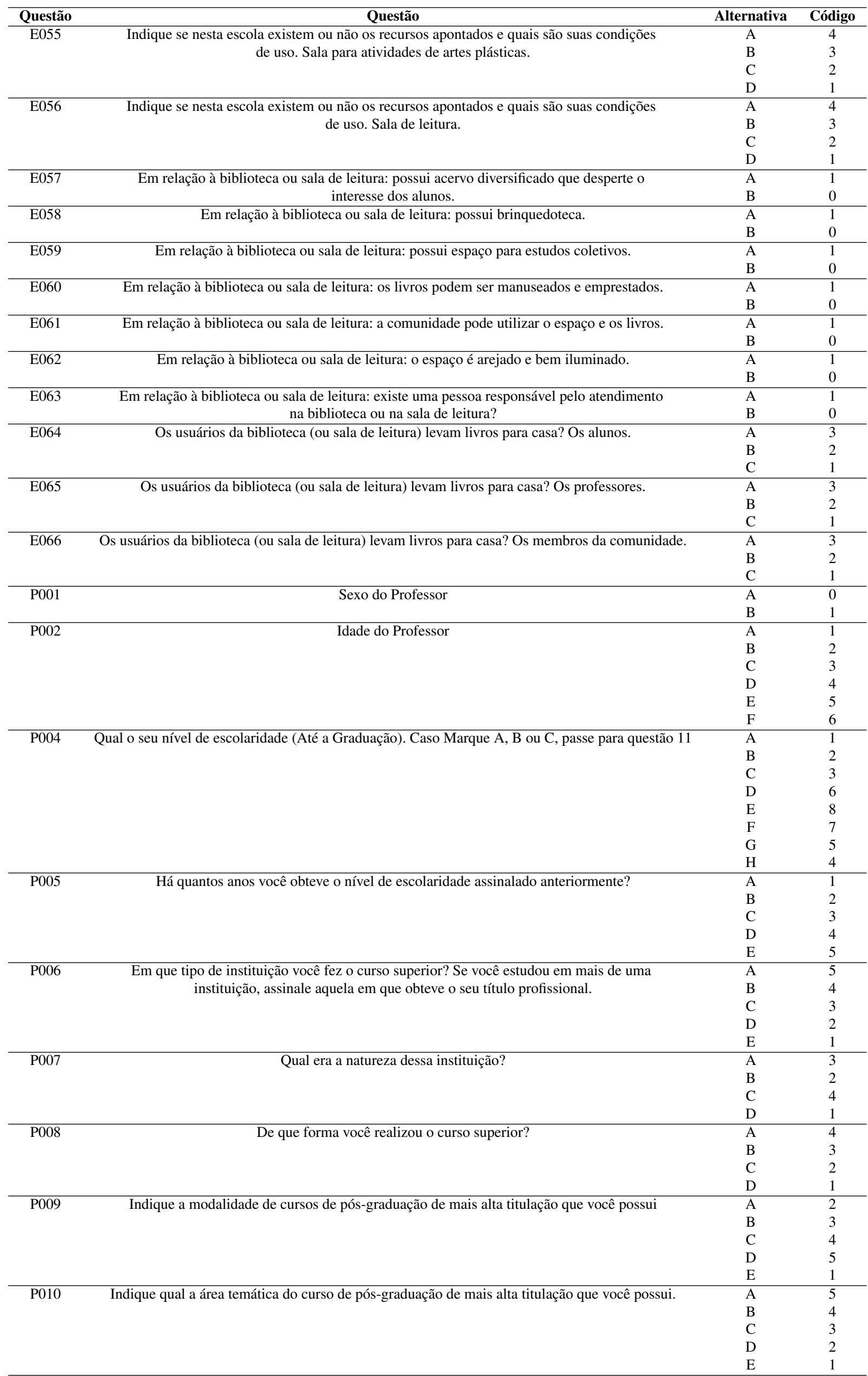




\begin{tabular}{|c|c|c|c|}
\hline Questão & Questão & Alternativa & Código \\
\hline \multirow[t]{2}{*}{ P011 } & Você participou de alguma atividade de formação continuada (atualização, treinamento, & A & 1 \\
\hline & capacitação, etc) nos últimos dois anos? & B & 0 \\
\hline \multirow[t]{4}{*}{ P012 } & Qual a carga horária da atividade considerada mais relevante dentre as quais você participou? & A & 1 \\
\hline & & B & 2 \\
\hline & & $\mathrm{C}$ & 3 \\
\hline & & $\mathrm{D}$ & 4 \\
\hline \multirow[t]{4}{*}{ P013 } & Você utiliza os conhecimentos adquiridos nas atividades de formação continuada para a melhoria & A & 4 \\
\hline & de sua prática em sala de aula? & B & 3 \\
\hline & & $\mathrm{C}$ & 2 \\
\hline & & $\mathrm{D}$ & 1 \\
\hline \multirow[t]{11}{*}{ P014 } & Nesta escola, qual, aproximadamente, o seu salário bruto? (com adicionais, se houver) (preencha & A & 1 \\
\hline & os espaços com o valor e marque, na folha de respostas, os campos correspondentes a cada & B & 2 \\
\hline & algarismo.) & $\mathrm{C}$ & 3 \\
\hline & & $\mathrm{D}$ & 4 \\
\hline & & $\mathrm{E}$ & 5 \\
\hline & & $\mathrm{F}$ & 6 \\
\hline & & G & 7 \\
\hline & & $\mathrm{H}$ & 8 \\
\hline & & I & 9 \\
\hline & & $\mathrm{J}$ & 10 \\
\hline & & $\mathrm{K}$ & 11 \\
\hline \multirow[t]{3}{*}{ P015 } & Além da atividade como docente nesta escola, você exerce outra atividade que contribui para sua & A & 3 \\
\hline & renda pessoal? & B & 2 \\
\hline & & $\mathrm{C}$ & 1 \\
\hline \multirow[t]{11}{*}{ P016 } & Qual é, aproximadamente, seu salário bruto (com adicionais, se houver) como professor(a)? (soma & A & 1 \\
\hline & de tudo o que você ganha como professor(a)) (preencha os espaços com o valor e marque, na folha & B & 2 \\
\hline & de respostas, os campos correspondentes a cada algarismo.) & $\mathrm{C}$ & 3 \\
\hline & & $\mathrm{D}$ & 4 \\
\hline & & $\mathrm{E}$ & 5 \\
\hline & & $\mathrm{F}$ & 6 \\
\hline & & $\mathrm{G}$ & 7 \\
\hline & & $\mathrm{H}$ & 8 \\
\hline & & $\mathrm{I}$ & 9 \\
\hline & & $\mathrm{J}$ & 10 \\
\hline & & $\mathrm{K}$ & 11 \\
\hline \multirow[t]{8}{*}{ P017 } & Há quantos anos você leciona? & $\mathrm{A}$ & 1 \\
\hline & & $\mathrm{B}$ & 2 \\
\hline & & $\mathrm{C}$ & 3 \\
\hline & & $\mathrm{D}$ & 4 \\
\hline & & $\mathrm{E}$ & 5 \\
\hline & & $\mathrm{F}$ & 6 \\
\hline & & $\mathrm{G}$ & 7 \\
\hline & & $\mathrm{H}$ & 8 \\
\hline \multirow[t]{8}{*}{ P018 } & Há quantos anos você trabalha nesta escola? & A & 1 \\
\hline & & $\mathrm{B}$ & 2 \\
\hline & & $\mathrm{C}$ & 3 \\
\hline & & $\mathrm{D}$ & 4 \\
\hline & & $\mathrm{E}$ & 5 \\
\hline & & $\mathrm{F}$ & 6 \\
\hline & & $\mathrm{G}$ & 7 \\
\hline & & $\mathrm{H}$ & 8 \\
\hline \multirow[t]{5}{*}{ P019 } & Há quantos anos você ministra aulas para alunos das série desta turma? & A & 1 \\
\hline & & B & 2 \\
\hline & & $\mathrm{C}$ & 3 \\
\hline & & $\mathrm{D}$ & 4 \\
\hline & & $\mathrm{E}$ & 5 \\
\hline \multirow[t]{9}{*}{ P020 } & Nesta escola, qual a sua carga horária semanal? (considere a carga horária contratual: & A & 1 \\
\hline & horas-aula mais horas para atividades, se houver.) & $\mathrm{B}$ & 2 \\
\hline & & $\mathrm{C}$ & 3 \\
\hline & & $\mathrm{D}$ & 4 \\
\hline & & $\mathrm{E}$ & 5 \\
\hline & & $\mathrm{F}$ & 6 \\
\hline & & G & 7 \\
\hline & & $\mathrm{H}$ & 8 \\
\hline & & $\mathrm{I}$ & 9 \\
\hline \multirow[t]{4}{*}{ P021 } & Em quantas escolas você trabalha? (caso marque a alternativa a, passe para a questão 23 ) & A & 1 \\
\hline & & $\mathrm{B}$ & 2 \\
\hline & & $\mathrm{C}$ & 3 \\
\hline & & $\mathrm{D}$ & 4 \\
\hline
\end{tabular}




\begin{tabular}{|c|c|c|c|}
\hline Questão & Questão & Alternativa & Código \\
\hline \multirow[t]{9}{*}{ P022 } & Ao todo, quantas horas-aula você ministra por semana? (não considere aulas particulares) & A & 1 \\
\hline & atividades, se houver.) & $\mathrm{B}$ & 2 \\
\hline & & $\mathrm{C}$ & 3 \\
\hline & & $\mathrm{D}$ & 4 \\
\hline & & $\mathrm{E}$ & 5 \\
\hline & & $\mathrm{F}$ & 6 \\
\hline & & G & 7 \\
\hline & & $\mathrm{H}$ & 8 \\
\hline & & I & 9 \\
\hline \multirow[t]{5}{*}{ P023 } & Qual é a sua situação trabalhista nesta escola? (marque apenas uma opção) & A & 5 \\
\hline & & $\mathrm{B}$ & 4 \\
\hline & & $\mathrm{C}$ & 3 \\
\hline & & $\mathrm{D}$ & 2 \\
\hline & & $\mathrm{E}$ & 1 \\
\hline \multirow[t]{4}{*}{$\mathrm{P} 024$} & Você costuma: frequentar bibliotecas. & A & 4 \\
\hline & & $\mathrm{B}$ & 3 \\
\hline & & $\mathrm{C}$ & 2 \\
\hline & & $\mathrm{D}$ & 1 \\
\hline \multirow[t]{4}{*}{$\mathrm{P} 025$} & Você costuma: ir ao cinema. & A & 4 \\
\hline & & $\mathrm{B}$ & 3 \\
\hline & & $\mathrm{C}$ & 2 \\
\hline & & $\mathrm{D}$ & 1 \\
\hline \multirow[t]{4}{*}{ P026 } & Você costuma: ir ao museu. & A & 4 \\
\hline & & B & 3 \\
\hline & & $\mathrm{C}$ & 2 \\
\hline & & $\mathrm{D}$ & 1 \\
\hline \multirow[t]{4}{*}{ P027 } & Você costuma: ver apresentações teatrais. & A & 4 \\
\hline & & $\mathrm{B}$ & 3 \\
\hline & & $\mathrm{C}$ & 2 \\
\hline & & $\mathrm{D}$ & 1 \\
\hline \multirow[t]{4}{*}{$\mathrm{P} 028$} & Você costuma: ver apresentações musicais ou de dança & A & 4 \\
\hline & & $\mathrm{B}$ & 3 \\
\hline & & $\mathrm{C}$ & 2 \\
\hline & & $\mathrm{D}$ & 1 \\
\hline \multirow[t]{3}{*}{ P029 } & Em seu tempo livre, você lê: jornais. & A & 3 \\
\hline & & B & 2 \\
\hline & & $\mathrm{C}$ & 1 \\
\hline \multirow[t]{3}{*}{ P030 } & Em seu tempo livre, você lê: revistas de informação geral. & A & 3 \\
\hline & & $\mathrm{B}$ & 2 \\
\hline & & $\mathrm{C}$ & 1 \\
\hline \multirow[t]{3}{*}{ P031 } & Em seu tempo livre, você lê: revistas de humor /quadrinhos. & A & 3 \\
\hline & & $\mathrm{B}$ & 2 \\
\hline & & $\mathrm{C}$ & 1 \\
\hline P032 & Em seu tempo livre, você lê: revistas de divulgação científica/cultural. & A & 3 \\
\hline & & B & 2 \\
\hline & & $\mathrm{C}$ & 1 \\
\hline P033 & Em seu tempo livre, você lê: revistas sobre comportamento, celebridades, esporte e tv & A & 3 \\
\hline & & $\mathrm{B}$ & 2 \\
\hline & & $\mathrm{C}$ & 1 \\
\hline P034 & Em seu tempo livre, você lê: livros. & A & 3 \\
\hline & & B & 2 \\
\hline & & $\mathrm{C}$ & 1 \\
\hline P035 & Em seu tempo livre, você lê: sites da internet. & A & 3 \\
\hline & & B & 2 \\
\hline & & $\mathrm{C}$ & 1 \\
\hline P036 & Dentro da sua carga horária, quantas horas semanais são dedicadas à atividades extra-classe & A & 1 \\
\hline & (formação e estudo, planejamento, produção de recursos didáticos etc)? & $\mathrm{B}$ & 2 \\
\hline & & $\mathrm{C}$ & 3 \\
\hline P037 & Indique se você utiliza ou não nesta escola: jornais e revistas informativas. & A & 3 \\
\hline & & B & 2 \\
\hline & & $\mathrm{C}$ & 1 \\
\hline P038 & Indique se você utiliza ou não nesta escola: livros de literatura em geral. & A & 3 \\
\hline & & B & 2 \\
\hline & & $\mathrm{C}$ & 1 \\
\hline P039 & Indique se você utiliza ou não nesta escola: projetor de slides. & A & 3 \\
\hline & & $\mathrm{B}$ & 2 \\
\hline & & $\mathrm{C}$ & 1 \\
\hline P040 & Indique se você utiliza ou não nesta escola: retroprojetor. & A & 3 \\
\hline & & $\mathrm{B}$ & 2 \\
\hline & & $\mathrm{C}$ & 1 \\
\hline P041 & Indique se você utiliza ou não nesta escola: máquina copiadora. & A & 3 \\
\hline & & B & 2 \\
\hline & & $\mathrm{C}$ & 1 \\
\hline
\end{tabular}




\begin{tabular}{|c|c|c|c|}
\hline Questão & Questão & Alternativa & Código \\
\hline \multirow[t]{5}{*}{ P043 } & Conselho de classe é um órgão formado por todos os professores que lecionam em cada turma/ & A & 3 \\
\hline & série. Neste ano, quantas vezes se reuniram os conselhos de classe desta escola? & B & 4 \\
\hline & & $\mathrm{C}$ & 5 \\
\hline & & $\mathrm{D}$ & 2 \\
\hline & & $\mathrm{E}$ & 1 \\
\hline \multirow[t]{2}{*}{ P044 } & Você tem conhecimento do conteúdo da lei número 11.645 de 2008 que determina a obrigatoriedade & A & 1 \\
\hline & $\begin{array}{c}\text { do estudo da temática História e cultura afro-brasileira e indígena nos estabelecimentos de } \\
\text { ensino do país? }\end{array}$ & B & 0 \\
\hline \multirow[t]{3}{*}{$\mathrm{P} 045$} & Neste ano, foram desenvolvidas atividades para atender o determinado pela lei $n .^{\circ} 11.645 \mathrm{de}$ & A & 3 \\
\hline & 2008 nesta escola? & B & 2 \\
\hline & & $\mathrm{C}$ & 1 \\
\hline \multirow[t]{2}{*}{ P046 } & Assinale sua posição em relação às afirmações abaixo, que se referem aos possíveis problemas de & A & 1 \\
\hline & $\begin{array}{c}\text { aprendizagem dos alunos da(s) série(s) avaliada(s): ocorrem na escola devido à carência de } \\
\text { infraestrutura física e/ou pedagógica. }\end{array}$ & B & 0 \\
\hline \multirow[t]{2}{*}{ P047 } & Assinale sua posição em relação às afirmações abaixo, que se referem aos possíveis problemas de & A & 1 \\
\hline & $\begin{array}{c}\text { aprendizagem dos alunos da(s) série(s) avaliada(s): são decorrentes do ambiente de insegurança } \\
\text { física da escola. }\end{array}$ & B & 0 \\
\hline \multirow[t]{2}{*}{ P048 } & Assinale sua posição em relação às afirmações abaixo, que se referem aos possíveis problemas de & A & 1 \\
\hline & $\begin{array}{l}\text { aprendizagem dos alunos da(s) série(s) avaliada(s): ocorrem na escola por oferecer poucas } \\
\text { oportunidades de desenvolvimento das capacidades intelectuais do aluno }\end{array}$ & B & 0 \\
\hline \multirow[t]{2}{*}{ P049 } & Assinale sua posição em relação às afirmações abaixo, que se referem aos possíveis problemas de & A & 1 \\
\hline & $\begin{array}{l}\text { aprendizagem dos alunos da(s) série(s) avaliada(s): estão relacionados aos conteúdos } \\
\text { curriculares, que são inadequados às necessidades dos alunos. }\end{array}$ & B & 0 \\
\hline \multirow[t]{2}{*}{$\mathrm{P} 050$} & Assinale sua posição em relação às afirmações abaixo, que se referem aos possíveis problemas de & A & 1 \\
\hline & $\begin{array}{c}\text { aprendizagem dos alunos da(s) série(s) avaliada(s): estão relacionados ao não-cumprimento do } \\
\text { conteúdo curricular. }\end{array}$ & B & 0 \\
\hline \multirow[t]{2}{*}{$\mathrm{P} 051$} & Assinale sua posição em relação às afirmações abaixo, que se referem aos possíveis problemas de & A & 1 \\
\hline & $\begin{array}{l}\text { aprendizagem dos alunos da(s) série(s) avaliada(s): relacionam-se à sobrecarga de trabalho } \\
\text { do(as) professores(as), dificultando o planejamento e o preparo das aulas. }\end{array}$ & B & 0 \\
\hline \multirow[t]{2}{*}{$\mathrm{P} 052$} & Assinale sua posição em relação às afirmações abaixo, que se referem aos possíveis problemas de & A & 1 \\
\hline & $\begin{array}{l}\text { aprendizagem dos alunos da(s) série(s) avaliada(s): ocorrem devido ao baixo salário dos } \\
\text { professores, que gera insatisfação e desestímulo para a atividade docente. }\end{array}$ & $\mathrm{B}$ & 0 \\
\hline \multirow[t]{2}{*}{$\mathrm{P} 053$} & Assinale sua posição em relação às afirmações abaixo, que se referem aos possíveis problemas de & A & 1 \\
\hline & aprendizagem dos alunos da(s) série(s) avaliada(s): são decorrentes do meio em que o aluno vive. & B & 0 \\
\hline \multirow[t]{2}{*}{$\mathrm{P} 054$} & Assinale sua posição em relação às afirmações abaixo, que se referem aos possíveis problemas de & A & 1 \\
\hline & $\begin{array}{l}\text { aprendizagem dos alunos da(s) série(s) avaliada(s): são decorrentes do nível cultural dos pais } \\
\text { dos alunos. }\end{array}$ & B & 0 \\
\hline \multirow[t]{2}{*}{ P055 } & Assinale sua posição em relação às afirmações abaixo, que se referem aos possíveis problemas de & A & 1 \\
\hline & $\begin{array}{l}\text { aprendizagem dos alunos da(s) série(s) avaliada(s): estão relacionadas à falta de assistência e } \\
\text { acompanhamento da família nos deveres de casa e pesquisas dos alunos. }\end{array}$ & B & 0 \\
\hline \multirow[t]{2}{*}{ P056 } & Assinale sua posição em relação às afirmações abaixo, que se referem aos possíveis problemas de & A & 1 \\
\hline & $\begin{array}{c}\text { aprendizagem dos alunos da(s) série(s) avaliada(s): ocorrem devido à falta de aptidão e } \\
\text { habilidades do aluno. }\end{array}$ & B & 0 \\
\hline \multirow[t]{2}{*}{$\mathrm{P} 057$} & Assinale sua posição em relação às afirmações abaixo, que se referem aos possíveis problemas de & A & 1 \\
\hline & $\begin{array}{c}\text { aprendizagem dos alunos da(s) série(s) avaliada(s): estão vinculados à baixa autoestima dos } \\
\text { alunos. }\end{array}$ & B & 0 \\
\hline \multirow[t]{2}{*}{$\mathrm{P} 058$} & Assinale sua posição em relação às afirmações abaixo, que se referem aos possíveis problemas de & A & 1 \\
\hline & $\begin{array}{c}\text { aprendizagem dos alunos da(s) série(s) avaliada(s): ocorrem devido ao desinteresse e falta de } \\
\text { esforço do aluno. }\end{array}$ & B & 0 \\
\hline \multirow[t]{2}{*}{ P059 } & Assinale sua posição em relação às afirmações abaixo, que se referem aos possíveis problemas de & A & 1 \\
\hline & $\begin{array}{c}\text { aprendizagem dos alunos da(s) série(s) avaliada(s): são decorrentes da indisciplina dos alunos } \\
\text { em sala de aula. }\end{array}$ & B & 0 \\
\hline \multirow[t]{5}{*}{ P060 } & Os itens de 60 a 74 apresentam algumas afirmações. Indique seu grau de concordância/ & A & 5 \\
\hline & discordância com cada uma delas. (marque apenas uma opção em cada linha.): o(a) diretor(a) me & B & 4 \\
\hline & anima e me motiva para o trabalho. & $\mathrm{C}$ & 3 \\
\hline & & $\mathrm{D}$ & 2 \\
\hline & & $\mathrm{E}$ & 1 \\
\hline P061 & Os itens de 60 a 74 apresentam algumas afirmações. Indique seu grau de concordância/ & A & 5 \\
\hline & discordância com cada uma delas. (marque apenas uma opção em cada linha.): tenho plena & B & 4 \\
\hline & confiança no(a) diretor(a) como profissional. & $\mathrm{C}$ & 3 \\
\hline & & $\mathrm{D}$ & 2 \\
\hline & & E & 1 \\
\hline P062 & Os itens de 60 a 74 apresentam algumas afirmações. Indique seu grau de concordância/ & A & 5 \\
\hline & discordância com cada uma delas. (marque apenas uma opção em cada linha.): o(a) diretor(a) & B & 4 \\
\hline & consegue que os professores se comprometam com a escola. & $\mathrm{C}$ & 3 \\
\hline & & $\mathrm{D}$ & 2 \\
\hline & & $\mathrm{E}$ & 1 \\
\hline P063 & Os itens de 60 a 74 apresentam algumas afirmações. Indique seu grau de concordância/ & A & 5 \\
\hline & discordância com cada uma delas. (marque apenas uma opção em cada linha.): o(a) diretor(a) & B & 4 \\
\hline & estimula as atividades inovadoras. & $\mathrm{C}$ & 3 \\
\hline & & $\mathrm{D}$ & 2 \\
\hline & & $\mathrm{E}$ & 1 \\
\hline
\end{tabular}




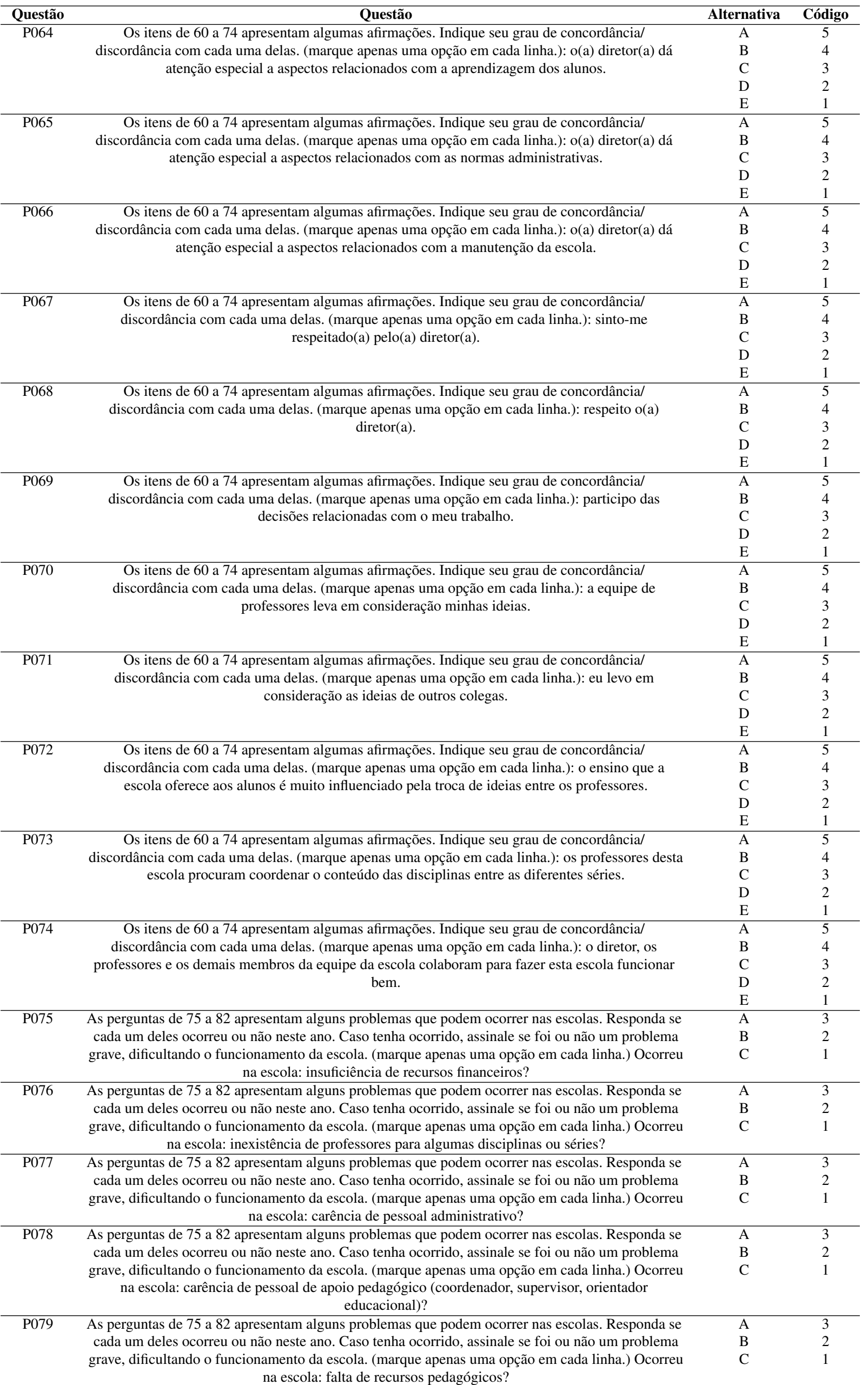




\begin{tabular}{|c|c|c|c|}
\hline Questão & Questão & Alternativa & Código \\
\hline \multirow[t]{3}{*}{ P080 } & \multirow{3}{*}{$\begin{array}{c}\text { As perguntas de } 75 \text { a } 82 \text { apresentam alguns problemas que podem ocorrer nas escolas. Responda se } \\
\text { cada um deles ocorreu ou não neste ano. Caso tenha ocorrido, assinale se foi ou não um problema } \\
\text { grave, dificultando o funcionamento da escola. (marque apenas uma opção em cada linha.) Ocorreu } \\
\text { na escola: alto índice de faltas por parte dos professores? }\end{array}$} & $\mathrm{A}$ & 3 \\
\hline & & B & 2 \\
\hline & & $\mathrm{C}$ & 1 \\
\hline \multirow[t]{3}{*}{ P081 } & \multirow{3}{*}{$\begin{array}{l}\text { As perguntas de } 75 \text { a } 82 \text { apresentam alguns problemas que podem ocorrer nas escolas. Responda se } \\
\text { cada um deles ocorreu ou não neste ano. Caso tenha ocorrido, assinale se foi ou não um problema } \\
\text { grave, dificultando o funcionamento da escola. (marque apenas uma opção em cada linha.) Ocorreu } \\
\text { na escola: alto índice de faltas por parte dos alunos? }\end{array}$} & $\mathrm{A}$ & 3 \\
\hline & & B & 2 \\
\hline & & $\mathrm{C}$ & 1 \\
\hline \multirow[t]{3}{*}{ P082 } & \multirow{3}{*}{$\begin{array}{c}\text { As perguntas de } 75 \text { a } 82 \text { apresentam alguns problemas que podem ocorrer nas escolas. Responda se } \\
\text { cada um deles ocorreu ou não neste ano. Caso tenha ocorrido, assinale se foi ou não um problema } \\
\text { grave, dificultando o funcionamento da escola. (marque apenas uma opção em cada linha.) Ocorreu } \\
\text { na escola: problemas disciplinares causados pelos alunos? }\end{array}$} & $\mathrm{A}$ & 3 \\
\hline & & $\mathrm{B}$ & 2 \\
\hline & & $\mathrm{C}$ & 1 \\
\hline \multirow[t]{2}{*}{ P083 } & \multirow{2}{*}{$\begin{array}{l}\text { Sobre os fatos listados abaixo, diga se eles aconteceram ou não este ano nesta escola. } \\
\text { (agressor: aluno) : agressão verbal a professores. }\end{array}$} & $\mathrm{A}$ & 1 \\
\hline & & B & 0 \\
\hline \multirow[t]{2}{*}{$\mathrm{P} 084$} & \multirow{2}{*}{$\begin{array}{l}\text { Sobre os fatos listados abaixo, diga se eles aconteceram ou não este ano nesta escola. } \\
\text { (agressor: aluno) : agressão física a professores. }\end{array}$} & $\mathrm{A}$ & 1 \\
\hline & & $\mathrm{B}$ & 0 \\
\hline \multirow[t]{2}{*}{$\mathrm{P} 085$} & & $\mathrm{~A}$ & 1 \\
\hline & (agressor: aluno) : agressão verbal a alunos. & $\mathrm{B}$ & 0 \\
\hline P086 & Sobre os fatos listados abaixo, diga se eles aconteceram ou não este ano nesta escola. & $\mathrm{A}$ & 1 \\
\hline & (agressor: aluno) : agressão física a alunos. & $\mathrm{B}$ & 0 \\
\hline P087 & Sobre os fatos listados abaixo, diga se eles aconteceram ou não este ano nesta escola. & $\mathrm{A}$ & 1 \\
\hline & (agressor: aluno) : agressão verbal a funcionários. & $\mathrm{B}$ & 0 \\
\hline P088 & Sobre os fatos listados abaixo, diga se eles aconteceram ou não este ano nesta escola. & A & 1 \\
\hline & (agressor: aluno) : agressão física a funcionários. & $\mathrm{B}$ & 0 \\
\hline P089 & Sobre os fatos listados abaixo, diga se eles aconteceram ou não este ano nesta escola. & A & 1 \\
\hline & (agressor: professor):agressão verbal a professores. & $\mathrm{B}$ & 0 \\
\hline P090 & Sobre os fatos listados abaixo, diga se eles aconteceram ou não este ano nesta escola. & A & 1 \\
\hline & (agressor: professor):agressão física a professores. & $\mathrm{B}$ & 0 \\
\hline P091 & Sobre os fatos listados abaixo, diga se eles aconteceram ou não este ano nesta escola. & A & 1 \\
\hline & (agressor: professor):agressão verbal a alunos. & $\mathrm{B}$ & 0 \\
\hline P092 & Sobre os fatos listados abaixo, diga se eles aconteceram ou não este ano nesta escola. & A & 1 \\
\hline & (agressor: professor):agressão física a alunos. & $\mathrm{B}$ & 0 \\
\hline P093 & Sobre os fatos listados abaixo, diga se eles aconteceram ou não este ano nesta escola. & A & 1 \\
\hline & (agressor: professor): agressão verbal a funcionários. & $\mathrm{B}$ & 0 \\
\hline P094 & Sobre os fatos listados abaixo, diga se eles aconteceram ou não este ano nesta escola. & A & 1 \\
\hline & (agressor: professor): agressão física a funcionários. & $\mathrm{B}$ & 0 \\
\hline P095 & Agressão verbal a professores. Sobre os fatos listados abaixo, diga se eles aconteceram ou não & A & 1 \\
\hline & este ano nesta escola. (agressor: funcionário): & $\mathrm{B}$ & 0 \\
\hline P096 & Agressão física a professores. Sobre os fatos listados abaixo, diga se eles aconteceram ou não & A & 1 \\
\hline & este ano nesta escola. (agressor: funcionário): & $\mathrm{B}$ & 0 \\
\hline P097 & Agressão verbal a alunos. Sobre os fatos listados abaixo, diga se eles aconteceram ou não este & A & 1 \\
\hline & ano nesta escola. (agressor: funcionário): & $\mathrm{B}$ & 0 \\
\hline P098 & Agressão física a alunos. Sobre os fatos listados abaixo, diga se eles aconteceram ou não este & A & 1 \\
\hline & ano nesta escola. (agressor: funcionário): & $\mathrm{B}$ & 0 \\
\hline P099 & Agressão verbal a funcionários. Sobre os fatos listados abaixo, diga se eles aconteceram ou não & A & 1 \\
\hline & este ano nesta escola. (agressor: funcionário): & $\mathrm{B}$ & 0 \\
\hline P100 & Agressão física a funcionários. Sobre os fatos listados abaixo, diga se eles aconteceram ou não & A & 1 \\
\hline & este ano nesta escola. (agressor: funcionário): & $\mathrm{B}$ & 0 \\
\hline P101 & Sobre os fatos listados abaixo, diga se eles aconteceram ou não este ano, nesta escola: você & A & 1 \\
\hline & foi vítima de atentado à vida? & $\mathrm{B}$ & 0 \\
\hline P102 & Sobre os fatos listados abaixo, diga se eles aconteceram ou não este ano, nesta escola: você & A & 1 \\
\hline & foi ameaçado por algum aluno? & $\mathrm{B}$ & 0 \\
\hline P103 & Sobre os fatos listados abaixo, diga se eles aconteceram ou não este ano, nesta escola: você & A & 1 \\
\hline & foi agredido verbalmente por algum aluno? & $\mathrm{B}$ & 0 \\
\hline P104 & Sobre os fatos listados abaixo, diga se eles aconteceram ou não este ano, nesta escola: você & A & 1 \\
\hline & foi agredido fisicamente por algum aluno? & $\mathrm{B}$ & 0 \\
\hline P105 & Sobre os fatos listados abaixo, diga se eles aconteceram ou não este ano, nesta escola: você & A & 1 \\
\hline & foi vítima de furto? & $\mathrm{B}$ & 0 \\
\hline P106 & Sobre os fatos listados abaixo, diga se eles aconteceram ou não este ano, nesta escola: você & A & 1 \\
\hline & foi vítima de roubo (com uso de violência)? & $\mathrm{B}$ & 0 \\
\hline P107 & Sobre os fatos listados abaixo, diga se eles aconteceram ou não este ano, nesta escola: alunos & A & 1 \\
\hline & frequentaram as suas aulas sob efeito de bebida alcoólica? & $\mathrm{B}$ & 0 \\
\hline P108 & Sobre os fatos listados abaixo, diga se eles aconteceram ou não este ano, nesta escola: alunos & A & 1 \\
\hline & frequentaram as suas aulas sob efeito de drogas ilícitas? & $\mathrm{B}$ & 0 \\
\hline P109 & Sobre os fatos listados abaixo, diga se eles aconteceram ou não este ano, nesta escola: alunos & A & 1 \\
\hline & frequentaram as suas aulas portando arma branca (facas, canivetes etc.)? & $\mathrm{B}$ & 0 \\
\hline P110 & Sobre os fatos listados abaixo, diga se eles aconteceram ou não este ano, nesta escola: alunos & A & 1 \\
\hline & frequentaram as suas aulas portando arma de fogo? & $\mathrm{B}$ & 0 \\
\hline P111 & A sua escola participou da Prova Brasil de 2009? & A & 1 \\
\hline & & $\mathrm{B}$ & 0 \\
\hline P112 & Você conhece os resultados do sistema de avaliação da educação básica (Saeb): da sua escola? & $\mathrm{A}$ & 1 \\
\hline & & $\mathrm{B}$ & 0 \\
\hline P113 & Você conhece os resultados do sistema de avaliação da educação básica (Saeb): do seu município? & $\mathrm{A}$ & 1 \\
\hline & & $\mathrm{B}$ & 0 \\
\hline
\end{tabular}




\begin{tabular}{|c|c|c|c|}
\hline Questão & Questão & Alternativa & Código \\
\hline \multirow[t]{2}{*}{ P114 } & Você conhece os resultados do sistema de avaliação da educação básica (Saeb): do seu estado? & A & 1 \\
\hline & & $\mathrm{B}$ & 0 \\
\hline \multirow[t]{3}{*}{ P115 } & Indique se você utiliza ou não nesta turma: (marque apenas uma opção em cada linha.): & A & 3 \\
\hline & computadores. & $\mathrm{B}$ & 2 \\
\hline & & $\mathrm{C}$ & 1 \\
\hline \multirow[t]{3}{*}{ P116 } & Indique se você utiliza ou não nesta turma: (marque apenas uma opção em cada linha.): internet. & A & 3 \\
\hline & & $\mathrm{B}$ & 2 \\
\hline & & $\mathrm{C}$ & 1 \\
\hline \multirow[t]{3}{*}{ P117 } & Indique se você utiliza ou não nesta turma: (marque apenas uma opção em cada linha.): fitas de & A & 3 \\
\hline & vídeo ou dvd. & $\mathrm{B}$ & 2 \\
\hline & & $\mathrm{C}$ & 1 \\
\hline \multirow[t]{3}{*}{ P118 } & Indique se você utiliza ou não nesta turma: (marque apenas uma opção em cada linha.): jornais e & A & 3 \\
\hline & 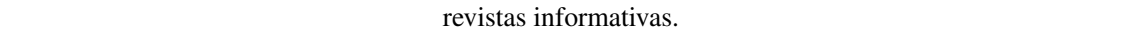 & B & 2 \\
\hline & & $\mathrm{C}$ & 1 \\
\hline \multirow[t]{3}{*}{ P119 } & Indique se você utiliza ou não nesta turma: (marque apenas uma opção em cada linha.): revistas & A & 3 \\
\hline & em quadrinhos. & B & 2 \\
\hline & & $\mathrm{C}$ & 1 \\
\hline \multirow[t]{3}{*}{ P120 } & Indique se você utiliza ou não nesta turma: (marque apenas uma opção em cada linha.): livros & A & 3 \\
\hline & didáticos. & B & 2 \\
\hline & & $\mathrm{C}$ & 1 \\
\hline \multirow[t]{4}{*}{ P121 } & Quanto dos conteúdos previstos você conseguiu desenvolver com os alunos desta turma, neste ano? & A & 1 \\
\hline & & $\mathrm{B}$ & 2 \\
\hline & & $\mathrm{C}$ & 3 \\
\hline & & $\mathrm{D}$ & 4 \\
\hline \multirow{5}{*}{ P122 } & Quantos dos alunos desta turma você acha que: concluirão os anos iniciais do ensino & A & 5 \\
\hline & fundamental? & $\mathrm{B}$ & 4 \\
\hline & & $\mathrm{C}$ & 3 \\
\hline & & $\mathrm{D}$ & 2 \\
\hline & & $\mathrm{E}$ & 1 \\
\hline \multirow[t]{5}{*}{ P123 } & Quantos dos alunos desta turma você acha que: concluirão o ensino fundamental $\left(8{ }^{a}{ }^{\mathrm{a}}\right.$ série/ & A & 5 \\
\hline & $9 .^{\circ}$ ano)? & $\mathrm{B}$ & 4 \\
\hline & & $\mathrm{C}$ & 3 \\
\hline & & $\mathrm{D}$ & 2 \\
\hline & & $\mathrm{E}$ & 1 \\
\hline \multirow[t]{5}{*}{ P124 } & Quantos dos alunos desta turma você acha que: concluirão o ensino médio? & A & 5 \\
\hline & & B & 4 \\
\hline & & $\mathrm{C}$ & 3 \\
\hline & & $\mathrm{D}$ & 2 \\
\hline & & $\mathrm{E}$ & 1 \\
\hline P125 & Quantos dos alunos desta turma você acha que: entrarão para a universidade? & A & 5 \\
\hline & & B & 4 \\
\hline & & $\mathrm{C}$ & 3 \\
\hline & & $\mathrm{D}$ & 2 \\
\hline & & $\mathrm{E}$ & 1 \\
\hline P126 & Os alunos desta turma têm livros didáticos? & A & 5 \\
\hline & & B & 4 \\
\hline & & $\mathrm{C}$ & 3 \\
\hline & & $\mathrm{D}$ & 2 \\
\hline & & $\mathrm{E}$ & 1 \\
\hline P127 & Os alunos desta turma receberam o livro didático no início do ano letivo? & A & 1 \\
\hline & & B & 0 \\
\hline P128 & O livro didático escolhido foi o recebido? & A & 1 \\
\hline & & $\mathrm{B}$ & 0 \\
\hline P129 & Como você considera o(s) livro(s) didático(s) utilizado(s) por você na(s) disciplina(s) que & A & 5 \\
\hline & ministra nesta turma? & B & 4 \\
\hline & & $\mathrm{C}$ & 3 \\
\hline & & $\mathrm{D}$ & 2 \\
\hline & & $\mathrm{E}$ & 1 \\
\hline P130 & Na escolha do livro didático utilizado nesta turma em que você leciona, foi consultado o guia & A & 1 \\
\hline & de livros didáticos da SEB/MEC? & $\mathrm{B}$ & 0 \\
\hline P131 & Para a disciplina que você ministra, como foi escolhido o livro didático para utilização nesta & A & 7 \\
\hline & turma? (marque apenas uma opção.) & $\mathrm{B}$ & 6 \\
\hline & & $\mathrm{C}$ & 5 \\
\hline & & $\mathrm{D}$ & 4 \\
\hline & & $\mathrm{E}$ & 3 \\
\hline & & $\mathrm{F}$ & 2 \\
\hline & & G & 1 \\
\hline P132 & Como você utiliza a biblioteca ou sala de leitura da escola em apoio às suas aulas nesta turma? & A & 1 \\
\hline & & $\mathrm{B}$ & 2 \\
\hline & & $\mathrm{C}$ & 3 \\
\hline & & $\mathrm{D}$ & 4 \\
\hline & & $\mathrm{E}$ & 5 \\
\hline
\end{tabular}




\begin{tabular}{|c|c|c|c|}
\hline Questão & Questão & Alternativa & Código \\
\hline \multirow[t]{5}{*}{ P142 } & (Professor de matemática) indique a frequência com a qual você desenvolve as seguintes práticas & A & 5 \\
\hline & pedagógicas com seus alunos nesta turma: fazer exercícios para fixar procedimentos e regras. & $\mathrm{B}$ & 4 \\
\hline & & $\mathrm{C}$ & 3 \\
\hline & & $\mathrm{D}$ & 2 \\
\hline & & $\mathrm{E}$ & 1 \\
\hline \multirow[t]{5}{*}{ P143 } & (Professor de matemática) indique a frequência com a qual você desenvolve as seguintes práticas & A & 5 \\
\hline & pedagógicas com seus alunos nesta turma: lidar com situações problemas que exigem raciocínios & $\mathrm{B}$ & 4 \\
\hline & diferentes e mais complexos que a maioria dos exemplos usuais. & $\mathrm{C}$ & 3 \\
\hline & & $\mathrm{D}$ & 2 \\
\hline & & $\mathrm{E}$ & 1 \\
\hline \multirow[t]{5}{*}{ P144 } & (Professor de matemática) indique a frequência com a qual você desenvolve as seguintes práticas & A & 5 \\
\hline & pedagógicas com seus alunos nesta turma: falar sobre suas soluções, discutindo os caminhos & $\mathrm{B}$ & 4 \\
\hline & usados para encontrá-las. & $\mathrm{C}$ & 3 \\
\hline & & $\mathrm{D}$ & 2 \\
\hline & & $\mathrm{E}$ & 1 \\
\hline \multirow[t]{5}{*}{ P145 } & (Professor de matemática) indique a frequência com a qual você desenvolve as seguintes práticas & A & 5 \\
\hline & pedagógicas com seus alunos nesta turma: gravar as regras que permitem obter as respostas & $\mathrm{B}$ & 4 \\
\hline & certas dos cálculos e problemas. & $\mathrm{C}$ & 3 \\
\hline & & $\mathrm{D}$ & 2 \\
\hline & & $\mathrm{E}$ & 1 \\
\hline \multirow[t]{5}{*}{ P146 } & (Professor de matemática) indique a frequência com a qual você desenvolve as seguintes práticas & A & 5 \\
\hline & pedagógicas com seus alunos nesta turma: lidar com temas que aparecem em jornais e/ou revistas, & $\mathrm{B}$ & 4 \\
\hline & discutindo a relação dos temas com a matemática. & $\mathrm{C}$ & 3 \\
\hline & & $\mathrm{D}$ & 2 \\
\hline & & $\mathrm{E}$ & 1 \\
\hline \multirow[t]{5}{*}{ P147 } & (Professor de matemática) indique a frequência com a qual você desenvolve as seguintes práticas & $\mathrm{A}$ & 5 \\
\hline & pedagógicas com seus alunos nesta turma: interpretar resultados numéricos obtidos para dar uma & $\mathrm{B}$ & 4 \\
\hline & resposta adequada ao problema. & $\mathrm{C}$ & 3 \\
\hline & & $\mathrm{D}$ & 2 \\
\hline & & $\mathrm{E}$ & 1 \\
\hline \multirow[t]{5}{*}{ P148 } & (Professor de matemática) indique a frequência com a qual você desenvolve as seguintes práticas & A & 5 \\
\hline & pedagógicas com seus alunos nesta turma: lidar com situações que lhes sejam familiares e & $\mathrm{B}$ & 4 \\
\hline & que apresentem temas de interesse dos alunos. & $\mathrm{C}$ & 3 \\
\hline & & $\mathrm{D}$ & 2 \\
\hline & & $\mathrm{E}$ & 1 \\
\hline \multirow[t]{5}{*}{ P149 } & (Professor de matemática) indique a frequência com a qual você desenvolve as seguintes práticas & A & 5 \\
\hline & pedagógicas com seus alunos nesta turma: experimentar diferentes modos de resolver um problema & $\mathrm{B}$ & 4 \\
\hline & ou de efetuar um cálculo. & $\mathrm{C}$ & 3 \\
\hline & & $\mathrm{D}$ & 2 \\
\hline & & $\mathrm{E}$ & 1 \\
\hline \multirow[t]{5}{*}{$\mathrm{P} 150$} & (Professor de matemática) indique a frequência com a qual você desenvolve as seguintes práticas & A & 5 \\
\hline & pedagógicas com seus alunos nesta turma: aprimorar a precisão e a velocidade de execução de & $\mathrm{B}$ & 4 \\
\hline & cálculos. & $\mathrm{C}$ & 3 \\
\hline & & $\mathrm{D}$ & 2 \\
\hline & & $\mathrm{E}$ & 1 \\
\hline \multirow[t]{5}{*}{ P151 } & (Professor de matemática) indique a frequência com a qual você desenvolve as seguintes práticas & $\mathrm{A}$ & 5 \\
\hline & pedagógicas com seus alunos nesta turma: experimentar diferentes ações (coletar informações, & $\mathrm{B}$ & 4 \\
\hline & recortar, analisar explorar, discutir, manipular etc.) Para resolver problemas. & $\mathrm{C}$ & 3 \\
\hline & & $\mathrm{D}$ & 2 \\
\hline & & $\mathrm{E}$ & 1 \\
\hline \multirow[t]{5}{*}{ P152 } & (Professor de matemática) indique a frequência com a qual você desenvolve as seguintes práticas & A & 5 \\
\hline & pedagógicas com seus alunos nesta turma: incentivar e estimular o aluno a analisar criticamente & $\mathrm{B}$ & 4 \\
\hline & se os resultados obtidos na resolução de um problema são plausíveis. & $\mathrm{C}$ & 3 \\
\hline & & $\mathrm{D}$ & 2 \\
\hline & & $\mathrm{E}$ & 1 \\
\hline
\end{tabular}


Tabela 32 - Descrição das variáveis Dicotomizadas da amostra obtida dos dados

\begin{tabular}{|c|c|c|c|}
\hline Variáveis Dicotomizadas & Categorias & Código & Frequência amostral \\
\hline \multirow[t]{2}{*}{ Q001 } & Masculino & 0 & 6105 \\
\hline & Feminino & 1 & 5940 \\
\hline \multirow[t]{2}{*}{ Q004 } & 1996 ou antes & 0 & 1274 \\
\hline & 1997 ou depois & 1 & 10857 \\
\hline \multirow[t]{2}{*}{ Q005 } & Sim & 1 & 11903 \\
\hline & Não & 0 & 161 \\
\hline \multirow[t]{2}{*}{ Q006 } & Sim & 1 & 10897 \\
\hline & Não & 0 & 1186 \\
\hline \multirow[t]{2}{*}{ Q007 } & Sim & 1 & 11199 \\
\hline & Não & 0 & 854 \\
\hline \multirow[t]{2}{*}{ Q008 } & Sim & 1 & 12043 \\
\hline & Não & 0 & 73 \\
\hline \multirow[t]{2}{*}{ Q009 } & Sim & 1 & 9316 \\
\hline & Não & 0 & 2709 \\
\hline \multirow[t]{2}{*}{ Q010 } & Sim & 1 & 1951 \\
\hline & Não & 0 & 10099 \\
\hline \multirow[t]{2}{*}{ Q012 } & Sim & 1 & 7443 \\
\hline & Não & 0 & 4676 \\
\hline \multirow[t]{2}{*}{ Q013 } & Sim & 1 & 8940 \\
\hline & Não & 0 & 3185 \\
\hline \multirow[t]{2}{*}{ Q014 } & Sim & 1 & 12059 \\
\hline & Não & 0 & 77 \\
\hline Q015 & Sim & 1 & 1056 \\
\hline & Não & 0 & 11063 \\
\hline Q016 & Sim & 1 & 11955 \\
\hline & Não & 0 & 71 \\
\hline Q017 & Mais de três pessoas & 1 & 9932 \\
\hline & Duas pessoas ou menos & 0 & 2177 \\
\hline Q018 & Sim & 1 & 11024 \\
\hline & Não & 0 & 1070 \\
\hline Q019 & Ingressou no Ensino Superior ou mais & 1 & 3698 \\
\hline & Terminou o Ensino Médio ou Menos & 0 & 8202 \\
\hline Q020 & Sim & 1 & 11395 \\
\hline & Não & 0 & 489 \\
\hline Q022 & Sim & 1 & 8010 \\
\hline & Não & 0 & 3997 \\
\hline Q023 & Ingressou no Ensino Superior para mais & 1 & 3004 \\
\hline & Concluiu o Ensino Médio ou menos & 0 & 7756 \\
\hline Q024 & Sim & 1 & 9843 \\
\hline & Não & 0 & 918 \\
\hline Q026 & Alta & 1 & 8263 \\
\hline & Baixa & 0 & 3795 \\
\hline Q032 & Alta & 1 & 1008 \\
\hline & Baixa & 0 & 10726 \\
\hline Q033 & Alta & 1 & 2559 \\
\hline & Baixa & 0 & 9175 \\
\hline Q034 & Alta & 1 & 1808 \\
\hline & Baixa & 0 & 9799 \\
\hline Q035 & Alta & 1 & 2900 \\
\hline & Baixa & 0 & 8756 \\
\hline Q036 & Alta & 1 & 3069 \\
\hline & Baixa & 0 & 8578 \\
\hline Q037 & Alta & 1 & 3744 \\
\hline & Baixa & 0 & 7929 \\
\hline Q038 & Alta & 1 & 6462 \\
\hline & Baixa & 0 & 5172 \\
\hline Q039 & Alta & 1 & 978 \\
\hline & Baixa & 0 & 10725 \\
\hline Q040 & Alta & 1 & 2481 \\
\hline & Baixa & 0 & 9284 \\
\hline Q041 & Alta & 1 & 504 \\
\hline & Baixa & 0 & 11129 \\
\hline Q042 & Alta & 1 & 1163 \\
\hline & Baixa & 0 & 10506 \\
\hline Q043 & Alta & 1 & 2443 \\
\hline & Baixa & 0 & 9304 \\
\hline Q044 & Muito Tempo & 1 & 9040 \\
\hline & Pouco Tempo & 0 & 2999 \\
\hline Q045 & Muito Tempo & 1 & 4524 \\
\hline & Pouco Tempo & 0 & 7507 \\
\hline Q047 & Antes da $1{ }^{\mathrm{a}}$ Serie & 1 & 1866 \\
\hline & $\mathrm{Na} 1^{\mathrm{a}}$ Serie ou depois & 0 & 10144 \\
\hline
\end{tabular}




\begin{tabular}{|c|c|c|c|}
\hline Variáveis Dicotomizadas & Categorias & Código & Frequência amostral \\
\hline \multirow[t]{2}{*}{ Q048 } & Somente em Particular & 1 & 148 \\
\hline & Estudou em escola pública em algum momento & 0 & 11872 \\
\hline \multirow[t]{2}{*}{ Q049 } & Sim & 1 & 2591 \\
\hline & Não & 0 & 9452 \\
\hline \multirow[t]{2}{*}{ Q050 } & Sim & 1 & \\
\hline & Não & 0 & \\
\hline \multirow[t]{2}{*}{ Q052 } & Alta & 1 & 11282 \\
\hline & Baixa & 0 & 737 \\
\hline \multirow[t]{2}{*}{ Q053 } & Alta & 1 & 11615 \\
\hline & Baixa & 0 & 415 \\
\hline \multirow[t]{2}{*}{ Q055 } & Alta & 1 & 10860 \\
\hline & Baixa & 0 & 1182 \\
\hline \multirow[t]{2}{*}{ Q056 } & Alta & 1 & 11517 \\
\hline & Baixa & 0 & 522 \\
\hline \multirow[t]{2}{*}{ Q057 } & Sim & 1 & 6104 \\
\hline & Não & 0 & 5951 \\
\hline \multirow[t]{2}{*}{ Q058 } & Sim & 1 & 3251 \\
\hline & Não & 0 & 8817 \\
\hline \multirow[t]{2}{*}{ E001 } & Tem & 1 & 605 \\
\hline & Não Tem & 0 & 1 \\
\hline E002 & Bom & 1 & 593 \\
\hline & Ruim & 0 & 15 \\
\hline E003 & Bom & 1 & 542 \\
\hline & Ruim & 0 & 65 \\
\hline E004 & Bom & 1 & 576 \\
\hline & Ruim & 0 & 33 \\
\hline E005 & Bom & 1 & 569 \\
\hline & Ruim & 0 & 35 \\
\hline E006 & Bom & 1 & 589 \\
\hline & Ruim & 0 & 16 \\
\hline E007 & Bom & 1 & 581 \\
\hline & Ruim & 0 & 23 \\
\hline E008 & Bom & 1 & 543 \\
\hline & Ruim & 0 & 66 \\
\hline E009 & Bom & 1 & 575 \\
\hline & Ruim & 0 & 32 \\
\hline E010 & Bom & 1 & 521 \\
\hline & Ruim & 0 & 84 \\
\hline E011 & Bom & 1 & 559 \\
\hline & Ruim & 0 & 42 \\
\hline E012 & Bom & 1 & 524 \\
\hline & Ruim & 0 & 84 \\
\hline E013 & Bom & 1 & 500 \\
\hline & Ruim & 0 & 109 \\
\hline E031 & Bom & 1 & 532 \\
\hline & Ruim & 0 & 72 \\
\hline E032 & Bom & 1 & 460 \\
\hline & Ruim & 0 & 146 \\
\hline E033 & Bom & 1 & 549 \\
\hline & Ruim & 0 & 59 \\
\hline E034 & Bom & 1 & 512 \\
\hline & Ruim & 0 & 94 \\
\hline E035 & Bom & 1 & 589 \\
\hline & Ruim & 0 & 17 \\
\hline E036 & Bom & 1 & 588 \\
\hline & Ruim & 0 & 19 \\
\hline E037 & Bom & 1 & 535 \\
\hline & Ruim & 0 & 69 \\
\hline E038 & Bom & 1 & 393 \\
\hline & Ruim & 0 & 214 \\
\hline E039 & Bom & 1 & 574 \\
\hline & Ruim & 0 & 33 \\
\hline E040 & Bom & 1 & 520 \\
\hline & Ruim & 0 & 84 \\
\hline E041 & Bom & 1 & 341 \\
\hline & Ruim & 0 & 258 \\
\hline E042 & Bom & 1 & 576 \\
\hline & Ruim & 0 & 32 \\
\hline E043 & Bom & 1 & 589 \\
\hline & Ruim & 0 & 20 \\
\hline E044 & Bom & 1 & 344 \\
\hline & Ruim & 0 & 264 \\
\hline E045 & Bom & 1 & 577 \\
\hline & Ruim & 0 & 30 \\
\hline
\end{tabular}




\begin{tabular}{|c|c|c|c|}
\hline Variáveis Dicotomizadas & Categorias & Código & Frequência amostral \\
\hline \multirow[t]{2}{*}{ E046 } & Bom & 1 & 249 \\
\hline & Ruim & 0 & 343 \\
\hline \multirow[t]{2}{*}{ E047 } & Bom & 1 & 589 \\
\hline & Ruim & 0 & 17 \\
\hline \multirow[t]{2}{*}{ E048 } & Bom & 1 & 491 \\
\hline & Ruim & 0 & 116 \\
\hline \multirow[t]{2}{*}{ E049 } & Bom & 1 & 586 \\
\hline & Ruim & 0 & 23 \\
\hline \multirow[t]{2}{*}{ E050 } & Bom & 1 & 448 \\
\hline & Ruim & 0 & 155 \\
\hline \multirow[t]{2}{*}{ E051 } & Bom & 1 & 513 \\
\hline & Ruim & 0 & 94 \\
\hline \multirow[t]{2}{*}{ E052 } & Bom & 1 & 213 \\
\hline & Ruim & 0 & 390 \\
\hline \multirow[t]{2}{*}{ E053 } & Bom & 1 & 119 \\
\hline & Ruim & 0 & 484 \\
\hline \multirow[t]{2}{*}{ E054 } & Bom & 1 & 44 \\
\hline & Ruim & 0 & 562 \\
\hline \multirow[t]{2}{*}{ E055 } & Bom & 1 & 76 \\
\hline & Ruim & 0 & 530 \\
\hline E056 & Bom & 1 & 343 \\
\hline & Ruim & 0 & 262 \\
\hline E063 & Bom & 1 & 396 \\
\hline & Ruim & 0 & 190 \\
\hline E064 & Bom & 1 & 554 \\
\hline & Ruim & 0 & 32 \\
\hline E065 & Bom & 1 & 550 \\
\hline & Ruim & 0 & 34 \\
\hline E066 & Bom & 1 & 219 \\
\hline & Ruim & 0 & 362 \\
\hline D001 & Feminino & 1 & 506 \\
\hline & Masculino & 0 & 96 \\
\hline D002 & 40 anos ou mais & 1 & 497 \\
\hline & Menos de 40 anos & 0 & 82 \\
\hline D004 & Com Ensino Superior & 1 & 596 \\
\hline & Sem Ensino Superior & 0 & 6 \\
\hline D005 & 15 anos ou mais & 1 & 416 \\
\hline & Menos de 15 anos & 0 & 183 \\
\hline D006 & Pública & 1 & 54 \\
\hline & Privada & 0 & 545 \\
\hline D007 & Universidade & 1 & 339 \\
\hline & Não era universidade & 0 & 262 \\
\hline D008 & Presencial & 1 & 584 \\
\hline & Não - Presencial & 0 & 20 \\
\hline D009 & Mestrado ou Doutorado & 1 & 31 \\
\hline & Não tem Mestrado ou Doutorado & 0 & 571 \\
\hline D010 & Educação & 1 & 464 \\
\hline & Outras Áreas que não a educação & 0 & 127 \\
\hline D012 & 21 horas ou mais & 1 & 517 \\
\hline & Menos de 20 horas & 0 & 24 \\
\hline D013 & Sim & 1 & 542 \\
\hline & Não & 0 & 0 \\
\hline D014 & 2 salários mínimos ou mais & 1 & 208 \\
\hline & Menos de 2 salários mínimos & 0 & 228 \\
\hline D015 & 2 salários mínimos ou mais & 1 & 91 \\
\hline & Menos de 2 salários mínimos & 0 & 365 \\
\hline D016 & Sim & 1 & 178 \\
\hline & Não & 0 & 422 \\
\hline D017 & 10 anos ou mais & 1 & 590 \\
\hline & Menos de 10 anos & 0 & 12 \\
\hline D018 & 10 anos ou mais & 1 & 236 \\
\hline & Menos de 10 anos & 0 & 363 \\
\hline D019 & 10 anos ou mais & 1 & 94 \\
\hline & Menos de 10 anos & 0 & 506 \\
\hline D020 & Mais de 40 horas & 1 & 136 \\
\hline & 40 horas ou menos & 0 & 464 \\
\hline D023 & Mais de $50 \%$ & 1 & 265 \\
\hline & $50 \%$ ou menos & 0 & 122 \\
\hline D024 & Uma vez ou mais & 1 & 592 \\
\hline & Nenhuma vez & 0 & 7 \\
\hline D029 & Uma vez ou mais & 1 & 601 \\
\hline & Nenhuma vez & 0 & 3 \\
\hline D030 & Elaborado pelo diretor & 1 & 170 \\
\hline & Elaborado por outros & 0 & 426 \\
\hline
\end{tabular}




\begin{tabular}{|c|c|c|c|}
\hline Variáveis Dicotomizadas & Categorias & Código & Frequência amostral \\
\hline \multirow{2}{*}{ D031 } & Diversos critérios são utilizados & 1 & 432 \\
\hline & Não existe critério de seleção & 0 & 168 \\
\hline \multirow[t]{2}{*}{ D032 } & Tinha vagas & 1 & 342 \\
\hline & Não tinha vagas & 0 & 262 \\
\hline \multirow[t]{2}{*}{ D033 } & Homogeneidade e heterogeneidade & 1 & 491 \\
\hline & Não houve critério & 0 & 104 \\
\hline \multirow[t]{2}{*}{ D034 } & Diversos critérios & 1 & 541 \\
\hline & Não houve critério & 0 & 18 \\
\hline \multirow[t]{2}{*}{ D035 } & Mais de 50\% & 1 & 415 \\
\hline & $50 \%$ ou menos & 0 & 184 \\
\hline \multirow[t]{2}{*}{ D036 } & Sim & 1 & 490 \\
\hline & Não & 0 & 112 \\
\hline \multirow[t]{2}{*}{ D037 } & Sim & 1 & 561 \\
\hline & Não & 0 & 43 \\
\hline \multirow[t]{2}{*}{ D045 } & Sim & 1 & 557 \\
\hline & Não & 0 & 31 \\
\hline \multirow{2}{*}{ D046 } & Ruim & 1 & 493 \\
\hline & Bom & 0 & 91 \\
\hline \multirow[t]{2}{*}{ D047 } & Ruim & 1 & 584 \\
\hline & Bom & 0 & 14 \\
\hline D048 & Ruim & 1 & 581 \\
\hline & Bom & 0 & 20 \\
\hline D049 & Ruim & 1 & 555 \\
\hline & Bom & 0 & 44 \\
\hline D050 & Ruim & 1 & 566 \\
\hline & Bom & 0 & 32 \\
\hline D051 & Ruim & 1 & 534 \\
\hline & Bom & 0 & 64 \\
\hline D052 & Ruim & 1 & 587 \\
\hline & Bom & 0 & 10 \\
\hline D053 & Ruim & 1 & 538 \\
\hline & Bom & 0 & 63 \\
\hline D054 & Ruim & 1 & 556 \\
\hline & Bom & 0 & 44 \\
\hline D055 & Sim & 1 & 221 \\
\hline & Não & 0 & 381 \\
\hline D056 & Sim & 1 & 476 \\
\hline & Não & 0 & 128 \\
\hline D057 & Sim & 1 & 409 \\
\hline & Não & 0 & 193 \\
\hline D058 & Sim & 1 & 151 \\
\hline & Não & 0 & 452 \\
\hline D059 & Sim & 1 & 113 \\
\hline & Não & 0 & 491 \\
\hline D060 & Sim & 1 & 42 \\
\hline & Não & 0 & 562 \\
\hline D061 & Sim & 1 & 468 \\
\hline & Não & 0 & 135 \\
\hline D062 & Sim & 1 & 357 \\
\hline & Não & 0 & 246 \\
\hline D063 & Sim & 1 & 288 \\
\hline & Não & 0 & 315 \\
\hline D064 & Sim & 1 & 508 \\
\hline & Não & 0 & 95 \\
\hline D084 & Sim & 1 & 143 \\
\hline & Não & 0 & 455 \\
\hline D085 & Sim & 1 & 291 \\
\hline & Não & 0 & 309 \\
\hline D086 & Sim & 1 & 92 \\
\hline & Não & 0 & 509 \\
\hline D116 & Sim & 1 & 508 \\
\hline & Não & 0 & 85 \\
\hline D125 & Sim & 1 & 521 \\
\hline & Não & 0 & 76 \\
\hline D126 & Sim & 1 & 455 \\
\hline & Não & 0 & 143 \\
\hline D127 & Sim & 1 & 153 \\
\hline & Não & 0 & 444 \\
\hline D128 & Professores & 1 & 487 \\
\hline & Outros & 0 & 105 \\
\hline D129 & Sim & 1 & 499 \\
\hline & Não & 0 & 97 \\
\hline D130 & Sim & 1 & 260 \\
\hline & Não & 0 & 333 \\
\hline
\end{tabular}




\begin{tabular}{|c|c|c|c|}
\hline Variáveis Dicotomizadas & Categorias & Código & Frequência amostral \\
\hline \multirow[t]{2}{*}{ D131 } & Sim & 1 & 188 \\
\hline & Não & 0 & 404 \\
\hline \multirow[t]{2}{*}{ D132 } & Sim & 1 & 530 \\
\hline & Não & 0 & 62 \\
\hline \multirow[t]{2}{*}{ P001 } & Feminino & 1 & 1193 \\
\hline & Masculino & 0 & 481 \\
\hline \multirow[t]{2}{*}{ P002 } & 40 anos ou mais & 1 & 951 \\
\hline & Menos de 40 anos & 0 & 718 \\
\hline \multirow[t]{2}{*}{$\mathrm{P} 004$} & Com ensino superior & 1 & 1662 \\
\hline & Sem ensino superior & 0 & 7 \\
\hline \multirow[t]{2}{*}{ P005 } & 15 anos ou mais & 1 & 785 \\
\hline & Menos de 15 anos & 0 & 876 \\
\hline \multirow[t]{2}{*}{$\mathrm{P} 006$} & Pública & 1 & 192 \\
\hline & Privada & 0 & 1475 \\
\hline \multirow[t]{2}{*}{$\mathrm{P} 007$} & Universidade & 1 & 951 \\
\hline & Não era universidade & 0 & 704 \\
\hline \multirow[t]{2}{*}{ P008 } & Presencial & 1 & 1640 \\
\hline & Não - Presencial & 0 & 20 \\
\hline \multirow[t]{2}{*}{ P009 } & Mestrado ou Doutorado & 1 & 63 \\
\hline & Não tem mestrado ou Doutorado & 0 & 1581 \\
\hline $\mathrm{P} 010$ & Educação & 1 & 760 \\
\hline & Outras áreas que não a educação & 0 & 64 \\
\hline P012 & 21 horas ou mais & 1 & 1062 \\
\hline & Menos de 20 horas & 0 & 163 \\
\hline $\mathrm{P} 013$ & Sim & 1 & 1214 \\
\hline & Não & 0 & 14 \\
\hline P014 & 2 salários mínimos ou mais & 1 & 1239 \\
\hline & Menos de 2 salários mínimos & 0 & 180 \\
\hline $\mathrm{P} 015$ & Sim & 1 & 652 \\
\hline & Não & 0 & 949 \\
\hline P016 & 2 salários mínimos ou mais & 1 & 513 \\
\hline & Menos de 2 salários mínimos & 0 & 246 \\
\hline P017 & 10 anos ou mais & 1 & 1151 \\
\hline & Menos de 10 anos & 0 & 517 \\
\hline P018 & 10 anos ou mais & 1 & 361 \\
\hline & Menos de 10 anos & 0 & 1305 \\
\hline P019 & 6 anos ou mais & 1 & 427 \\
\hline & Menos de 6 anos & 0 & 1233 \\
\hline P020 & Até 20 horas & 1 & 1468 \\
\hline & Mais de 20 horas & 0 & 192 \\
\hline P021 & Uma escola & 1 & 610 \\
\hline & Mais de uma escola & 0 & 1062 \\
\hline P022 & Até 20 horas & 1 & 1425 \\
\hline & Mais de 20 horas & 0 & 87 \\
\hline P024 & Sim & 1 & 1577 \\
\hline & Não & 0 & 93 \\
\hline $\mathrm{P} 025$ & Sim & 1 & 1606 \\
\hline & Não & 0 & 64 \\
\hline $\mathrm{P} 026$ & Sim & 1 & 1521 \\
\hline & Não & 0 & 150 \\
\hline P027 & Sim & 1 & 1548 \\
\hline & Não & 0 & 121 \\
\hline P028 & Sim & 1 & 1473 \\
\hline & Não & 0 & 0 \\
\hline P029 & Alta & 1 & 1014 \\
\hline & Baixa & 0 & 656 \\
\hline P030 & Alta & 1 & 1053 \\
\hline & Baixa & 0 & 618 \\
\hline P031 & Alta & 1 & 224 \\
\hline & Baixa & 0 & 1446 \\
\hline P032 & Alta & 1 & 620 \\
\hline & Baixa & 0 & 1049 \\
\hline $\mathrm{P} 033$ & Alta & 1 & 269 \\
\hline & Baixa & 0 & 1402 \\
\hline $\mathrm{P} 034$ & Alta & 1 & 1024 \\
\hline & Baixa & 0 & 644 \\
\hline $\mathrm{P} 035$ & Alta & 1 & 1380 \\
\hline & Baixa & 0 & 290 \\
\hline P036 & Mais de um terço da carga horária & 1 & 512 \\
\hline & Um terço ou menos da carga horária & 0 & 1153 \\
\hline P037 & Sim & 1 & 1278 \\
\hline & Não & 0 & 388 \\
\hline $\mathrm{P} 038$ & Sim & 1 & 778 \\
\hline & Não & 0 & 878 \\
\hline
\end{tabular}




\begin{tabular}{|c|c|c|c|}
\hline Variáveis Dicotomizadas & Categorias & Código & Frequência amostral \\
\hline \multirow[t]{2}{*}{ P039 } & Sim & 1 & 572 \\
\hline & Não & 0 & 1088 \\
\hline \multirow{2}{*}{ P040 } & Sim & 1 & 537 \\
\hline & Não & 0 & 1123 \\
\hline \multirow[t]{2}{*}{ P041 } & Sim & 1 & 537 \\
\hline & Não & 0 & 1123 \\
\hline \multirow[t]{2}{*}{ P043 } & Uma vez ou mais & 1 & 1636 \\
\hline & Não se reuniu & 0 & 32 \\
\hline \multirow[t]{2}{*}{ P045 } & Sim & 1 & 1167 \\
\hline & Não & 0 & 189 \\
\hline \multirow{2}{*}{ P060 } & Concordo & 1 & 1187 \\
\hline & Não Concordo & 0 & 491 \\
\hline \multirow[t]{2}{*}{ P061 } & Concordo & 1 & 1406 \\
\hline & Não Concordo & 0 & 276 \\
\hline \multirow[t]{2}{*}{ P062 } & Concordo & 1 & 1290 \\
\hline & Não Concordo & 0 & 392 \\
\hline \multirow[t]{2}{*}{ P063 } & Concordo & 1 & 1287 \\
\hline & Não Concordo & 0 & 392 \\
\hline \multirow{2}{*}{ P064 } & Concordo & 1 & 1334 \\
\hline & Não Concordo & 0 & 345 \\
\hline P065 & Concordo & 1 & 1550 \\
\hline & Não Concordo & 0 & 131 \\
\hline P066 & Concordo & 1 & 1553 \\
\hline & Não Concordo & 0 & 128 \\
\hline P067 & Concordo & 1 & 1542 \\
\hline & Não Concordo & 0 & 140 \\
\hline P068 & Concordo & 1 & 1644 \\
\hline & Não Concordo & 0 & 35 \\
\hline P069 & Concordo & 1 & 1534 \\
\hline & Não Concordo & 0 & 145 \\
\hline P070 & Concordo & 1 & 1419 \\
\hline & Não Concordo & 0 & 263 \\
\hline P071 & Concordo & 1 & 1585 \\
\hline & Não Concordo & 0 & 97 \\
\hline P072 & Concordo & 1 & 1350 \\
\hline & Não Concordo & 0 & 332 \\
\hline P073 & Concordo & 1 & 1389 \\
\hline & Não Concordo & 0 & 291 \\
\hline P074 & Concordo & 1 & 1539 \\
\hline & Não Concordo & 0 & 140 \\
\hline P075 & Sim & 1 & 797 \\
\hline & Não & 0 & 876 \\
\hline P076 & Sim & 1 & 1178 \\
\hline & Não & 0 & 499 \\
\hline P077 & Sim & 1 & 823 \\
\hline & Não & 0 & 857 \\
\hline P078 & Sim & 1 & 364 \\
\hline & Não & 0 & 1314 \\
\hline P079 & Sim & 1 & 607 \\
\hline & Não & 0 & 1076 \\
\hline P080 & Sim & 1 & 952 \\
\hline & Não & 0 & 728 \\
\hline P081 & Sim & 1 & 1014 \\
\hline & Não & 0 & 670 \\
\hline P082 & Sim & 1 & 1488 \\
\hline & Não & 0 & 193 \\
\hline P115 & Sim & 1 & 858 \\
\hline & Não & 0 & 752 \\
\hline P116 & Sim & 1 & 862 \\
\hline & Não & 0 & 749 \\
\hline P117 & Sim & 1 & 813 \\
\hline & Não & 0 & 800 \\
\hline P118 & Sim & 1 & 1157 \\
\hline & Não & 0 & 457 \\
\hline P119 & Sim & 1 & 331 \\
\hline & Não & 0 & 1282 \\
\hline $\mathrm{P} 120$ & Sim & 1 & 1544 \\
\hline & Não & 0 & 79 \\
\hline P121 & Mais de $60 \%$ & 1 & 1384 \\
\hline & Até $60 \%$ & 0 & 230 \\
\hline P122 & Mais da Metade & 1 & 743 \\
\hline & Metade ou menos & 0 & 224 \\
\hline P123 & Mais da Metade & 1 & 1547 \\
\hline & Metade ou menos & 0 & 71 \\
\hline
\end{tabular}




\begin{tabular}{|c|c|c|c|}
\hline Variáveis Dicotomizadas & Categorias & Código & Frequência amostral \\
\hline \multirow[t]{2}{*}{ P124 } & Mais da Metade & 1 & 1187 \\
\hline & Metade ou menos & 0 & 245 \\
\hline \multirow[t]{2}{*}{ P125 } & Mais da Metade & 1 & 390 \\
\hline & Metade ou menos & 0 & 1165 \\
\hline \multirow[t]{2}{*}{ P126 } & Sim & 1 & 1561 \\
\hline & Não & 0 & 61 \\
\hline \multirow[t]{2}{*}{ P129 } & Não é Ruim & 1 & 1584 \\
\hline & Ruim & 0 & 38 \\
\hline \multirow[t]{2}{*}{ P131 } & Professor escolheu & 1 & 1230 \\
\hline & Outros membros da equipe escolar escolheram & 0 & 370 \\
\hline \multirow[t]{2}{*}{ P132 } & Encaminhar os alunos que atrapalham & 1 & 1478 \\
\hline & Atividades pedagógicas & 0 & 24 \\
\hline \multirow[t]{2}{*}{ P142 } & Alta & 1 & 1562 \\
\hline & Baixa & 0 & 32 \\
\hline \multirow[t]{2}{*}{ P143 } & Alta & 1 & 1562 \\
\hline & Baixa & 0 & 37 \\
\hline \multirow[t]{2}{*}{ P144 } & Alta & 1 & 1587 \\
\hline & Baixa & 0 & 14 \\
\hline \multirow[t]{2}{*}{ P145 } & Alta & 1 & 1478 \\
\hline & Baixa & 0 & 121 \\
\hline \multirow[t]{2}{*}{ P146 } & Alta & 1 & 1169 \\
\hline & Baixa & 0 & 430 \\
\hline \multirow[t]{2}{*}{ P147 } & Alta & 1 & 1555 \\
\hline & Baixa & 0 & 46 \\
\hline \multirow[t]{2}{*}{ P148 } & Alta & 1 & 1430 \\
\hline & Baixa & 0 & 171 \\
\hline \multirow[t]{2}{*}{ P149 } & Alta & 1 & 321 \\
\hline & Baixa & 0 & 15 \\
\hline \multirow[t]{2}{*}{ P150 } & Alta & 1 & 1381 \\
\hline & Baixa & 0 & 217 \\
\hline \multirow[t]{2}{*}{ P151 } & Alta & 1 & 1255 \\
\hline & Baixa & 0 & 346 \\
\hline \multirow[t]{2}{*}{ P152 } & Alta & 1 & 1546 \\
\hline & Baixa & 0 & 53 \\
\hline
\end{tabular}


APÊNDICE

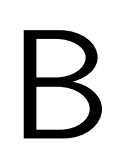

AMOSTRAGEM

Primeiramente, temos as regiões administrativas do Estado de São Paulo e os municípios que as compõe, posteriormente temos a distribuição amostral dos dados em cada uma das regiões, baseado nos critérios amostrais colocados no capítulo 2.

\section{B.1 Regiões amostrais}

Presidente Prudente: ADAMANTINA, ALFREDO MARCONDES, ALVARES MACHADO, ANHUMAS, CAIABU, CAIUA, DRACENA, EMILIANOPOLIS, ESTRELA DO NORTE, EUCLIDES DA CUNHA PAULISTA, FLORA RICA, FLORIDA PAULISTA, INDIANA, INUBIA PAULISTA, IRAPURU, JOAO RAMALHO, JUNQUEIROPOLIS, LUCELIA, MARABA PAULISTA, MARIAPOLIS, MARTINOPOLIS, MIRANTE DO PARANAPANEMA, MONTE CASTELO, NARANDIBA, NOVA GUATAPORANGA, OSVALDO CRUZ, OURO VERDE, PACAEMBU, PANORAMA, PARAPUA, PAULICEIA, PIQUEROBI, PIRAPOZINHO, PRACINHA, PRESIDENTE BERNARDES, PRESIDENTE EPITACIO, PRESIDENTE PRUDENTE, PRESIDENTE VENCESLAU, RANCHARIA, REGENTE FEIJO, RIBEIRAO DOS INDIOS, RINOPOLIS, ROSANA, SAGRES, SALMOURAO, SANDOVALINA, SANTA MERCEDES, SANTO ANASTACIO, SANTO EXPEDITO, SAO JOAO DO PAU D' ALHO, TACIBA, TARABAI, TEODORO SAMPAIO e TUPI PAULISTA.

Araçatuba: ALTO ALEGRE, ANDRADINA, ARAÇATUBA, AVANHANDAVA, BARBOSA, BENTO DE ABREU, BILAC, BIRIGUI, BRAÚNA, BREJO ALEGRE, BURITAMA, CASTILHO, CLEMENTINA, COROADOS, GABRIEL MONTEIRO, GLICERIO, GUARAÇAI, GUARARAPES, ILHA SOLTEIRA, ITAPURA, LAVINIA, LOURDES, LUIZIANIA, MIRANDOPOLIS, MURUTINGA DO SUL, NOVA INDEPENDENCIA, PENÁPOLIS, PEREIRA BARRETO, PENÁPOLIS, PIACATU, RUBIACEA, SANTO ANTONIO DO ARACANGUA, SANTOPOLIS DO AGUAPEI, SUD MENNUCCI, SUZANAPOLIS, TURIUBA e VALPARAISO. 
Jales: ALVARES FLORENCE, AMERICO DE CAMPOS, APARECIDA D'OESTE, ASPASIA, AURIFLAMA, CARDOSO, COSMORAMA, DIRCE REIS, DOLCINOPOLIS, ESTRELA D'OESTE, FERNANDOPOLIS, FLOREAL, GASTAO VIDIGAL, GENERAL SALGADO, GUARANI D'OESTE, GUZOLANDIA, INDIAPORA, JALES, MACEDONIA, MAGDA, MARINOPOLIS, MERIDIANO, MESOPOLIS, MIRA ESTRELA, NOVA CANAA PAULISTA, NOVA CASTILHO, NOVA LUZITANIA, OUROESTE, PALMEIRA D' OESTE, PARANAPUA, PARISI, PEDRANOPOLIS, PONTALINDA, PONTES GESTAL, POPULINA, RIOLANDIA, RUBINEIA, SANTA ALBERTINA, SANTA CLARA D'OESTE, SANTA FÉ DO SUL, SANTA RITA D'OESTE, SANTA SALETE, SANTANA DA PONTE PENSA, SÃO FRANCISCO, SÃO JOAO DAS DUAS PONTES, SÃO JOAO DE IRACEMA, TRÊS FRONTEIRAS, TURMALINA, URÂNIA, VALENTIM GENTIL, VITORIA BRASIL e VOTUPORANGA.

São José do Rio Preto: ADOLFO, ALTAIR, BADY BASSITT, ARIRANHA, BALSAMO, CAJOBI, CATANDUVA, CATIGUA, CEDRAL, ELISIARIO, EMBAUBA, GUAPIACU, GUARACI, IBIRA, ICEM, IPIGUA, IRAPUA, ITAJOBI, JACI, JOSÉ BONIFACIO, MACAUBAL, MARAPOAMA, MENDONÇA, MIRASSOL, MIRASSOLANDIA, MONCOES, MONTE APRAZIVEL, NEVES PAULISTA, NHANDEARA, NIPOA, NOVA ALIANÇA, NOVA GRANADA, NOVAIS, NOVO HORIZONTE, OLÍMPIA, ONDA VERDE, ORINDIÚVA, PALESTINA, PALMARES PAULISTA, PARAÍSO, PAULO DE FARIA, PINDORAMA, PLANALTO, POLONI, POTIRENDABA, SALES, SANTA ADÉLIA, SÃO JOSE DO RIO PRETO, SEBASTIANÓPOLIS DO SUL, SEVERINIA, TABAPUA, TANABI, UBARANA, UCHOA, UNIÃO PAULISTA, URUPÊS E ZACARIAS.

Marília: ALVARO DE CARVALHO, ALVINLANDIA, ARCO-IRIS, ASSIS, BASTOS, BERNARDINO DE CAMPOS, BORA, CAMPOS NOVOS PAULISTA, CANDIDO MOTA, CANITAR, CHAVANTES, CRUZÁLIA, ECHAPORÃ, ESPIRITO SANTO DO TURVO, FARTURA, FERNÃO, FLORINIA, GÁLIA, GARÇA, HERCULÂNDIA, IACRI, IBIRAREMA, IEPE, IPAUSSU, LUPÉRCIO, LUTÉCIA, MANDURI, MARACAÍ, MARÍLIA, NANTES, OCAUCU, ÓLEO, ORIENTE, OSCAR BRESSANE, OURINHOS, PEDRINHAS PAULISTA, PALMITAL, PARAGUAÇU PAULISTA, PIRAJU, PLATINA, POMPÉIA, QUATÁ, QUEIROZ, QUINTANA, RIBEIRÃO DO SUL, SALTO GRANDE, SANTA CRUZ DO RIO PARDO, SÃO PEDRO DO TURVO, SARUTAIÁ, TAGUAI, TARUMÃ, TEJUPA, TIMBURI, TUPÃ e VERA CRUZ.

Bauru: AGUAS DE SANTA BARBARA, AGUDOS, ANHEMBI, ARANDU, AREALVA, AREIÓPOLIS, AVAÍ, AVARÉ, BALBINOS, BARIRI, BARRA BONITA, BAURU, BOCAINA, BOFETE, BORACÉIA, BOREBI, BOTUCATU, CABRÁLIA PAULISTA, CAFELÂNDIA, CERQUEIRA CÉSAR, CONCHAS, DOIS CORREGOS, DUARTINA, GETULINA, GUAICARA, GUAIMBE, GUARANTA, IACANGA, IARAS, IGARACU DO TIETE, ITAI, ITAJU, ITAPUI, ITATINGA, JAU, JULIO MESQUITA, LENCOIS PAULISTA, LINS, LUCIA- 
NOPOLIS, MACATUBA, MINEIROS DO TIETE, PARANAPANEMA, PARDINHO, PAULISTANIA, PEDERNEIRAS, PIRAJUI, PIRATININGA, PONGAI, PRATANIA, PRESIDENTE ALVES, PROMISSAO, REGINOPOLIS, SABINO, SAO MANUEL, UBIRAJARA e URU.

São Carlos: AMERICO BRASILIENSE, ANALANDIA, ARARAQUARA, BOA ESPERANCA DO SUL, BORBOREMA, DESCALVADO, DOBRADA, DOURADO, GAVIAO PEIXOTO, IBATE, IBITINGA, ITAPOLIS, MATAO, MOTUCA, NOVA EUROPA, RIBEIRAO BONITO, RINCAO, SANTA LUCIA, SAO CARLOS, TABATINGA e TRABIJU.

Ribeirão Preto: ALTINOPOLIS, ARAMINA, BARRETOS, BARRINHA, BATATAIS, BEBEDOURO, BRODOWSKI, BURITIZAL, CAJURU, CANDIDO RODRIGUES, CASSIA DOS COQUEIROS, COLINA, COLOMBIA, CRAVINHOS, CRISTAIS PAULISTA, DUMONT, FERNANDO PRESTES, FRANCA, GUAIRA, GUARA, GUARIBA, GUATAPARA, IGARAPAVA, IPUA, ITIRAPUA, ITUVERAVA, JABORANDI, JABOTICABAL, JARDINOPOLIS, JERIQUARA, LUIS ANTONIO, MIGUELOPOLIS, MONTE ALTO, MONTE AZUL PAULISTA, MORRO AGUDO, NUPORANGA, ORLANDIA, PATROCINIO PAULISTA, PEDREGULHO, PIRANGI, PITANGUEIRAS, PONTAL, PRADOPOLIS, RESTINGA, RIBEIRAO CORRENTE, RIBEIRAO PRETO, RIFAINA, SALES OLIVEIRA, SANTA CRUZ DA ESPERANCA, SANTA ERNESTINA, SANTA RITA DO PASSA QUATRO, SANTA ROSA DE VITERBO, SANTO ANTONIO DA ALEGRIA, SÃO JOAQUIM DA BARRA, SÃO JOSE DA BELA VISTA, SÃO SIMÃO, SERRA AZUL, SERRANA, SERTÃOZINHO, TAIAÇU, TAIUVA, TAQUARAL, TAQUARITINGA, TERRA ROXA, VIRADOURO e VISTA ALEGRE DO ALTO.

Registro: BARRA DO TURVO, CAJATI, CANANÉIA, ELDORADO, IGUAPÉ, ILHA COMPRIDA, ITANHAEM, ITARIRI, JACUPIRANGA, JUQUIA, MIRACATU, MONGAGUA, PARIQUERA-AÇU, PEDRO DE TOLEDO, PERUÍBE, REGISTRO e SETE BARRAS.

Itapetininga: ALAMBARI, ANGATUBA, APIAI, BARAO DE ANTONINA, BARRA DO CHAPEU, BOITUVA, BOM SUCESSO DE ITARARE, BURI, CAMPINA DO MONTE ALEGRE, CAPAO BONITO, CERQUILHO, CESARIO LANGE, CORONEL MACEDO, GUAPIARA, GUAREI, IPORANGA, ITABERA, ITAOCA, ITAPETININGA, ITAPEVA, ITAPIRAPUA PAULISTA, ITAPORANGA, ITARARE, LARANJAL PAULISTA, NOVA CAMPINA, PEREIRAS, PORANGABA, QUADRA, RIBEIRA, RIBEIRAO BRANCO, RIBEIRAO GRANDE, RIVERSUL, TAQUARITUBA, TAQUARIVAI, TATUÍ e TORRE DE PEDRA.

Piracicaba: AGUAS DE SAO PEDRO, ARARAS, BROTAS, CAPIVARI, CHARQUEADA, CONCHAL, CORDEIROPOLIS, CORUMBATAI, IPEUNA, IRACEMAPOLIS, ITIRAPINA, JUMIRIM, LEME, LIMEIRA, MOMBUCA, PIRACICABA, RAFARD, RIO CLARO, RIO DAS PEDRAS, SALTINHO, SANTA CRUZ DA CONCEICAO, SANTA GERTRUDES, SANTA MARIA DA SERRA, SAO PEDRO, TIETE e TORRINHA.

Campinas: AGUAI, AGUAS DA PRATA, AGUAS DE LINDOIA, AMERICANA, AM- 
PARO, ARTUR NOGUEIRA, CACONDE, CAMPINAS, CASA BRANCA, COSMOPOLIS, DIVINOLANDIA, ELIAS FAUSTO, ENGENHEIRO COELHO, ESPIRITO SANTO DO PINHAL, ESTIVA GERBI, HOLAMBRA, HORTOLANDIA, INDAIATUBA, ITAPIRA, ITOBI, JAGUARIUNA, LINDOIA, MOCOCA, MOGI GUACU, MOGI MIRIM, MONTE ALEGRE DO SUL, MONTE MOR, NOVA ODESSA, PAULINIA, PEDRA BELA, PEDREIRA, PINHALZINHO, PIRASSUNUNGA, PORTO FERREIRA, SANTA BARBARA D'OESTE, SANTA CRUZ DAS PALMEIRAS, SANTO ANTONIO DE POSSE, SANTO ANTONIO DO JARDIM, SAO JOAO DA BOA VISTA, SAO JOSE DO RIO PARDO, SAO SEBASTIAO DA GRAMA, SERRA NEGRA, SOCORRO, SUMARE, TAMBAU, TAPIRATIBA, VALINHOS, VARGEM GRANDE DO SUL e VINHEDO.

Jundiaí: ALUMINIO, ARACARIGUAMA, ARACOIABA DA SERRA, ATIBAIA, BOM JESUS DOS PERDOES, BRAGANCA PAULISTA, CABREUVA, CAMPO LIMPO PAULISTA, CAPELA DO ALTO, IBIUNA, IPERO, ITATIBA, ITU, ITUPEVA, JARINU, JOANOPOLIS, JUNDIAI, LOUVEIRA, MAIRINQUE, MORUNGABA, NAZARE PAULISTA, PIEDADE, PILAR DO SUL, PIRACAIA, PORTO FELIZ, SALTO, SALTO DE PIRAPORA, SAO MIGUEL ARCANJO, SAO ROQUE, SARAPUI, SOROCABA, TAPIRAI, TUIUTI, VARGEM, VARZEA PAULISTA E VOTORANTIM.

São Paulo: ARUJA, BARUERI, BERTIOGA, BIRITIBA-MIRIM, CAIEIRAS, CAJAMAR, CARAPICUIBA, COTIA, CUBATAO, DIADEMA, EMBU, EMBU-GUACU, FERRAZ DE VASCONCELOS, FRANCISCO MORATO, FRANCO DA ROCHA, GUARAREMA, GUARUJA, GUARULHOS, ITAPECERICA DA SERRA, ITAPEVI, ITAQUAQUECETUBA, JANDIRA, JUQUITIBA, MAIRIPORA, MAUA, MOGI DAS CRUZES, OSASCO, PIRAPORA DO BOM JESUS, POA, PRAIA GRANDE, RIBEIRAO PIRES, RIO GRANDE DA SERRA, SALESOPOLIS, SANTA ISABEL, SANTANA DE PARNAIBA, SANTO ANDRE, SANTOS, SAO BERNARDO DO CAMPO, SAO CAETANO DO SUL, SAO LOURENCO DA SERRA, SAO PAULO, SAO VICENTE, SUZANO, TABOAO DA SERRA e VARGEM GRANDE PAULISTA.

São José dos Campos: APARECIDA, ARAPEI, AREIAS, BANANAL, CACAPAVA, CACHOEIRA PAULISTA, CAMPOS DO JORDAO, CANAS, CARAGUATATUBA, CRUZEIRO, CUNHA, GUARATINGUETA, IGARATA, ILHABELA, JACAREI, JAMBEIRO, LAGOINHA, LAVRINHAS, LORENA, MONTEIRO LOBATO, NATIVIDADE DA SERRA, PARAIBUNA, PINDAMONHANGABA, PIQUETE, POTIM, QUELUZ, REDENCAO DA SERRA, ROSEIRA, SANTA BRANCA, SANTO ANTONIO DO PINHAL, SAO BENTO DO SAPUCAI, SAO JOSE DO BARREIRO, SAO JOSE DOS CAMPOS, SAO LUIS DO PARAITINGA, SAO SEBASTIAO, SILVEIRAS, TAUBATE, TREMEMBE e UBATUBA.

\section{B.2 Distribuições amostrais por região}


Tabela 33 - Distribuição amostral das escolas da região de Presidente Prudente segundo os critérios pré-estabelecidos.

\begin{tabular}{ccccc}
\hline $\begin{array}{c}\text { Dependência } \\
\text { Administrativa }\end{array}$ & Quartis & Pequena & Média & Grande \\
\hline \multirow{5}{*}{ Estadual } & ABAIXO DO PERCENTIL 25 & 1 & 1 & 0 \\
& ENTRE O PERCENTIL 25 E 50 & 2 & 1 & 0 \\
& ENTRE O PERCENTIL 50 E 75 & 1 & 2 & 1 \\
& ACIMA DO PERCENTIL 75 & 1 & 1 & 1 \\
\hline \multirow{5}{*}{ Municipal } & ABAIXO DO PERCENTIL 25 & 0 & 0 & 0 \\
& ENTRE O PERCENTIL 25 E 50 & 0 & 0 & 0 \\
& ENTRE O PERCENTIL 50 E 75 & 0 & 1 & 0 \\
& ACIMA DO PERCENTIL 75 & 0 & 0 & 0 \\
\hline
\end{tabular}

Tabela 34 - Distribuição amostral das escolas da região de Araçatuba segundo os critérios préestabelecidos.

\begin{tabular}{ccccc}
\hline $\begin{array}{c}\text { Dependência } \\
\text { Administrativa }\end{array}$ & Quartis & Pequena & Média & Grande \\
\hline \multirow{5}{*}{ Estadual } & ABAIXO DO PERCENTIL 25 & 0 & 1 & 0 \\
& ENTRE O PERCENTIL 25 E 50 & 1 & 1 & 1 \\
& ENTRE O PERCENTIL 50 E 75 & 1 & 2 & 0 \\
& ACIMA DO PERCENTIL 75 & 1 & 2 & 0 \\
\hline \multirow{5}{*}{ Municipal } & ABAIXO DO PERCENTIL 25 & 0 & 0 & 0 \\
& ENTRE O PERCENTIL 25 E 50 & 0 & 0 & 0 \\
& ENTRE O PERCENTIL 50 E 75 & 0 & 0 & 0 \\
& ACIMA DO PERCENTIL 75 & 0 & 0 & 0 \\
\hline
\end{tabular}

Tabela 35 - Distribuição amostral das escolas da região de Jales segundo os critérios pré-estabelecidos.

\begin{tabular}{ccccc}
\hline $\begin{array}{c}\text { Dependência } \\
\text { Administrativa }\end{array}$ & Quartis & Pequena & Média & Grande \\
\hline \multirow{5}{*}{ Estadual } & ABAIXO DO PERCENTIL 25 & 0 & 0 & 0 \\
& ENTRE O PERCENTIL 25 E 50 & 1 & 0 & 0 \\
& ENTRE O PERCENTIL 50 E 75 & 2 & 1 & 0 \\
& ACIMA DO PERCENTIL 75 & 3 & 2 & 0 \\
\hline \multirow{5}{*}{ Municipal } & ABAIXO DO PERCENTIL 25 & 0 & 0 & 0 \\
& ENTRE O PERCENTIL 25 E 50 & 0 & 0 & 0 \\
& ENTRE O PERCENTIL 50 E 75 & 0 & 0 & 0 \\
& ACIMA DO PERCENTIL 75 & 0 & 0 & 0 \\
\hline
\end{tabular}


Tabela 36 - Distribuição amostral das escolas da região de São José do Rio Preto segundo os critérios pré-estabelecidos.

\begin{tabular}{ccccc}
\hline $\begin{array}{c}\text { Dependência } \\
\text { Administrativa }\end{array}$ & Quartis & Pequena & Média & Grande \\
\hline \multirow{4}{*}{ Estadual } & ABAIXO DO PERCENTIL 25 & 1 & 0 & 0 \\
& ENTRE O PERCENTIL 25 E 50 & 1 & 1 & 0 \\
& ENTRE O PERCENTIL 50 E 75 & 2 & 2 & 1 \\
& ACIMA DO PERCENTIL 75 & 1 & 3 & 1 \\
\hline \multirow{5}{*}{ Municipal } & ABAIXO DO PERCENTIL 25 & 0 & 0 & 0 \\
& ENTRE O PERCENTIL 25 E 50 & 0 & 1 & 0 \\
& ENTRE O PERCENTIL 50 E 75 & 0 & 0 & 0 \\
& ACIMA DO PERCENTIL 75 & 2 & 2 & 0 \\
\hline
\end{tabular}

Tabela 37 - Distribuição amostral das escolas da região de Marília segundo os critérios pré-estabelecidos.

\begin{tabular}{ccccc}
\hline $\begin{array}{c}\text { Dependência } \\
\text { Administrativa }\end{array}$ & Quartis & Pequena & Média & Grande \\
\hline \multirow{5}{*}{ Estadual } & ABAIXO DO PERCENTIL 25 & 1 & 1 & 0 \\
& ENTRE O PERCENTIL 25 E 50 & 2 & 2 & 0 \\
& ENTRE O PERCENTIL 50 E 75 & 2 & 3 & 0 \\
& ACIMA DO PERCENTIL 75 & 2 & 3 & 1 \\
\hline \multirow{5}{*}{ Municipal } & ABAIXO DO PERCENTIL 25 & 0 & 0 & 0 \\
& ENTRE O PERCENTIL 25 E 50 & 0 & 0 & 0 \\
& ENTRE O PERCENTIL 50 E 75 & 0 & 0 & 0 \\
& ACIMA DO PERCENTIL 75 & 0 & 1 & 0 \\
\hline
\end{tabular}

Tabela 38 - Distribuição amostral das escolas da região de Bauru segundo os critérios pré-estabelecidos.

\begin{tabular}{ccccc}
\hline $\begin{array}{c}\text { Dependência } \\
\text { Administrativa }\end{array}$ & Quartis & Pequena & Média & Grande \\
\hline \multirow{5}{*}{ Estadual } & ABAIXO DO PERCENTIL 25 & 1 & 3 & 0 \\
& ENTRE O PERCENTIL 25 E 50 & 2 & 2 & 1 \\
& ENTRE O PERCENTIL 50 E 75 & 1 & 4 & 1 \\
& ACIMA DO PERCENTIL 75 & 1 & 3 & 1 \\
\hline \multirow{5}{*}{ Municipal } & ABAIXO DO PERCENTIL 25 & 0 & 0 & 0 \\
& ENTRE O PERCENTIL 25 E 50 & 0 & 0 & 0 \\
& ENTRE O PERCENTIL 50 E 75 & 0 & 0 & 0 \\
& ACIMA DO PERCENTIL 75 & 1 & 1 & 0 \\
\hline
\end{tabular}


Tabela 39 - Distribuição amostral das escolas da região de São Carlos segundo os critérios préestabelecidos.

\begin{tabular}{ccccc}
\hline $\begin{array}{c}\text { Dependência } \\
\text { Administrativa }\end{array}$ & Quartis & Pequena & Média & Grande \\
\hline \multirow{5}{*}{ Estadual } & ABAIXO DO PERCENTIL 25 & 1 & 1 & 0 \\
& ENTRE O PERCENTIL 25 E 50 & 1 & 1 & 0 \\
& ENTRE O PERCENTIL 50 E 75 & 1 & 2 & 0 \\
& ACIMA DO PERCENTIL 75 & 1 & 2 & 1 \\
\hline \multirow{5}{*}{ Municipal } & ABAIXO DO PERCENTIL 25 & 0 & 0 & 0 \\
& ENTRE O PERCENTIL 25 E 50 & 1 & 0 & 0 \\
& ENTRE O PERCENTIL 50 E 75 & 1 & 0 & 0 \\
& ACIMA DO PERCENTIL 75 & 1 & 1 & 0 \\
\hline
\end{tabular}

Tabela 40 - Distribuição amostral das escolas da região de Ribeirão Preto segundo os critérios préestabelecidos.

\begin{tabular}{ccccc}
\hline $\begin{array}{c}\text { Dependência } \\
\text { Administrativa }\end{array}$ & Quartis & Pequena & Média & Grande \\
\hline \multirow{5}{*}{ Estadual } & ABAIXO DO PERCENTIL 25 & 1 & 1 & 0 \\
& ENTRE O PERCENTIL 25 E 50 & 1 & 3 & 1 \\
& ENTRE O PERCENTIL 50 E 75 & 1 & 4 & 2 \\
& ACIMA DO PERCENTIL 75 & 1 & 5 & 2 \\
\hline \multirow{5}{*}{ Municipal } & ABAIXO DO PERCENTIL 25 & 1 & 1 & 0 \\
& ENTRE O PERCENTIL 25 E 50 & 1 & 1 & 0 \\
& ENTRE O PERCENTIL 50 E 75 & 2 & 2 & 1 \\
& ACIMA DO PERCENTIL 75 & 3 & 2 & 1 \\
\hline
\end{tabular}

Tabela 41 - Distribuição amostral das escolas da região de Registro segundo os critérios pré-estabelecidos.

\begin{tabular}{ccccc}
\hline $\begin{array}{c}\text { Dependência } \\
\text { Administrativa }\end{array}$ & Quartis & Pequena & Média & Grande \\
\hline \multirow{5}{*}{ Estadual } & ABAIXO DO PERCENTIL 25 & 2 & 1 & 0 \\
& ENTRE O PERCENTIL 25 E 50 & 1 & 1 & 0 \\
& ENTRE O PERCENTIL 50 E 75 & 2 & 2 & 0 \\
& ACIMA DO PERCENTIL 75 & 1 & 0 & 0 \\
\hline \multirow{5}{*}{ Municipal } & ABAIXO DO PERCENTIL 25 & 0 & 0 & 0 \\
& ENTRE O PERCENTIL 25 E 50 & 0 & 0 & 0 \\
& ENTRE O PERCENTIL 50 E 75 & 0 & 0 & 0 \\
& ACIMA DO PERCENTIL 75 & 0 & 0 & 0 \\
\hline
\end{tabular}


Tabela 42 - Distribuição amostral das escolas da região de Itapetininga segundo os critérios préestabelecidos.

\begin{tabular}{ccccc}
\hline $\begin{array}{c}\text { Dependência } \\
\text { Administrativa }\end{array}$ & Quartis & Pequena & Média & Grande \\
\hline \multirow{4}{*}{ Estadual } & ABAIXO DO PERCENTIL 25 & 2 & 1 & 0 \\
& ENTRE O PERCENTIL 25 E 50 & 2 & 1 & 0 \\
& ENTRE O PERCENTIL 50 E 75 & 1 & 2 & 0 \\
& ACIMA DO PERCENTIL 75 & 1 & 1 & 0 \\
\hline \multirow{5}{*}{ Municipal } & ABAIXO DO PERCENTIL 25 & 0 & 0 & 0 \\
& ENTRE O PERCENTIL 25 E 50 & 1 & 1 & 0 \\
& ENTRE O PERCENTIL 50 E 75 & 1 & 1 & 0 \\
& ACIMA DO PERCENTIL 75 & 2 & 1 & 0 \\
\hline
\end{tabular}

Tabela 43 - Distribuição amostral das escolas da região de Piracicaba segundo os critérios préestabelecidos.

\begin{tabular}{ccccc}
\hline $\begin{array}{c}\text { Dependência } \\
\text { Administrativa }\end{array}$ & Quartis & Pequena & Média & Grande \\
\hline \multirow{5}{*}{ Estadual } & ABAIXO DO PERCENTIL 25 & 0 & 1 & 0 \\
& ENTRE O PERCENTIL 25 E 50 & 1 & 2 & 0 \\
& ENTRE O PERCENTIL 50 E 75 & 1 & 2 & 1 \\
& ACIMA DO PERCENTIL 75 & 2 & 6 & 1 \\
\hline \multirow{5}{*}{ Municipal } & ABAIXO DO PERCENTIL 25 & 0 & 0 & 0 \\
& ENTRE O PERCENTIL 25 E 50 & 0 & 0 & 0 \\
& ENTRE O PERCENTIL 50 E 75 & 1 & 0 & 0 \\
& ACIMA DO PERCENTIL 75 & 1 & 1 & 0 \\
\hline
\end{tabular}

Tabela 44 - Distribuição amostral das escolas da região de Campinas segundo os critérios préestabelecidos.

\begin{tabular}{ccccc}
\hline $\begin{array}{c}\text { Dependência } \\
\text { Administrativa }\end{array}$ & Quartis & Pequena & Média & Grande \\
\hline \multirow{4}{*}{ Estadual } & ABAIXO DO PERCENTIL 25 & 1 & 2 & 1 \\
& ENTRE O PERCENTIL 25 E 50 & 3 & 5 & 2 \\
& ENTRE O PERCENTIL 50 E 75 & 4 & 8 & 3 \\
& ACIMA DO PERCENTIL 75 & 5 & 10 & 3 \\
\hline \multirow{5}{*}{ Municipal } & ABAIXO DO PERCENTIL 25 & 0 & 0 & 0 \\
& ENTRE O PERCENTIL 25 E 50 & 1 & 0 & 0 \\
& ENTRE O PERCENTIL 50 E 75 & 1 & 1 & 0 \\
& ACIMA DO PERCENTIL 75 & 4 & 3 & 1 \\
\hline
\end{tabular}


Tabela 45 - Distribuição amostral das escolas da região de Jundiaí segundo os critérios pré-estabelecidos.

\begin{tabular}{ccccc}
\hline $\begin{array}{c}\text { Dependência } \\
\text { Administrativa }\end{array}$ & Quartis & Pequena & Média & Grande \\
\hline \multirow{5}{*}{ Estadual } & ABAIXO DO PERCENTIL 25 & 1 & 2 & 1 \\
& ENTRE O PERCENTIL 25 E 50 & 1 & 4 & 2 \\
& ENTRE O PERCENTIL 50 E 75 & 1 & 6 & 3 \\
& ACIMA DO PERCENTIL 75 & 2 & 5 & 3 \\
\hline \multirow{5}{*}{ Municipal } & ABAIXO DO PERCENTIL 25 & 1 & 0 & 0 \\
& ENTRE O PERCENTIL 25 E 50 & 1 & 1 & 0 \\
& ENTRE O PERCENTIL 50 E 75 & 1 & 1 & 0 \\
& ACIMA DO PERCENTIL 75 & 3 & 3 & 0 \\
\hline
\end{tabular}

Tabela 46 - Distribuição amostral das escolas da região de São José dos Campos segundo os critérios pré-estabelecidos.

\begin{tabular}{ccccc}
\hline $\begin{array}{c}\text { Dependência } \\
\text { Administrativa }\end{array}$ & Quartis & Pequena & Média & Grande \\
\hline \multirow{5}{*}{ Estadual } & ABAIXO DO PERCENTIL 25 & 2 & 2 & 0 \\
& ENTRE O PERCENTIL 25 E 50 & 3 & 2 & 1 \\
& ENTRE O PERCENTIL 50 E 75 & 3 & 5 & 1 \\
& ACIMA DO PERCENTIL 75 & 2 & 3 & 1 \\
\hline \multirow{5}{*}{ Municipal } & ABAIXO DO PERCENTIL 25 & 2 & 0 & 0 \\
& ENTRE O PERCENTIL 25 E 50 & 1 & 2 & 0 \\
& ENTRE O PERCENTIL 50 E 75 & 2 & 3 & 0 \\
& ACIMA DO PERCENTIL 75 & 2 & 4 & 1 \\
\hline
\end{tabular}

Tabela 47 - Distribuição amostral das escolas da região de São Paulo segundo os critérios préestabelecidos.

\begin{tabular}{ccccc}
\hline $\begin{array}{c}\text { Dependência } \\
\text { Administrativa }\end{array}$ & Quartis & Pequena & Média & Grande \\
\hline \multirow{5}{*}{ Estadual } & ABAIXO DO PERCENTIL 25 & 13 & 33 & 36 \\
& ENTRE O PERCENTIL 25 E 50 & 8 & 22 & 29 \\
& ENTRE O PERCENTIL 50 E 75 & 6 & 16 & 14 \\
& ACIMA DO PERCENTIL 75 & 3 & 10 & 9 \\
\hline \multirow{5}{*}{ Municipal } & ABAIXO DO PERCENTIL 25 & 6 & 20 & 4 \\
& ENTRE O PERCENTIL 25 E 50 & 4 & 14 & 4 \\
& ENTRE O PERCENTIL 50 E 75 & 4 & 11 & 1 \\
& ACIMA DO PERCENTIL 75 & 3 & 7 & 2 \\
\hline
\end{tabular}



APÊNDICE

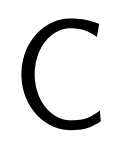

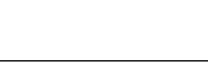

\section{MODELOS CLÁSSICOS}

Neste apêndice apresentamos os procedimentos computacionais utilizados para a estimação de modelos clássicos, para tanto foi utilizados os pacotes lme4, nlme, lmerTest e bbmle. Mais detalhes com relação aos pacotes citados podem ser encontrados em (BATES et al., 2015; PINHEIRO et al., 2017; KUZNETSOVA; BROCKHOFF; CHRISTENSEN, 2015; BOLKER; TEAM, 2010)

\section{C.1 Estimação dos parâmetros}

Nesta seção temos as rotinas computacionais para estimação de parâmetros nos casos: efeitos fixos, intercepto aleatório e intercepto e inclinações aleatórias.

\section{C.1.1 Modelos com efeitos fixos}

O modelo (6.7), foi estimado numa abordagem clássica, vejamos o código a seguir.

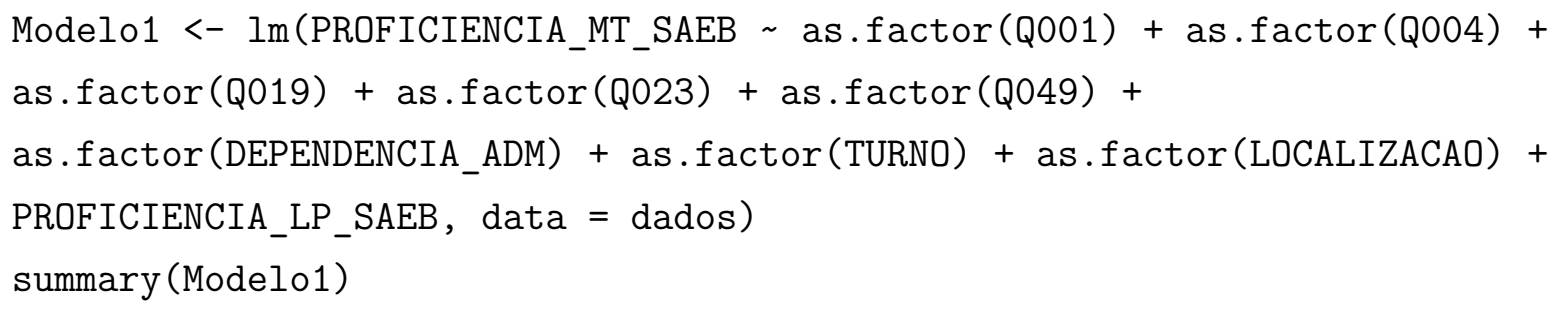

\section{C.1.2 Modelo com interceptos aleatórios}

Os códigos para estimação do modelo (6.10), encontram - se a seguir.

require (lme4)

require(lmerTest) 
Modelo2 <- lmer(PROFICIENCIA_MT_SAEB as.factor $($ Q001) + as.factor $($ Q004) + as.factor (Q019) + as.factor (Q023) + as.factor (Q049) + as.factor (DEPENDENCIA_ADM) + as.factor (TURNO) + as.factor (LOCALIZACAO) + PROFICIENCIA_LP_SAEB $+(1 \mid$ REGIAO $)$, data $=$ dados $)$ summary (Modelo2)

\section{C.1.3 Modelo com interceptos e inclinações aleatórios}

Abaixo temos os códigos, para estimação do modelo (6.13).

require (nlme)

Modelo3 <- lme(PROFICIENCIA_MT_SAEB as.factor $(Q 001)+$ as.factor $(Q 004)+$ as.factor (Q019) + as.factor (Q023) + as.factor (Q049) + as.factor (DEPENDENCIA_ADM) + as.factor (TURNO) + as.factor (LOCALIZACAO) + PROFICIENCIA_LP_SAEB, random $=\sim$ as.factor $($ Q001) + as.factor $(Q 004)+$ as.factor (Q019) + as.factor (Q023) + as.factor (Q049) + as.factor (DEPENDENCIA_ADM) + as.factor (TURNO) + as.factor (LOCALIZACAO) + PROFICIENCIA_LP_SAEB $\mid$ REGIAO, control=lmeControl (opt="optim", maxIter= 50000, msMaxIter $=200$, tolerance $=1 \mathrm{e}-4$, niter $=50, \operatorname{msTol}=1 \mathrm{e}-5$, nlmStepMax=500, msVerbose=TRUE, returnObject=TRUE), data=dados ) summary (Modelo3)

\section{C.2 Seleção de Modelos}

Como já foi dito nos capítulos 4 e 5 a seleção de modelos no caso clássico foi feita usando os critérios AIC, AICc e BIC, a seguir podemos ver como foi computacionalmente realizado esse procedimento.

require (bbmle)

AICctab (Modelo1, Modelo2, Modelo3, base $=\mathrm{T}$, weights $=\mathrm{T}$ )

AICtab (Modelo1, Modelo2, Modelo3, base $=\mathrm{T}$, weights $=\mathrm{T}$ )

BICtab (Modelo1, Modelo2, Modelo3, base $=\mathrm{T}$, weights $=\mathrm{T}$ ) 
APÊNDICE

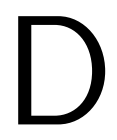

D

\section{MODELOS BAYESIANOS: STAN}

Quando se trabalha com dados em que há medidas repetidas e com grande número de observações, uma possível abordagem seria o ajuste de modelos mistos. Essa classe de modelos tem se popularizado muito nos últimos anos, principalmente em ciências cognitivas e educacionais, por se tratar de vertentes científicas que possuem dados com grande quantidade de observações. Houve um amplo desenvolvimento computacional para dar suporte a esses profissionais. Com esse pensamento surgiu à interface Stan, que posteriormente foi adaptada para ser utilizada na linguagem $R$, para ajustes bayesianos. O Stan possibilita que o pesquisador leve em consideração seus conhecimentos prévios sobre o tema para a modelagem do problema e utiliza como método de estimação o Monte Carlo Hamiltoniano.

Segundo Neal et al. (2011), Monte Carlo Hamiltoniano (HMC) é um método de Monte Carlo (MCMC) de cadeia de Markov que utiliza a derivada da função de densidade dos dados que estão sendo amostrados para gerar transições eficientes que abrangem a distribuiição $a$ posteriori geradas dos dados originais.

O primeiro passo é escrever a função de densidade da distribuição que se pretende amostrar como função de energia potencial e cinética, essa função será da forma:

$$
H(\rho, \theta)=-\log p(\rho, \theta),
$$

onde $\rho$ é uma variável auxiliar de impulso, daí simula-se cadeias de Markov e em seguida faz-se um atualização via algoritmo de Metropolis. Em Mecânica Estatística, a função $H$ é conhecida como distribuição canônica da distribuição que se pretende amostrar.

Cada iteração do algoritmo HMC tem duas etapas. Na primeira etapa, novos valores para as variáveis de $\rho$ são aleatoriamente extraídos de sua distribuição, este passo, obviamente, deixa a distribuição canônica comum invariante. Na segunda etapa, uma atualização Metropolis é realizada, usando a dinâmica hamiltoniana para propor um novo estado. Começando com 
o estado atual, $(\rho, \theta)$. Se o estado proposto não for aceito (ou seja, ele é rejeitado), o estado seguinte é o mesmo que o estado atual.

Segundo Neal et al. (2011), se olharmos para HMC como amostragem da distribuição conjunta de $\rho$ e $\theta$, o passo Metropolis deixa a função densidade de probabilidade para $(\rho, \theta)$ inalterada ou quase inalterada. O movimento para pontos $(\rho, \theta)$ com uma densidade de probabilidade diferente é realizado somente pelo primeiro passo em uma iteração de HMC, em que $\rho$ é substituído por um novo valor.

Neste apêndice encontram - se os códigos em Stan que foram usados para construção dos modelos bayesianos do capítulo 5 .

\section{D.1 Modelos com efeitos fixos}

O modelo (6.14), foi estimado numa abordagem bayesiana, vejamos o código no stan

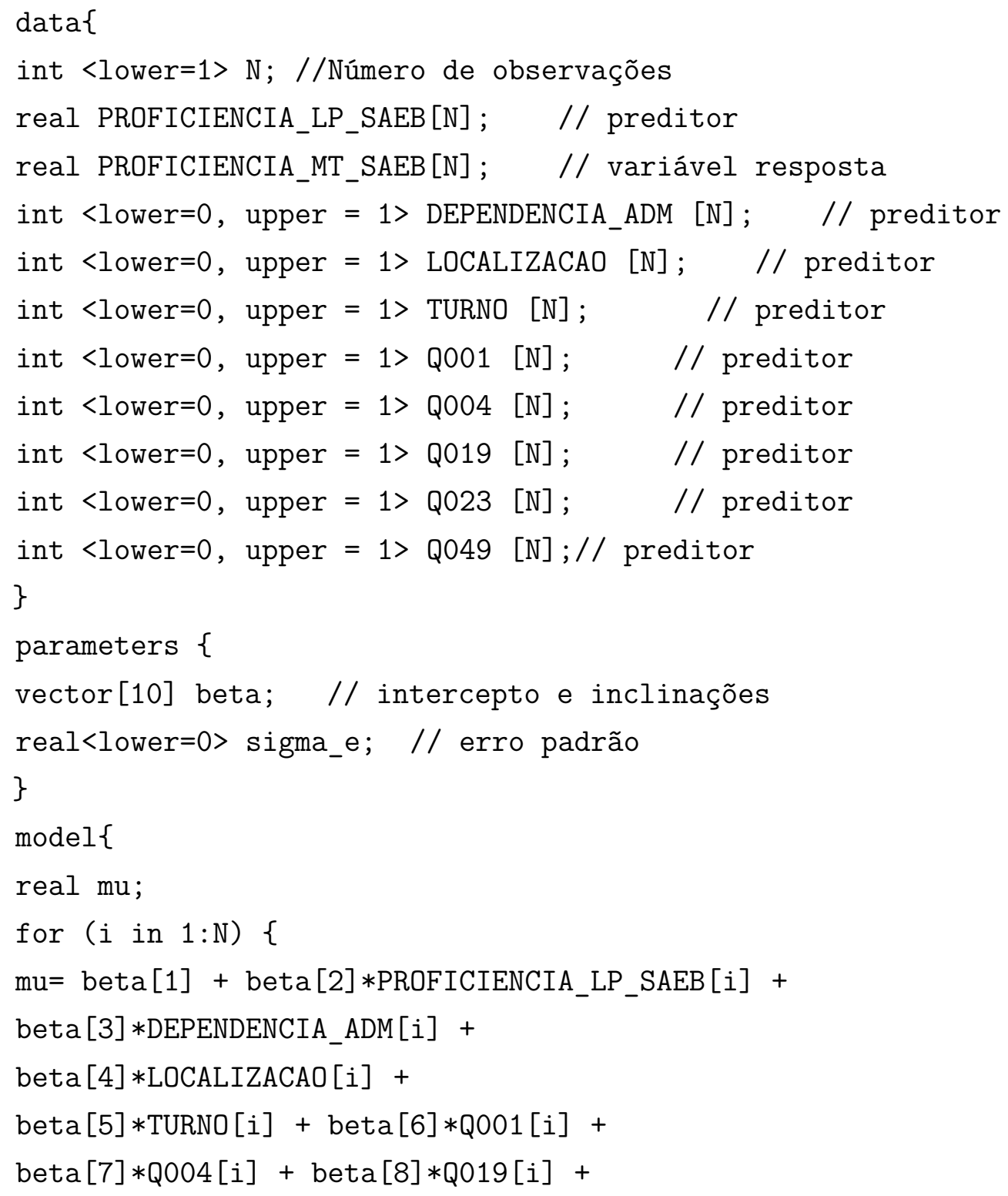




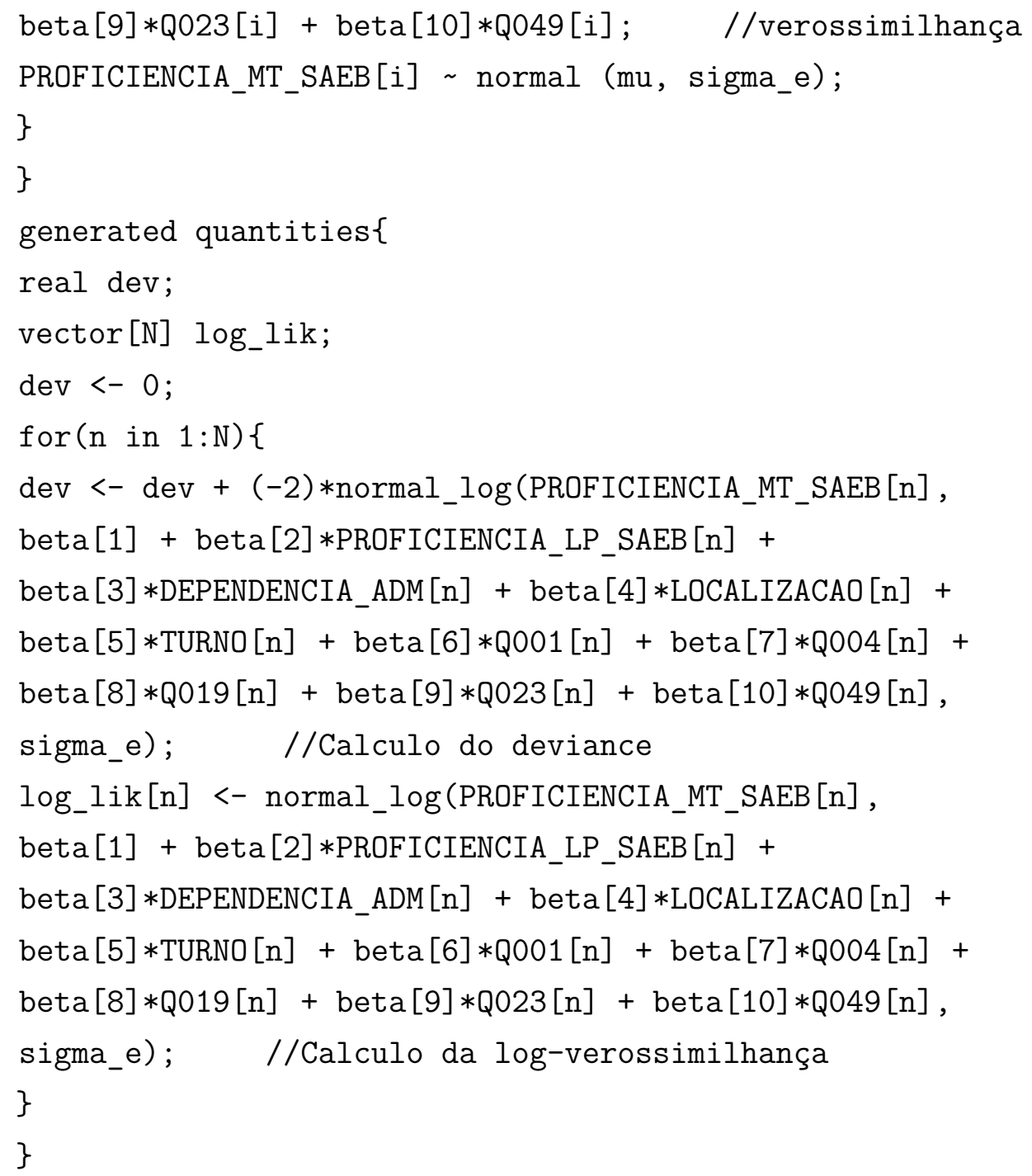

\section{D.2 Modelo com interceptos aleatórios}

Os códigos do Stan para estimação bayesiana do modelo (6.15), encontram - se a seguir.

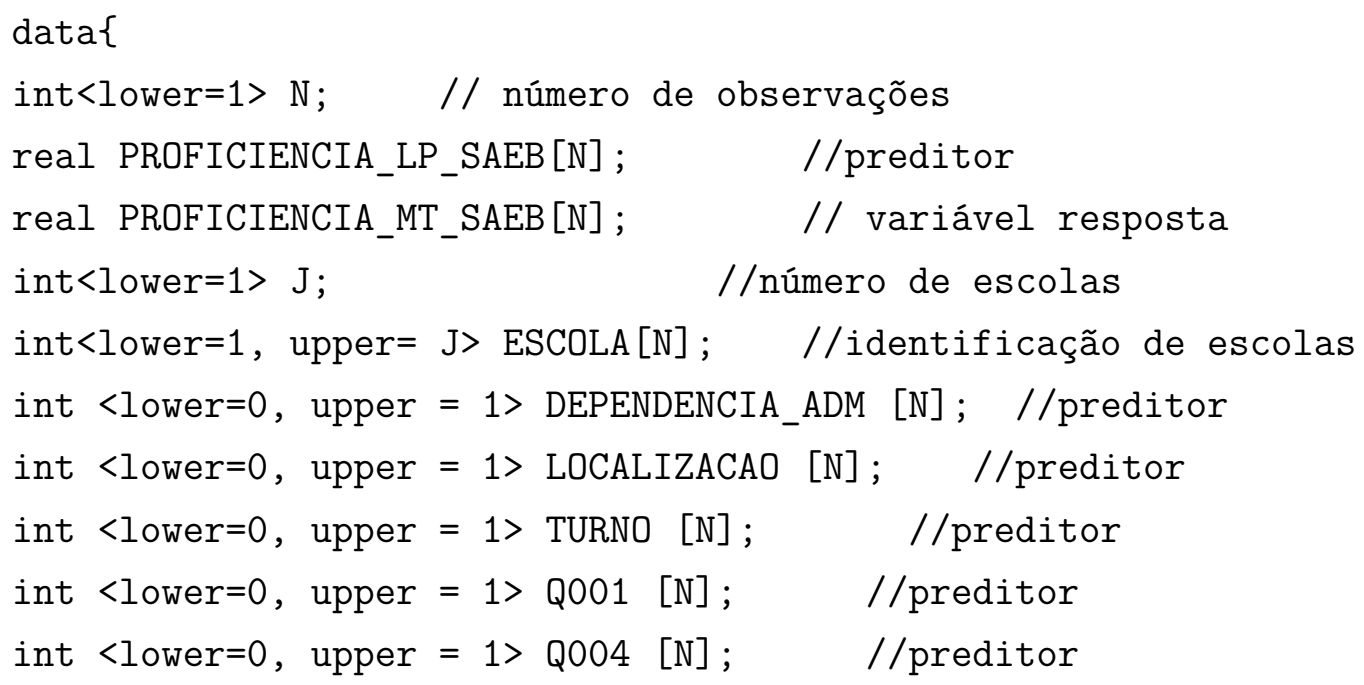




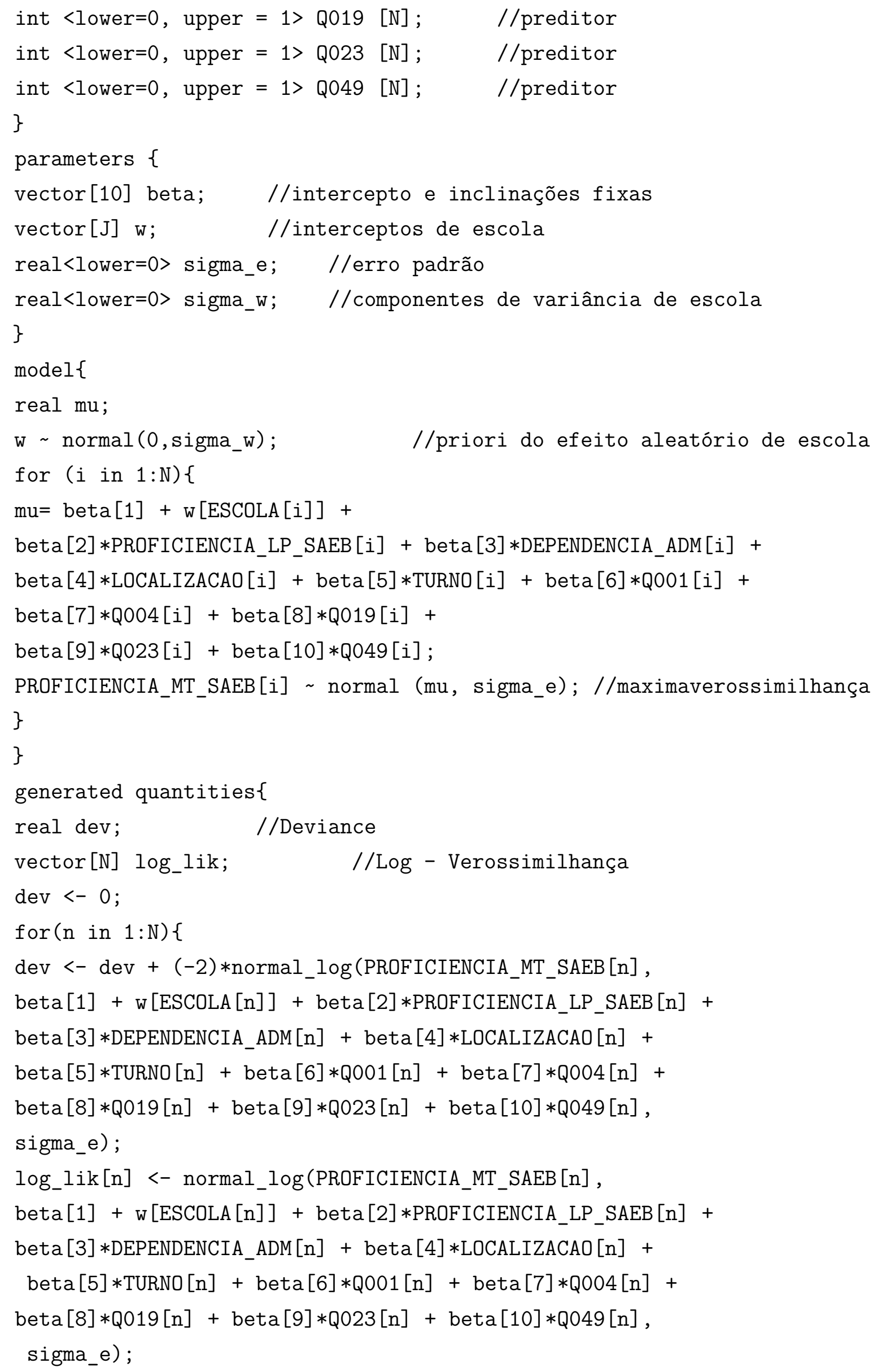




\section{D.3 Modelo com interceptos e inclinações aleatórios}

Abaixo temos os códigos, da interface Stan, para estimação do modelo (6.16).

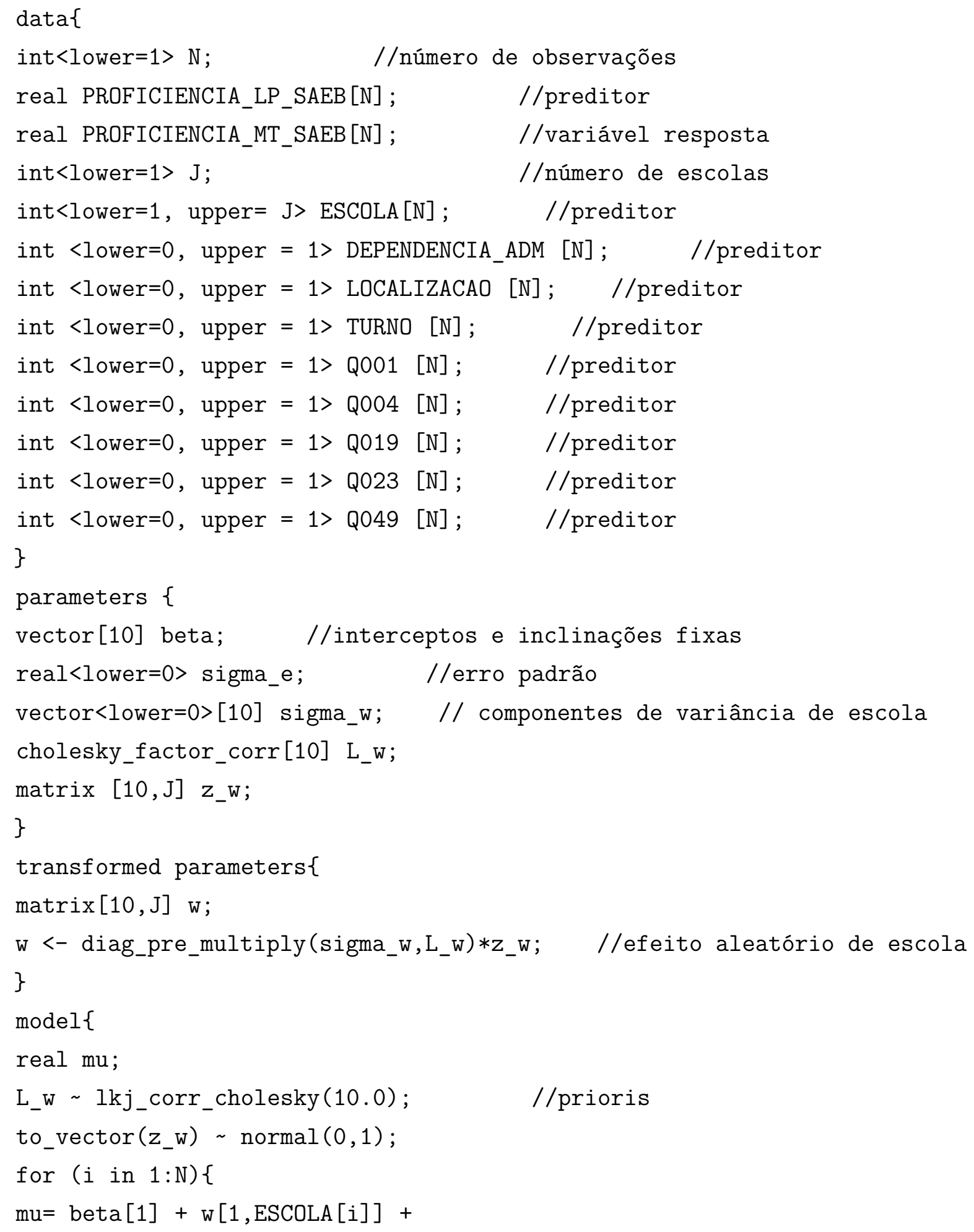




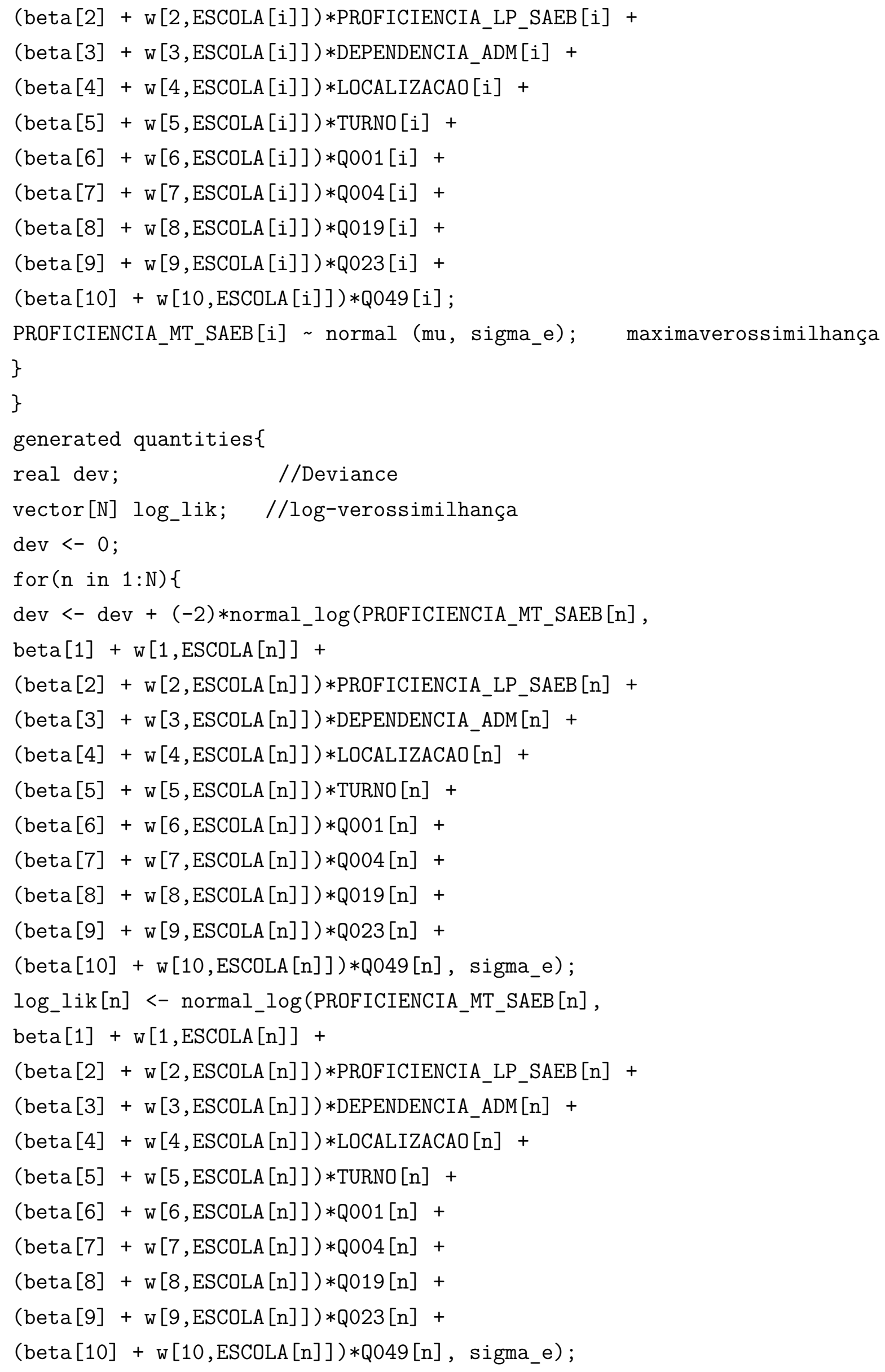


\}

\} 


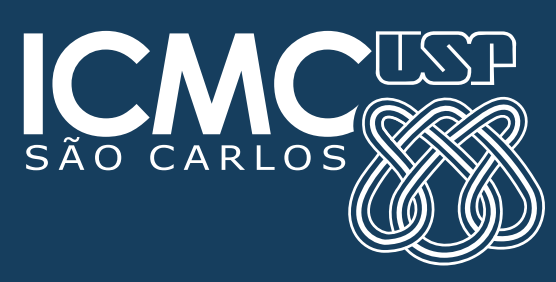

